\title{
A Review of Dynamic Experimental Techniques and Mechanical Behaviour of Rock Materials
}

\author{
Q. B. Zhang $\cdot$ J. Zhao
}

Received: 10 March 2013/Accepted: 22 July 2013/Published online: 13 September 2013

(C) Springer-Verlag Wien 2013

\begin{abstract}
The purpose of this review is to discuss the development and the state of the art in dynamic testing techniques and dynamic mechanical behaviour of rock materials. The review begins by briefly introducing the history of rock dynamics and explaining the significance of studying these issues. Loading techniques commonly used for both intermediate and high strain rate tests and measurement techniques for dynamic stress and deformation are critically assessed in Sects. 2 and 3. In Sect. 4, methods of dynamic testing and estimation to obtain stress-strain curves at high strain rate are summarized, followed by an in-depth description of various dynamic mechanical properties (e.g. uniaxial and triaxial compressive strength, tensile strength, shear strength and fracture toughness) and corresponding fracture behaviour. Some influencing rock structural features (i.e. microstructure, size and shape) and testing conditions (i.e. confining pressure, temperature and water saturation) are considered, ending with some popular semi-empirical rate-dependent equations for the enhancement of dynamic mechanical properties. Section 5 discusses physical mechanisms of strain rate effects. Section 6 describes phenomenological and mechanically based ratedependent constitutive models established from the knowledge of the stress-strain behaviour and physical
\end{abstract}

Q. B. Zhang · J. Zhao

École Polytechnique Fédérale de Lausanne (EPFL), School of Architecture, Civil and Environmental Engineering, Laboratory of Rock Mechanics (LMR), Bâtiment GC D0-407, Station 18, 1015 Lausanne, Switzerland

e-mail: qianbing.zhang@epfl.ch; jian.zhao@eplf.ch

J. Zhao $(\bowtie)$

Department of Civil Engineering, Monash University,

Building 72, Clayton, Melbourne, VIC 3800, Australia

e-mail: jian.zhao@monash.edu mechanisms. Section 7 presents dynamic fracture criteria for quasi-brittle materials. Finally, a brief summary and some aspects of prospective research are presented.

Keywords Rock material - Strain rate ·

Experimental techniques - Mechanical behaviour .

Dynamic loading · Rock dynamics · Dynamic fracture

\begin{tabular}{|c|c|}
\hline List of Symbols & \\
\hline$a$ & Crack length \\
\hline$A_{\mathrm{B}}, A_{\mathrm{s}}, A_{\text {shear }}$ & $\begin{array}{l}\text { Cross-sectional area of the bar } \\
\text { and the specimen, and shear area } \\
\text { of the specimen }\end{array}$ \\
\hline$A(v)$ & Universal function \\
\hline$B_{\mathrm{s}}, B_{\mathrm{ws}}$ & $\begin{array}{l}\text { Thickness of the specimen and } \\
\text { wall thickness of the tube } \\
\text { specimen }\end{array}$ \\
\hline$C_{\mathrm{B}}, C_{\mathrm{s}}$ & $\begin{array}{l}\text { Longitudinal wave speeds of the } \\
\text { bar and the specimen }\end{array}$ \\
\hline$C_{\mathrm{L}}, C_{\mathrm{S}}, C_{\mathrm{R}}$ & $\begin{array}{l}\text { Longitudinal wave speed, shear } \\
\text { wave speed and Rayleigh wave } \\
\text { speed }\end{array}$ \\
\hline$d$ & Grain size of the specimen \\
\hline$D_{\mathrm{B}}, D_{\mathrm{s}}$ & $\begin{array}{l}\text { Diameter of the bar and the } \\
\text { specimen }\end{array}$ \\
\hline$E_{\mathrm{B}}, E_{\mathrm{s}}$ & $\begin{array}{l}\text { Young's modulus of the bar and } \\
\text { the specimen }\end{array}$ \\
\hline$E, E_{\mathrm{d}}$ & $\begin{array}{l}\text { Quasi-static and dynamic } \\
\text { Young's modulus }\end{array}$ \\
\hline$E_{\max }, E_{\min }, E_{\mathrm{avg}}$ & $\begin{array}{l}\text { Maximum, minimum and average } \\
\text { Young's modulus of the specimen }\end{array}$ \\
\hline$f$ & Frequency factor \\
\hline$f(a / R), f(a / W), f(S / 2 R)$ & Geometric correction function \\
\hline$F$ & Return force \\
\hline
\end{tabular}


$G_{\mathrm{dC}}$

h

$\dot{h}$

$\mathrm{H}$

K

$K_{\text {IC }}, K_{\text {IIC }}$

$K_{\mathrm{Id}}, K_{\mathrm{ID}}$

$K_{\mathrm{I}}^{\mathrm{dyn}}(t)$

$\dot{K}_{\mathrm{I}}^{\text {dyn }}$

$L_{\mathrm{s}}, L_{\mathrm{str}}$

$n$

$P(t)$

$P_{1}, P_{2}$

$P_{\mathrm{c}}$

$Q$

$\mathrm{R}$

$R$

$R(t)$

S

$t_{0}$

$t_{\text {equil }}$

$t_{\mathrm{f}}$

$t_{\text {In. }}$

$t_{\text {rise }}$

$T$

$T_{\mathrm{d}}$

$\dot{u}_{1}, \dot{u}_{2}$

$v, v_{\text {lim }}, v_{\max }$

$v_{1}, v_{2}$

V

$V_{\text {eject }}$

$V_{\mathrm{p}}$

$\Delta V_{\mathrm{pb}}$

$V_{\text {str }}$

$W$

$W_{\mathrm{FD}}$

$W_{\text {In. }}, W_{\text {Re. }}, W_{\text {Tr. }}$

$W_{\mathrm{s}}$

$x_{\mathrm{f}}$
Dynamic fracture energy

Initial distance between two

plates

Velocity of two plates in the

Stefan effect equation

Loading history

Kinetic energy of the fragment

Mode I and II fracture toughness

Dynamic crack initiation and

propagation toughness

Dynamic stress intensity factor

Loading rate of fracture toughness

Length of the specimen and the striker bar

Number of reflections

Applied dynamic load

Forces at bar-specimen

interfaces

Confining pressure

Activation energy

Air constant in Arrhenius

equation

Radius of the specimen

Ratio of stress difference

Span of bending

Transit time to travel through the specimen once

Time to reach stress equilibrium

Time to fracture

Duration of the incident pulse

Rise time of the stress history

Temperature

Dynamic torque

Velocities at the incident

bar-specimen and specimen-

transmitted bar interfaces

Crack propagation velocity, limit

of velocity and maximum velocity

Velocities of fragments

Volume of liquid

Ejection velocity of fragment

Particle velocity

'Pull-back' velocity

Velocity of the striker

Width of the specimen

Fracture and damage energy

Strain energies of the incident, reflected and transmitted stress

waves

Energy absorbed by the specimen

Distance from free end to fracture position

\section{Greek Symbols}

$\alpha$

$\gamma$

$\dot{\gamma}(t)$

$\varepsilon_{1}$

$\varepsilon_{\mathrm{f}}$

$\varepsilon_{\text {In. }}, \varepsilon_{\text {Re. }}, \varepsilon_{\mathrm{Tr}}$.

$\dot{\varepsilon}, \dot{\varepsilon}_{\mathrm{lim}}, \dot{\varepsilon}_{\mathrm{cri}}, \dot{\varepsilon}_{\max }$

$\eta$

$\dot{\theta}_{1}(t), \dot{\theta}_{2}(t)$

$\mu$

$v$

$\rho_{\mathrm{s}}$

$\sigma_{\mathrm{d}}(t)$

$\sigma_{\mathrm{d}}, \sigma_{\mathrm{s}}$

$\sigma_{\text {spall }}$

$\sigma_{\mathrm{t}}, \sigma_{\mathrm{td}}$

$\sigma_{\mathrm{tc}}, \sigma_{\mathrm{tcd}}$

$\sigma_{\mathrm{uc}}, \sigma_{\mathrm{ucd}}$

$\sigma_{\mathrm{t}, \max }^{\mathrm{Re}}$

$\sigma_{\text {ucd }} / \sigma_{\text {uc }}$

$\sigma_{1}-\sigma_{3}$

$\dot{\sigma}$

$\tau(t)$

$\tau, \tau_{\mathrm{d}}$

$\omega$

$\begin{array}{ll}\text { Abbreviations } \\ \text { ASTM } & \text { American Society for Testing and Materials } \\ \text { BD } & \text { Brazilian disc } \\ \text { CB } & \text { Chevron bend } \\ \text { CCNBD } & \text { Cracked chevron notched BD } \\ \text { CCNSCB } & \text { Cracked chevron NSCB } \\ \text { CDM } & \text { Continuum damage mechanics } \\ \text { CEB } & \text { Comité Euro-International du Béton } \\ \text { COD } & \text { Crack opening displacement } \\ \text { CPG } & \text { Crack propagation gauge } \\ \text { CRD } & \text { Commission on Rock Dynamics } \\ \text { CSR } & \text { Constant strain rate } \\ \text { CSTFBD } & \text { Cracked straight through FBD } \\ \text { CT } & \text { Compact tension } \\ \text { DCA } & \text { Dominant crack algorithm } \\ \text { DIC } & \text { Digital image correlation } \\ \text { DIF } & \text { Dynamic increase factor } \\ \text { DT } & \text { Direct tension }\end{array}$

Angle of the wedge

Shear strain

Shear strain rate

Axial strain

Strain to failure

Incident, reflected and transmitted strains measured by strain gauges on the bars

Strain rate, limit of strain rate, critical strain rate and maximum strain rate Viscosity of liquid

Angular velocities of the specimen ends

Friction coefficient between the wedge and the bar

Poisson's ratio

Density of the specimen

Dynamic stress history

Dynamic strength and quasi-static strength Spalling strength

Quasi-static and dynamic tensile strength

Quasi-static and dynamic triaxial compressive strength

Quasi-static and dynamic uniaxial compressive strength

Maximum reflected tensile stress

Normalized dynamic uniaxial

compressive strength

Differential stress

Stress rate

Shear stress

Quasi-static and dynamic shear strength Angular velocity of fragment 


\begin{tabular}{|c|c|}
\hline FBD & Flattened BD \\
\hline FEM & Finite-element method \\
\hline HCBD & Holed cracked BD \\
\hline HCFBD & Holed cracked FBD \\
\hline HS & High speed \\
\hline HSR & High strain rate \\
\hline In-DT & Indirect tension \\
\hline IRT & Infrared thermography \\
\hline ISR & Intermediate strain rate \\
\hline ISRM & International Society for Rock Mechanics \\
\hline ITFC & Incubation-time fracture criterion \\
\hline LECEI & Loading edge cracks by edge impact \\
\hline LGG & Laser gap gauge \\
\hline MDM & Micromechanical damage mechanics \\
\hline NSCB & Notched SCB \\
\hline RST & Rocking spalling test \\
\hline SCB & Semi-circular bending \\
\hline $\mathrm{SCM}$ & Sliding crack model \\
\hline SCRAM & Statistical crack mechanical model \\
\hline SE & Stress equilibrium \\
\hline SEM & Scanning electron microscope \\
\hline SENB & Single edge notched bending \\
\hline SG & Strain gauge \\
\hline SHB & Split Hopkinson bar \\
\hline SHPB & Split Hopkinson pressure bar \\
\hline SHPSB & Split Hopkinson pressure shear bar \\
\hline SHTB & Split Hopkinson tension bar \\
\hline SIF & Stress intensity factor \\
\hline SM & Suggested method \\
\hline SR & Short rod \\
\hline TC & Triaxial compression \\
\hline TPB & Three-point bending \\
\hline TriHB & Triaxially compressed Hopkinson bar \\
\hline TSHB & Torsional split Hopkinson bar \\
\hline UC & Uniaxial compression \\
\hline VHSR & Very high strain rate \\
\hline WLCT & Wedge loaded compact tension \\
\hline
\end{tabular}

\section{Introduction}

Rock dynamics or dynamic rock mechanics studies the mechanical behaviour of rock (masses and materials) under dynamic loading conditions, where an increased rate of loading induces a change in mechanical properties and fracture behaviour. Sources of dynamic loads include explosion, impact and seismic events existing in the form of time histories of particle acceleration, velocity and displacement. Understanding the effects of dynamic loading on rock is essential in dealing with various rock engineering problems, for example underground excavation projects, earthquake research, penetration and blasting events, rock disintegration processes, large-amplitude stress wave studies and protective construction design. Rock Dynamics and Geophysical Exploration might be the first book to systematically outline the fundamental principles and experiments of stress waves in rocks (Persen 1975). 'Dynamic rock mechanics' and 'rock dynamics', respectively, as the theme of the 12th US Symposium on Rock Mechanics held in Missouri on 16-18 November 1970, and one of the themes of the 5th International Society for Rock Mechanics (ISRM) Congress held in Melbourne on 10-15 April 1983, have received considerable attention in rock mechanics. In 2008, the Commission on Rock Dynamics (CRD) was set up within the ISRM and organized a sequence of workshops. The 1st International Conference on Rock Dynamics and Applications was held in Lausanne, on 6-8 June 2013. The above conference/workshop proceedings provide the state of the art of rock dynamics scientific research and engineering applications.

Rock dynamics has applications in earthquakes, mining, energy, environmental and civil engineering, when dynamic loads are encountered. Figure 1 illustrates typical rock dynamics issues related to the construction and utilization of an underground cavern, in which environmental factors (e.g. confining pressure, temperature and ground water) and intrinsic rock factors (e.g. jointing, anisotropy, composition and grain size) should be taken into account. However, guidance and standards in dynamic testing and design are generally lacking, and moreover advances in understanding of dynamic behaviour have been paced to an important degree by advances in experimental techniques. The experiments of principal interest in this review are those whose purpose is to design reliable testing methods and to critically examine mechanical behaviour of rock materials at laboratory scale.

Considerable research effort has been devoted over recent decades to develop experimental techniques and to characterize the dynamic mechanical behaviour of materials. A list of international conferences on this topic follows:

- International Conferences on the Mechanical Properties of Materials at High Rates of Strain were held in Oxford in 1974, 1979, 1984 and 1989.

- The European Association for the Promotion of Research into the Dynamic Behaviour of Materials and its Applications (DYMAT) has organized International Conferences on Mechanical and Physical Behaviour of Materials under Dynamic Loading each 3 years since 1985.

- The Dynamic Behavior of Materials Technical Division of the Society for Experimental Mechanics (SEM) has sponsored the 'Dynamic Behavior of Materials' track and organized the 'High Rate Image' panel at the SEM Annual Conferences since 2011.

It should be noted that, although recent, more comprehensive reviews have been given by Lindholm (1974), 


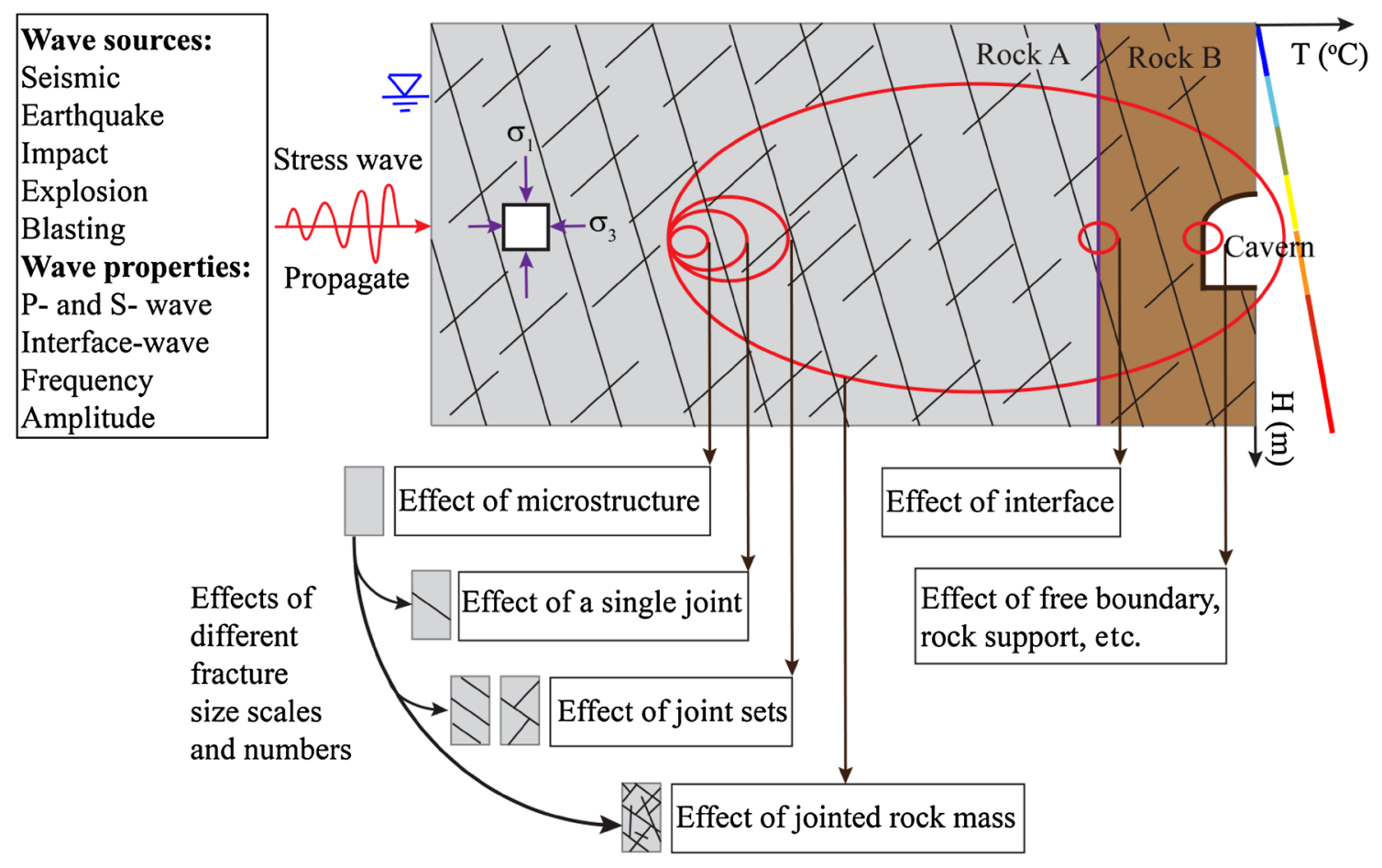

Fig. 1 Overview of rock dynamics problems and influencing factors in underground engineering design (after Zhao et al. 1999b, Fig. 1, p. 514)

Nicholas (1982), Malvern (1984), Sierakowski (1997), ASM (2000), Field et al. (2004) and Ramesh (2008) regarding dynamic experimental techniques and material behaviours, reviews emphasizing rock-like materials, e.g. concrete, mortar, ceramic and rock materials, are very limited in number and scope (Bischoff and Perry 1991; Fu et al. 1991; Malvar and Ross 1998; Zhao et al. 1999b; Subhash et al. 2008; Toutlemonde and Gary 2009; Walley 2010; Zhao 2011). In the 1990s, Bischoff and Perry (1991) and Fu et al. (1991) reviewed experimental techniques and compressive behaviour of concrete and dynamic loading, Malvar and Ross (1998) presented a review summarizing strain rate effects on concrete in tension, and Zhao et al. (1999b) reviewed advances in research on rock dynamics related to cavern development. The journal Rock Mechanics and Rock Engineering (Barla and Zhao 2010) edited a special issue on 'Rock Dynamics and Earthquake Engineering' to provide a consensus summary of the current state of knowledge. Several chapters in the book Advances in Rock Dynamics and Applications (Zhou and Zhao 2011) and some recent conference papers (Zhao et al. 2012; Xia 2013b) contain only outlines of fundamental principles and/ or their own research results. Work on dynamic experimental techniques and mechanical behaviour of rock materials is neither complete nor systematic, and therefore a comprehensive review is essential for research leading to a deeper understanding of rock dynamics.

This review updates our previous review papers (Zhao et al. 1999b, 2008, 2012; Zhao 2011) and concentrates on experimental techniques for both intermediate and high strain rate testing and dynamic mechanical behaviours of rock materials. All literature available to the authors (in total 384 references) concerning this topic was extensively reviewed. This review is arranged in eight sections: After the 'Introduction', loading techniques and measurement techniques are critically assessed in Sects. 2 and 3. In Sect. 4, first, dynamic testing methods and estimation methods for obtaining stressstrain behaviour at high strain rate are summarized; next, an in-depth description of the results of various dynamic mechanical properties and corresponding fracture behaviours is presented; then, some influencing environmental and intrinsic rock factors are considered; finally, some popular semi-empirical rate-dependent equations for predicting the dynamic strength of rock-like materials are briefly described. Section 5 reviews several physical mechanisms of strain rate effects, and Sect. 6 outlines classic rate-dependent constitutive models concerning the stress-strain behaviour and these physical mechanisms. Section 7 presents widely used phenomenological and mechanically based dynamic fracture criteria for brittle materials. Finally, a brief summary and some prospective research are presented.

\section{Loading Techniques for Dynamic Testing}

Loading techniques are those experimental techniques or methods to generate reproducible dynamic loading for the purpose of performing experimental tests and investigating 
dynamic behaviour of materials. The principles of loading techniques and their applications for engineering materials, such as concrete, mortar and ceramics, have been extensively reviewed (Ramesh 2008; Gama et al. 2004; Field et al. 2004; Kuhn and Medlin 2000). Therefore, only a short outline of specific applications to rock materials is given in this paper.

A classification of loading techniques and mechanical states for rock materials over a wide range of strain rates is shown in Fig. 2, which is modified after Lindholm (1971), Nemat-Nasser (2000) and Ramesh (2008), and particularly based on experimental results. At strain rates ranging from $10^{-8}$ to $10^{-5} \mathrm{~s}^{-1}$, the creep behaviour is the primary consideration and creep laws are used to describe mechanical behaviour. At higher strain rate, i.e. in the range of $10^{-5}$ $10^{-3} \mathrm{~s}^{-1}$, or about $1-100 \mathrm{~s}$ loading duration to failure, the quasi-static stress-strain curve obtained from constant strain rate (CSR) testing has been used to describe the mechanical behaviour. Ordinary hydraulic servo-controlled testing machines can load specimens at strain rates up to $10^{-3} \mathrm{~s}^{-1}$. With the aid of fast pumps and valves to increase the flow rate of hydraulic oil, some specialized hydraulic servo-controlled machines can achieve strain rates as high as $10^{-1} \mathrm{~s}^{-1}$. For higher strain rates, pneumatic-hydraulic or completely gasdriven machines have been developed to reach strain rates on the order of $10^{0} \mathrm{~s}^{-1}$, and drop-weight machines have been commonly used to achieve strain rates on the order of $10^{1} \mathrm{~s}^{-1}$. The term 'intermediate/medium strain rate' (Green and Perkins 1968, 1969; Logan and Handin 1970) or 'quasidynamic' (Logan and Handin 1970) is usually used to describe the mechanical behaviour of rock materials at strain rates ranging from $10^{-1}$ to $10^{1} \mathrm{~s}^{-1}$, within which strain rate effects first become a consideration, although their magnitude may be quite small or even non-existent in some cases.

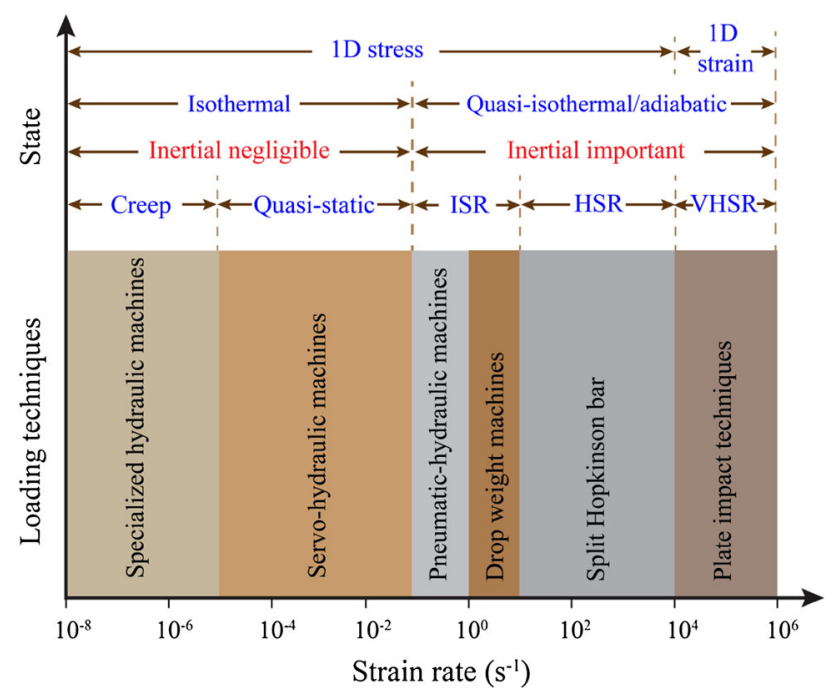

Fig. 2 Classification of loading techniques and the state of rock materials over a wide range of strain rates
In the present paper, the term 'intermediate strain rate (ISR)' is employed. Strain rates of $10^{1}-10^{4} \mathrm{~s}^{-1}$ are generally treated as the range of high strain rate (HSR) response, for which the most successful loading technique is the split Hopkinson pressure bar (SHPB). Effects of inertia and stress wave propagation should be considered to ensure proper interpretation of experimental data. Strain rates of $10^{4} \mathrm{~s}^{-1}$ or higher are generally referred to as the very high strain rate (VHSR) regime, for which plate impact techniques have been successfully employed.

A fundamental difference between quasi-static and dynamic tests is that inertia and wave propagation effects become more pronounced at higher strain rates. At high rates, there exists a transition from nominally isothermal condition to quasi-isothermal/adiabatic condition. Low strain rate experiments all maintain uniaxial [one-dimensional (1D)] stress states in the tested material, while shock wave techniques produce 1D strain states. Examples of the effect of strain rate on flow stresses of Solnhofen limestone combined with the transition from 1D stress to 1D strain are given in Fig. 3. In this study, impact loading studies are not included; the interested reader is referred to the excellent book by Meyers (1994) and critical review by Field et al. (2004) for the general principle and experimental techniques, and a recent $\mathrm{PhD}$ thesis (Braithwaite 2009) for knowledge of impact mechanical behaviour of eight types of rock material.

\subsection{Techniques for Intermediate Strain Rate Testing}

Pneumatic-hydraulic and completely gas-driven machines have mainly been developed for studying the ISR behaviour of rock materials in uniaxial compression (Green and Perkins 1968, 1969; Friedman et al. 1970; Zhao et al. 1999a),

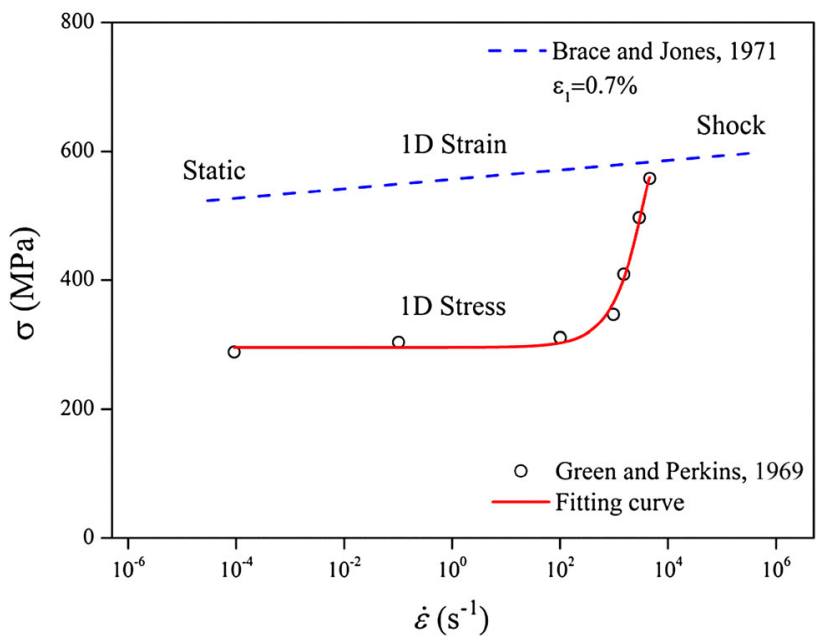

Fig. 3 Flow stress and the state of Solnhofen limestone at various strain rates (after Field et al. 2004, Fig. 2b, p. 727; data from Brace and Jones 1971 and Green and Perkins 1969) 
triaxial compression (Serdengecti and Boozer 1961; Logan and Handin 1970; Perkins et al. 1970; Ehrgott and Sloan 1971; Green et al. 1972; Friedman and Logan 1973; Lindholm et al. 1974; Blanton 1981; Gran et al. 1989; Li et al. 1999) (refer to Sect. 4.4 for details) and direct tension (Asprone et al. 2009; Cadoni 2010; Li et al. 2013). The loading frames are made of steel with very high stiffness, and a gas reservoir is used to pressurize the oil reservoir (pneumatichydraulic system) in order to reach a value of $10^{0} \mathrm{~s}^{-1}$, thus reducing the duration of the rise time to a few milliseconds. Strain rate of $10^{1} \mathrm{~s}^{-1}$ has also been achieved by some machines with rise time of approximately $500 \mu$ s (Logan and Handin 1970; Friedman and Logan 1973; Blanton 1981; Gran et al. 1989). The load is applied by movement of a lightweight piston driven by expansion of compressed gas. An important feature is the piston displacement limiting device that mechanically stops the piston after a predetermined displacement of travel (Friedman et al. 1970). The axial load is commonly measured by a load cell, and strains are usually measured by strain gauges mounted on the specimen. Therefore, at such a short duration, the strain rate becomes more dependent on the relationship between the specimen stiffness and machine stiffness. Even if wave propagation effects can be neglected, the characteristic response time of the load cell and its distance from the end of the specimen must be checked (ASM 2000).

The testing principle of drop-weight machines is gravitational potential energy, through controlling a hammer with known height and weight. Specimen deformation and energy calculations are based on measuring the momentum impulse acting on the falling weight and calculating the resultant temporal impact velocity. Drop-weight machines have been used to achieve strain rate of $10^{1} \mathrm{~s}^{-1}$, which is equivalent to a $500 \mu$ s loading duration. A rubber buffer can be placed on top of the specimen to prolong the duration of loading, reducing the strain rate to $10^{0} \mathrm{~s}^{-1}$. Although a gas gun can be used to accelerate the hammer so as to increase the strain rate up to $10^{2} \mathrm{~s}^{-1}$, the transient effect inside the machine cannot be neglected. Moreover, such strain rates can also be obtained by using the SHPB technique that explicitly takes wave propagation into account. There are some limitations on using drop-weight machines: (1) the technique is passive, and testing conditions are determined by trial and error or from empirical parameters; (2) the rate and form of the compressive loading depend on both the specimen and machine compliances, as well as the average energy of the falling weight; (3) great care should be taken in interpreting experimental data because of the coupling effects between machine vibration and wave propagation; (4) the calculated displacement might be inaccurate because the deformation in the system could be greater than the specimen deflection; and (5) the loading rate cannot be well controlled, and thus multiaxial tests are unreliable. Therefore, only a few studies have been conducted using drop-weight machines, to investigate the characteristics of fragmentation (Whittles et al. 2006; Hogan et al. 2012) and fracture toughness (Yang et al. 2009; Islam and Bindiganavile 2012).

\subsection{Techniques for High Strain Rate Testing}

One of the most widely used loading techniques at HSR is the split Hopkinson bar (SHB), or the Kolsky bar developed by Kolsky (1949). Readers interested in the historical background, recent advances and extensive modifications of the SHB are referred to a recent book (Chen and Song 2011), the ASM handbook (Gray 2000) and several recent reviews (Field et al. 2004; Ramesh 2008; Gama et al. 2004), and a review of its application to dynamic fracture toughness tests (Jiang and Vecchio 2009). The principle of the traditional SHPB technique is briefly described in this section. The SHPB consists of a striker bar, an incident bar and a transmission bar, with a specimen sandwiched between the incident and transmission bars, as shown in Fig. 4. When the striker bar impacts the incident bar, a compressive pulse is generated and propagates towards the specimen. Upon reaching the interface between the incident bar and the specimen, a portion of the stress pulse travels through the specimen and then transmits into the transmission bar as a compression pulse, while the remaining portion is reflected back into the incident bar as a tension pulse. Strain gauges are usually mounted at midpoints along the length of the incident and transmission bars to record the stress pulses.

The dimensions (length $L$, diameter $D$, cross-sectional area $A$ ) and properties (wave speed $C$, Young's modulus $E$, density $\rho$ ) of the bars and the specimen should be known prior to interpretation of data from a SHPB test. The subscripts ' $\mathrm{B}$ ' and ' $\mathrm{s}$ ' correspond to the bar and the specimen, respectively. The duration of the incident pulse $\left(t_{\mathrm{In}}\right)$ is equal to the round-trip travel time of the longitudinal wave in the striker bar, which can be expressed in terms of the length $\left(L_{\mathrm{str}}\right)$ and longitudinal wave speed $\left(C_{\mathrm{B}}\right)$ of the striker
Fig. 4 Schematic of a conventional split Hopkinson pressure bar (SHPB) or Kolsky bar
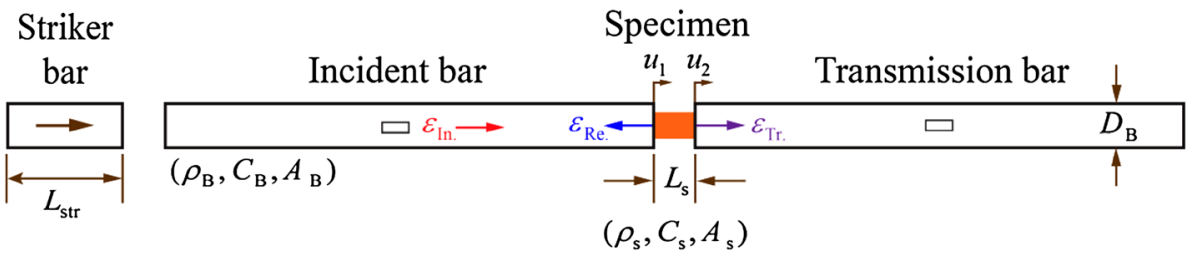
bar as $t_{\text {In. }}=2 L_{\mathrm{str}} / C_{\mathrm{B}} \quad$ (e.g. $L_{\mathrm{str}}=500 \mathrm{~mm}$ and $C_{\mathrm{B}}=$ $8,000 \mathrm{~m} / \mathrm{s}$, thus $\left.t_{\text {In. }}=125 \mu \mathrm{s}\right)$.

The strain rate, $\dot{\varepsilon}$, in the test specimen is given by Gray (2000) as

$\dot{\varepsilon}=\frac{\left(\dot{u}_{1}-\dot{u}_{2}\right)}{L_{\mathrm{s}}}$,

where $\dot{u}_{1}$ and $\dot{u}_{2}$ are the velocities at the incident bar-specimen and specimen-transmitted bar interfaces, respectively.

From elementary wave theory, the strain rate is

$\dot{\varepsilon}=\frac{C_{\mathrm{B}}}{L_{\mathrm{s}}}\left(-\varepsilon_{\text {In. }}+\varepsilon_{\text {Re. }}+\varepsilon_{\mathrm{Tr} .}\right)$.

The forces at the bar-specimen interfaces are defined as

$P_{1}=A_{\mathrm{B}} E_{\mathrm{B}}\left(\varepsilon_{\text {In. }}+\varepsilon_{\text {Re. }}\right), \quad P_{2}=A_{\mathrm{B}} E_{\mathrm{B}} \varepsilon_{\mathrm{Tr}}$,

where $\varepsilon$ is the strain measured by the strain gauges on the bars. The subscripts 'In.', 'Re.' and 'Tr.' correspond to the incident, reflected and transmitted pulse, respectively.

Methods for determining the stress and strain histories in the specimen for the SHPB test are presented in Sect. 4.2. The principles of the SHTB and TSHB are similar to those of the SHPB, while the primary differences are the method of generating the tensile and torsional loading pulses, specimen geometries and the methods of attaching the specimen to the two bars, which are presented in Sect. 4.1. Recent major developments in SHB testing have been presented by Field et al. (2004) (Table 1, p. 732). We focus on key techniques for characterizing the dynamic response of rock materials, as summarized in Table 1.

The SHB was originally developed to study the dynamic behaviour of ductile metals. When the specimen is a brittle/ quasi-brittle rock material, the testing conditions on the specimen may not be satisfactory to produce valid experimental results, and therefore the following conditions need to be carefully checked.

\subsubsection{Pulse Shaping Techniques}

The conditions of CSR and stress equilibrium (SE) need to be satisfied simultaneously for a SHB test. It is important to record the time histories of strain and strain rate in order to ascertain the extent to which the CSR and SE conditions exist during a test (Foster 2012; Yang and Shim 2005). The time to achieve nearly CSR is primarily governed by the rise of the incident wave. The transit time required for the leading edge of the incident wave to travel through the specimen once is given by the length and the longitudinal wave speed of the specimen, $t_{0}=L_{\mathrm{S}} / C_{\mathrm{s}}$. To reach the SE condition, it has been suggested that the equilibrium time should be 5-10 times (Lindholm 1971), $\pi$ times (Davies and Hunter 1963), or at least four times the transit time (Ravichandran and Subhash 1994) (e.g. $L_{\mathrm{s}}=50 \mathrm{~mm}$,
$C_{\mathrm{s}}=5,000 \mathrm{~m} / \mathrm{s}, t_{0}=10 \mu \mathrm{s}$, and thus $t_{\text {equil }}$ is around $40 \mu \mathrm{s}$ ). The SE condition can be evaluated by considering the stress histories at both ends of the specimen, $R(t)=2\left|\frac{\varepsilon_{\mathrm{In} .}+\varepsilon_{\mathrm{Re} .}-\varepsilon_{\mathrm{TT}} .}{\varepsilon_{\mathrm{In} .}+\varepsilon_{\mathrm{Re} .}+\varepsilon_{\mathrm{Tr} .}}\right| \leq 5 \%$, assuming that both bars are made of the same material and have the same cross-sectional area (Ravichandran and Subhash 1994). The rectangular stress pulse generated in the traditional SHPB test should be modified to satisfy the SE condition, because the diameter of the rock specimen is very large and the rise time should be much longer than the equilibrium time. Moreover, a rectangular stress pulse with its steep rise can impose a nonuniform strain rate during the elastic deformation of the rock specimen. A ramp pulse in the incident bar produced by changing the geometry and material of the pulse shaper and the striker can filter out the high-frequency oscillations. These methods are generally called pulse shaping techniques, which can be classified into three groups: pulse shaping by placing a thin ductile metallic (e.g. copper, aluminium) disc (Frew et al. 2001, 2002) or a geometrical pulse shaper rod (Gerlach et al. 2011) on the impact end of the incident bar, and using a shaped striker (Christensen et al. 1972; Howe et al. 1974; Li et al. 2000b; Zhou et al. 2011) and a preloading bar by placing a dummy specimen of the same material as the tested specimen on the impact end of the incident bar (Ellwood et al. 1982). Indepth discussions on pulse shaping techniques can be found in Nemat-Nasser et al. (1991).

\subsubsection{End Friction Effects}

The end friction between the specimen and the loading device may lead to a complex stress state of multiaxial compression, and rock materials are very sensitive to the confining pressure, even for low values. Gray (2000) suggested that friction and inertia effects can be lessened by minimizing the area mismatch between the specimen and the bars $\left(D_{\mathrm{s}} \approx 0.8 D_{\mathrm{B}}\right)$ and choosing the ratio $L_{\mathrm{s}} / D_{\mathrm{s}}$ between 0.50 and 1.0, which is based on the corrections for both axial and radial inertia effects originally proposed by Davies and Hunter (1963). Although fiction effects can be physically minimized in tests by proper lubrication, they cannot be completely eliminated. Furthermore, use of lubricants may affect the acoustic behaviour of the interface and is particularly difficult for tests at high temperature since their performance decreases with increasing temperature. Some researchers have conducted experiments on ring specimens (Hartley et al. 2007; Zhang et al. 2009; Alves et al. 2012) and numerical simulations (Iwamoto and Yokoyama 2012; Hao and Hao 2013) to assess the end friction effect. These results have generally shown that friction should be well reduced and/or be corrected using numerical simulations. Three obviously 
Table 1 Major developments in split Hopkinson bar testing of rock materials

\begin{tabular}{|c|c|c|}
\hline Year(s) & Major developments & References \\
\hline 1966 & Stress-strain relation & Hauser (1966) \\
\hline 1967 & The first thesis: stress-strain, size effect, energy transmission and failure characteristics & Hakalehto (1967) \\
\hline 1968 & Temperature effect & Kumar (1968) \\
\hline 1968 & High-speed camera for recording dynamic fracturing & Perkins and Green (1968) \\
\hline 1970 & Stress-strain curve, temperature effect & Perkins et al. (1970) \\
\hline 1972 & Hydrostatic confining pressure chamber, stress-strain curves, truncated cone striker & Christensen et al. (1972) \\
\hline 1974 & Anisotropy effect, cylindro-conical striker, direct tension test & Howe et al. (1974) \\
\hline 1974 & Effects of confining pressure and temperature, hydrostatic confining pressure chamber & Lindholm et al. (1974) \\
\hline 1976 & Anisotropy effect, direct tension and torsion tests & Goldsmith et al. (1976) \\
\hline 1977 & Pure shear test using the TSHB and a thin-walled tubular specimen & Lipkin et al. (1977) \\
\hline 1979 & Radial inertia effects & Powell (1979), Young and Powell (1979) \\
\hline 1984 & WLCT method for fracture toughness & Klepaczko et al. (1984) \\
\hline 1987 & Spalling test & Khan and Irani (1987) \\
\hline 1990 & SENB method for fracture toughness, an optical technique for measuring COD & Tang and $\mathrm{Xu}(1990)$ \\
\hline 1993 & BD method for tensile strength & Dutta and Kim (1993) \\
\hline 1993 & Effects of stress waveforms produced by rams on energy dissipation and fragmentation & Li et al. (1993) \\
\hline 1994 & Saturation effect in the spalling test & Lou (1994) \\
\hline 1995 & Dynamic moiré method for detecting time to fracture and measuring COD & Yu and Zhang (1995) \\
\hline 1997 & Inverse analysis for stress-strain curve, separation of stress waves & Zhao and Gary (1997) \\
\hline 1999-2001 & SR method for fracture toughness, temperature effect, fracture characteristics, energy & Zhang et al. $(1999,2000,2001 a, b)$ \\
\hline 2000 & Truncated-cone-shaped striker, oscillation elimination & Li et al. (2000b) \\
\hline 2001 & Pulse shaper, size effect & Frew et al. (2001) \\
\hline 2005 & 75-mm-diameter bar, intermediate strain rate, fracture modes, energy & Li et al. (2005) \\
\hline 2006 & FBD method for tensile strength and elastic modulus & Wang et al. (2006) \\
\hline 2007 & Wave propagation through fractured rocks with fractal joint surfaces & Ju et al. (2007) \\
\hline 2007 & Infrared thermography for measuring temperature & Shi et al. (2007) \\
\hline 2008 & SCB method for flexural strength & Dai et al. (2008) \\
\hline 2008 & TSHB to study frictional slip resistance & Yuan and Prakash (2008) \\
\hline 2008 & Size effects on both bars and specimens & Li et al. (2008a) \\
\hline 2008 & Development of coupled quasi-static and dynamic SHPB & Li et al. (2008b) \\
\hline 2009 & SHTB for direct tensile strength & Asprone et al. (2009) \\
\hline 2009 & Rock pulverization under uniaxial compressive loading & Doan and Gary (2009) \\
\hline 2009-2012 & CCNBD, NSCB and CCNSCB methods for fracture toughness, temperature effect & $\begin{array}{l}\text { Chen et al. (2009), Dai et al. } \\
\text { (2010a, 2011), Yin et al. (2012a) }\end{array}$ \\
\hline 2010 & Triaxial SHPB, hydrostatic confining pressure chamber & Frew et al. (2010) \\
\hline $2010-2011$ & HCFBD and CSTFBD methods for mode I and mode II fracture toughness, size effect & Wang et al. (2010c, 2011a) \\
\hline 2010-2012 & Rock-SHPB, rock bars & Wu et al. (2012), Li et al. (2010a) \\
\hline 2011 & Punch shear method for shear strength & Huang et al. (2011a) \\
\hline 2011 & Rock pulverization under confining pressure, shrink-fit metal sleeve & Yuan et al. (2011) \\
\hline 2011 & Design of triaxially compressed split Hopkinson bar (TriSHB) & Cadoni and Albertini (2011) \\
\hline 2012 & Coupling effects of confining pressure and temperature & Fang et al. (2012) \\
\hline 2012 & Suggested methods for UC, BD and NSCB testing & Zhou et al. (2012) \\
\hline 2013 & HS-DIC for UC, BD and NSCB testing & Zhang and Zhao (2013a) \\
\hline
\end{tabular}

$B D$ Brazilian disc, $C C N B D$ cracked chevron notched $\mathrm{BD}, C O D$ crack opening displacement, $F B D$ flattened $\mathrm{BD}, C S T F B D$ cracked straight through FBD, $H C F B D$ holed cracked FBD, $S C B$ semi-circular bending, $N S C B$ notched SCB, $C C N S C B$ cracked chevron NSCB, SENB single edge notched bending, SR short rod, SHPB split Hopkinson pressure bar, SHTB split Hopkinson tension bar, TSHB torsional split Hopkinson bar, $H S$-DIC high-speed digital image correlation, $U C$ uniaxial compression, WLCT wedge loaded compact tension 
different contact conditions, i.e. lubricated, dry and bonded using high-strength adhesive, were performed by Dai et al. (2010c) to examine the friction effects on the rock specimen. In torsional testing, friction does not exist.

\subsubsection{Inertia Effects}

Due to the Poisson's ratio effect, the stress wave loading in HSR tests causes inertia to have an influence on measured mechanical properties (Davies and Hunter 1963). Dynamic stresses associated with axial and radial inertia should be small compared with the flow stress of the material under investigation. The magnitude of the inertial contribution to the apparent stress also depends on the density and size of the specimen (Field et al. 2004). Davies and Hunter (1963) firstly found the inertia effect and suggested that there exists an optimal length-to-diameter ratio $\left(L_{\mathrm{s}} / D_{\mathrm{s}}=\sqrt{3 v} / 2\right)$ to minimize it. Gorham (1989) derived equations to estimate the inertial effect, which were rewritten by Ramesh (Eq. 33.20, 2008) to emphasize the specimen size and the ratio $L_{\mathrm{s}} / D_{\mathrm{s}}$. Difficulties have been met in carrying out valid and accurate tests at higher strain rates because the radial inertia effect becomes more significant, as pointed out by Follansbee and Frantz (1983), being coupled with the axial acceleration. However, for a specimen in stress equilibrium, only radial inertia effects need to be considered in the analysis and discussions. Powell (1979) and Young and Powell (1979) might have been the first authors to investigate radial inertia effects on rock behaviour. They observed that the radial stress increased towards the centre of the specimen during fracturing, and concluded that failure propagates inwardly in a progressive manner. Bischoff and Perry (1991) presented a review of the lateral inertia effect ('2.3 Lateral inertia confinement' in Bischoff and Perry 1991) on the compression behaviour of concrete. Recent progress on the lateral inertia effect has included the following work: $\mathrm{Li}$ and co-workers conducted numerical simulation (Li and Meng 2003; Lu et al. 2010) and experimental tests on tubular mortar specimens (Zhang et al. 2009) and stated that inertia-induced radial confinement makes a large contribution to the enhancement of compressive strength when the strain rate is greater than a critical transition value. Theoretical studies (Forrestal et al. 2007) and numerical simulations (Li et al. 2009) have also demonstrated that the effect of radial inertia is proportional to $D_{\mathrm{s}}^{2}$. In dynamic fracture toughness tests, the inertia effects are different for various loading configurations, as critically reviewed by Jiang and Vecchio (2009). An easy way to reduce the inertia effect can be through the use of pulse shaping techniques (Weerasooriya et al. 2006; Chen et al. 2009; Zhang and Zhao 2013a). In TSHB testing, due to the absence of a Poisson's ratio effect, the radial inertia effect does not exist and the stress pulse will not be dispersed during wave propagation (Lipkin et al. 1977, 1979; Gilat 2000).

\subsubsection{Dispersion Effects}

The effects of dispersion (known as the PochhammerChree mode) accumulate as waves propagate over distance, and become more significant as the bar diameter increases, thus they must be corrected and minimized for brittle materials due to the small value of strain to failure. Analytical, numerical and experimental corrections for wave dispersion were first proposed for testing of ductile materials by Follansbee and Frantz (1983) and Gorham (1983), for concrete by Gong et al. (1990) and for rock by Li et al. (2000b). For detailed discussions of the correction methods, refer to the review by Gama et al. ('Data processing and dispersion correction in SHPB testing' in 2004). The dispersion effect can also be physically minimized in the test through the use of pulse shaping techniques ( $\mathrm{Li}$ et al. 2000b; Frew et al. 2001, 2002), although some uncertainties still exist regarding the initial portion of the stressstrain curve.

\subsubsection{Limit of Strain Rate}

Attempts to push the SHB to higher strain rates have led to three modifications: (1) decrease of the specimen size, especially the length; (2) direct impact on the specimen; and (3) miniaturization of the entire system. The first approach is typically limited by frictional effects (Hakalehto 1967). In the second approach, a projectile directly impacts on a specimen placed in front of an elastic bar (Gorham et al. 1992). Since there is no incident bar, the impact velocity can be very high; however, in turn, there is no reflected signal from which the strain rate and strain in the specimen can be extracted. Using the third approach, several miniaturized versions on the millimetre order in diameter have been developed, and the strain rate can reach up to about $10^{5} \mathrm{~s}^{-1}$ (Jia and Ramesh 2004). There are, however, practical limitations on the size of specimen that can be used. Therefore, the above-mentioned methods are not applicable for heterogeneous rock-like materials. Although materials can be tested over a wide range of strain rates, standardized tests require well-characterized strain rates that do not exceed a limiting value. Classical equations for the limiting strain rate have been presented (Ravichandran and Subhash 1994; Pan et al. 2005; Ramesh 2008), as summarized in Table 2. This is also helpful for clarifying the sometimes dramatic changes of strength in the HSR range by helping to distinguish valid from invalid tests. 
Table 2 Summary of limiting strain rate equations at high strain rate (after Chen and Song 2011)

\begin{tabular}{|c|c|c|c|c|}
\hline Reference & Limit of strain rate $\dot{\varepsilon}_{\text {lim }}$ & Controlling factor & $\begin{array}{l}\text { Material } \\
\text { constant }\end{array}$ & Comments \\
\hline $\begin{array}{l}\text { Ravichandran and Subhash } \\
\text { (1994) }\end{array}$ & $\dot{\varepsilon}_{\lim }=\frac{\varepsilon_{\mathrm{f}} C_{\mathrm{s}}}{n L_{\mathrm{s}}}$ & $\begin{array}{l}\varepsilon_{\mathrm{f}} \text { strain to failure, } n \text { no. of } \\
\text { reflections }\end{array}$ & $C_{\mathrm{s}}, L_{\mathrm{s}}$ & Consideration of SE \\
\hline Pan et al. (2005) & $\dot{\varepsilon}_{\lim }=\frac{\beta \varepsilon_{\mathrm{f}}}{\tau(\beta / \eta-1)}$ & $\varepsilon_{\mathrm{f}}$ strain to failure, $\tau=f\left(\varepsilon_{\mathrm{f}}\right)$ & $\beta, \eta$ & Consideration of CSR \\
\hline Ramesh (2008) & $\dot{\varepsilon}_{\mathrm{lim}}=\frac{1}{l_{\mathrm{s}}} \sqrt{\frac{\sigma}{\rho}} r\left(\frac{192}{32+3 / \beta^{2}}\right)$ & $\begin{array}{l}\sigma \text { actual yield stress of the } \\
\text { material } \\
r \text { relative error in stress } \\
\text { measurement }\end{array}$ & $\begin{array}{l}L_{\mathrm{s}}, \rho_{\mathrm{s}} \\
\beta=D_{\mathrm{s}} / L_{\mathrm{s}}\end{array}$ & $\begin{array}{l}\text { Consideration of CSR and inertia } \\
\text { effect }\end{array}$ \\
\hline
\end{tabular}

Refer to the original papers for the definition of some undefined parameters in this review

The suggested limit of strain rate should be the minimum of these estimating equations, taking the conditions of SE and CSR into account, i.e.

$$
\dot{\varepsilon}_{\lim }=\min \left\{\frac{\varepsilon_{\mathrm{f}} C_{\mathrm{s}}}{n L_{\mathrm{s}}}, \frac{\beta \varepsilon_{\mathrm{f}}}{\tau(\beta / \eta-1)}, \frac{1}{L_{\mathrm{s}}} \sqrt{\frac{\sigma}{\rho} r\left(\frac{192}{32+3 / \beta^{2}}\right)}\right\} .
$$

Attempts have also been made to reduce the strain rate by using (1) a very long bar (Gilat and Matrka 2011; Song et al. 2008), (2) a very large-diameter (from 50 to $100 \mathrm{~mm}$ ) bar (Li et al. 2005; Albertini et al. 1999) and (3) a 'slow bar' technique (Zhao and Gary 1997). Large bar diameters have been widely used for rock-like materials; however, they have specific disadvantages and challenges when testing rock-like materials, i.e. (1) launching the striker requires substantial gun facilities; (2) specimens with large diameter need a longer time to reach stress equilibrium, the assumption of which is thus violated; and (3) for small strain to failure, the effects of friction, inertia and wave dispersion become more significant. The applicability of the conventional SHPB technique needs to be carefully examined before interpretation of reliable dynamic experimental data is possible.

\section{Measurement Techniques for High Rate Deformation}

The ability to quantitatively obtain dynamic mechanical properties and deformation fields, to fully understand failure mechanisms and to effectively validate theoretical models of material behaviour is largely dependent on measurement techniques. Traditional contact measurement techniques such as electrical resistance strain gauges and mechanical extensometers have limitations in terms of measuring range and frequency response and do not provide enough information to address the complexity of the dynamic mechanical behaviour. In terms of high-speed, high-resolution and microscopic monitoring and observation, optical techniques such as photoelasticity, moiré, interferometry, caustics, coherent gradient sensors and digital image correlation (DIC) must be advocated to represent fracture processes and failure mechanisms, and can also help in examining proposed hypotheses and establishing constitutive models, as well as validating numerical simulations. A critical review on optical techniques for high rate deformation has been presented by Field et al. (2004). It should be noted that most of these techniques require many optical components and somewhat elaborate surface preparation of the specimen; therefore they are only applicable for transparent materials. For heterogeneous materials, such as concrete, composite and rock material, inhomogeneous deformation and strain localization demand more sophisticated measurement techniques. High-speed photography has been widely used since it was first used in SHPB testing of rock materials (Perkins and Green 1968). However, the goal in using high-speed imaging is quantitative and accurate measurement of data as another diagnostic tool in research, rather than just for imaging in the qualitative sense. The Handbook of Experimental Solid Mechanics (Hartley 2008) provides detailed theories of measurement techniques. In this section, we only outline the most frequently used optical techniques and their applications to rock materials, but do not consider them as an integral part of loading techniques.

\subsection{Laser Measurement Techniques}

The equipment required for these techniques usually consists of three major components: an optical arrangement for generating a laser sheet of uniform intensity per unit length, optics and photoelectronics for detecting and measuring the light, and the necessary mounting system. The laser occlusive radius detector was developed to measure radial deformations of a specimen in dynamic compression (Ramesh and Narasimhan 1996) and tension 
Fig. 5 Isochromatic-fringe patterns around a crack propagating in a marble plate dynamically loaded by a steel wedge in notch technique; interframe interval is $4 \mu \mathrm{s}$, and crack propagation velocity is $965 \mathrm{~m} / \mathrm{s}$. Reproduced from Daniel and Rowlands (1975, Fig. 13, p. 457)

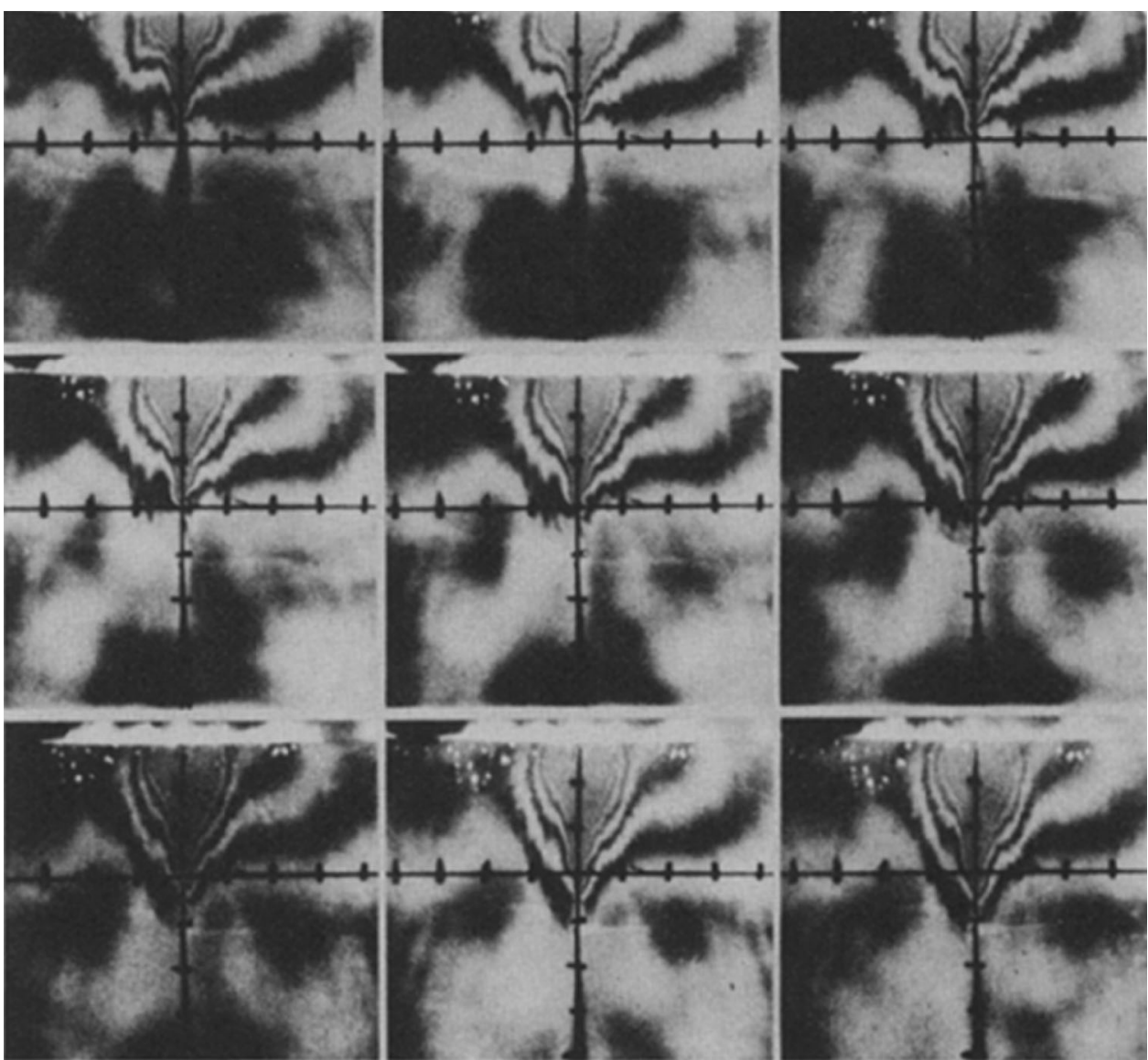

(Li and Ramesh 2007) tests. Laser/light passing-detection techniques were developed by Tang and Xu (1990), in which the luminous flux passing through a narrow chink on the specimen increases with increase of the crack opening displacement (COD), which in turn leads to increase of the illuminated area. Because the electrical signal is proportional to the light signal, the groove-opening displacement can be recorded by using transient waveform storage. A laser gap gauge (LGG) system was developed to measure the COD history (Chen et al. 2009) in SHPB testing. Attention should be paid to the following factors: the very high frequency of the laser/light detector; the calibration of the technique before the test; its successful application for testing with large deformations, although remaining a challenge for testing of quasi-brittle materials; and the roughness of the fracture surface in the COD measurement.

\subsection{Photoelastic Coating}

Although photoelectric techniques are most widely used for transparent materials, it is also possible to examine the dynamic fracture characteristics of opaque materials by using photoelastic coating techniques. Studies of wave and fracture propagation using coatings have been performed previously by several researchers (Daniel and Rowlands
1975; Glenn and Jaun 1978); however, the results obtained were qualitative. Figure 5 shows isochromatic-fringe patterns around a crack propagating in a marble specimen dynamically loaded by a steel wedge in notch technique (Daniel and Rowlands 1975). A continuous sheet of birefringent coating over the specimen was employed. The use of a continuous coating caused uncertainty since the coating responded to fracture in the specimen and to failure of the coating itself (Daniel and Rowlands 1975). This problem may be alleviated by using a split birefringent coating where a separate sheet of coating is bonded to either side of the anticipated path of the crack. In addition, the technique needs many optical components and elaborate surface preparation of the specimen.

\subsection{Moiré}

Moiré techniques have been developed to measure in-plane and out-of-plane displacement fields. For in-plane displacements, experimental stress-analysis techniques have been used to study wave and fracture propagation in rock specimens (Daniel and Rowlands 1975; Yu and Zhang 1995; Zhang et al. 1999). The process of wave propagation was observed through isochromatic-fringe patterns on bonded photoelastic coatings and moiré-fringe patterns 

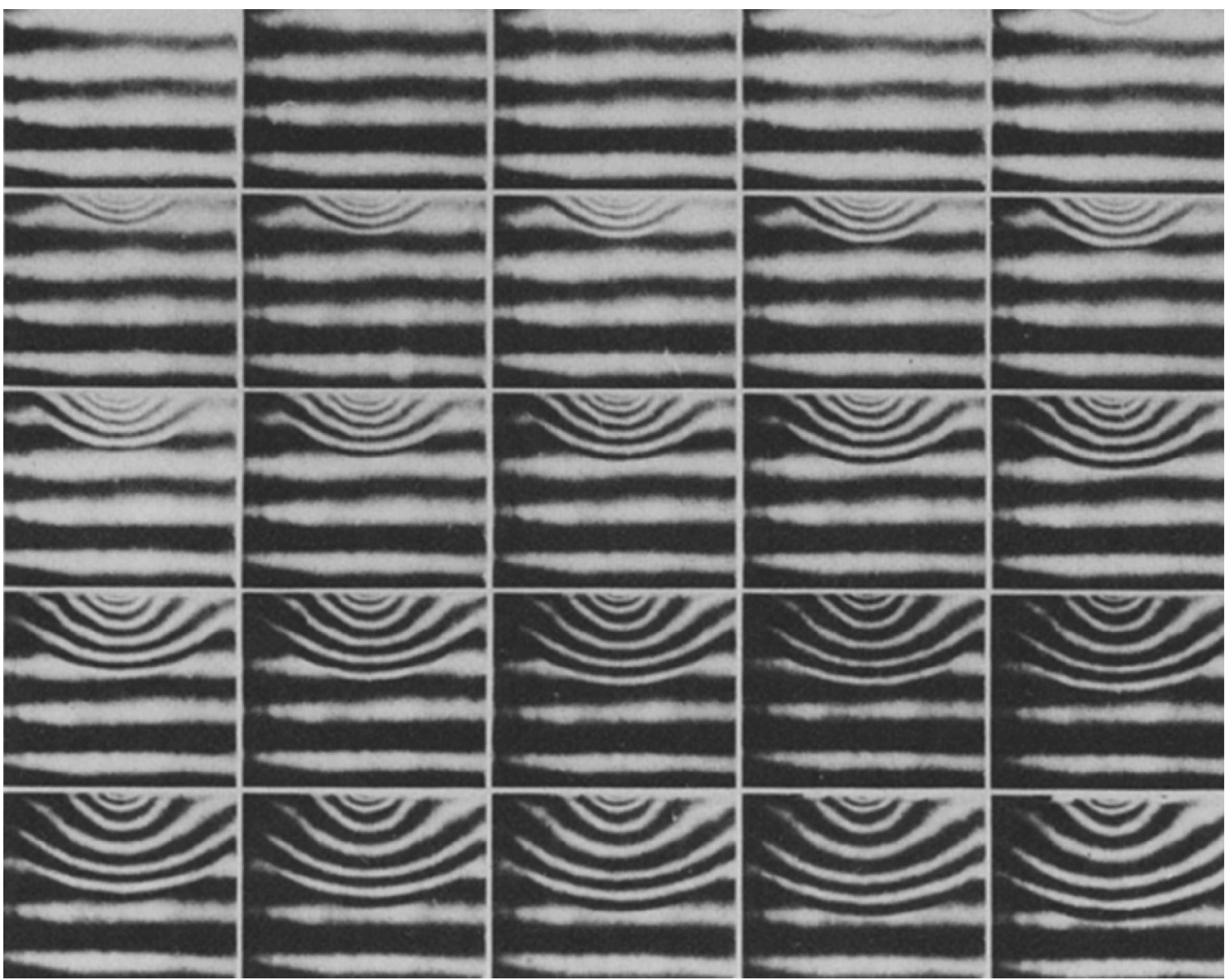

Fig. 6 Moiré-fringe patterns corresponding to vertical displacements in a marble specimen dynamically loaded on the edge; camera speed 1,004,500 frames/s; ruling 400 lines/cm. Reproduced from Daniel and Rowlands (1975, Fig. 6, p. 453)

(Daniel and Rowlands 1975), as shown in Fig. 6. A detailed experimental procedure was given to determine dynamic fracture parameters in SHPB testing ( $\mathrm{Yu}$ and Zhang 1995; Zhang et al. 1999): two pieces of grating were installed near the notch of a cracked specimen to form the moiré fringe, then the value of COD versus time could be monitored from the movement of the moiré fringes, and finally the time to fracture could be determined from the COD velocity.

\subsection{Caustics}

The method of caustics has been popular in dynamic fracture investigations of transparent materials (Field et al. 2004; Ravi-Chandar 2004), and it can equally well apply when light rays are reflected from the surface of an opaque specimen. The following changes should be taken into account: the screen plane behind the specimen is a virtual plane captured by focussing the camera on this plane; only the thickness of the specimen contributes to the formation of caustic images (Ravi-Chandar 2004). Figure 7 shows dynamic caustic images of a three-point bending (TPB) rock specimen impacted by a drop-weight machine (Yang et al. 2009). The dynamic stress intensity factor (SIF) can be determined by measurements of the transverse diameter of the caustic curve.

\subsection{Holographic Interferometry}

Holloway et al. (1977) presented the application of holographic interferometry for visualization of wave propagation in Westerly granite. To improve the coherence properties, a pulsed ruby laser was applied as the light source in their studies. Cai and Liu (2009) recently observed the evolution of deformation and cracking in rock materials using laser holographic interferometry. Although the technique produces very high-quality fringe patterns and requires no specimen preparation, it should be performed in a dark space and requires seismic isolation. Therefore, it is difficult to perform in combination with dynamic loading techniques and to record sequences of holograms using a high-speed camera. 
Fig. 7 Dynamic caustic images of a three-point bending rock specimen impacted by a dropweight machine; the inter-frame time may be found in Yang et al. (2009). After Yang et al. (2009, Fig. 3, p. 81)
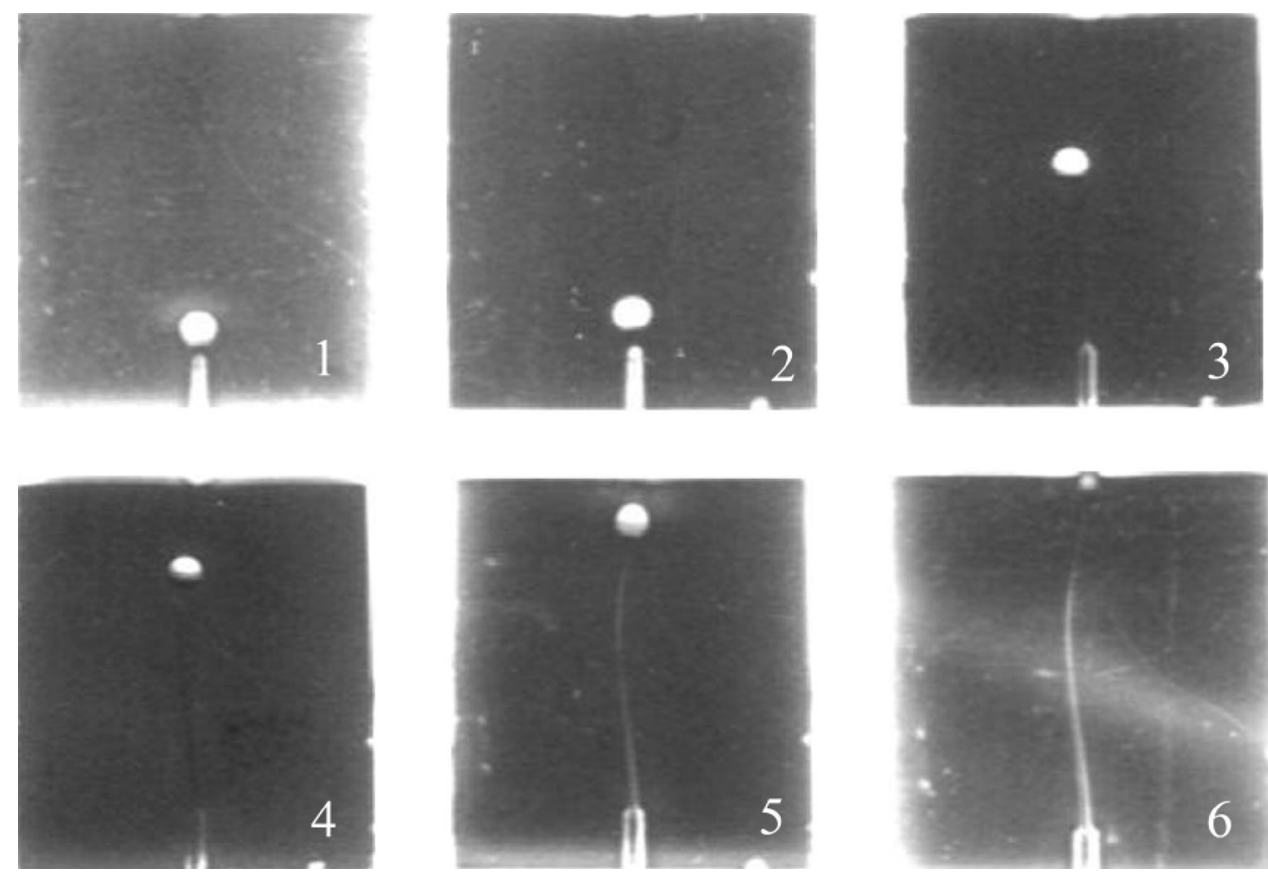

\subsection{Digital Image Correlation}

The DIC technique has been particularly popular for brittle heterogeneous materials across a wide range of length and time scales (Sutton et al. 2009; Field et al. 2004; Siviour and Grantham 2009; Zhang and Zhao 2013a). On the one hand, the technique has no inherent length scale, and thus is applicable to experiments covering a broad range of fields of view not only from the nano/microscale to the field scale, but also from two dimensions (2D) to three dimensions (3D). On the other hand, with recent progress in the advent of high-speed cameras with high spatial and temporal resolution, advanced image processing methods and high-speed computation, the DIC technique has also been applied to testing over a wide range of loading rates (Zhang and Zhao 2013a). For details of applications of the HS-DIC technique to rock-like materials, refer to Sect. 4.1.3.

\subsection{Dynamic Infrared Thermography}

There has been renewed interest in the energy dissipation and temperature rises associated with bulk dynamic deformation and fracture. Infrared thermography has great potential to be exploited in these fields by transforming the thermal energy emitted by objects in the infrared band of the electromagnetic spectrum into a visible image. However, this technique is still not adequately assessed in the application of rock dynamics, because of a lack of adequate knowledge; at first sight, it seems too expensive and difficult to use (Carosena and Giovanni 2004). Figure 8 shows transient target thermographs of a marble plate after impaction at different impacting velocities (Shi et al. 2007).
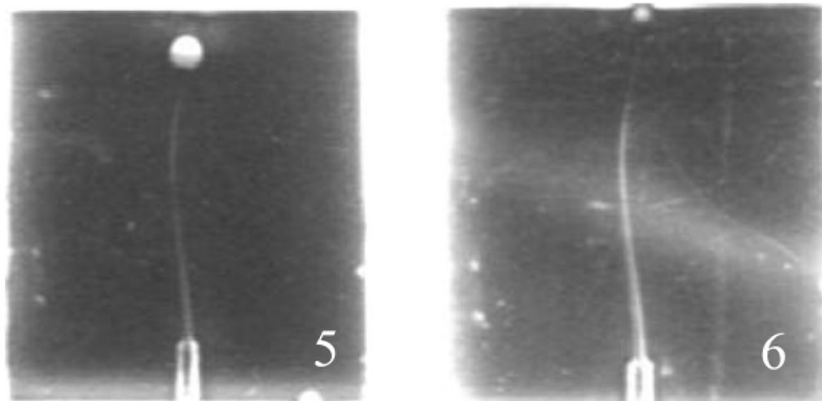

\section{Dynamic Mechanical Properties and Fracture Behaviour}

The dynamic mechanical behaviour of rock materials has been extensively studied; in particular, significant progress in experimental methodology has been made with the advent of HSR loading techniques starting from the work of Kolsky (1949), as well as high-speed and high-resolution measurement techniques (Perkins and Green 1968). It has been previously presented that mechanical properties of rock materials are sensitive to loading rate, and a definite increase in mechanical properties has been commonly recognized. Thorough knowledge is required to properly design rock engineering structures for all types of loading likely to be encountered during the design lifetime. Although an increase of about $30 \%$ is suggested for the design compressive strength for engineering structures under dynamic loading (Agbabian 1985), the enhancement of mechanical properties seems higher than this value. Therefore, a current and comprehensive review of dynamic mechanical properties is essential for engineering design.

Mechanical properties (e.g. strength and fracture toughness) and fracture behaviours (e.g. single fracturing, multiple fracturing and pulverization) exhibit a general trend; i.e. they change with the loading rate. In particular, the responses distinguishably change after the loading rate exceeds a critical value $\left(\dot{\varepsilon}_{\text {cri }}\right)$, as shown schematically in Fig. 9. Dynamic experimental results are usually presented as the ratio of the measured dynamic strength/toughness to that in the quasi-static test. This ratio, generally referred to as the dynamic increase factor or normalized dynamic strength $\left(\sigma_{\mathrm{d}} / \sigma_{\mathrm{s}}\right)$, is usually presented as a function of the 
Fig. 8 Transient target thermographs of marble plates impacted by split Hopkinson bar at different impacting velocities (reproduced from Shi et al. 2007, Fig. 4, p. 995)

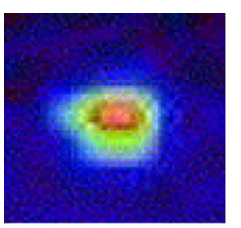

$v=7.1 \mathrm{~m} / \mathrm{s}$

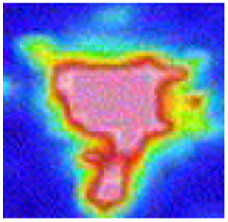

$v=18.0 \mathrm{~m} / \mathrm{s}$

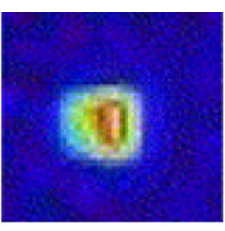

$\nu=8.5 \mathrm{~m} / \mathrm{s}$

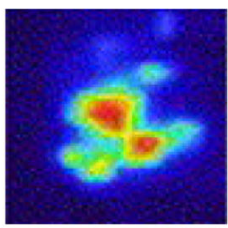

$v=20.8 \mathrm{~m} / \mathrm{s}$

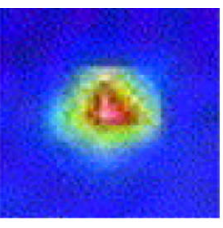

$\nu=9.8 \mathrm{~m} / \mathrm{s}$

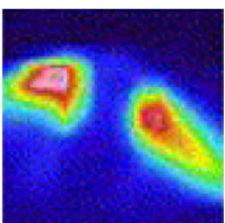

$v=23.4 \mathrm{~m} / \mathrm{s}$

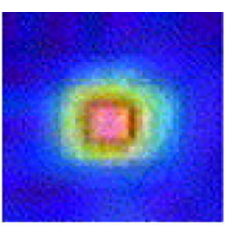

$\nu=12.1 \mathrm{~m} / \mathrm{s}$

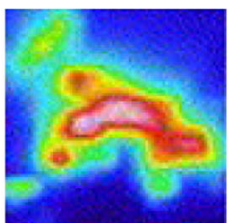

$v=26.6 \mathrm{~m} / \mathrm{s}$

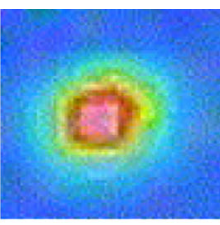

$\nu=14.7 \mathrm{~m} / \mathrm{s}$

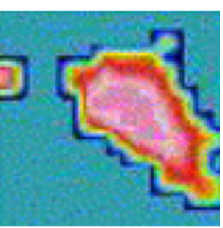

$\nu=30.2 \mathrm{~m} / \mathrm{s}$

logarithm of loading rate. The loading rate has been indicated variously by the time to failure (i.e. the loading duration), the instantaneous stress rate (i.e. the slope of the stress-time response) or strain rate, the average stress or strain rate, or sometimes the rate of piston travel. Also, because of the nature of loading required for rapid straining and the complicated specimen configurations, the rate of loading or straining has not always been constant. Dynamic mechanical properties and fracture behaviours largely depend on the loading and measurement technique, testing method and influencing environmental factors. The following subsections present a detailed description of the quantitative interpretation of each mechanical property and a summary of the corresponding results.

\subsection{Dynamic Testing Methods}

Suggested methods (SM) from the ISRM and American Society for Testing and Materials (ASTM) for determining mechanical properties of rock materials under quasi-static loading are based on core-shaped samples, since such specimens can be easily prepared. Although three dynamic testing methods (uniaxial compression, Brazilian disc and notched semi-circular bend tests) have recently been suggested by the ISRM (Zhou et al. 2012), some suspicious and unclear points need to be addressed. Most dynamic testing methods are extended or modified from quasi-static ones, as summarized in Table 3 , which also includes measurement techniques and methods for interpreting experimental data.

\subsubsection{Uniaxial Compression Tests}

In quasi-static tests, the rock specimen is recommended to be a circular cylinder with length-to-diameter ratio $\left(L_{\mathrm{s}} / D_{\mathrm{s}}\right)$ of 2.5-3.0, and the diameter should be related to the size of the largest grain by a ratio of at least 10:1 (ISRM 1979). The numerous uniaxial compression tests conducted under

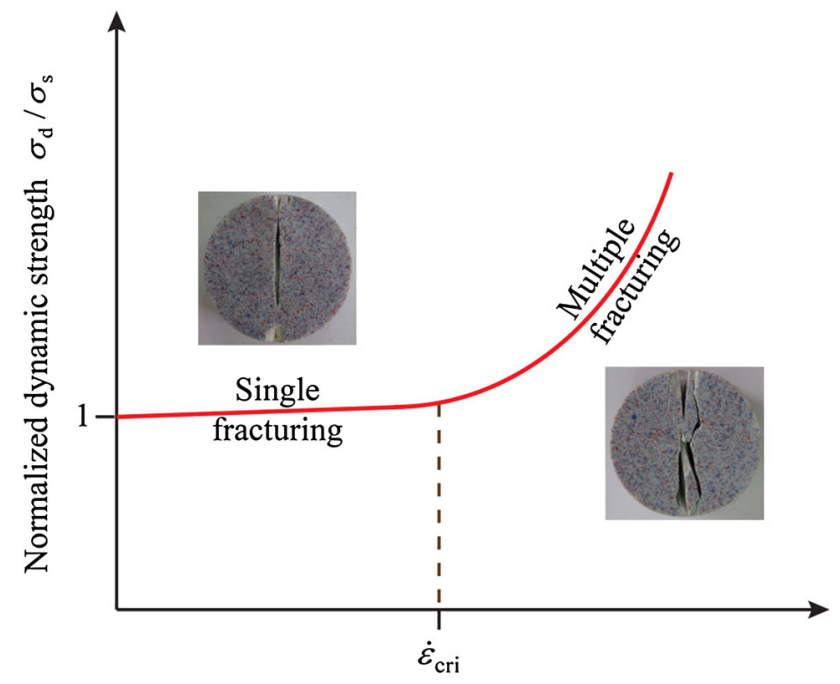

Strain rate $\log (\dot{\varepsilon})$

Fig. 9 Schematic of normalized mechanical properties and failure patterns of rock materials at various strain rates

dynamic loading differ in the measurement type and in the size, shape (e.g. cube, cylinder or prism) and aspect ratio of the specimens. In ISR tests, the size and shape of the specimen are normally defined by the same value of the ratio $L_{\mathrm{s}} / D_{\mathrm{s}}$ of 2.5-3.0 as suggested for quasi-static tests. The design of the specimen should obey the following general assumptions during a SHPB test: (1) the specimen deforms uniformly, which implies that there is no friction or inertia effect; (2) the specimen is in stress equilibrium; and (3) the specimen is under a uniaxial stress condition. As previously noted, Davies and Hunter (1963) firstly suggested that there exists an optimal ratio $\left(L_{\mathrm{s}} / D_{\mathrm{s}}=\sqrt{3 v} / 2\right)$ to minimize the inertia effect. Friction and inertia effects can be lessened by minimizing the area mismatch between the specimen and the bars $\left(D_{\mathrm{s}} \approx 0.8 D_{\mathrm{B}}\right)$ and choosing the $L_{\mathrm{s}} / D_{\mathrm{s}}$ ratio between 0.50 and 1.0 (Gray 2000). The specimen diameter needs to be large enough to 
Table 3 Summary of primary testing methods for determining mechanical properties of rock materials under both quasi-static and dynamic loading conditions

\begin{tabular}{|c|c|c|c|c|c|}
\hline $\begin{array}{l}\text { Loading } \\
\text { type }\end{array}$ & $\begin{array}{l}\text { Testing } \\
\text { methods }\end{array}$ & Quasi-static properties & Dynamic properties & $\begin{array}{l}\text { Calculation for } \sigma_{\mathrm{d}}(t), \\
K_{\mathrm{I}}^{\mathrm{dyn}}(t ; v)\end{array}$ & $\begin{array}{l}\text { Determination of } \\
\sigma_{\mathrm{d}}, K_{\mathrm{Id}, \mathrm{D}}\left(t_{\mathrm{f}} ; v\right)\end{array}$ \\
\hline Tension & DT & $\sigma_{\mathrm{t}}(\mathrm{ASTM} 2008 \mathrm{a})$ & $\begin{array}{l}\sigma_{\text {td }}(\text { Cadoni 2010; Goldsmith } \\
\text { et al. 1976) }\end{array}$ & $\begin{array}{l}\text { Pressure transducer or SG } \\
\text { on bars }\end{array}$ & Peak load \\
\hline \multirow[t]{11}{*}{ Compression } & $\mathrm{BD}$ & $\sigma_{\mathrm{t}}(\mathrm{ISRM} 1978)$ & $\begin{array}{l}\sigma_{\mathrm{td}}(\text { Zhao and Li 2000; Zhou } \\
\text { et al. 2012) }\end{array}$ & & \\
\hline & FBD & $\sigma_{\mathrm{t}}$ (Wang et al. 2004) & $\sigma_{\text {td }}($ Wang et al. 2009) & & \\
\hline & $\mathrm{UC}$ & $\sigma_{\mathrm{uc}}($ ISRM 1979) & $\sigma_{\text {ucd }}($ Zhou et al. 2012) & & \\
\hline & $\mathrm{TC}$ & $\sigma_{\mathrm{tc}}($ ISRM 1983) & $\sigma_{\text {tcd }}($ Christensen et al. 1972) & & \\
\hline & Shear & $\begin{array}{l}\tau \text { (Ulusay et al. 2001; Stacey } \\
\text { 1980) }\end{array}$ & $\begin{array}{l}\tau_{\mathrm{d}} \text { (Zhao et al. 1998; Huang } \\
\text { et al. 2011a) }\end{array}$ & & \\
\hline & $\mathrm{HC}(\mathrm{F}) \mathrm{BD}$ & $K_{\text {IC }}$ (Fischer et al. 1996) & $K_{\text {Id }}$ (Wang et al. 2010c) & FEM modelling and SG & SG \\
\hline & $\mathrm{CST}(\mathrm{F}) \mathrm{BD}$ & $K_{\mathrm{IC}}, K_{\mathrm{IIC}}$ (Atkinson et al. 1982) & $\begin{array}{l}K_{\text {Id }}, K_{\text {IId }}(\text { Wang et al. 2011a; } \\
\text { Nakano et al. 1994) }\end{array}$ & & \\
\hline & SR & $K_{\text {IC }}($ Ouchterlony 1988) & $\begin{array}{l}K_{\mathrm{Id}}(\text { Zhang et al. 2000) } \\
K_{\mathrm{Id}}(\text { Costin 1981) }\end{array}$ & $\begin{array}{l}\text { Quasi-static theory, FEM } \\
\text { calibrating } f(a / R)\end{array}$ & $\begin{array}{l}\text { Dynamic moiré } \\
\text { Peak load }\end{array}$ \\
\hline & WLCT & $K_{\text {IC }}($ Klepaczko et al. 1984) & $K_{\text {Id }}($ Klepaczko et al. 1984) & & \\
\hline & HCBD & $K_{\text {IC }}($ Fischer et al. 1996) & $K_{\text {Id }}($ Lambert and Ross 2000) & & \\
\hline & CCNBD & $K_{\mathrm{IC}}($ Fowell 1995) & $K_{\text {Id }}$ (Dai et al. 2010a) & & \\
\hline \multirow[t]{8}{*}{ Bending } & ТРВ & $\sigma_{\mathrm{t}}($ Jaeger 1967) & $\sigma_{\mathrm{td}}($ Zhao and Li 2000) & & \\
\hline & SCB & $\sigma_{\mathrm{t}}($ Van de Ven et al. 1997) & $\sigma_{\mathrm{td}}$ (Dai et al. 2008) & & \\
\hline & SENB & $K_{\mathrm{IC}}(\mathrm{ASTM} 2011)$ & $\begin{array}{l}K_{\mathrm{Id}}(\text { Tang and Xu } 1990 ; \\
\text { Zhao et al. 1999b) }\end{array}$ & & \\
\hline & CCNSCB & $K_{\text {IC }}$ (Kuruppu 1997) & $K_{\text {Id }}$ (Dai et al. 2011) & & \\
\hline & NSCB & $K_{\text {IC }}$ (Chong and Kuruppu 1984; & $K_{\text {Id }}($ Chen et al. 2009) & & \\
\hline & & Kuruppu et al. 2013) & $K_{\mathrm{ID}}($ Chen et al. 2009) & Thermodynamics + LGG & LGG, HS camera \\
\hline & & & $K_{\text {Id }}($ Zhang and Zhao 2013a) & Quasi-static theory & SG, CPG, DIC, HS \\
\hline & & & $K_{\mathrm{ID}}$ (Zhang and Zhao 2013b) & $\mathrm{FEM}+\mathrm{SG}$ & camera \\
\hline
\end{tabular}

$D T$ direct tension, $H C B D$ holed cracked BD, $T C$ triaxial compression, $T P B$ three-point bending, $\sigma_{\mathrm{t}}$ tensile strength, $\sigma_{\mathrm{uc}}$ uniaxial compressive strength, $\sigma_{\text {tc }}$ triaxial compressive strength, $\tau$ shear strength, $K_{\mathrm{IC}}, K_{\mathrm{IIC}}$ mode I, II fracture toughness; the subscript 'd' after the quasi-static subscript is used for dynamic mechanical properties, $K_{\mathrm{Id}}, K_{\mathrm{ID}}$ dynamic crack initiation, propagation toughness, $\sigma_{\mathrm{d}}(t)$ dynamic stress history, $K_{\mathrm{I}}^{\mathrm{dyn}}(t ; v)$ dynamic stress intensity factor as a function of time and crack velocity, $f(a / R)$ geometric correction function, $S G$ strain gauge, $L G G$ laser gap gauge, FEM finite-element method, $\sigma_{\mathrm{d}}$ dynamic strength, $t_{\mathrm{f}}$ time to fracture, $C P G$ crack propagation gauge, $H S$ high speed

contain 1,000 or more structural grains, but small enough to consider stress equilibrium and to minimize the inertia effect (Siviour and Grantham 2009). Furthermore, as recently suggested by the ISRM (Zhou et al. 2012), the diameter should be close to $50 \mathrm{~mm}$ or at least 10 times the average grain size, with the ratio $L_{\mathrm{s}} / D_{\mathrm{s}}$ taking values of $1: 1$ and $0.5: 1$ for small and large specimens, respectively.

\subsubsection{Triaxial Compression Tests}

There are two main types of methods to subject a specimen to multiaxial loading, through either a pressure or displacement boundary condition (Chen and Song 2011). The pressure boundary condition is achieved through hydrostatic pressure by a hydraulic confining chamber or a truetriaxial loading apparatus, as shown in Fig. 10a, b. In such a test, the specimen is placed inside a pressure chamber and isotropically loaded by hydrostatic pressure using various confining fluids (e.g. air, water and hydraulic oil). The confining pressure can be applied using water or hydraulic oil (up to $50 \mathrm{MPa}$ ) or using air (up to $10 \mathrm{MPa}$ ) (Gary and Bailly 1998), and the deformation is measured by resistance wire extensometers/strain gauges mounted on the specimen. Maintaining the hydrostatic pressure constant, additional axial loads are applied by either a loading piston or an incident bar for ISR or HSR testing. Although a truetriaxial loading apparatus has been designed (Cadoni and Albertini 2011), the very short loading times do not enable one to carry out multiaxial dynamic loading in synchronicity. The displacement boundary condition is typically achieved by using either a shrink-fit metal sleeve or a passive thick vessel jacketing the cylindrical surface of the 
Fig. 10 Four types of designs for dynamic triaxial compression tests: a hydrostatic confining chamber, $\mathbf{b}$ triaxially compressed Hopkinson bar (TriHB) (reproduced from Cadoni and Albertini 2011),

c shrink-fit metal sleeve, and d passive thick vessel

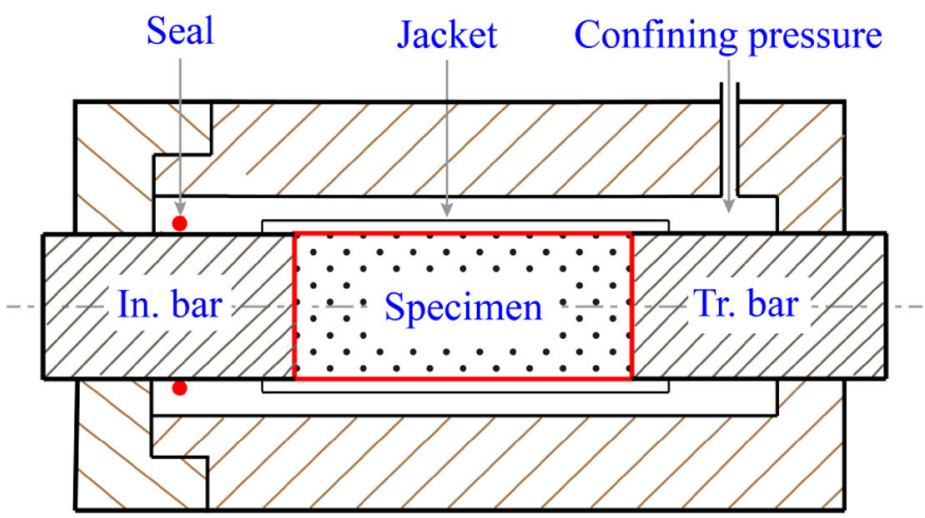

(a)

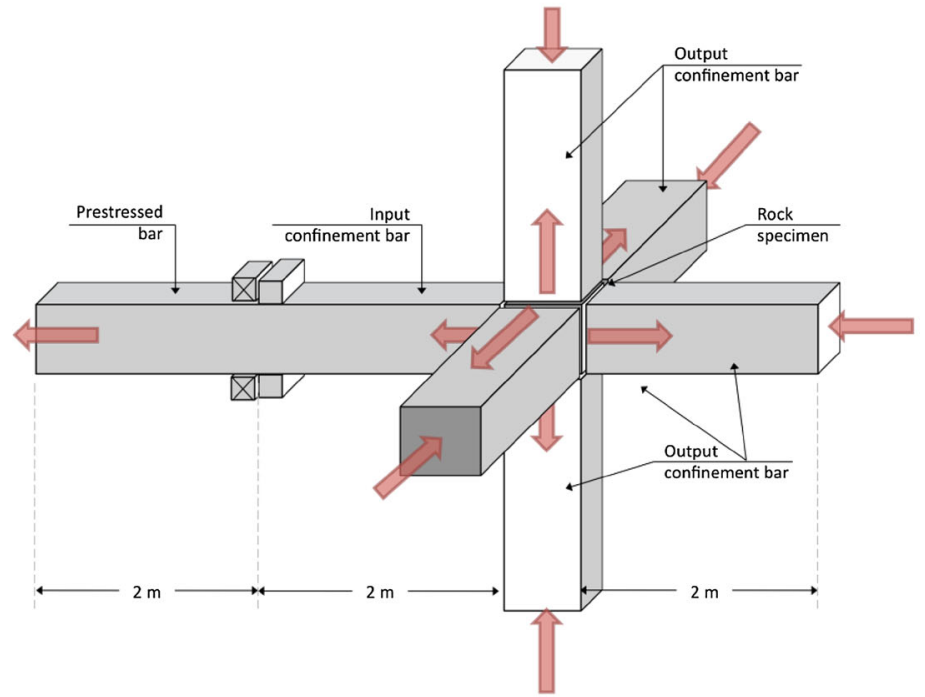

(b)

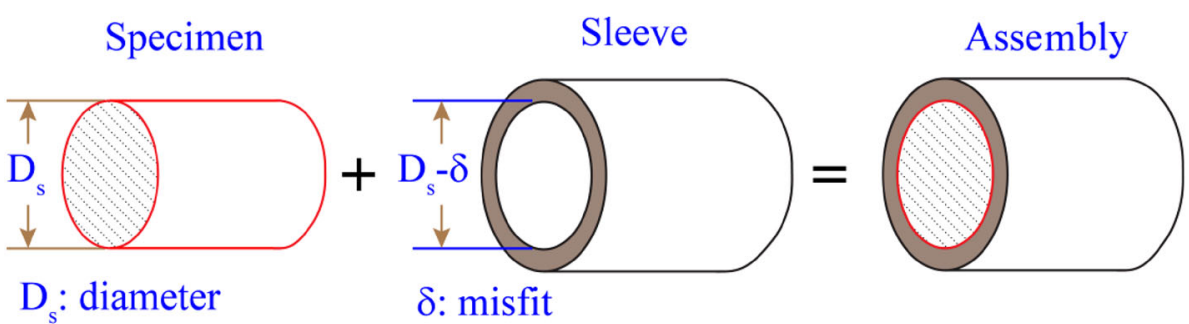

(c)

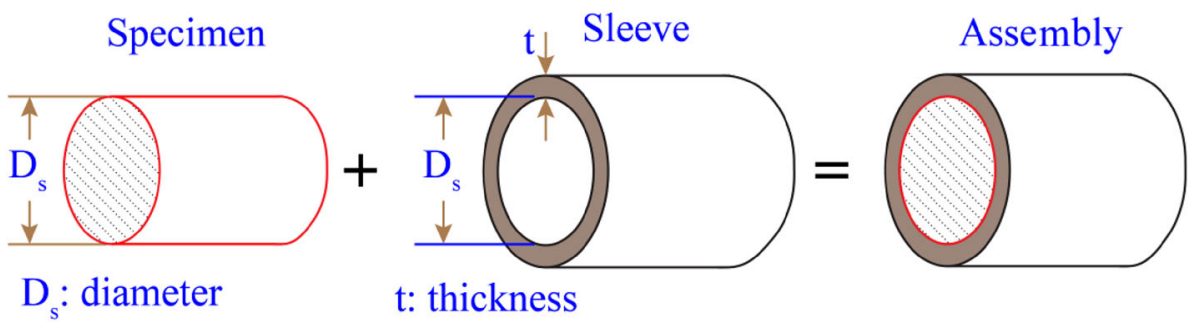

(d) 
specimen, as shown in Fig. 10c, d. The confining pressure depends on the thickness and material type of the sleeve. Strain gauges are mounted on the sleeve surface to record the stress state of the specimen. Chen and Ravichandran (1997) firstly employed a shrink-fit metal sleeve to impose controlled lateral confinement on a cylindrical specimen, as further performed by Rome et al. (2004), Forquin et al. (2008) and Nemat-Nasser et al. (2000). Another passive confining jacket system provides an inexpensive method to study experimentally the multiaxial compressive response of rock-like specimens (Gong and Malvern 1990).

Some specific technical factors should be taken into account for the hydrostatic confining apparatus: (1) whether the confining pressure is constant or not during the test (Malvern et al. 1991; Gary and Bailly 1998); (2) it cannot apply high pressure; and (3) such work is time-consuming. For the passive confining techniques, one must also consider: (1) ensuring that no gap exists at the specimensleeve interface, (2) that the specimen should be under uniform axial and radial deformation and (3) frictional stresses, especially at the specimen-sleeve interface.

A summary presenting a classification and the major developments of dynamic confining pressure tests for rocklike materials is presented in Table 4. There exist general trends for: an increase of triaxial strength with increasing strain rate at all confining pressures; an increase of triaxial strength with increasing confining pressure, as had been demonstrated in quasi-static tests; the deformation behaviour to become more ductile at HSR; and a lower confining pressure than in quasi-static tests, in particular for sedimentary materials (Logan and Handin 1970; Friedman and Logan 1973; Frew et al. 2010; Sato et al. 1981; Green et al. 1972) and granite for small sizes (Yuan et al. 2011). The detailed results are given in Sect. 4.4.

\subsubsection{Tension Tests}

There have been two types of standard methods, i.e. direct tension (ISRM 1978; ASTM 2008a) and indirect tension (ISRM 1978; ASTM 2008b) tests, suggested by the ISRM and ASTM for determining the quasi-static tensile strength of rock materials. Coviello et al. (2005) critically assessed quasi-static testing methods and experimental results, namely the direct tension, BD, ring, three- and four-point bending and Luong methods. For dynamic loading, Malvar and Ross (1998) presented a short review summarizing experimental data to characterize the dynamic tensile strength of concrete, and proposed a modified Comité EuroInternational du Béton (CEB) formulation on the basis of experimental results. In-depth numerical investigations have been performed to examine testing methods of DT, BD and spalling (Lu and Li 2011) and the DT method (Cotsovos and Pavlovic 2008) on concrete. Numerous dynamic tension tests on rock materials have been performed (e.g. Cadoni 2010; Asprone et al. 2009; Goldsmith et al. 1976; Wang et al. 2009; Dutta and Kim 1993; Kubota et al. 2008; Cho et al. 2003; Khan and Irani 1987; Howe et al. 1974; Zhang and Zhao 2013a; Yan et al. 2012; Huang et al. 2010a, b; Dai et al. 2010c, d; Dai and Xia 2010; Zhao and Li 2000; Zhao et al. 1998). As outlined in Table 3, dynamic tension testing methods are being continuously modified and improved from the original quasi-static ones to precisely determine the dynamic tensile strength. Tension tests can be approximately categorized into four groups: DT-type (Asprone et al. 2009), BD-type [BD (Zhou et al. 2012) and FBD (Wang et al. 2009)], bending type [TPB (Zhao and Li 2000) and SCB (Dai et al. 2008)] and spalling (Klepaczko and Brara 2001; Wu et al. 2005; Gálvez et al. 2002; Schuler et al. 2006; Erzar and Forquin 2010; Kubota et al. 2008) methods, as summarized in Table 5.

From the experimental point of view, even under quasistatic loads, direct tension tests are difficult to perform because even very slight misalignments and stress concentrations in the loading system may produce undesirable failure modes. For ISR values ranging from $10^{-1}$ to $10^{0} \mathrm{~s}^{-1}$, Cadoni and co-workers performed direct tension tests on Neapolitan tuff (Asprone et al. 2009) and Onsernone anisotropic orthogneiss (Cadoni 2010) using a hydropneumatic machine. At higher strain rate, several different versions of SHTB have been developed, as shown schematically in Fig. 11 (ASM 2000; Cadoni and Albertini 2011). As compared with SHPB testing, the techniques used to grip specimens in SHTB tests are much more complicated. Screw or clamp connections are widely used for metal or ductile materials; however, rock specimens are either glued onto or threaded into the ends of both bars using high-strength epoxy resin. Pioneering work on direct tension tests was conducted on bone-shaped specimens of transversely isotropic Yule marble (Howe et al. 1974) and anisotropic Barre granite (Goldsmith et al. 1976) using the SHTB as shown in Fig. 11a with ballistic impact. Huang et al. (2010a) performed tests on dumbbell-shaped specimens of Laurentian granite using the modified SHTB of Fig. 11b with a striker tube. Cadoni and co-workers performed direct tension tests on Neapolitan tuff (Asprone et al. 2009) and Onsernone anisotropic orthogneiss (Cadoni 2010) using the SHTB of Fig. 11d with a pre-stressed bar. The effects of microstructure and strain rate on the tensile strength of rock materials (Howe et al. 1974; Goldsmith et al. 1976; Cadoni 2010) are described in Sect. 4.8.4. The complicated specimen geometry and the SHPB techniques make it more challenging to check the testing conditions, as mentioned in Sect. 2.2, and to accurately measure the stress and strain in the specimen.

The limitations on direct tension tests include the following: (1) the same limitations as for quasi-static tests; (2) 
Table 4 Classification and major developments of dynamic testing of rock-like materials under confining pressure

\begin{tabular}{|c|c|c|c|c|c|c|}
\hline Class & Rock type & $\begin{array}{l}\text { Dimensions } \\
\left(D \times L, \mathrm{~mm}^{2}\right) \text { or } \\
\left(L \times W \times H, \mathrm{~mm}^{3}\right)\end{array}$ & $\begin{array}{l}\text { Max. } \\
\text { pressure } \\
(\mathrm{MPa})\end{array}$ & $\begin{array}{l}\text { Strain } \\
\text { rate } \\
\left(\mathrm{s}^{-1}\right)\end{array}$ & Research activities & References \\
\hline \multicolumn{7}{|c|}{ I. $\sigma_{1}>\sigma_{2}=\sigma_{3}>0$} \\
\hline \multirow[t]{10}{*}{$a^{\text {ISR }}$} & $\begin{array}{l}\text { B-sandstone, } \\
\text { S-limestone, } \\
\text { Gabbro }\end{array}$ & $\begin{array}{l}12.7 \times 25.4 \\
19.05 \times 38.1\end{array}$ & 138 & $\sim 10^{-1}$ & $\begin{array}{l}P_{\mathrm{c}} \text { (confining pressure), } T \text { (temperature), and } \dot{\varepsilon} \text { dependent; } \\
\text { shear failure patterns under } P_{\mathrm{c}}\end{array}$ & $\begin{array}{r}\text { Serdengecti and } \\
\text { Boozer }(1961)\end{array}$ \\
\hline & W-granite & $20 \times 40$ & 700 & $\begin{array}{c}10^{-2}- \\
10^{0}\end{array}$ & Brittle failure, no brittle-ductile (B-D) transition & $\begin{array}{l}\text { Logan and Handin } \\
\text { (1970) }\end{array}$ \\
\hline & S-limestone & $20 \times 40$ & 300 & $10^{-2}-$ & B-D transition: $P_{\mathrm{c}}=150 \mathrm{MPa}$ at $\dot{\varepsilon}=10 \mathrm{~s}^{-1}$ & $\begin{array}{l}\text { Logan and Handin } \\
\text { (1970), Friedman } \\
\text { and Logan (1973) }\end{array}$ \\
\hline & $\begin{array}{l}\text { Siltstone, } \\
\text { Sandstone }\end{array}$ & $76.2 \times ?$ & 103 & $\sim 10^{0}$ & Rise and decay times: 3 and $20 \mathrm{~ms}$; no results & $\begin{array}{l}\text { Ehrgott and Sloan } \\
\text { (1971) }\end{array}$ \\
\hline & $\begin{array}{l}\text { S-limestone, } \\
\text { W-granite }\end{array}$ & $25.4 \times 50.8$ & 300 & $\sim 10^{-1}$ & $\begin{array}{l}\text { B-D transition for limestone; brittle failure for granite; the } \\
\text { same conclusions as Logan and Handin (1970) and } \\
\text { Friedman and Logan (1973) }\end{array}$ & Green et al. (1972) \\
\hline & D-basalt & $12.7 \times 25.4$ & 345 & $\sim 10^{-1}$ & $\sigma_{\text {tcd }}$ increases with increasing $P_{\mathrm{c}}$ & $\begin{array}{l}\text { Lindholm et al. } \\
\text { (1974) }\end{array}$ \\
\hline & Granodiorite & $124(L \times W) \times 53$ & 450 & \multirow{2}{*}{$\begin{array}{r}10^{-1}- \\
10^{1}\end{array}$} & \multirow{2}{*}{$\begin{array}{l}\text { Machine inertia induced increase in } \sigma_{\mathrm{tcd}} \text {; machine the same } \\
\text { as in Logan and Handin (1970) }\end{array}$} & \multirow[t]{2}{*}{ Blanton (1981) } \\
\hline & $\begin{array}{l}\text { B-sandstone, } \\
\text { I-limestone }\end{array}$ & $214(L \times W) \times 50$ & 250 & & & \\
\hline & Concrete & $150 \times 300$ & 124 & $\begin{array}{r}10^{-1}- \\
10^{1}\end{array}$ & Rise time: $0.5 \mathrm{~ms}$; shear failure envelope & Gran et al. (1989) \\
\hline & BT-granite & $30 \times 60$ & 170 & $\begin{array}{r}10^{-4}- \\
10^{0}\end{array}$ & $\begin{array}{l}\text { Rise time: } 12 \mathrm{~ms} \text {; dynamic Mohr-Coulomb (M-C) and } \\
\text { Hoek-Brown }(\mathrm{H}-\mathrm{B}) \text { criteria }\end{array}$ & $\begin{array}{l}\text { Li et al. (1999), Zhao } \\
\text { (2000) }\end{array}$ \\
\hline \multirow[t]{12}{*}{$a^{\mathrm{HSR}}$} & Sandstone & $12.7 \times 25.4$ & 95 & $\begin{array}{l}10^{2}- \\
10^{3}\end{array}$ & $\begin{array}{l}\text { Stress-strain curves similar in shape to quasi-static ones; } \\
\sigma_{\text {tcd }} \text { about } 20 \% \text { higher than } \sigma_{\text {tc }} \text {; shear and dilatation } \\
\text { stress-strain curves }\end{array}$ & $\begin{array}{l}\text { Christensen et al. } \\
\text { (1972) }\end{array}$ \\
\hline & D-basalt & $12.7 \times 25.4$ & 138 & $\begin{array}{r}10^{2}- \\
10^{3}\end{array}$ & $P_{\mathrm{c}}$ dependent; three failure modes, see Fig. 32(a) & $\begin{array}{l}\text { Lindholm et al. } \\
\text { (1974) }\end{array}$ \\
\hline & Oil shale & $12.7 \times 25.4$ & 34.5 & $\sim 10^{3}$ & $\begin{array}{l}\text { Dependence of } \dot{\varepsilon} \text { more pronounced than that of } P_{\mathrm{c}} \text {; same } \\
\text { conclusion as Lindholm et al. (1974) }\end{array}$ & Lankford (1976) \\
\hline & Concrete & $76.2 \times 76.2$ & 10.3 & $\begin{array}{r}10^{1}- \\
10^{2}\end{array}$ & Apparent elastic recovery at the ending period & Malvern et al. (1991) \\
\hline & $\begin{array}{l}\text { Sedimentary } \\
\text { rocks }\end{array}$ & $25 \times 25$ & 35 & $\begin{array}{r}10^{1}- \\
10^{2}\end{array}$ & $\begin{array}{l}\text { More ductile at a lower } P_{\mathrm{c}} \text { than in quasi-static condition; } \\
\text { dynamic } \mathrm{M}-\mathrm{C} \text { criterion }\end{array}$ & Sato et al. (1981) \\
\hline & Marble & $30 \times 30$ & 20 & $\begin{array}{r}10^{2}- \\
10^{3}\end{array}$ & & Yu (1992) \\
\hline & Concrete & $40 \times 40$ & 10 & $\sim 10^{2}$ & Residual stress depends on $P_{\mathrm{c}}$ & $\begin{array}{l}\text { Gary and Bailly } \\
\text { (1998) }\end{array}$ \\
\hline & I-limestone & $12.7 \times 12.6$ & 200 & $\sim 10^{2}$ & The $P_{\mathrm{c}}$ of B-D transition increases with increasing $\dot{\varepsilon}$ & Frew et al. (2010) \\
\hline & Granite & $50 \times 30$ & 10 & $\begin{array}{r}10^{1}- \\
10^{2}\end{array}$ & $P_{\mathrm{c}}, \dot{\varepsilon}$ dependent; unbroken under high $P_{\mathrm{c}}$ & Chen et al. (2011) \\
\hline & Ceramic & $14.5 \times 14.5$ & 15 & $\sim 10^{2}$ & M-C criterion; ductile behaviour under high $P_{\mathrm{c}}$ & Wang and Liu (2011) \\
\hline & Salt rock & $37 \times 74$ & 25 & $\sim 10^{2}$ & Coupling effects of $P_{\mathrm{c}}, T$ and $\dot{\varepsilon}$ & Fang et al. (2012) \\
\hline & F-marble & $50 \times 50$ & 10 & $\begin{array}{r}10^{1}- \\
10^{2}\end{array}$ & $P_{\mathrm{c}}, \dot{\varepsilon}$ dependent; unbroken under high $P_{\mathrm{c}}$ & $\begin{array}{l}\text { Zhang and Zhao } \\
\text { (2013c) }\end{array}$ \\
\hline \multirow[t]{3}{*}{$\mathrm{b}$} & Siltstone & $50 \times 25$ & w/o & $\begin{array}{r}10^{1}- \\
10^{2}\end{array}$ & Hand pump-operated confinement; no results & Li et al. (2008b) \\
\hline & Sandstone & $50 \times 50$ & 12 & $\begin{array}{r}10^{1}- \\
10^{2}\end{array}$ & Cyclic dynamic loading in axial direction & Jin et al. (2012) \\
\hline & Sandstone & $50 \times 50$ & 40 & $\begin{array}{r}10^{1}- \\
10^{2}\end{array}$ & Unloading rate of $P_{\mathrm{c}}: 1 \mathrm{MPa} / \mathrm{s}$ & Yin et al. (2012b) \\
\hline \multirow[t]{2}{*}{$\mathrm{c}$} & Ceramic & $4.76 \times 5.48$ & 230 & $\begin{array}{r}10^{2}- \\
10^{3}\end{array}$ & Localized faulting; $P_{\mathrm{c}}$ dependent & $\begin{array}{l}\text { Chen and } \\
\text { Ravichandran } \\
\text { (1996) }\end{array}$ \\
\hline & W-granite & $6.0 \times 3.5-4.5$ & 132 & $\begin{array}{c}10^{2}- \\
10^{3}\end{array}$ & $\begin{array}{l}\text { Strain at failure increases with increasing } \dot{\varepsilon} \text {; the B-D } \\
\text { transition increases as } P_{\mathrm{c}} \text { is increased }\end{array}$ & Yuan et al. (2011) \\
\hline
\end{tabular}


Table 4 continued

\begin{tabular}{|c|c|c|c|c|c|c|}
\hline Class & Rock type & $\begin{array}{l}\text { Dimensions } \\
\left(D \times L, \mathrm{~mm}^{2}\right) \text { or } \\
\left(L \times W \times H, \mathrm{~mm}^{3}\right)\end{array}$ & $\begin{array}{l}\text { Max. } \\
\text { pressure } \\
\text { (MPa) }\end{array}$ & $\begin{array}{l}\text { Strain } \\
\text { rate } \\
\left(\mathrm{s}^{-1}\right)\end{array}$ & Research activities & References \\
\hline \multirow[t]{4}{*}{$\mathrm{d}$} & Concrete & $76.2 \times 152.4$ & 45 & $\begin{array}{l}10^{1}- \\
10^{2}\end{array}$ & Severe deformation at the beginning period & $\begin{array}{l}\text { Gong and Malvern } \\
\text { (1990) }\end{array}$ \\
\hline & Concrete & $19.1 \times ?$ & $\sim 18$ & $\sim 10^{2}$ & Teflon sleeve and aluminium sleeve & Rome et al. (2004) \\
\hline & Concrete & $30 \times 40$ & 550 & $\begin{array}{l}10^{1}- \\
10^{2}\end{array}$ & $\begin{array}{l}\text { Deviatoric and hydrostatic behaviours appear almost } \\
\text { independent of } \dot{\varepsilon}\end{array}$ & Forquin et al. (2008) \\
\hline & F-marble & $50 \times 50$ & 15 & $\begin{array}{l}10^{1}- \\
10^{2}\end{array}$ & Different thicknesses of vessel; $P_{\mathrm{c}}, \dot{\varepsilon}$ dependent & $\begin{array}{l}\text { Zhang and Zhao } \\
\text { (2013c) }\end{array}$ \\
\hline \multicolumn{7}{|c|}{ II. $\sigma_{1} \geq \sigma_{2} \geq \sigma_{3} \geq 0$} \\
\hline $\mathrm{e}$ & $\mathrm{W}$-granite & $(48.2-43.1) \times 96.4$ & 501 & $\sim 10^{-1}$ & Biaxial stress tests using tubular specimens & Green et al. (1972) \\
\hline $\mathrm{f}$ & Ceramic & $4.2 \times 2.3 \times 5.2$ & 400 & $\begin{array}{l}10^{2}- \\
10^{3}\end{array}$ & High $P_{\mathrm{c}} ;$ observing fracture process; $\sigma_{3}=0$ & Paliwal et al. (2008) \\
\hline $\mathrm{g}$ & Geomaterials & $50 \times 50 \times 50$ & $\sim 50$ & $\begin{array}{c}10^{1}- \\
10^{2}\end{array}$ & Three pairs of bars; true triaxial stress state & $\begin{array}{l}\text { Cadoni and Albertini } \\
\text { (2011) }\end{array}$ \\
\hline
\end{tabular}

a, hydraulic confinement; b, coupled static-dynamic; c, shrink-fit metal sleeve; d, thick confining vessel; e, tangential load; f, planar confinement (SG on specimen); g, true triaxial pressure (SG on bars)

Table 5 Summary of classic testing methods to determine the dynamic tensile strength of rock-like materials

\begin{tabular}{|c|c|c|c|c|}
\hline Method & Dynamic strength & Controlling factors & $\begin{array}{l}\text { Measurement } \\
\text { technique }\end{array}$ & Strain/stress rate \\
\hline DT (Asprone et al. 2009) & $\sigma_{\mathrm{DT}}=\sigma(t)_{\max }$ & $\begin{array}{l}\sigma(t)=E_{\mathrm{B}} A_{\mathrm{B}} \varepsilon_{\mathrm{Tr} .}(t) / A_{\mathrm{s}}, \text { the measured stress } \\
\text { history }\end{array}$ & Strain gauge & $\dot{\varepsilon}=2 C_{\mathrm{B}} \varepsilon_{\mathrm{Re} .}(t) / L_{\mathrm{s}}$ \\
\hline BD (Zhou et al. 2012) & $\sigma_{\mathrm{BD}}=2 P(t)_{\max } / \pi D_{\mathrm{s}} B_{\mathrm{s}}$ & $P(t)$, the applied load history & Strain gauge & $\dot{\sigma}=\partial \sigma / \partial t$ \\
\hline FBD (Wang et al. 2009) & $\sigma_{\mathrm{FBD}}=1.9 P(t)_{\max } / \pi D_{\mathrm{s}} B_{\mathrm{s}}$ & $\begin{array}{l}P(t), \varepsilon_{\mathrm{SG}}, \text { strain measured by SG on } \\
\text { specimen }\end{array}$ & Strain gauge & $\dot{\varepsilon}=\partial \varepsilon_{\mathrm{SG}} / \partial t$ \\
\hline TPB (Zhao and Li 2000) & $\sigma_{\mathrm{TPB}}=1.5 P(t)_{\max } L_{\mathrm{s}} / B_{\mathrm{s}} H^{2}$ & $P(t)$ & Strain gauge & $\dot{\sigma}=\partial \sigma / \partial t$ \\
\hline SCB (Dai et al. 2008) & $\sigma_{\mathrm{SCB}}=f\left(\frac{S}{2 R}\right) \frac{P(t)_{\max }}{\pi R B_{\mathrm{s}}}$ & $P(t)$ & Strain gauge & $\dot{\sigma}=\partial \sigma / \partial t$ \\
\hline $\begin{array}{l}\text { Spalling I (Klepaczko and } \\
\text { Brara 2001) }\end{array}$ & $\sigma_{\text {spall }}=\rho C_{\mathrm{s}} V_{\text {eject }}$ & $V_{\text {eject }}$, ejection velocity of fragment & HS camera & $\dot{\varepsilon}=\sigma_{\text {spall }} / E t_{\mathrm{f}}$ \\
\hline $\begin{array}{l}\text { Spalling II (Wu et al. 2005; } \\
\text { Gálvez et al. 2002) }\end{array}$ & $\sigma_{\text {spall }}=\sigma_{\mathrm{t}, \max }^{\mathrm{Re}}\left(x_{\mathrm{f}}\right)$ & $\begin{array}{l}\sigma_{\mathrm{t}, \text { max }}^{\mathrm{Re}}, \text { maximum reflected tensile stress; } x_{\mathrm{f}}, \\
\text { distance from free end to fracture } \\
\text { position }\end{array}$ & Strain gauge & $\dot{\varepsilon}=\partial \sigma_{\text {spall }} / E \partial t$ \\
\hline $\begin{array}{l}\text { Spalling III (Schuler et al. } \\
\text { 2006; Erzar and Forquin } \\
\text { 2010) }\end{array}$ & $\sigma_{\mathrm{spall}}=\frac{1}{2} \rho C_{\mathrm{s}} \Delta V_{\mathrm{pb}}$ & $\begin{array}{l}\Delta V_{\mathrm{pb}} \text {, 'pull-back' velocity; } t_{\text {rise }} \text { rise time of } \\
\text { the stress history }\end{array}$ & $\begin{array}{l}\text { Acceleration } \\
\text { gauge }\end{array}$ & $\dot{\varepsilon}=f\left(t_{\text {rise }}\right)$ \\
\hline $\begin{array}{l}\text { Spalling IV (Kubota et al. } \\
\text { 2008) }\end{array}$ & $\sigma_{\text {spall }}=\frac{1}{2} \rho C_{\mathrm{s}} \Delta V_{\mathrm{p}}$ & $\begin{array}{l}\Delta V_{\mathrm{p}}=V_{\mathrm{p}}\left(t_{\text {rise }}\right)-V_{\mathrm{p}}\left(t_{\text {rise }}+2 \Delta t_{\mathrm{f}}\right) \\
\Delta t_{\mathrm{f}}=x_{\mathrm{f}} / C_{\mathrm{s}} \\
V_{\mathrm{p}}, \text { particle velocity; } t_{\text {rise }}\end{array}$ & $\begin{array}{l}\text { HS camera, } \\
\text { laser vibration } \\
\text { meter }\end{array}$ & $\dot{\varepsilon}=\varepsilon /\left(t_{\text {rise }}+\Delta t_{\mathrm{g}}\right)$ \\
\hline
\end{tabular}

the complexity of the specimen shape (such as bone-shaped and dumbbell-shaped specimens) and the presence of the epoxy resin glue between the specimen and the bars lead to high cost of machining and manufacturing specimens, as well as gripping and alignment issues, which all complicate the experimental setup and may produce unwanted stress concentrations and lead to premature failure; (3) pulse shaping techniques are hard to apply, thus the condition of stress equilibrium may be violated.
To overcome these difficulties, several indirect tension testing methods have been devised and are widely used, i.e. the well-known BD, bending and spalling methods shown schematically in Fig. 12.

Indirect testing methods provide a convenient alternative in terms of specimen manufacturing, experimental setup and data reduction, to determine the tensile strength. Complete assessment of an indirect test as a reliable method for determining the tensile strength at HSR values 
Fig. 11 Schematics of four types of split Hopkinson tension bar (SHTB) techniques: a a mass is impacted directly on an anvil attached to the incident bar; $\mathbf{b}$ an anvil is loaded by a compressive wave transmitted through a hollow tube; c a pulse is generated by the detonation of an explosive against the anvil (after ASM 2000); and d a prestressed bar is connected to the incident bar to produce the loading pulse (after Cadoni and Albertini 2011)

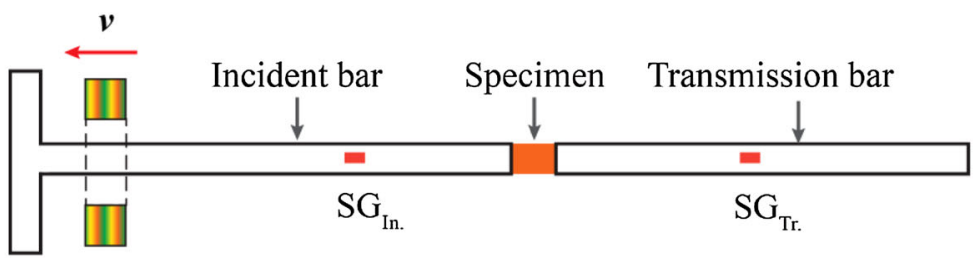

(a)

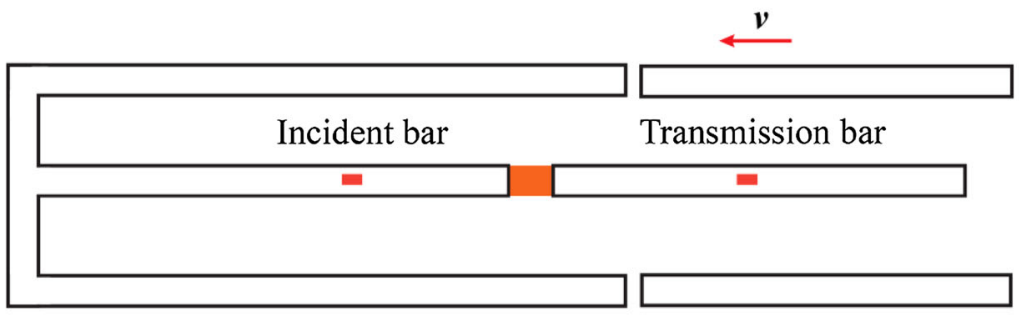

(b)

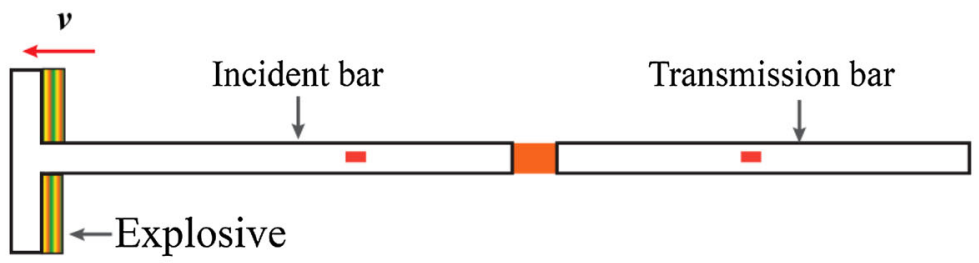

(c)

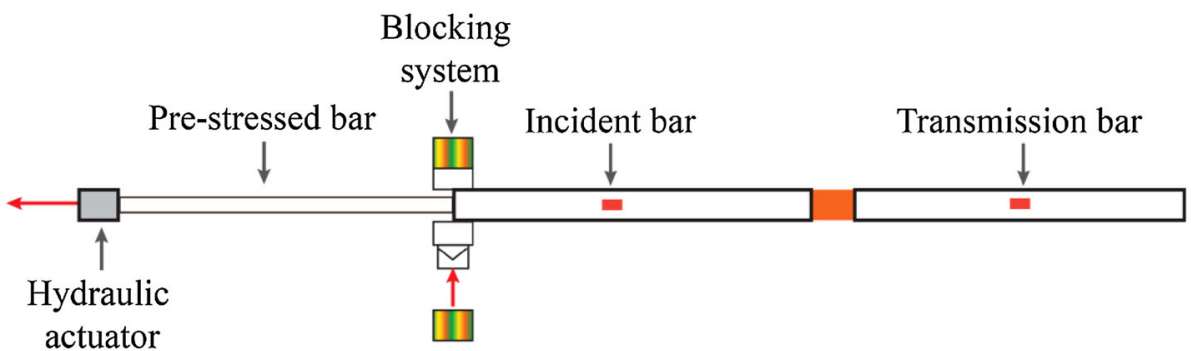

(d) should be carefully performed, considering at least the following aspects: (1) material hypothesis verification, (2) time evolution of stress distribution and (3) fracturing and failure modes (Rodríguez et al. 1994; Gálvez et al. 2002). The first assumption is not discussed here, since the mechanical properties of rock-like materials are commonly considered to correspond to quasi-brittle behaviour. It is especially important to detect failure by direct observation using high-speed photography and to verify that failure occurs at a time when the stress histories at both ends of the specimen are quasi-equal.

At ISR values ranging from $10^{-1}$ to $10^{4} \mathrm{MPa} / \mathrm{s}$, the $\mathrm{BD}$ method has also been conducted to determine the tensile strength of Bukit Timah granite by means of an air-oil hydraulically driven machine (Zhao and Li 2000). At HSR values, the $\mathrm{BD}$ method was firstly extended to dynamic tests on ceramic by Nojima and Ogawa (1989), on concrete by Ross et al. (1989) and Tedesco et al. (1989) and on rock by Dutta and Kim (1993) using the SHPB technique. BD tests are widely employed to determine the dynamic tensile strength of rock-like materials, and we only outline the major developments: (1) Stress field and photoelastic fringes were captured from a Homalite-100 specimen (Gomez et al. 2002), as shown in Fig. 13; (2) DIC combined with a HS camera was used to calculate the strain fields of polymer-bonded sugar (Grantham et al. 2004) and rock material (Fig. 14) (Zhang and Zhao 2013a); (3) the FBD method (Wang et al. 2006); (4) the effects of temperature (Nojima and Ogawa 1989), anisotropy (Dai and Xia 2010) and water saturation (Huang et al. 2010b); (5) an ISRM-suggested method (Zhou et al. 2012); and (6) under coupled static-dynamic loads (Zhou et al. 2013a). 
Fig. 12 Schematics of indirect tension testing methods: a Brazilian disc, b flattened Brazilian disc, c semi-circular bending and $\mathbf{d}$ spalling

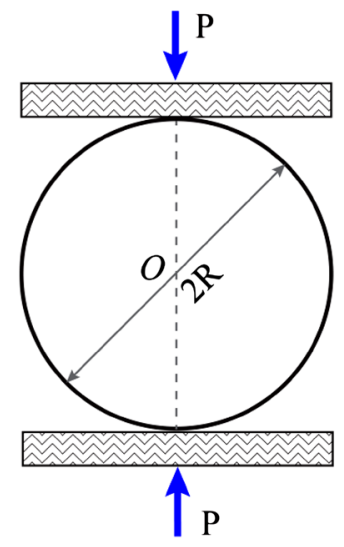

(a)

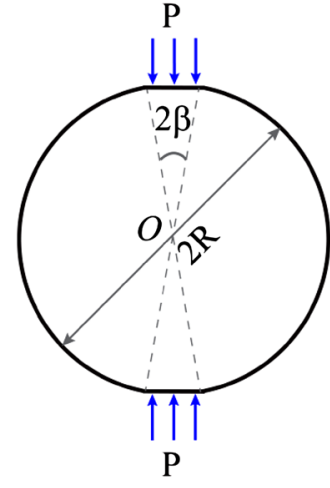

(b)

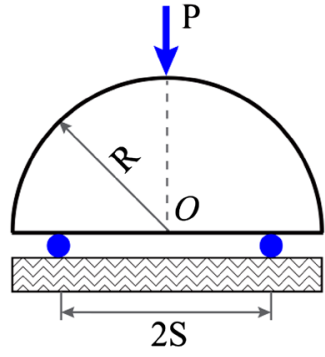

(c)

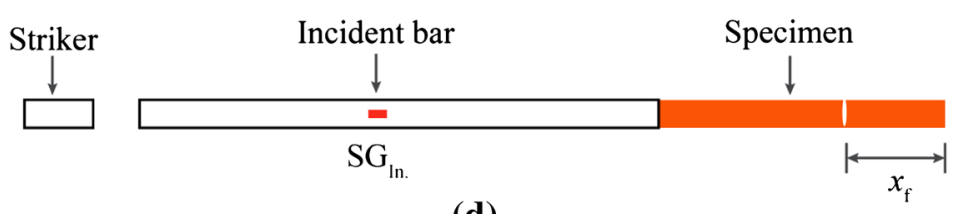

(d)

The limitations on the BD method include the following: (1) the stress state tends to be biaxial, (2) taking the peak stress recorded by the strain gauge as the tensile strength without any correction may lead to a suspicious value and (3) compressive stress-induced failure near the loading points.

Numerical simulations are widely used to verify the stress equilibrium condition in dynamic BD testing (Hughes et al. 1993; Zhu and Tang 2006; Rodríguez et al. 1994; Ruiz et al. 2000). We only outline the experimental assessment in the scope of this review. Figures 13 and 14 show that the SE condition is satisfied, and thus the quasistatic equation can be used to calculate the dynamic tensile strength.

Typical failure patterns of $\mathrm{BD}$ specimens after the SHPB test are shown schematically in Fig. 15 (Bohloli 1997; Zhang and Zhao 2013a; Zhou et al. 2013b). The main crack orientation was parallel to the impact direction, and the axial crack divided the specimen into at least two pieces. Two types of failure mode, i.e. shear failure and tensile failure, were obviously observed, and the extent of the two shear failure zones at the contact points of the disc depended on the strain rate. To prevent failure near the loading points, several improvements were introduced, namely using steel bearing bars (Gomez et al. 2001), using curved anvils (Dai et al. 2010c; Grantham et al. 2004) and the flattened BD method (Wang et al. 2009). In the first approach, impedance mismatch and reproducibility issues arise, and the accuracy of the experimental results is decreased (Johnstone and Ruiz 1995). Dai et al. (2010c) indicated that the second approach might not be necessary. The third approach partially solves the loading problem, but it also has some other limitations ( $\mathrm{Yu}$ et al. 2009).

At ISR tests, the TPB method has been performed to determine the tensile strength of Bukit Timah granite using the same machine as (Zhao and Li 2000). At HSR values, Dai et al. (2008) recently extended the semi-circular bending ( $\mathrm{SCB}$ ) method to dynamic testing using the SHPB. The evolution of the tensile stress at the failure spot was determined by numerical analysis using the dynamic loading measured from the SHPB as input. The pulse shaping technique was used to achieve dynamic force balance, and the momentum-trap technique was employed to achieve single-pulse loading. A combined finite-discrete-element method was used to simulate the dynamic SCB test, and the simulated fracture pattern agreed with that from the recovered specimen (Dai et al. 2010d).

There are only limited dynamic bending test results due to the following reasons: (1) it still has the same limitations as the BD specimen; (2) the measured result is the flexural strength rather than the tensile strength; (3) the stress equilibrium requirements are hard to attain, especially when using geometries with free ends such as the prismatic ones typical of bending tests; (4) modelling the configuration is rather complex; and (5) there is a lack of numerical simulations and optical measurement techniques to check the time evolution of the stress equilibrium.

The spalling method fundamentally relies on controlled propagation and reflection of elastic waves along 


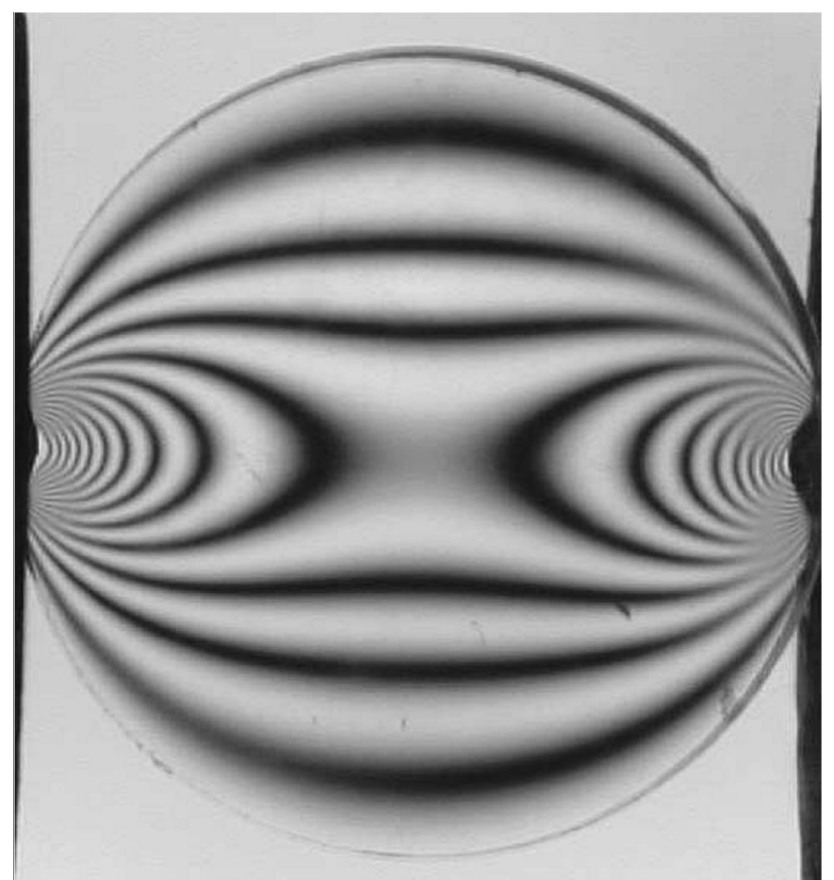

(a)
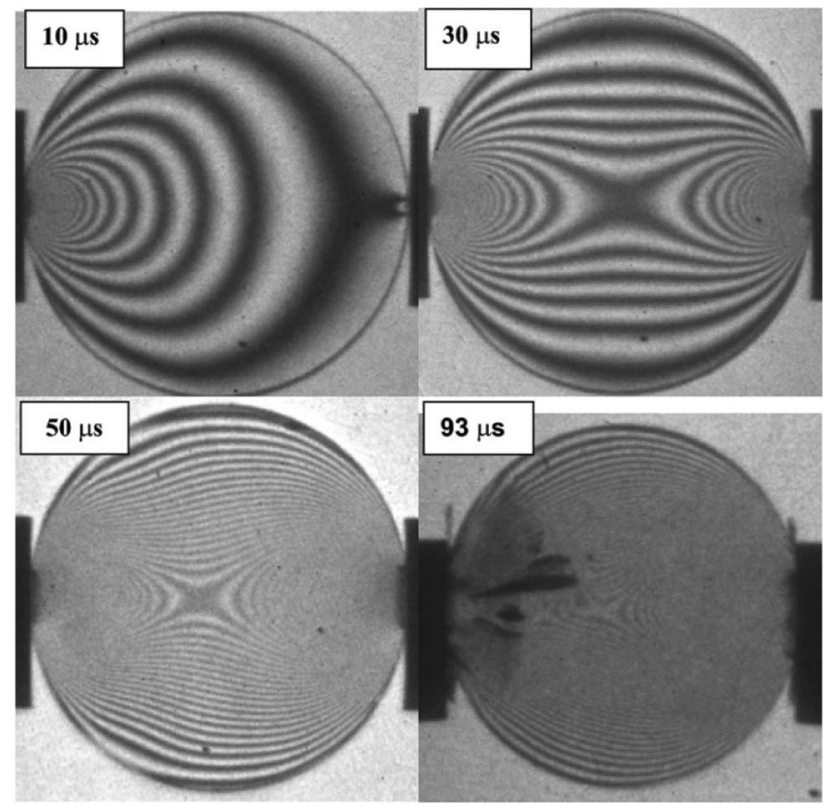

(b)

Fig. 13 Photoelastic fringe patterns of Homalite-100 disc specimens (25.4 mm diameter, $6.4 \mathrm{~mm}$ thickness) under quasi-static (a) and dynamic (b) loading conditions (reproduced from Gomez et al. 2001)

cylindrical bars. A projectile impacts against one of the ends of a cylindrical bar, generating a compressive wave, which is reflected as tension at the free end of the specimen. The tensile strength of rock-like materials is lower than their compressive strength, and thus this test is also widely used (Khan and Irani 1987; Cho et al. 2003; Kubota et al. 2008; Klepaczko and Brara 2001; Wu et al. 2005; Schuler et al. 2006). Several methods have been proposed to determine the spalling strength, and four classic methods are summarized in Table 5. A complete assessment of the spalling test has also been performed (Gálvez et al. 2002; Cho et al. 2003; Erzar and Forquin 2010). HS photographs, particularly in combination with the DIC method, have been widely used to measure the fragment velocity (Kubota et al. 2008; Klepaczko and Brara 2001) and strain field (Pierron and Forquin 2012; Pérez-Martín et al. 2012).

The limitations of the spalling method include the following: (1) a substantially long homogeneous specimen is required to ensure the 1D stress state; (2) whether or not the incident compressive wave could have affected the material before the tensile wave initiates its way back; (3) complicated data processing because of the complexity of the transient loading in time and space.

\subsubsection{Shear Tests}

Quasi-static torsion tests on cylindrical specimens have been widely used to study large shear strains of rock materials (Paterson and Olgaard 2000). For higher strain rates, the TSHB technique has been developed, which overcomes the limitations of lateral inertia, friction and wave dispersion effects on the experimental results in the traditional SHPB test. Dynamic torque is produced by explosive loading or a sudden release of torsional deformation energy. A schematic of the TSHB technique and a typical design of the thin-walled tubular specimen for the TSHB test are shown in Fig. 16a, b. The dynamic shear strength of the thin-walled tubular specimen, $\tau_{\mathrm{d}}$, was calculated from the dynamic torque, $T_{\mathrm{d}}$, by Gilat (2000) as

$\tau_{\mathrm{d}}=\frac{T_{\mathrm{d}}}{2 \pi R^{2} B_{\mathrm{ws}}}$,

where $B_{\text {ws }}$ is the wall thickness and $R$ is the mean radius of the specimen.

The shear strain rate, $\dot{\gamma}(t)$, is determined from the difference in angular velocity between its two ends (Gilat 2000), which is similar to the SHPB test,

$\dot{\gamma}(t)=\frac{R}{L_{\mathrm{s}}}\left[\dot{\theta}_{1}(t)-\dot{\theta}_{2}(t)\right]$,

where $\dot{\theta}_{1}(t)$ and $\dot{\theta}_{2}(t)$ are the angular velocities of the specimen ends and $L_{\mathrm{s}}$ is the length of the specimen.

Readers interested in the details and applications of the TSHB are referred to the ASM handbook (Gilat 2000). Goldsmith et al. (1976) firstly used the TSHB to determine the rate dependence of the shear strength of Barre granite using solid cylindrical specimens. However, a unique strain rate could not be assigned to the failure strength values 

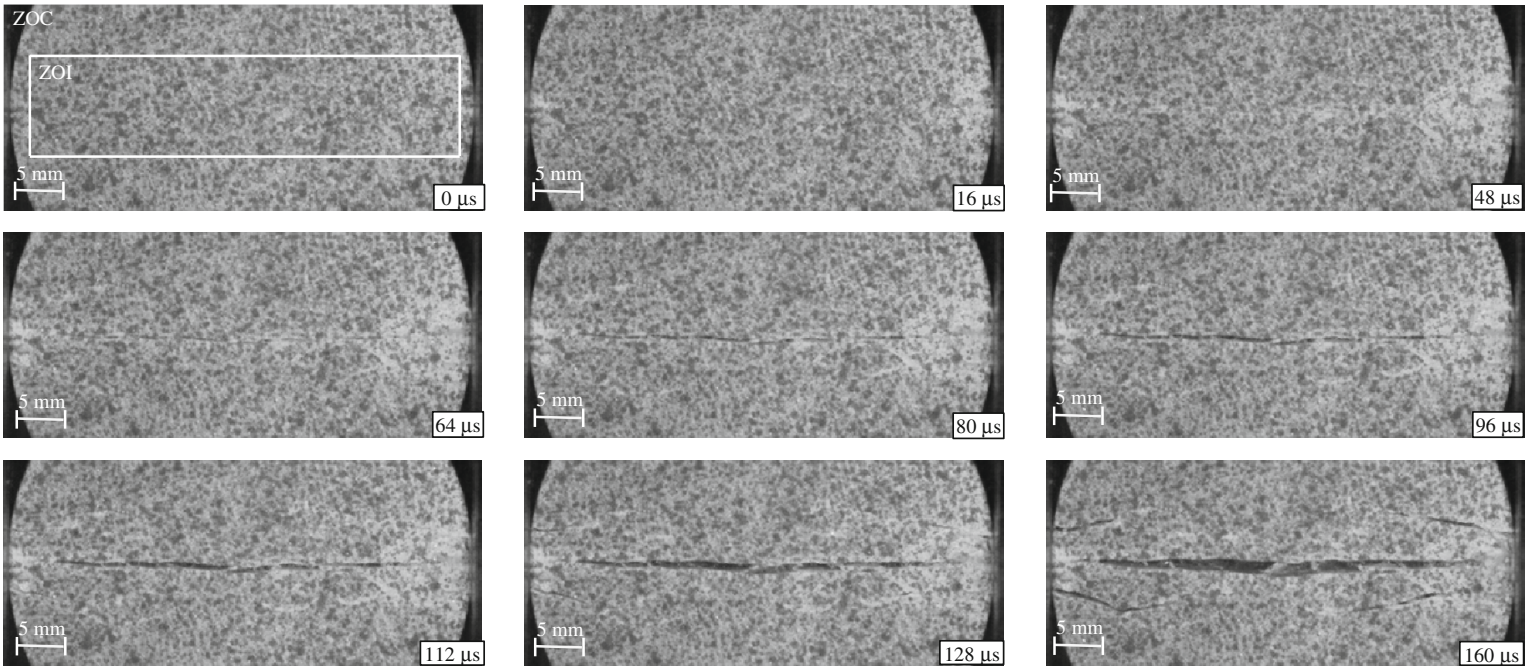

(a)
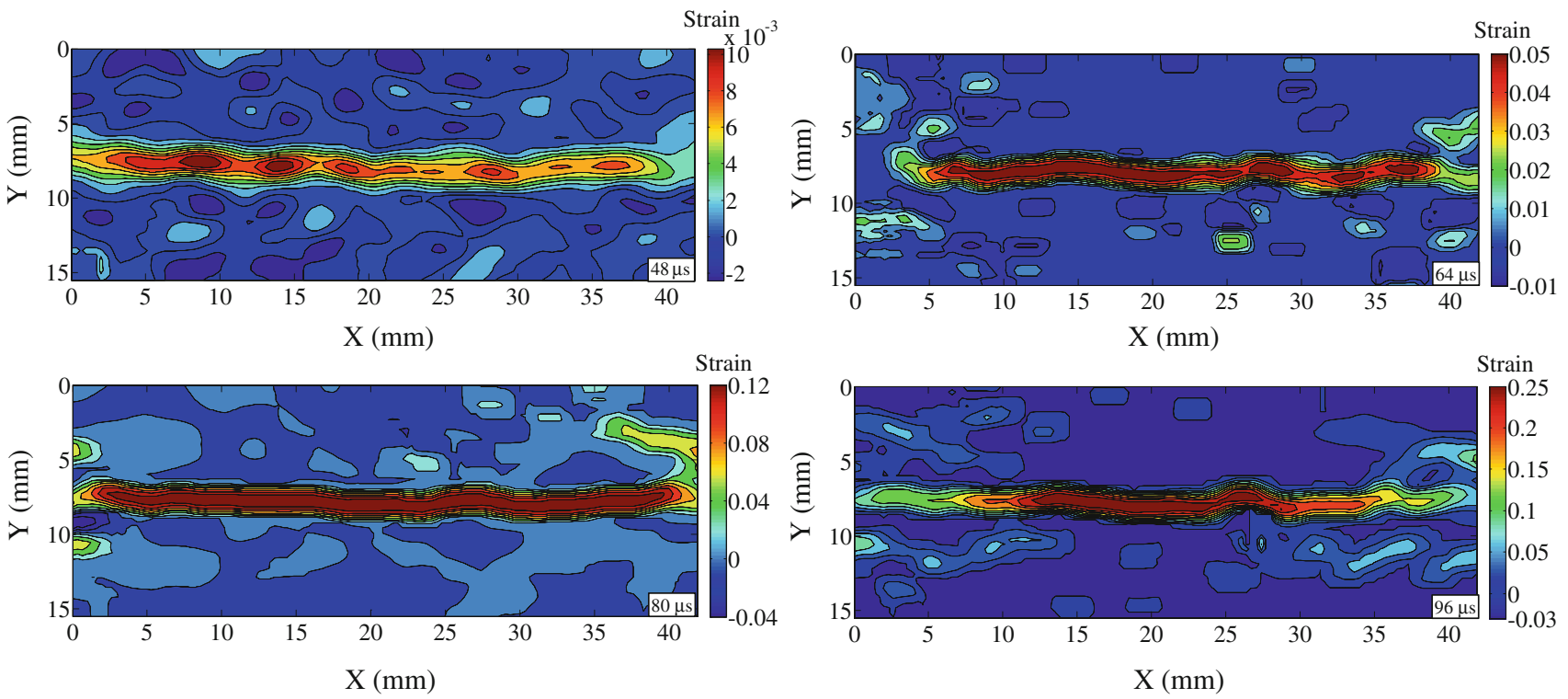

(b)

Fig. 14 High-speed images and dynamic strain fields of Brazilian specimen of Fangshan marble (50 mm diameter, 20 mm thickness) using the split Hopkinson pressure bar (reproduced from Zhang and Zhao 2013a)

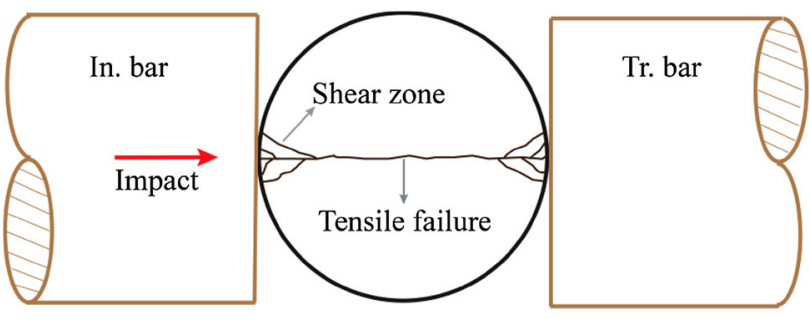

Fig. 15 Failure transition between shear and tensile failure modes in a Brazilian disc specimen under dynamic loading using the split Hopkinson pressure bar (reproduced from Zhang and Zhao 2013a) obtained. Lipkin et al. (1977, 1979) performed pure shear tests using the TSHB test with short thin-walled tubes as specimens.

Although friction and inertial effects do not exist in the TSHB test, the preparation of thin-walled rock specimens and gripping them to the bars are very difficult. Therefore, some novel testing methods, e.g. compression-shear tests (Rittel et al. 2002), direct shear-box tests (Fukui et al. 2004), a split Hopkinson pressure shear bar (SHPSB) (Zhao et al. 2011) and punch shear tests (Zhao et al. 1998; Huang et al. 2011a), have been developed to subject a specimen to 
Fig. 16 a Schematic of a torsional split Hopkinson bar (TSHB), b thin-walled tubular specimen configuration, $\mathbf{c}$ punch shear specimen



(a)

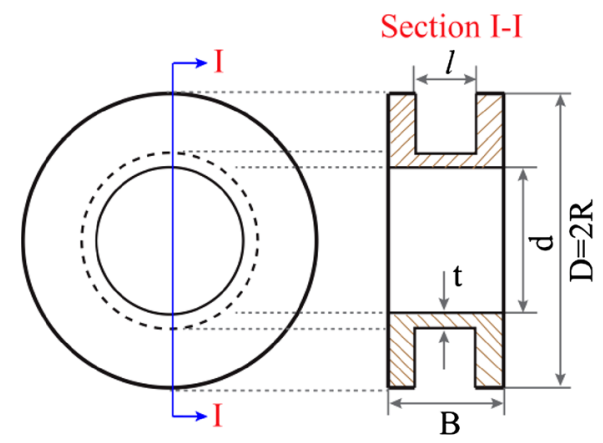

(b)

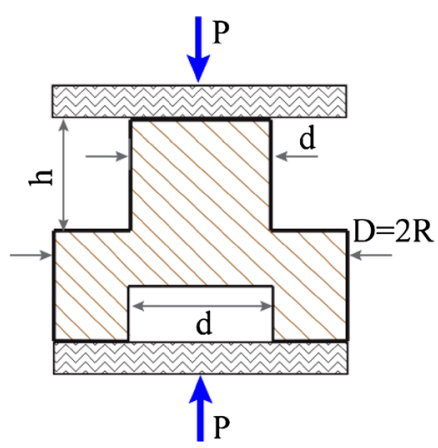

(c) the shear stress state. Rittel et al. (2002) designed a shearcompression specimen for large-strain testing using the SHPB technique. Fukui et al. (2004) designed a shear box to perform direct shear tests on Sanjome andesite under quasi-static loads. They observed that, when the loading rate increased by an order of magnitude, the shear strength increased by approximately $6.1 \%$, whereas the internal friction angle and residual strength did not increase. The recently developed SHPSB technique includes an incident bar with a wedge-shaped end and two transmitted bars; quartz transducers and an optical system were employed to measure the shear force and shear strain (Zhao et al. 2011). Early works on punch shear tests were performed for measurement of the direct shear strength of thin rock plates (Stacey 1980). A schematic of a punch shear specimen is shown in Fig. 16c. Dynamic punch shear tests have been widely used to determine shear strength and to study the adiabatic shear band stability of materials. Since shear strain is extremely hard to measure by the punch shear test, the loading rate from the time evolution of the shear stress is used. The shear stress in the specimen, $\tau(t)$, is defined as the applied load, $P(t)$, divided by the shear area, $A_{\text {shear }}$. Zhao et al. (1998) performed punch shear tests on Bukit Timah granite at intermediate loading rates ranging from $10^{1}$ to $10^{4} \mathrm{MPa} / \mathrm{s}$ using a pneumatic-hydraulic machine. Without considering the wave propagation effect, the shear strength was determined from the maximum load. Huang et al. (2011a) designed a special holder to support a thin disc specimen and performed punch shear tests to determine the dynamic shear strength of Longyou sandstone using the SHPB at loading rates ranging from 566 to $1,800 \mathrm{GPa} / \mathrm{s}$. In their study, the pulse shaping technique was used to achieve dynamic force equilibrium, and thus the shear strength was also calculated from the maximum load. There is still a lack of optical measurement and numerical modelling techniques to validate the reliability of the method of the dynamic punch shear test.

\subsubsection{Fracture Toughness Tests}

Fracture toughness is one of the fundamental material parameters in fracture mechanics, being defined as the resistance to crack propagation. Since the stress state near a crack tip is described in terms of the dynamic SIF, the fracture toughness can be identified with the SIF reaching a critical value. Four regions can be distinguished as extended from Atkinson (1987) and Bieniawski (1968), in which regions I and II are subcritical crack growth, region III is under quasi-static loading, and region IV is dynamic crack growth, as shown in Fig. 17. For the region of subcritical crack growth, readers are referred to the critical review by Atkinson (1982). Experimental techniques employed in determining quasi-static fracture toughness have been well established for rock materials. The ISRM has recommended four methods, namely the chevron bend (CB) and short rod (SR) methods (Ouchterlony 1988), the cracked chevron notched Brazilian disc (CCNBD) method (Fowell 1995) and the notched semi-circular bend (NSCB) method (Kuruppu et al. 2013), for determining fracture toughness under quasi-static loads. In addition, some popular testing methods are also summarized in Table 3. In the field of rock dynamics, regime IV is studied.

Since the concept of fracture dynamics of rock was originally introduced by Bieniawski (1968), numerous studies have demonstrated that fracture behaviour under dynamic loading is dramatically different from that under quasi-static loading conditions. However, accurate determination of dynamic fracture parameters at HSR remains a 


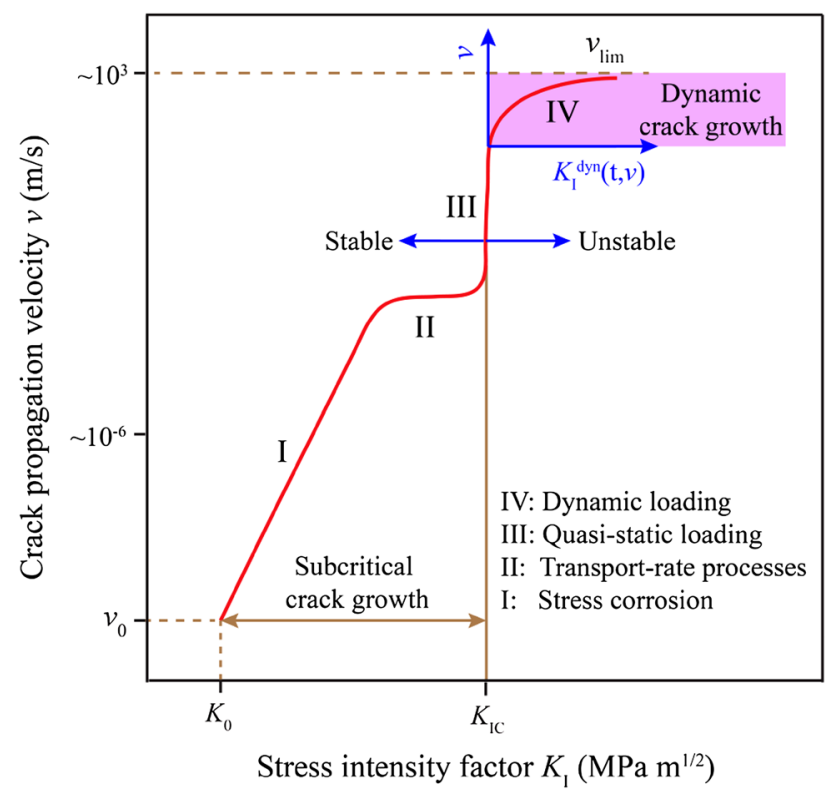

Fig. 17 Schematic of crack velocity versus stress intensity factor behaviour of rock materials. Note that crack branching may occur during dynamic crack propagation; after Atkinson (1987, Fig. 1.3, p. 11) and Bieniawski (1968, Fig. 3, p. 423)

challenge, and there is still no standard experimental procedure. The primary focus of dynamic fracture tests on rock materials has been measurement of the dynamic fracture toughness for crack initiation and its dependence on loading rate, as well as the study of the propagation toughness and its possible dependence on parameters such as crack velocity, acceleration and temperature.

Unlike quasi-static fracture toughness tests, dynamic fracture testing does not have an accepted set of testing standards. Dynamic fracture properties are generally characterized in terms of events, such as crack initiation, crack propagation and crack arrest, and dynamic fracture energy, occurring around the crack tip at different periods of crack evolution. Considerable confusion has resulted from ambiguous use of some terms in the literature on the subject. The terms used in this section are consistent with the classic book by Ravi-Chandar (2004).

Kalthoff (1985) presented a review reporting experimental methods for determining dynamic fracture toughness in 1985, but no progress on rock materials is mentioned. Jiang and Vecchio (2009) recently reviewed dynamic fracture toughness tests using the SHPB, but only some BD testing methods on rock materials were summarized. Reviews of dynamic fracture toughness tests for rock materials are limited in number and scope. It should be noted that, although there is an ISRM suggested method (Zhou et al. 2012), namely the NSCB method using the SHPB technique, neither K-dominated crack-tip stress nor strain/deformation fields are validated during such experimental testing. Therefore, a current, comprehensive review is essential for research in experimental techniques and results on dynamic fracture toughness, and some controversial issues should be discussed.

In this section, core-based methods using the SHPB are described in detail, since these methods have been widely used for rock materials, and even four ISRM suggested methods, i.e. CB, SR, CCNBD and NSCB, are all core based, as listed in Table 3. A review of core-based methods for determination of quasi-static fracture toughness has been presented by Chang et al. (2002). Dynamic testing methods are mostly extended from quasi-static ones, which can be approximately categorized into three groups, i.e. BD-type methods [CCNBD (Dai et al. 2010a), CSTBD (Wang et al. 2011a; Nakano et al. 1994), HCFBD (Wang et al. 2010c; Lambert and Ross 2000)], bending-type methods [SENB (Tang and Xu 1990; Zhao et al. 1999b; Yang et al. 2009), NSCB (Chen et al. 2009; Zhang and Zhao 2013a), CCNSCB (Dai et al. 2011)] and compacttension (CT)-type methods [WLCT (Klepaczko et al. 1984), SR (Zhang et al. 2000)], as shown schematically in Fig. 18.

We do not discuss in any detail methods for determining the dynamic SIF, since this topic is heavily discussed in the book by Ravi-Chandar (Chap. 4, 2004) and the critical review by Jiang and Vecchio ('5.1 Stress-intensity factor determination' in 2009). As summarized in Table 3, the dynamic SIF in rock testing is determined by either the theory of quasi-static fracture mechanics (Tang and Xu 1990; Zhao et al. 1999b; Zhang et al. 1999; Chen et al. 2009; Dai et al. 2010a, b, 2011; Klepaczko et al. 1984; Lambert and Ross 2000; Zhang and Zhao 2013a) or the hybrid strain gauge/numerical method (Wang et al. 2010c, 2011a; Nakano et al. 1994). The former is a direct measure of the stress state, which can be conveniently obtained from load transducers in ISR tests or by comparing the incident, reflected and transmitted pulses in the SHPB test. Although better suited to analysis of stress equilibrium, high-speed photography is also recommended to examine the processes of crack initiation and propagation. Furthermore, it is worth mentioning that, although optical measurement methods are most widely applied for transparent materials, they also have a few applications to rock materials. Attempts have been made to determine the dynamic SIF of a SENB specimen using methods of caustics (Yang et al. 2009), and to measure the strain/deformation fields of a NSCB specimen using high-speed DIC (Zhang and Zhao 2013a).

The equations for calculating the dynamic SIF, usually determined by the SE condition, are given as 

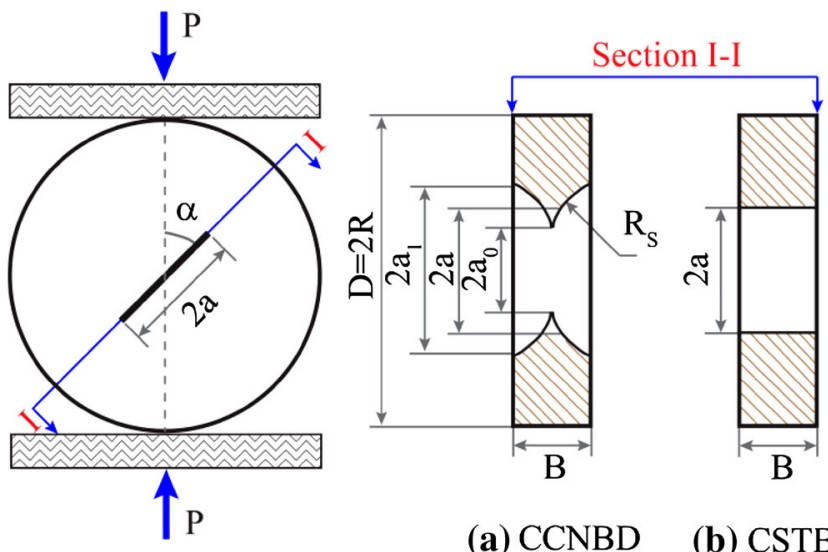

(a) CCNBD

(b) CSTBD

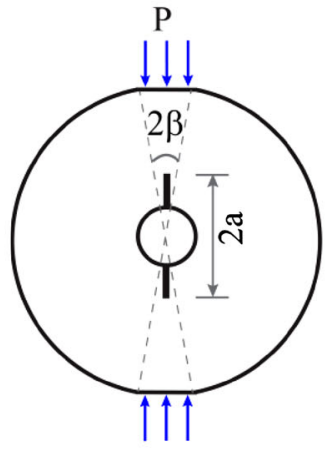

$\mathrm{P}$

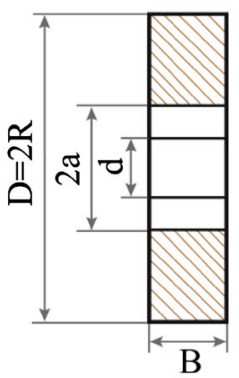

(c) HCFBD



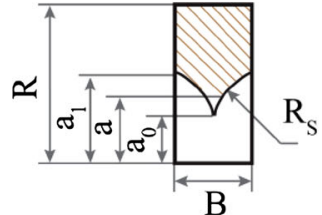

(d) CCNSCB

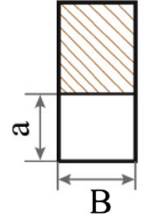

(e) NSCB
Fig. 18 Geometry of fracture toughness testing methods: a cracked chevron notched Brazilian disc, $\mathbf{b}$ cracked straight through Brazilian disc, $\mathbf{c}$ holed cracked flattened Brazilian disc, d cracked chevron

$K_{\mathrm{I}}^{\mathrm{dyn}}(t)=f\left(\frac{a}{R}\right) \frac{P(t)}{\pi B_{\mathrm{s}} R} \sqrt{\pi a}$,

$K_{\mathrm{I}}^{\mathrm{dyn}}(t)=f\left(\frac{a}{R}\right) \frac{P(t) S}{B_{\mathrm{s}} R^{3 / 2}}$

and

$K_{\mathrm{I}}^{\mathrm{dyn}}(t)=f\left(\frac{a}{W}\right) \frac{P(t)}{2 B_{\mathrm{s}} \sqrt{W} \tan \left[\left(\alpha / 2+\tan ^{-1} \mu\right)\right]}$

for BD-type (Dong et al. 2004), bending-type (Chen et al. 2009) and CT-type (Klepaczko et al. 1984) methods, respectively. In the above equations, the geometric

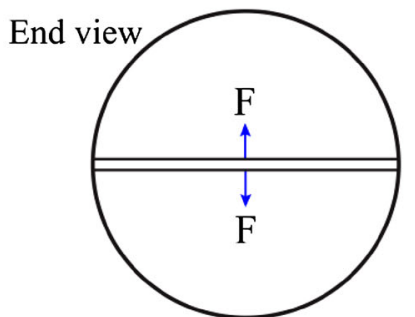

Middle section view
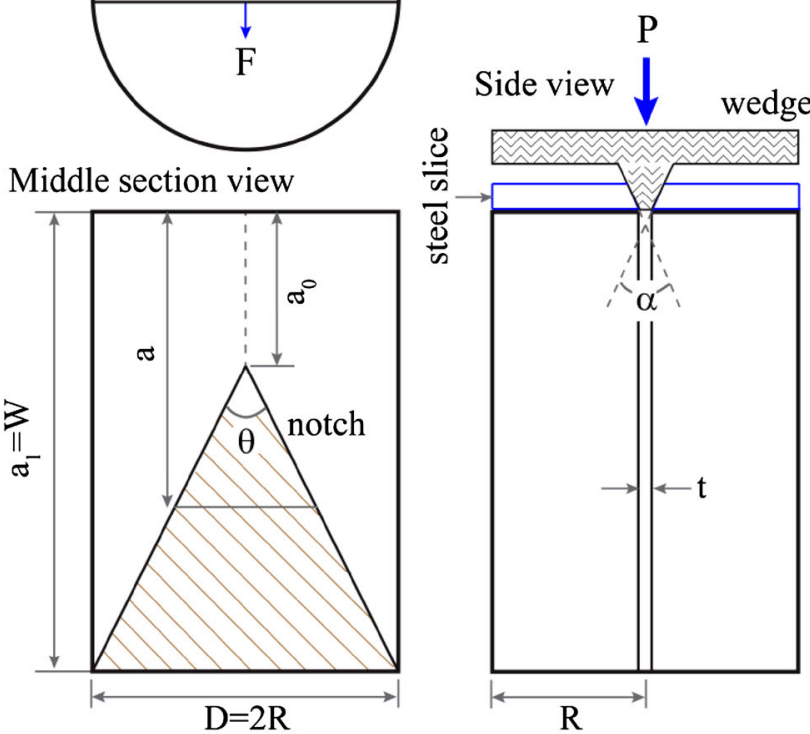

notched semi-circular bending, e notched semi-circular bending and f short rod or wedge loaded compact tension

correction function $f(a / R)$ or $f(a / W)$ has different forms for each specimen geometry, $a$ is the crack length, $B_{\mathrm{s}}$ is the thickness of the specimen, $R$ is the radius of the specimen, $S$ is the span of bending, $W$ is the width of the specimen, $\alpha$ is the angle of the wedge, and $\mu$ is the friction coefficient between the wedge and the bar.

\subsection{Stress-Strain Behaviour at High Strain Rate}

It is well known that strength, strain to failure, Young's modulus, Poisson's ratio and brittle/ductile behaviour can be extracted from stress-strain curves. The ISRM has 
proposed a SM for determining stress-strain curves in quasi-static compression tests (Fairhurst and Hudson 1999). In ISR testing, stress-strain curves are commonly determined by load transducers and on-specimen strain gauges/extensometers without considering inertia effects (Zhao et al. 1999a; Li et al. 1999; Logan and Handin 1970; Friedman and Logan 1973; Green and Perkins 1968, 1969; Perkins et al. 1970; Green et al. 1972), and therefore dynamic mechanical properties can also be easily obtained. In HSR tests, several methods have been proposed to determine the stress-strain curve, as summarized in Table 6. The terms and formulas for one-wave, two-wave and three-wave analysis are given by Gray (2000). Gama et al. (2004) critically reviewed these methods and concluded that the starting point of the incident, reflected and transmitted pulses should be identified and that data from wave dispersion effects need to be well corrected. Recently, Mohr et al. (2010) theoretically evaluated four methods (i.e. one-wave analysis, three-wave analysis, direct estimate and foot-shifting methods) and pointed out that the method of direct estimate could provide the most accurate results; the foot-shifting method is particularly convenient when neglecting wave dispersion in the bars; one-wave and two-wave analysis methods involve some implicit 'foot-shifting' in strain histories, i.e. $\varepsilon_{\text {In. }}(t)+\varepsilon_{\text {Re. }}(t)=\varepsilon_{\text {Tr. }}(t)$. Stress-strain curves obtained by one of the above methods have been widely used in testing of rock materials, in particular the one-wave analysis method due to its simple formula. The hybrid analysis method was first employed by Perkins et al. (1970) and Green and Perkins (1968, 1969), in which the stress is measured directly by using quartz discs sandwiched between the specimen and the bars, while the strain is measured by strain gauges mounted on the specimen (Shan et al. 2000). Due to the limitations of the single-point measurement of the strain gauge for wave dispersion effects and strain localization in the dynamically loaded specimen, application of optical techniques offers an independent means of measuring the strain associated with propagating waves (Gilat et al. 2009; Zhang and Zhao 2013a). Furthermore, optical full-field measurements and/or numerical simulations are promising tools for identification of constitutive parameters (Avril et al. 2008), and attempts have been made to correct and determine stress-strain curves in compression (Zhao and Gary 1996), spalling (Pierron and Forquin 2012) and tensile-shear (Peirs et al. 2011) tests, as presented in each subsection below. However, some specific problems still remain, mainly concerning previously mentioned effects (see Sect. 2.2 for details) and the small strain to failure of rock materials. Consequently, the direct estimate method is recommended to determine the stressstrain curve, whereas other methods, especially the hybrid and inverse analysis methods, should be used for validation.

\subsection{Dynamic Uniaxial Compressive Behaviour}

In ISR testing, as mentioned above, dynamic mechanical parameters are usually obtained from stress-strain curves extracted directly from load transducers and on-specimen strain gauges (Zhao et al. 1999a; Perkins et al. 1970; Logan and Handin 1970). Therefore, we do not discuss the details in this review.

In HSR testing, the effects of inertia and wave propagation should be considered when interpreting experimental data. Several reviews have been presented on the stress-strain behaviour of metal materials (Lindholm and Yeakley 1968; Hauser 1966), brittle materials (Zhao and Gary 1996), sand (Omidvar et al. 2012) and rock (Hauser

Table 6 Summary of methods for determining the stress-strain curve at high strain rate

\begin{tabular}{|c|c|c|c|}
\hline Method & Strain history $\varepsilon(t)$ & Stress history $\sigma(t)$ & References \\
\hline One-wave analysis & $\varepsilon(t)=-\left(2 C_{\mathrm{B}} / L_{\mathrm{s}}\right) \cdot \int_{0}^{t} \varepsilon_{\mathrm{Re} .}(t) d t$ & $\sigma(t)=\left(A_{\mathrm{B}} E_{\mathrm{B}} / A_{\mathrm{s}}\right) \cdot \varepsilon_{\operatorname{Tr} .}(t)$ & Gray (2000) \\
\hline Two-wave analysis & $\varepsilon(t)=-\left(2 C_{\mathrm{B}} / L_{\mathrm{s}}\right) \cdot \int_{0}^{t} \varepsilon_{\text {Re. }}(t) d t$ & $\sigma(t)=\left(A_{\mathrm{B}} E_{\mathrm{B}} / A_{\mathrm{s}}\right) \cdot\left[\varepsilon_{\text {In. }}(t)+\varepsilon_{\text {Re. }}(t)\right]$ & Gray (2000) \\
\hline Three-wave analysis & $\varepsilon(t)=\left(C_{\mathrm{B}} / L_{\mathrm{s}}\right) \cdot \int_{0}^{t}\left[\varepsilon_{\mathrm{In} .}(t)-\varepsilon_{\mathrm{Re} .}(t)-\varepsilon_{\mathrm{Tr} .}(t)\right] d t$ & $\sigma(t)=\left(A_{\mathrm{B}} E_{\mathrm{B}} / 2 A_{\mathrm{s}}\right) \cdot\left[\varepsilon_{\text {In. }}(t)+\varepsilon_{\text {Re. }}(t)+\varepsilon_{\operatorname{Tr} .}(t)\right]$ & Gray (2000) \\
\hline Direct estimate & $\varepsilon(t)=\left(C_{\mathrm{B}} / L_{\mathrm{s}}\right) \cdot \int_{0}^{t}\left[\varepsilon_{\mathrm{In} .}(t)-\varepsilon_{\mathrm{Re} .}(t)-\varepsilon_{\operatorname{Tr} .}(t)\right] d t$ & $\sigma(t)=\left(A_{\mathrm{B}} E_{\mathrm{B}} / A_{\mathrm{s}}\right) \cdot \varepsilon_{\mathrm{Tr} .}(t)$ & Mohr et al. (2010) \\
\hline Foot-shifting & $\varepsilon(t)=\left(C_{\mathrm{B}} / L_{\mathrm{s}}\right) \cdot \int_{0}^{t}\left[\varepsilon_{\mathrm{In} .}(t)-\varepsilon_{\mathrm{Re} .}(t)-\varepsilon_{\mathrm{Tr} .}\left(t+t_{0}\right)\right] d t$ & $\sigma(t)=\left(A_{\mathrm{B}} E_{\mathrm{B}} / A_{\mathrm{s}}\right) \cdot \varepsilon_{\mathrm{Tr} .}(t)$ & Mohr et al. (2010) \\
\hline Hybrid analysis & Direct measurement & One of the above or load transducer & $\begin{array}{l}\text { Shan et al. (2000), } \\
\text { Gilat et al. (2009), } \\
\text { Perkins et al. (1970) }\end{array}$ \\
\hline Inverse analysis & $\begin{array}{l}\text { Combination of FEM simulation } \\
\text { and/or direct measurement }\end{array}$ & $\begin{array}{l}\text { Combination of FEM simulation } \\
\text { and/or one of the above }\end{array}$ & $\begin{array}{l}\text { Peirs et al. (2011), } \\
\text { Pierron and Forquin } \\
\text { (2012), Zhao and } \\
\text { Gary (1996) }\end{array}$ \\
\hline
\end{tabular}


1966) at HSRs. The one-wave analysis method has been widely used for rock materials due to its simple formula (Perkins et al. 1970; Zhou et al. 2010; Li et al. 2000b, 2005; Frew et al. 2001; Xia et al. 2008; Dai et al. 2010c; Shan et al. 2000).

Confusion arises about whether the initial tangent modulus and the critical strain at maximum stress should change with strain rate, and there seems to be no consensus conclusion, as shown in Fig. 19. It has been generally accepted that the Young's modulus of rock-like materials should increase with an increase in strain rate (e.g. Bischoff and Perry 1991). The difference is that the critical strain (the strain to maximum stress) increases or decreases with increasing strain rate, which means that the critical strain becomes more brittle or ductile at higher strain rate. Figure $19 \mathrm{c}$ shows that the slope remains linear up to higher stress level under a higher strain rate, which indicates a delay in the internal microcracking process. Zhao et al. (1999a) showed that the Young's modulus decreases slightly and the Poisson's ratio increases slightly with increasing loading rate for Bukit Timah granite under ISR. At HSR, a number of researchers have stated increases in the tangent modulus with increasing strain rate (e.g. Perkins et al. 1970), while some reported that the initial

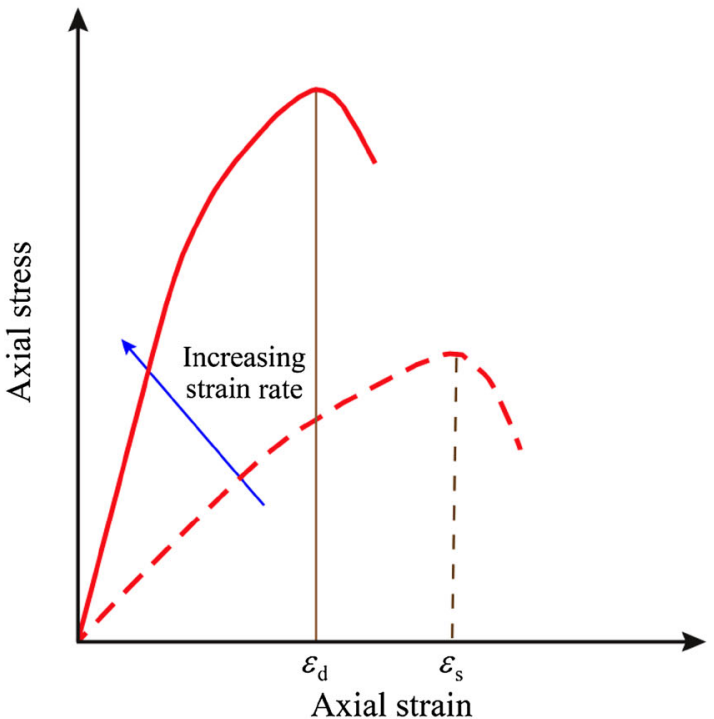

(b)

(a)

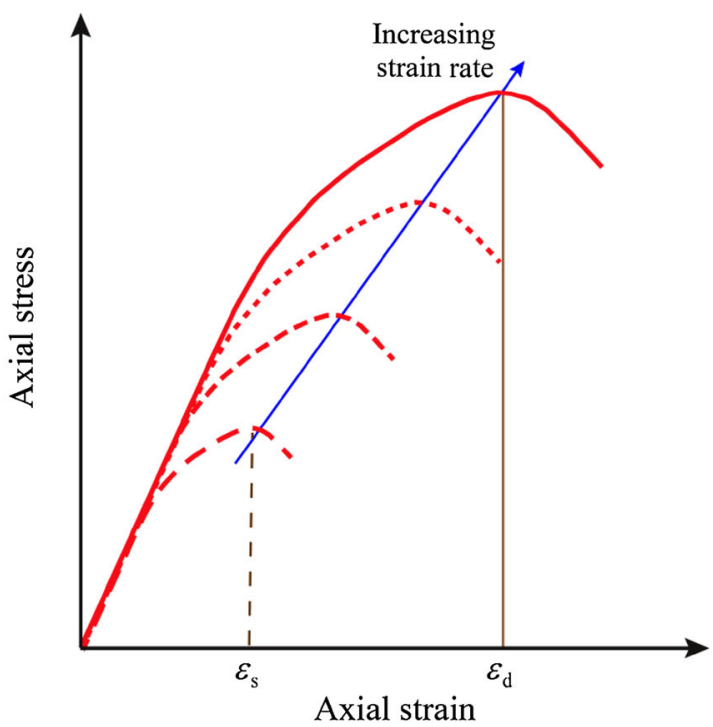

(c)

Fig. 19 Schematic representations of the effect of strain rate on the stress-strain curve of rock materials in uniaxial compression. Increase in initial tangent modulus plus $\mathbf{a}$ increase or $\mathbf{b}$ decrease in critical strain with increasing strain rate; $\mathbf{c}$ initial tangent modulus unaffected by strain rate 


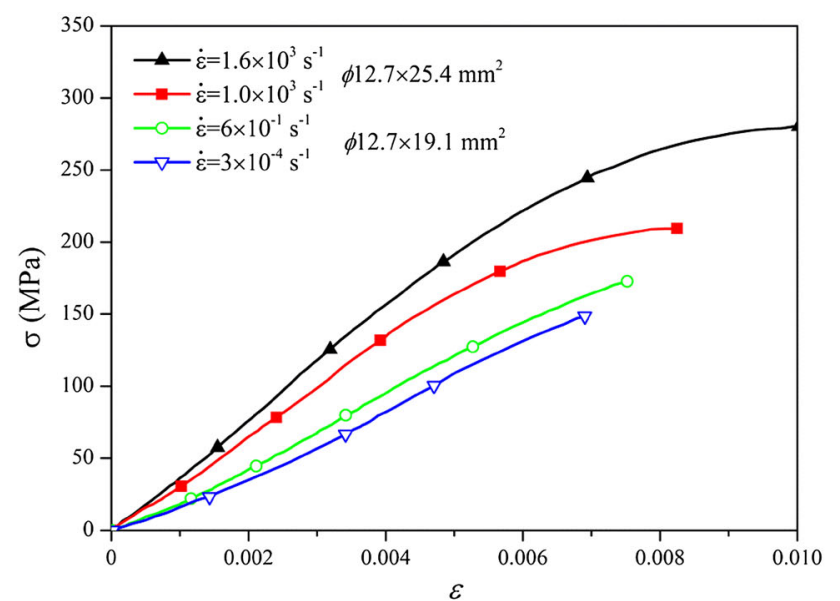

(a)

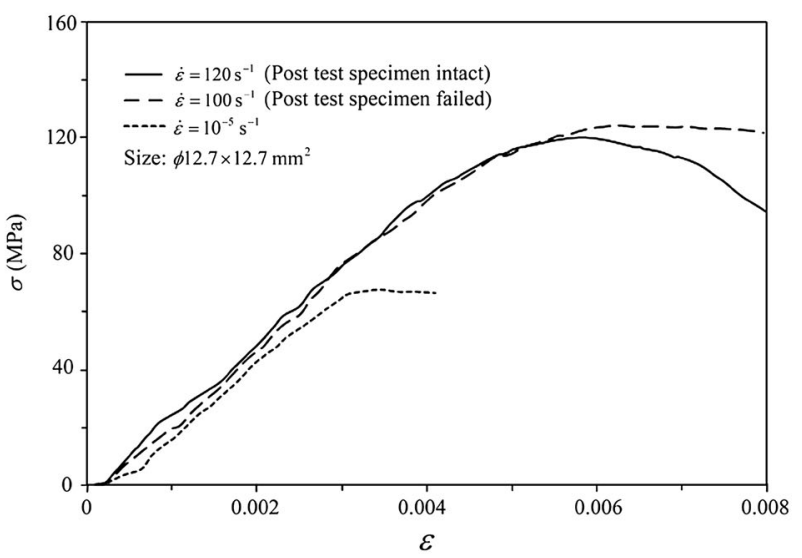

(b)

Fig. 20 Dynamic and quasi-static compressive stress-strain curves of porphyritic tonalite (a) (data from Perkins et al. 1970, Fig. 3, p. 530) and Indiana limestone (b) (modified after Frew et al. 2001, Fig. 10, p. 45)

tangent modulus was unaffected by strain rate (e.g. Frew et al. 2001), as shown in Fig. 20. The CEB (1988) recommended a semi-empirical rate-dependent formula to predict the dynamic elastic modulus, $E_{\mathrm{d}}=E\left(\dot{\varepsilon} / \dot{\varepsilon}_{\mathrm{s}}\right)^{0.026}$, where $\dot{\varepsilon}_{\mathrm{s}}=3 \times 10^{-5} \mathrm{~s}^{-1}$. It should be noted that the stress equilibrium condition cannot be satisfied in the initial range of small strain, and thus it is not possible to measure the dynamic Young's modulus of materials accurately at HSR (Gray 2000). However, it seems to be reasonable to assume that the initial elastic modulus should be unaffected by strain rate, since there is no significant microcracking during the initial stage of loading (Bischoff and Perry 1991). Further experimental and numerical works on the fracturing mechanisms at the initial stage are required to confirm this conclusion.

The stress-strain curve of salt obtained by the inverse method is compared with those obtained by the two- and three-wave analysis methods (Zhao and Gary 1996) in

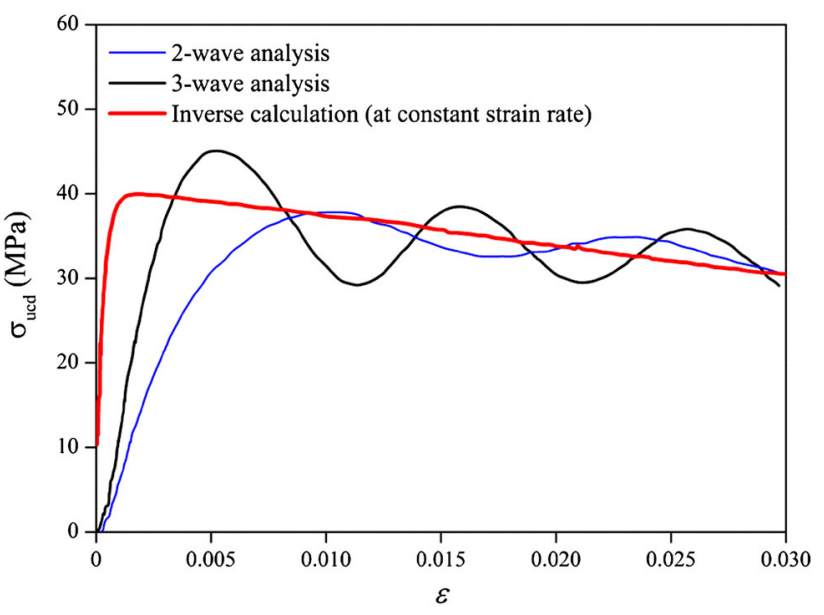

Fig. 21 Dynamic stress-strain curves obtained by three different analysis methods for rock-like material (data from Zhao and Gary 1996, Fig. 9, p. 3,373)

Fig. 21. It can be seen that the two curves obtained by the wave analysis methods are quite far from the one obtained by the inverse method in the range of initial small strains. The inverse method employed force and particle velocities measured at both sides of the specimen, which has been successfully used to determine the stress-strain curves of concrete and salt (Zhao and Gary 1996). Therefore, the inverse analysis method produces accurate and repeatable results for rock-like materials at HSR.

Lundberg (1976) performed compression tests on Bohus granite and Solnhofen limestone using the SHPB technique in combination with a high-speed camera. It was observed that the main crack orientation of the fracturing process was axially parallel to the compression direction and the degree of fragmentation increased with increasing load. Although crack extension phenomena are common also in quasi-static tests (e.g. Brace and Bombolakis 1963; Bieniawski 1967a), the degree of fragmentation is much higher in dynamic tests. The most probable mechanisms (Lundberg 1976; Wu 1971) are that the critical crack extends through the specimen in a very short time compared with the time in the quasi-static test, whereas initiated cracks extend through the specimen more slowly than the loading propagates, and thus extensive crack initiation may occur before general failure of the specimen and prevents further increase of the applied load. Furthermore, although the ability to absorb energy and the enhancement of the uniaxial compressive strength increase with increasing strain rate, the end friction becomes more pronounced for the shorter specimen. Several tests on Bohus granite showed intact cones from the ends of the specimens (Lundberg 1976), which are due to the confining action of the friction at the specimen-bar interfaces (Wu 1971). Figure 22 shows a 


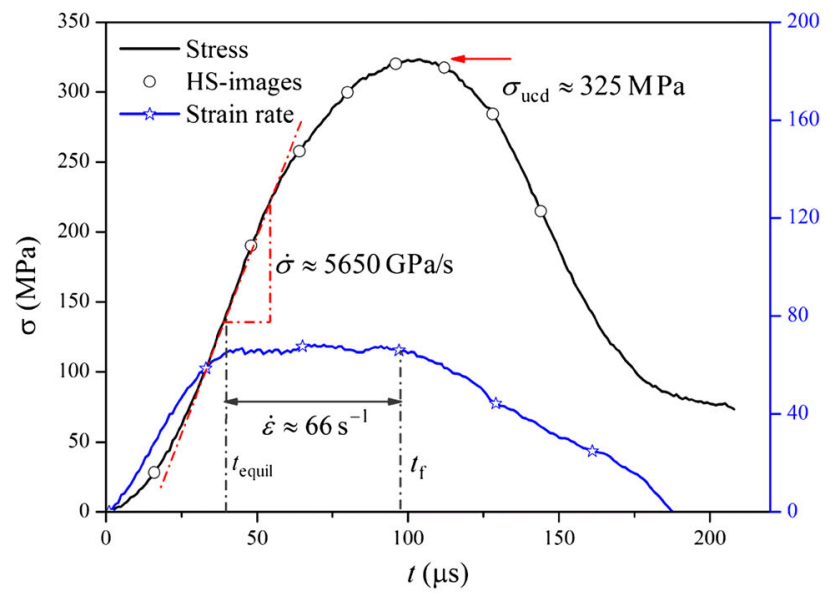

(a)

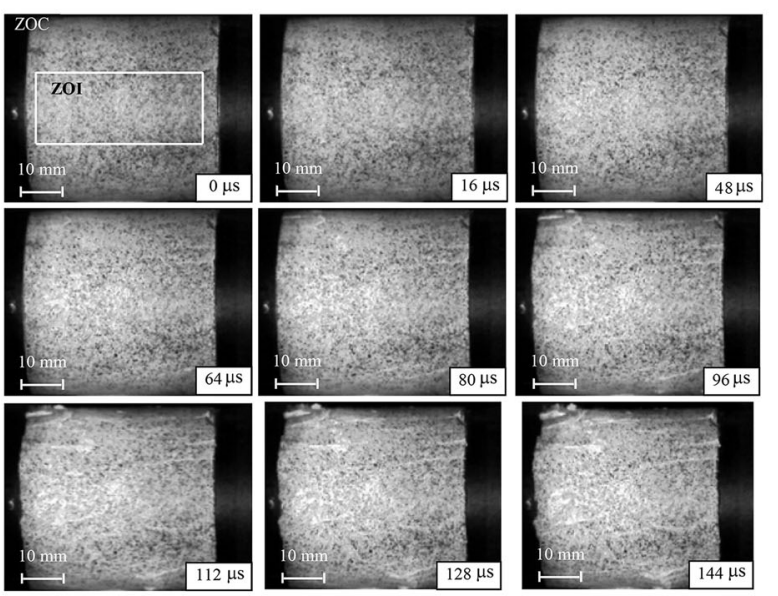

(b)

Fig. 22 Determination of dynamic uniaxial compressive strength, stress rate and strain rate of a typical specimen $\left(\varnothing 50 \times 50 \mathrm{~mm}^{2}\right)(\mathbf{a})$, and corresponding images of the fracture process (b) (ZOC Zone of camera, ZOI Zone of Interest. Reproduced from Zhang and Zhao 2013a)

typical result of the loading history and corresponding images of the fracture process at strain rate of $66 \mathrm{~s}^{-1}$ using the SHPB technique. It is noted that cracks initiate from the edges at $96 \mu$ s and propagate approximately along the axial direction of the specimen, then many cracks become visible on the cylindrical surface. The crack propagation leads to a stress drop observed in the stress-time plot. The observed axial fracture process shows that the end friction is minimized.

In HSR testing, the energy of the incident wave $W_{\text {In. }}$, the energy of the reflected wave $W_{\mathrm{Re}}$ and the energy of the transmitted wave $W_{\text {Tr. }}$ can be expressed as

$W_{\text {In. }}=\frac{A_{\mathrm{B}} C_{\mathrm{B}}}{E_{\mathrm{B}}} \int \varepsilon_{\text {In. }}(t)^{2} \mathrm{~d} t$,

$W_{\text {Re. }}=\frac{A_{\mathrm{B}} C_{\mathrm{B}}}{E_{\mathrm{B}}} \int \varepsilon_{\text {Re. }}(t)^{2} \mathrm{~d} t$,
$W_{\text {Tr. }}=\frac{A_{\mathrm{B}} C_{\mathrm{B}}}{E_{\mathrm{B}}} \int \varepsilon_{\text {Tr. }}(t)^{2} \mathrm{~d} t$.

Assuming that the energy lost at the specimen-bar interfaces is negligible, the energy delivered to the specimen is $W_{\text {In. }}-W_{\text {Re. }}$, and the energy absorbed by the specimen is $W_{\mathrm{s}}=W_{\text {In. }}-W_{\text {Re. }}-W_{\text {Tr. }}$. Fracturing will tend to attenuate the amplitude of a propagating pulse and reduce the transmitted stress, as considered by Hakalehto (1970), Li et al. (1993) and Hong et al. (2009). Figure 23 presents the total energy transmission versus the total energy input for three types of rock. It can be seen that, the shorter the specimen, the greater the amount of energy that can be transmitted, the same conclusion as presented by $\mathrm{Li}$ et al. (2005). The curve can be separated into three regions (Fig. 23b): the first region is linear, in which virtually all of the incident energy is transmitted; in the second region, an increasing proportion of the input energy is absorbed by the specimen; finally, in the third region, an upper limit of transmitted energy is reached, such that practically all additional input energy is absorbed by the specimen. Figure 24 shows the relationship between the normalized dynamic uniaxial compressive strength and the ratio of the energy absorbed by the specimen to the incident energy (Lundberg 1976). It can also be seen that the strain rate sensitivity of Bohus granite is more pronounced than that of Solnhofen limestone. Several tests on Bohus granite showed intact cones from the ends of the specimens, due to the confining action of the friction at the specimen-bar interfaces (Wu 1971).

As mentioned above, failure patterns can be classified into apparently intact, single fracturing or split, and multiple fracturing or pulverization, as is generally accepted (Li et al. 2005, 2008a; Doan and Gary 2009; Cai et al. 2007; Xia et al. 2008). Li et al. (2005) performed tests on Bukit Timah granite using a 75-mm-diameter bar, observing two distinctive failure modes as shown in Fig. 25a. The transition from single fracturing to intense pulverization depends on the strain rate (Doan and Gary 2009), and the threshold occurs between 100 and $150 \mathrm{~s}^{-1}$ as shown in Fig. 25b. Although the size distribution of fragments has also been investigated after dynamic tests (e.g. Doan and Gary 2009; Hong et al. 2009), the results were not satisfactory unless careful consideration was given to single pulse loading and high-speed photography was employed for validation.

Figure 26 shows results for the normalized uniaxial compressive strength as a function of strain rate obtained over the last five decades (Zhang and Zhao 2013a; Xia et al. 2008; Frew et al. 2001; Li et al. 2005; Kimberley and Ramesh 2011; Yuan et al. 2011; Doan and Gary 2009; Doan and Billi 2011; Cai et al. 2007; Zhao et al. 1999a; Olsson 1991; Klepaczko 1990; Blanton 1981; Chong et al. 


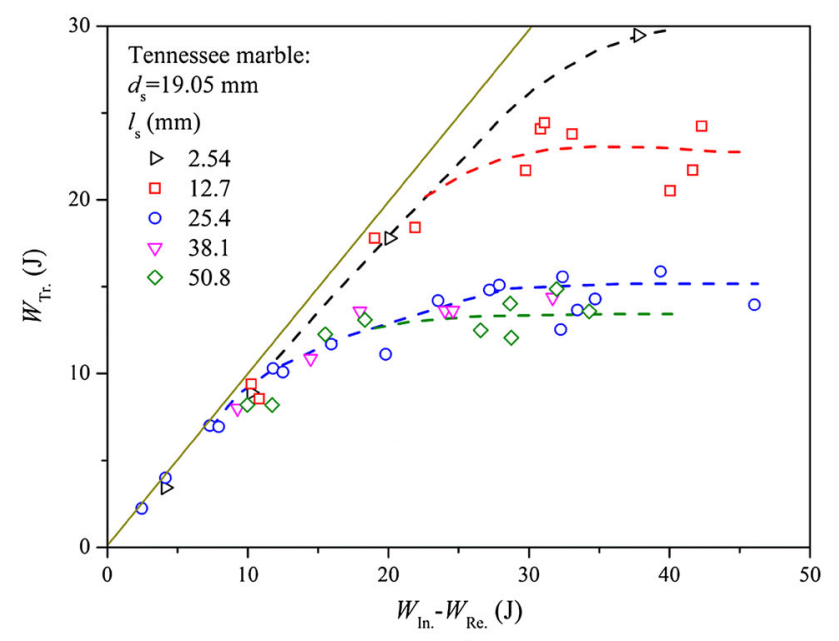

(a)

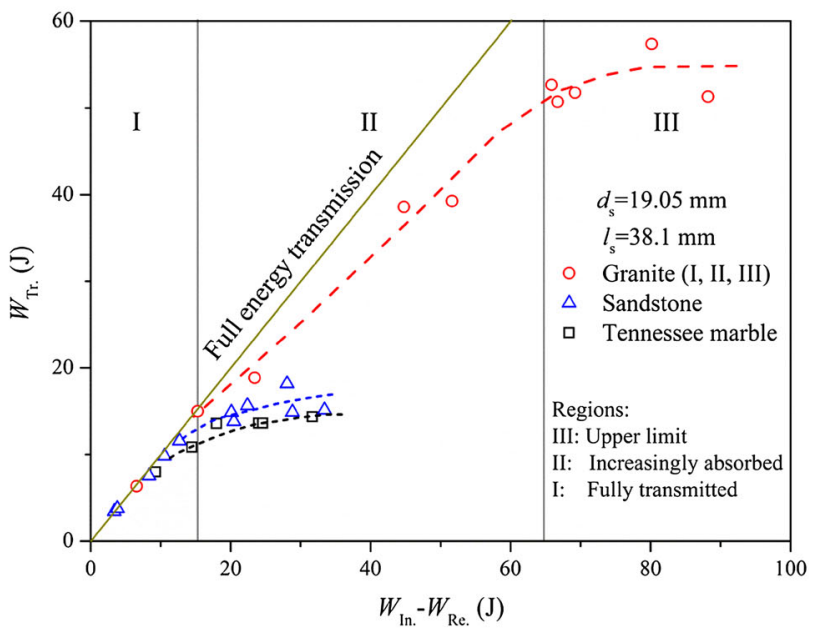

(b)

Fig. 23 Energy transmission in specimens of Tennessee marble (a), and of Tennessee marble, granite and sandstone (b) (data from Hakalehto 1969)

1980; Lankford 1976; Lindholm et al. 1974; Perkins et al. 1970; Green and Perkins 1969; Stowe and Ainsworth 1968; Kumar 1968; Goldsmith et al. 1976; Wang and Tonon 2011; Howe et al. 1974; Sylven et al. 2004). Although it has been generally accepted that there is a definite increase in the uniaxial compressive strength of rock materials under dynamic loading, not all investigators agree regarding the strain rate at which this increase in strength becomes significant (e.g. Green and Perkins 1969; Kumar 1968; Chong et al. 1980). Furthermore, the size effect (see Sect. 4.8.3 for details) must be taken into account when comparing the dynamic strength with a quasi-statically loaded specimen with different size ratio.

Confusion arises regarding the values of the critical strain rate $\left(\dot{\varepsilon}_{\text {cri }}\right)$, the limiting strain rate $\left(\dot{\varepsilon}_{\text {lim }}\right)$ and the degree of strength enhancement $\left(\sigma_{\mathrm{ucd}} / \sigma_{\mathrm{uc}}\right)$; For example, the critical strain rate result reported by Blanton (1981) is



Fig. 24 Relationship between normalized dynamic uniaxial compressive strength and the ratio of the energy absorbed by the specimen to the incident energy (data from Lundberg 1976)

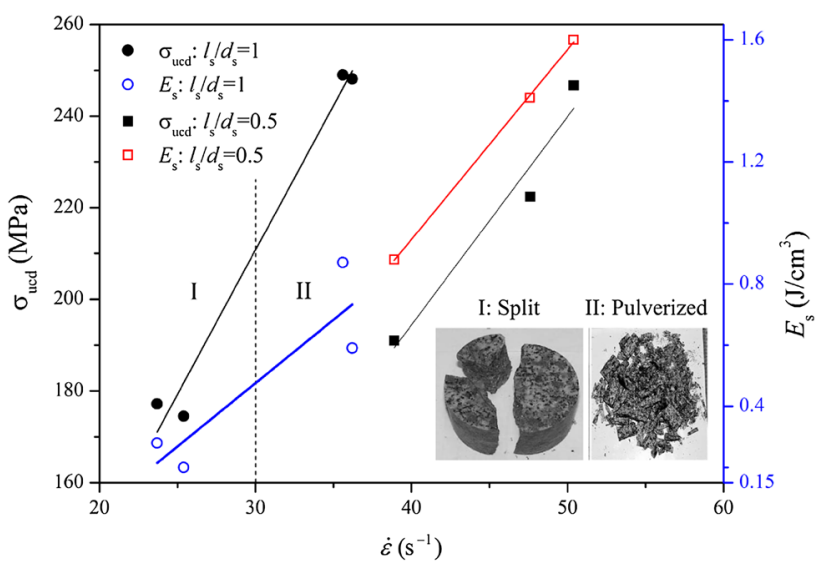

(a)

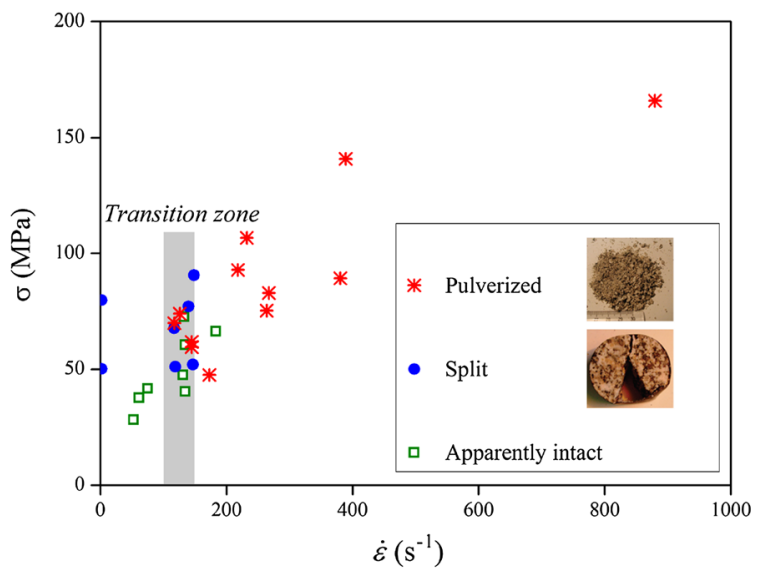

(b)

Fig. 25 Dynamic uniaxial compressive strength and energy absorption of BT-granite $\left(\varnothing 70 \times 70 / 35 \mathrm{~mm}^{2}\right)$ and corresponding failure patterns (a) (data and photos from Li et al. 2005); the final state relative to strength and the peak strain rate of San Andreas Fault granite $\left(\varnothing 25 \times 25 \mathrm{~mm}^{2}\right)$ (b) (modified after Doan and Gary 2009, S-Fig. 1, S-p. 6) 


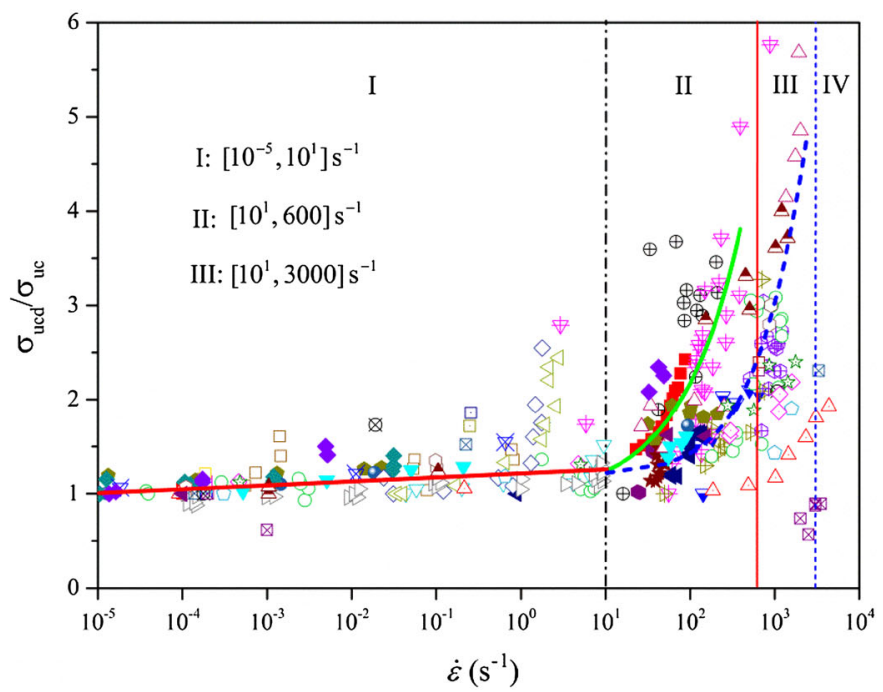

\begin{tabular}{|c|c|}
\hline \\
\hline \multicolumn{2}{|c|}{$\begin{array}{l}\text { A. With pulse shaping }(\mathrm{mm}) \text { : } \\
\text { - Zhang, } 2013 \mathrm{~F} \text {-marble: } \phi 50 \times 50\end{array}$} \\
\hline \multicolumn{2}{|r|}{$\Delta \quad$ Kimberley, 2011 O-chondrite: $5 \times 5 \times 5$} \\
\hline \multicolumn{2}{|r|}{ Wan } \\
\hline \multirow{2}{*}{\multicolumn{2}{|c|}{$\nabla \quad$ Yuan, $2011 \mathrm{~W}$-granite: $\phi 10.2 \times(6-8)$}} \\
\hline & \\
\hline \multicolumn{2}{|r|}{ - Li, 2005 BT-granite: $\phi 70 \times 70$} \\
\hline \multicolumn{2}{|r|}{$\star \quad \mathrm{Li}, 2005$ BT-granite: $\phi 70 \times 35$} \\
\hline \multicolumn{2}{|r|}{ Frew, 2001 I-limestone: $\phi 12.7 \times 12.7$} \\
\hline \\
\hline \multicolumn{2}{|r|}{$\begin{array}{l}\text { Frew, } 2001 \text { I-limestone: } \phi 12.7 \times 19.05 \\
\text { Frew, } 2001 \text { I-limestone: } \phi 12.7 \times 25.4\end{array}$} \\
\hline \multicolumn{2}{|r|}{ B. Without pulse shaping $(\mathrm{mm})$ : } \\
\hline \multicolumn{2}{|c|}{$\oplus$ Doan, $2011 \mathrm{C}$-marble: $\phi 25 \times 25$} \\
\hline \multicolumn{2}{|r|}{$\forall \quad$ Doan, 2009 SA-granite: $\phi 25 \times 25$} \\
\hline \multicolumn{2}{|r|}{$\rightarrow \quad$ Doan, 2009 T-granite: $\phi 25 \times 25$} \\
\hline \multirow{2}{*}{\multicolumn{2}{|c|}{$\begin{array}{ll}\oplus \quad \text { Cai, } 2007 \text { Argillite: } \phi 13.22 \times(4.51-5.9) \\
\otimes \quad \text { Sylven, } 2004 \text { Kidney stone: } \phi 19 \times 4.6\end{array}$}} \\
\hline & \\
\hline \multicolumn{2}{|r|}{$\square \quad$ Zhao, 1999 BT-granite: $\phi 30 \times 60$} \\
\hline \multicolumn{2}{|r|}{ Olsson, 1991 Tuff: $\phi 12.5 \times 12.5 / 25$} \\
\hline \multicolumn{2}{|r|}{$\triangle$ Klepaczko, 1990 Coal: $\phi 20 \times 40$} \\
\hline \multicolumn{2}{|r|}{$\nabla \quad$ Blanton, 1981 Granodiorite: $\phi 12.6 \times 53$} \\
\hline \multicolumn{2}{|r|}{$\diamond \quad$ Blanton, 1981 I-limestone: $\phi 16.5 \times 50$} \\
\hline \multicolumn{2}{|r|}{ Blanton, 1981 Sandstone: $\phi 16.5 \times 50$} \\
\hline \multicolumn{2}{|r|}{$\triangleright \quad$ Chong, 1980 M-oil shale: $\phi 12.7 \times 25.4$} \\
\hline \multicolumn{2}{|r|}{4 Goldsmith, 1976 B-granite: $\phi 25.4 \times 64.5$} \\
\hline \multicolumn{2}{|r|}{ Lankford, 1976 M-oil shale: $\phi 12.7 \times 25.4$} \\
\hline \multicolumn{2}{|r|}{ Howe, 1974 M-marble: $\phi 19.5 \times 19.05 / 31.75$} \\
\hline \multicolumn{2}{|r|}{ Lindholm, 1974 D-basalt: $\phi 12.7 \times 25.4$} \\
\hline \multicolumn{2}{|r|}{$\square \quad$ Perkins, 1970 Tonalite: $\phi 12.7 \times 19.05$} \\
\hline \multicolumn{2}{|r|}{ Green, $1969 \mathrm{~W}$-granite: $\phi 12.7 \times 25.4$} \\
\hline$\otimes$ & Green, 1969 Tuff: $\phi 12.7 \times 25.4$ \\
\hline & Green, 1969 S-limestone: $\phi 12.7 \times 25.4$ \\
\hline & Stowe, 1968 Basalt: $\phi 54 \times 108$ \\
\hline & Kumar, 1968 Basalt: $12.7 \times 12.7 \times 12.7$ \\
\hline & Kumar, 1968 Granite: $12.7 \times 12.7 \times 12.7$ \\
\hline
\end{tabular}

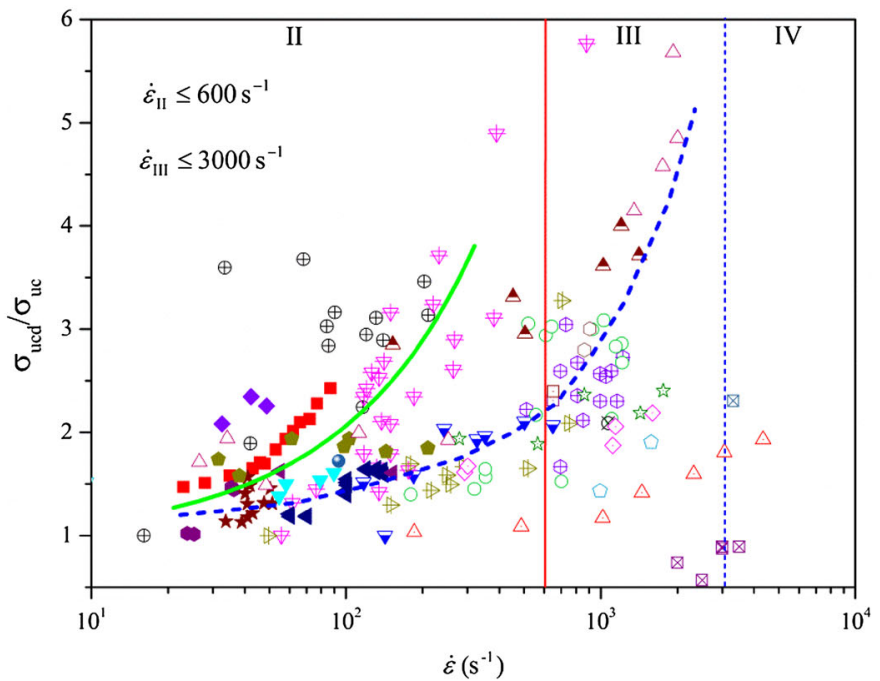

1968; Kumar 1968; Goldsmith et al. 1976; Wang and Tonon 2011; Howe et al. 1974; Sylven et al. 2004). Abbreviations of some wellknown rock materials: $B$ Berea sandstone, $D$ Dresser basalt, $I$ Indiana limestone, $S$ Solnhofen limestone, $C$ Carrara marble, $F$ Fangshan marble, $Y$ Yule marble, $B$ Barre granite, $B T$ Bukit Timah granite, $L$ Laurentian granite, $S A$ San Andreas granite, $W$ Westerly granite

about $1 \mathrm{~s}^{-1}$, which seems to be much lower than others. Some popular semi-empirical equations for the enhancement in dynamic compressive strength are summarized in Sect. 4.9, with values of the critical strain rate of, e.g., $10^{2} \mathrm{~s}^{-1}$ (Lankford 1981) and $76 \mathrm{~s}^{-1}$ (Olsson 1991). Conclusions are primarily based on results determined by various experimental techniques to load the specimens and to measure stress/strain, and testing methods to analyse and interpret experimental data.

Although specimens can be loaded over a wide range of strain rates, standardized tests require well-characterized strain rates that do not exceed a limiting value, as discussed

in Sect. 2.2.5. Based on loading techniques and specimen sizes, we divide the stress-strain rate curve in Fig. 26 into four regions as follows: Region I corresponds to quasistatic and ISR tests, and the maximum strain rate, $\dot{\varepsilon}_{\max }$, is $10 \mathrm{~s}^{-1}$, which is also regarded as the limit of ISR testing; Regions II and III are classified to distinguish valid from invalid tests according to an approximate criterion, $\dot{\varepsilon}_{\max }=V_{\text {str }} / L_{\mathrm{s}}$, where $V_{\text {str }}$ is the velocity of the striker, suggested by Ramesh (2008), as shown in Fig. 27. The strain rate depends on the size and density of the specimen; i.e. the larger the specimen and the higher its density, the lower the strain rate (Field et al. 2004). Specimen lengths 
Fig. 27 Response diagram for the SHPB showing the intersection of the material response curve with the test response line (redrawn from Ramesh 2008, Fig. 33.6, p. 934)

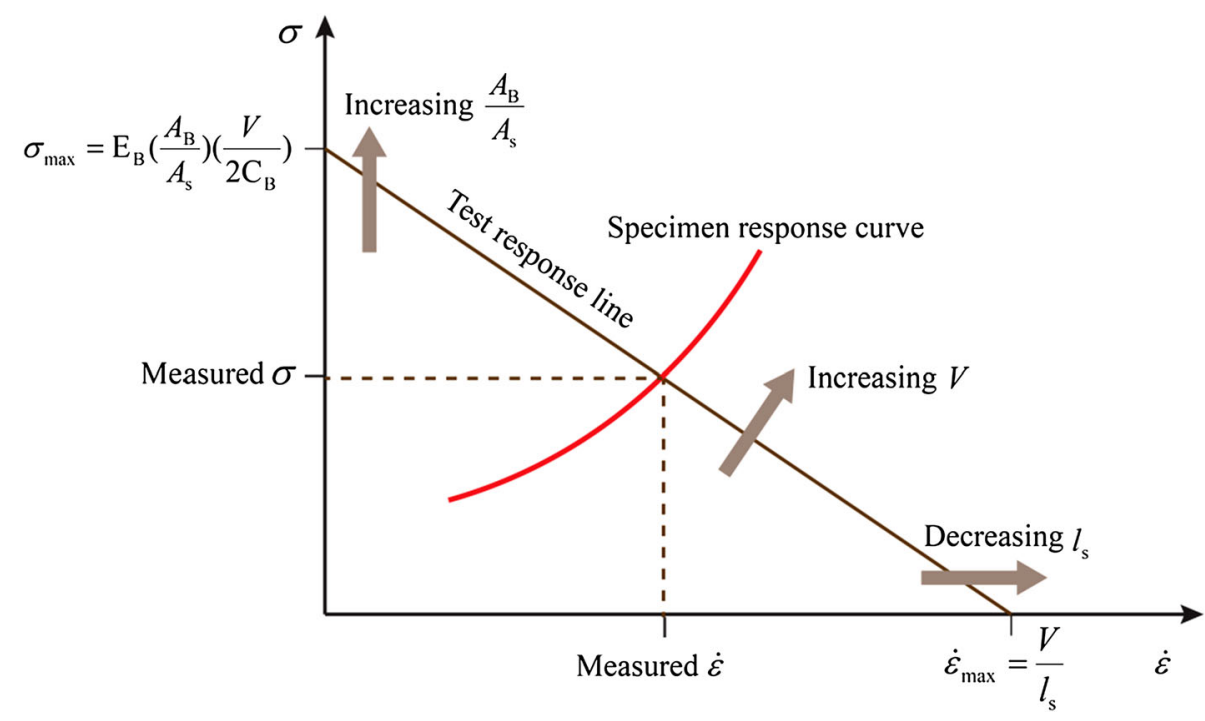

of 50 and $10 \mathrm{~mm}$ are used to estimate the limiting strain rate, and the maximum launch velocity of the striker is usually $30 \mathrm{~m} / \mathrm{s}$. Therefore, the calculated limiting values are 600 and 3,000 s $\mathrm{s}^{-1}$ for regions II and III, respectively; In region IV, experimental results are dubious unless detailed explanations are given. In region I, the normalized uniaxial compressive strength increases linearly with increasing strain rate, while it increases dramatically after the ISR regime in regions II and III.

\subsection{Dynamic Triaxial Compressive Behaviour}

Mechanical loads applied to rock materials in applications are commonly not uniaxial. Therefore, the development and calibration of constitutive models for numerical simulations require experimental data under various stress and/ or strain paths, strain rates and confinement typically observed in impacts of testing systems. Confusion arises about whether the sensitivity to confining pressure is rate dependent or not, and how to separate the confining pressure sensitivity and the strain rate sensitivity.

Dynamic stress-strain curves of Horonai sandstone under various confining pressures were obtained by the three-wave analysis method (Sato et al. 1981) and are shown in Fig. 28a. It can be seen that the stress-strain curves at HSR under 0.1 and $10 \mathrm{MPa}$ confining pressures are approximately consistent with those under 27 and $55 \mathrm{MPa}$ confining pressures in the quasi-static tests, respectively. The confining pressure of the brittle-ductile transition seems to be about 55-85 MPa in the quasi-static tests, while this transition pressure is relatively lower under dynamic loading, ranging from 10 to $35 \mathrm{MPa}$. It appears that the deformation behaviour of Horonai sandstone becomes more ductile at lower confining pressures in HSR tests than in quasi-static conditions. Compared with the results for uniaxial compressive strength (Fig. 20b), a significant strength enhancement of limestone is observed in both quasi-static and dynamic tests at confining pressure of $20 \mathrm{MPa}$ (Frew et al. 2010), as shown in Fig. 28b, c. The responses in these tests show that the brittle-ductile transition occurs below the $100 \mathrm{MPa}$ confining level in both quasi-static and dynamic tests, and the strength enhancement is similar to those observed in the range of lower confining pressures. Although at ISRs it has been reported that the Young's modulus is unaffected by the strain rate while the Poisson's ratio seems to increase slightly with increasing strain rate and confining pressure ( $\mathrm{Li}$ et al. 1999), very little information is available at HSRs for the reasons mentioned above.

Rock-like materials are very sensitive to the confining pressure under quasi-static loads (Paterson and Wong 2005). In ISR tests, hydrostatic confining chambers are also widely used and data are usually obtained without considering the inertia effect. Serdengecti and Boozer (1961) might be the first authors to have investigated the effect of confining pressure on three typical rocks. Logan and Handin (1970) performed tests on Westerly granite and Solnhofen limestone at confining pressures up to 700 and $300 \mathrm{MPa}$, respectively. They observed that brittle deformation dominated the mechanical behaviour of Westerly granite, and the brittle-ductile transition occurred at confining pressure of $150 \mathrm{MPa}$ and strain rate of $10^{1} \mathrm{~s}^{-1}$ for Solnhofen limestone. Li et al. (1999) performed tests on Bukit Timah granite at four strain rates up to $10^{0} \mathrm{~s}^{-1}$ and six confining pressures $(20,50,80,110,140$ and $170 \mathrm{MPa})$. Figure 29 shows that the dynamic differential stress increases with increasing confining pressure at CSR, and the rate of strength enhancement with strain rate is lower at higher confining pressures. They also reported that the dynamic triaxial strength can be represented by the Hoek- 


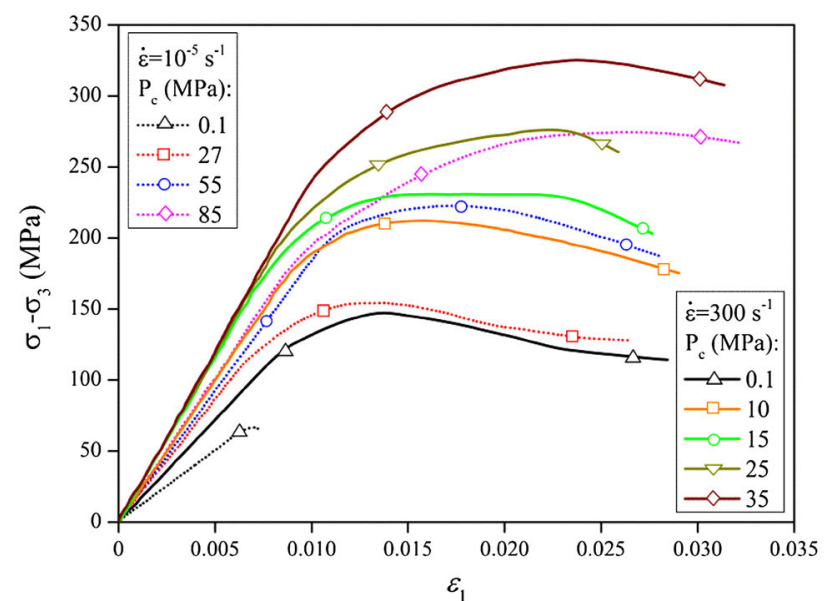

(a)

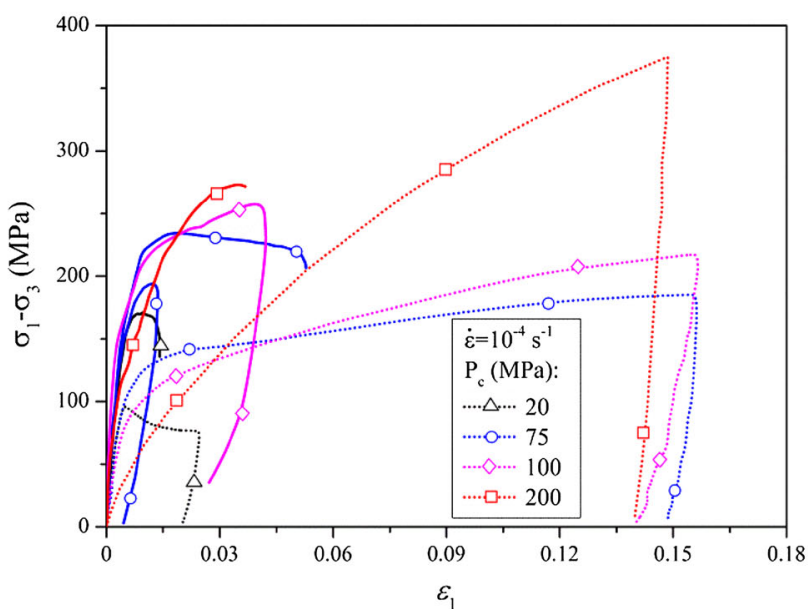

(b)

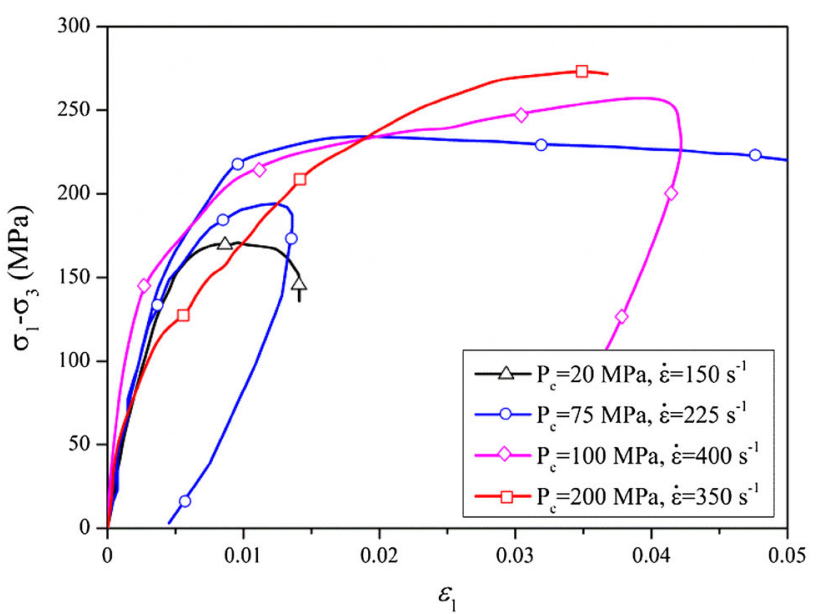

(c)

Fig. 28 Quasi-static and dynamic stress-strain curves under confining pressures for: a Horonai sandstone (data from Sato et al. 1981, three-wave analysis method, Fig. 3, p. 470) and b Indiana limestone; c magnified view of (b) (data from Frew et al. 2010, one-wave analysis method, Figs. 15-18, pp. 7-8)

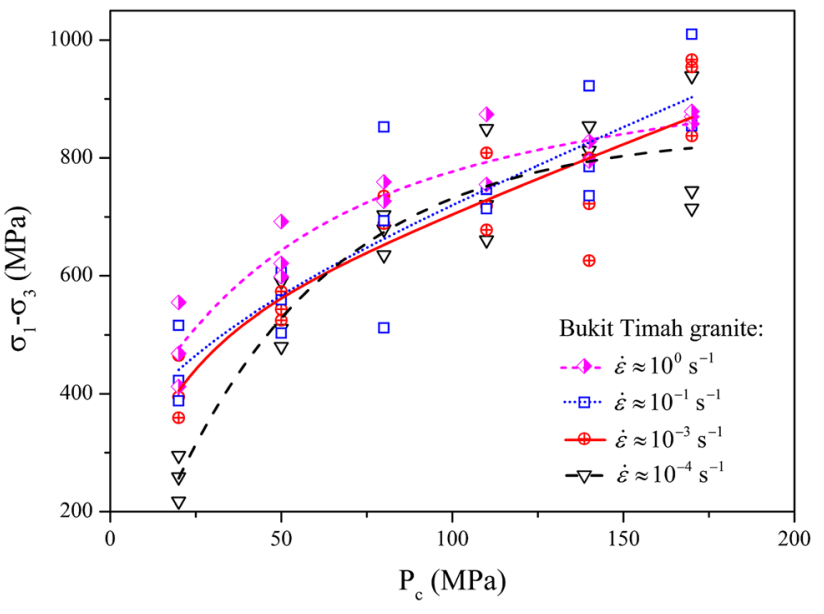

Fig. 29 Variation of the dynamic differential stress with confining pressure at different strain rates for Bukit Timah granite (data from $\mathrm{Li}$ et al. 1999, Fig. 4, p. 1061)

Brown criterion at both low and high confining pressures whereas the Mohr-Coulomb criterion is only applicable in the range of low confining pressure (Zhao 2000) (see Sect. 7 for details).

At HSR, Christensen et al. (1972) performed pioneering work on sandstone using the SHPB technique with active confining pressures up to $95 \mathrm{MPa}$. The techniques applied have thereafter been continuously modified and improved to precisely determine the triaxial compressive strength of rock-like materials (Gary and Bailly 1998; Malvern and Jenkens 1990; Lindholm et al. 1974; Sato et al. 1981). Recently, an additional pressure chamber was added to the free end of the transmission bar to apply the axial portion of the hydraulic pressure to the specimen, which is either used to perform combined static-dynamic tests (Yin et al. 2012b; Jin et al. 2012; Li et al. 2008b) or applied to conduct triaxial tests (Frew et al. 2010). Six types of sedimentary rock were tested under hydrostatic confining pressures up to $40 \mathrm{MPa}$ at strain rates of $10^{-5}$ and $300 \mathrm{~s}^{-1}$ (Sato et al. 1981), as shown in Fig. 30. It can be seen that the dynamic strength curve relative to confining pressure is almost parallel to the static one for each rock type. Therefore, the Mohr-Coulomb criterion is applicable to both the quasi-static and dynamic tests, and the same conclusion was also reached by $\mathrm{Yu}$ (1992).

At constant confining pressure, the normalized dynamic triaxial compressive strength increases with increasing strain rate, as shown in Fig. 31. Although the dynamic strength curve relative to confining pressure is almost parallel to the static one for each rock type, the triaxial compressive strength at HSR is about $20 \%$ (Christensen et al. 1972), $100 \%$ (Lindholm et al. 1974), $150 \%$ (Sato 


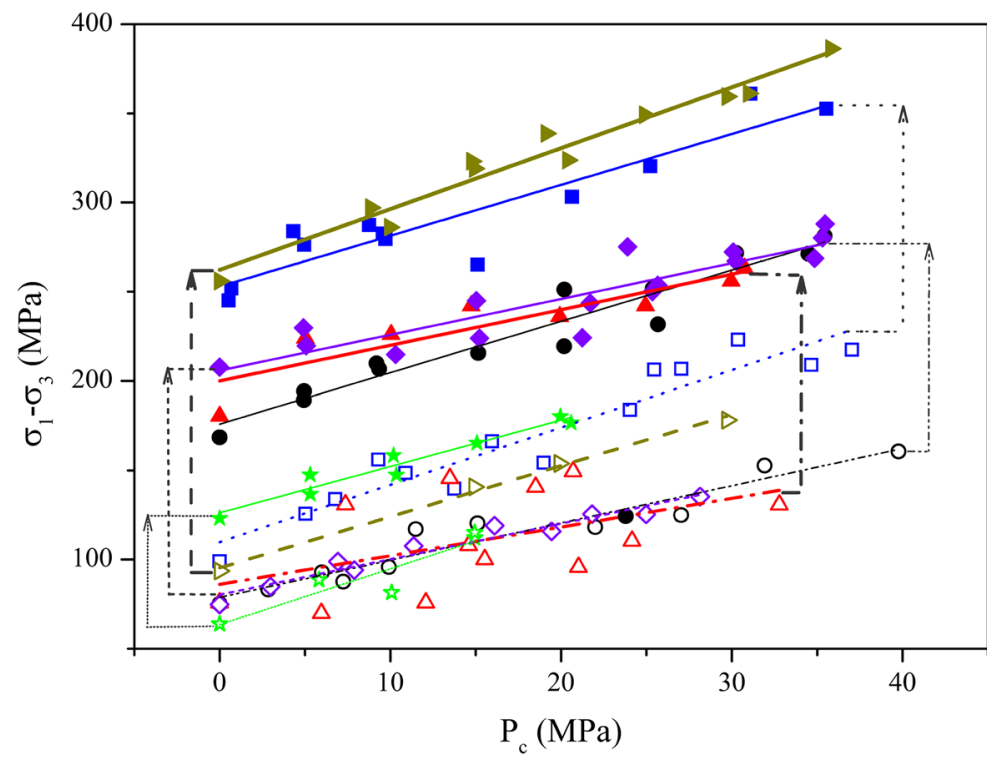

Sedimentary rocks $\left(\phi 25 \times 25 \mathrm{~mm}^{2}\right)$ :

(CG-Coarse grained; FG-Fine grained)

Dynamic tests $\left(\dot{\varepsilon}=300 \mathrm{~s}^{-1}\right)$ :

- Horonai sandstone

- Sunagawa sandstone

- Horokabetsu shale

- Akiyoshi limestone-CG

- Akiyoshi limestone-FG

$\star$ Ogino tuff

Quasi-static tests $\left(\dot{\varepsilon}=10^{-5} \mathrm{~s}^{-1}\right)$ :

o Horonai sandstone

口 Sunagawa sandstone

$\triangle$ Horokabetsu shale

$\diamond \quad$ Akiyoshi limestone CG

$\triangleright$ Akiyoshi limestone-FG

次 Ogino tuff

Fig. 30 Variation of dynamic differential stress with confining pressure at different strain rates for six types of sedimentary rock (data from Sato et al. 1981, Fig. 4, pp. 471-2)

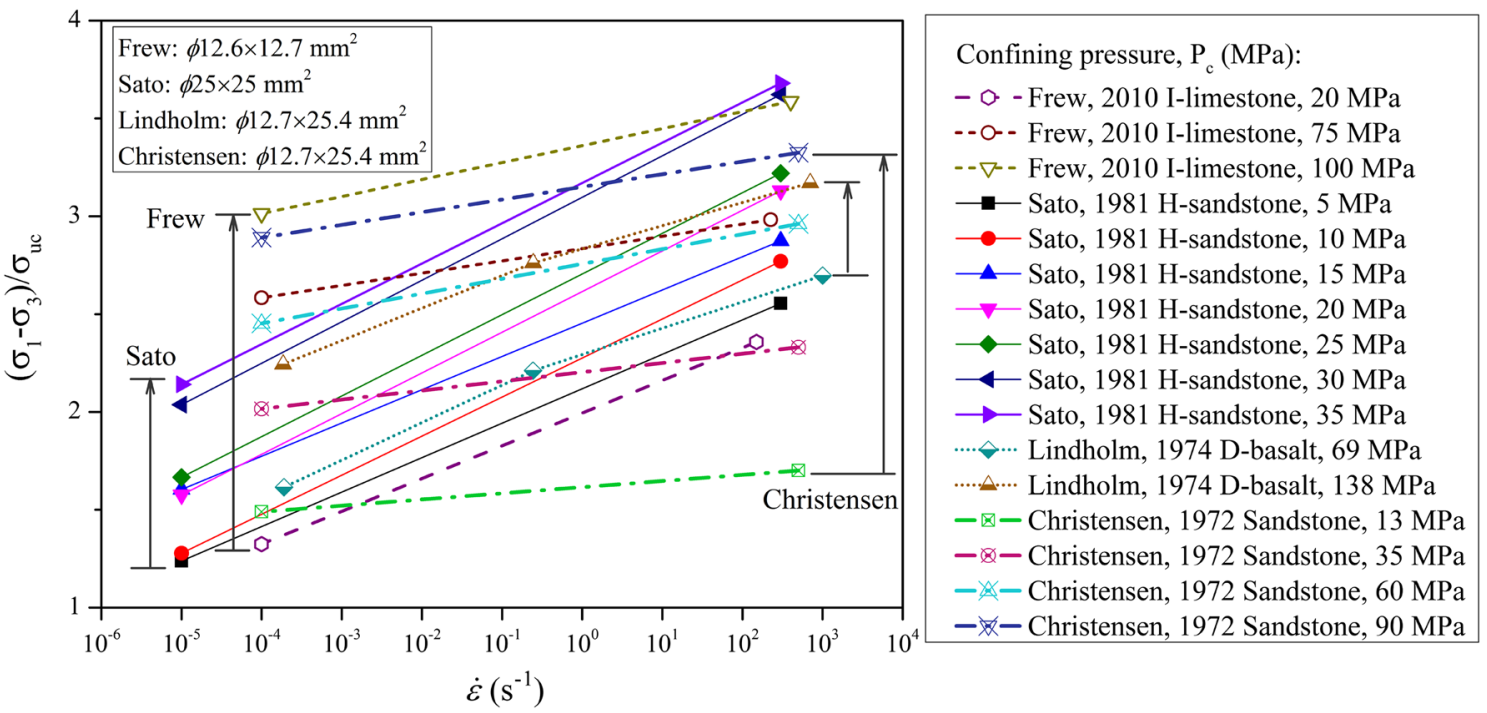

Fig. 31 Normalized dynamic differential stress versus strain rate at various confining pressures (data from Frew et al. 2010; Lindholm et al. 1974; Christensen et al. 1972; Sato et al. 1981). Abbreviations of rock materials: I Indiana limestone, $H$ Horonai sandstone

et al. 1981) and 30-100\% (Frew et al. 2010) higher than those obtained in quasi-static tests. The most probable reasons are due to differences in rocks, specimen sizes and confining pressure apparatus.

As summarized by Lindholm et al. (1974), failure modes in compression tests fall into three groups, namely shear, cataclasis and cataclasis/cleavage. Examples of these modes are shown in Fig. 32a. The relationship between these failure modes and confining pressure under various strain rates is shown in Fig. 32b. A gradual transition from cataclastic cleavage, to shear, to cataclasis is manifested as the triaxial compressive state becomes more intense, irrespective of strain rate. For unconfined uniaxial compression tests, the predominant failure mode was cataclastic cleavage. The range of shear-type failures is in general agreement with the result by Serdengecti and Boozer for Pala gabbro tested at strain rate of $10^{-1} \mathrm{~s}^{-1}$ and confining pressures of 69 and $138 \mathrm{MPa}$.

Four stages of the conical fault formation process of ceramic specimens confined by metal sleeves were revealed by inspection of the failure patterns on crosssections (Chen and Ravichandran 1997; Chen et al. 2007), as schematically shown in Fig. 33. 




(I) Shear

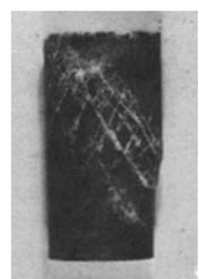

(II) Cataclasis

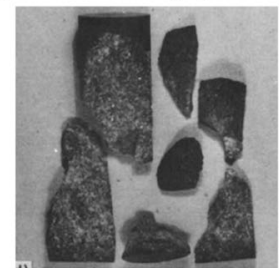

(III) Cataclasis/Cleavage

(a)

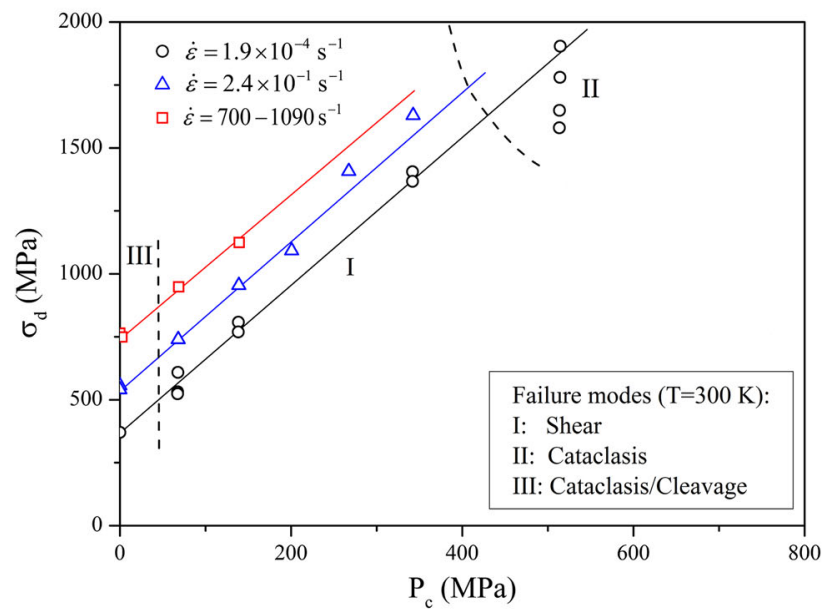

(b)

Fig. 32 Representative failure modes: shear, cataclasis and cataclasis/cleavage under active confining pressures (a), correlation of these failure modes with confining pressure and strain rate for Dresser basalt (b) (data and photos from Lindholm et al. 1974)

\subsection{Dynamic Tensile Behaviour}

Experimental data from direct tension tests (Asprone et al. 2009) have been processed to obtain the relationship between tensile stress and strain curves at different strain rates, as shown in Fig. 34. It can be seen that the tensile strength increases with increasing strain rate, whereas the corresponding strain decreases. The increase in the tensile strength and the decrease in the strain to failure indicate that the material displays more brittle features in higher strain rate tests.

Attempts have been made to determine the tensile stress-strain curve by means of indirect testing methods under quasi-static loads (Carmona and Aguado 2012). The stress-strain curve of a spalling specimen was reconstructed by the virtual fields method in combination with the high-speed DIC method (Pierron and Forquin 2012), as shown in Fig. 35. Although strains were measured by strain gauges perpendicular to the loading axis, mounted at the centre and on both sides of the disc specimen (Zhao and $\mathrm{Li}$ 2000; Wang et al. 2006, 2009; Zhang and Zhao 2013a), it is extremely difficult to obtain the true tensile strain by a single-point measurement technique.

Figure 36 shows the normalized dynamic tensile strength as a function of strain rate (Cadoni 2010; Asprone et al. 2009; Goldsmith et al. 1976; Wang et al. 2009; Dutta and Kim 1993; Kubota et al. 2008; Cho et al. 2003; Khan and Irani 1987; Howe et al. 1974) and as a function of loading rate (Zhang and Zhao 2013a; Yan et al. 2012; Huang et al. 2010a, b; Dai et al. 2010c, d; Dai and Xia 2010; Zhao and Li 2000; Zhao et al. 1998). It can be seen that the strain rates of the direct tension results are higher than those obtained by indirect tension testing methods, since the specimen sizes are usually smaller in indirect tension tests. Figure 36 indicates that the dynamic tensile
Fig. 33 Schematic of dynamic fracturing process of fault formation under passive confining pressure: a elastic region, b initial microcrack propagation, $\mathbf{c}$ macroscopic crack formed by interaction of cracks initiated at corners, d sliding of fragments across the faults (reproduced from Chen et al. 2007 after Chen and Ravichandran 1997, Fig. 12, p. 1,012)
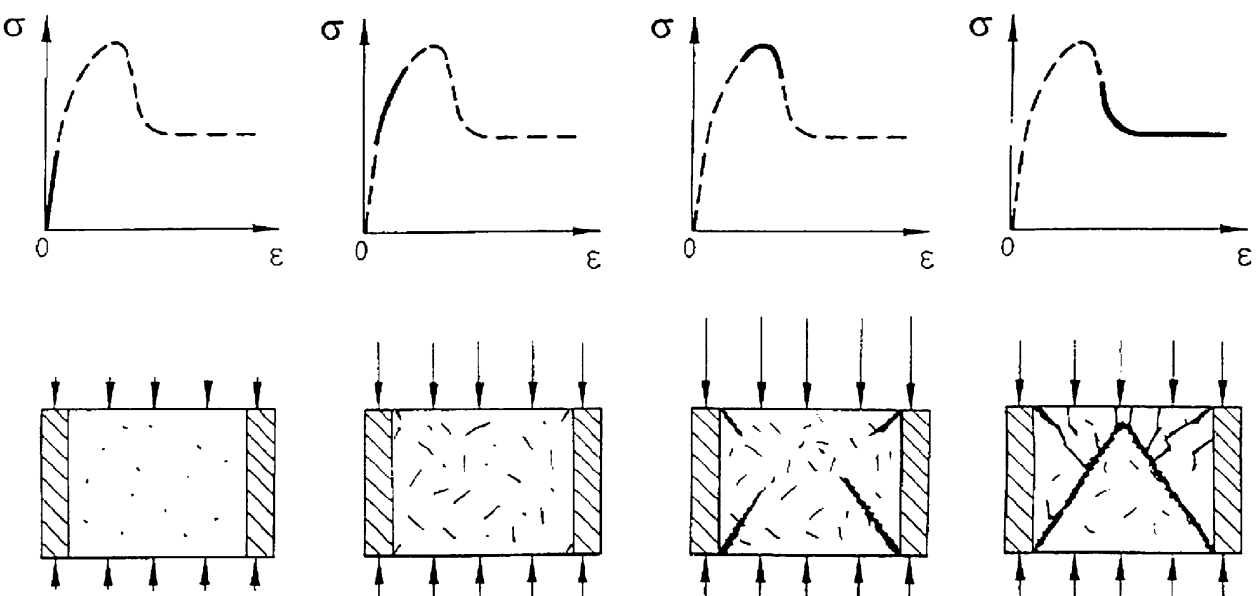

(a)

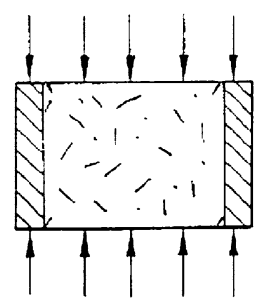

(b)



(c)

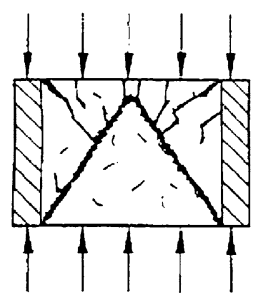

(d) 


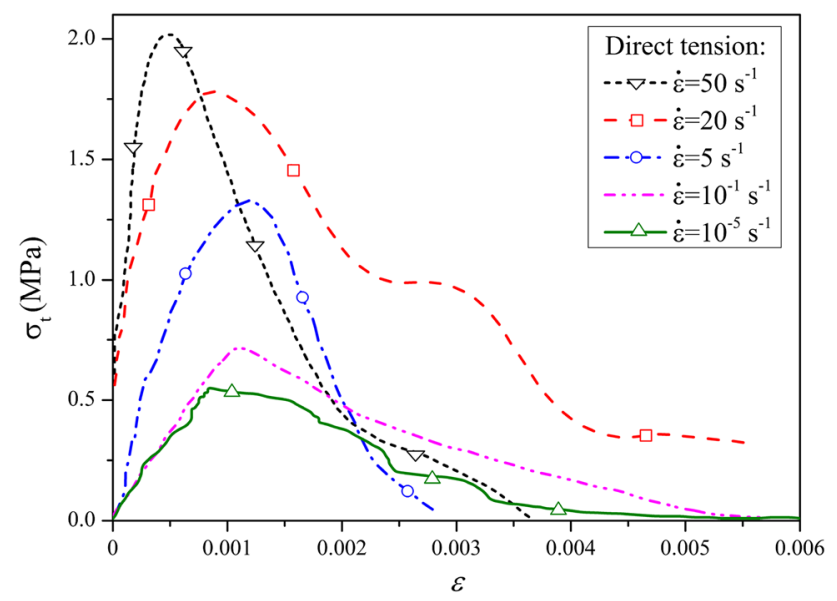

Fig. 34 Tensile stress-strain curves of tuff at different strain rates (data from Asprone et al. 2009, Fig. 5, p. 518) (tensile strain measured by displacement transducer in quasi-static and intermediate strain rate tests, and calculated by one-wave analysis in high strain rate tests)

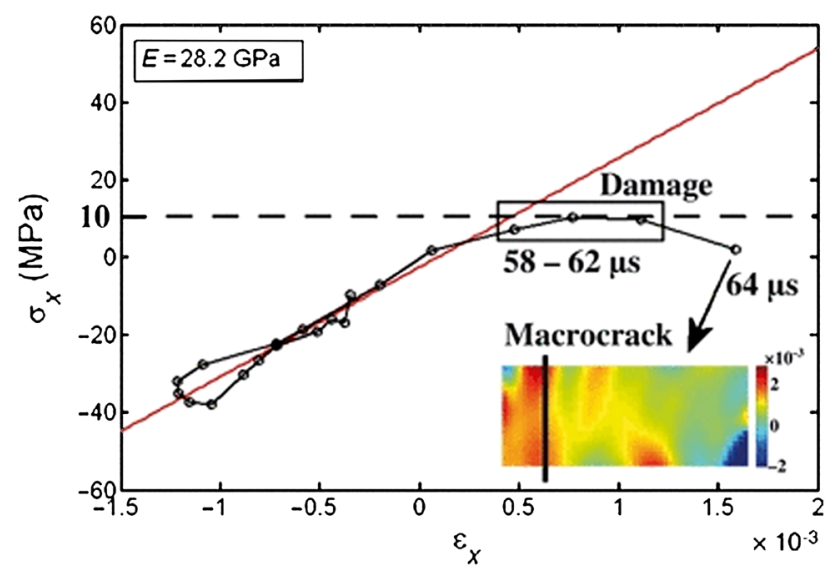

Fig. 35 Stress-strain curves for a spalling specimen at $40 \mathrm{~mm}$ from the free end, reconstructed by the virtual fields method in combination with high-speed photographs (inter-frame time $2 \mu \mathrm{s}$, strain rate $40 \mathrm{~s}^{-1}$ ). Red line indicates linear regression on the linear elastic portion. The Young's modulus remains reasonably linear elastic until $56 \mu \mathrm{s}$, then the curve flattens out between 58 and $62 \mu \mathrm{s}$, indicating diffuse damage until the macrocrack appears at $64 \mu \mathrm{s}$. Reproduced from Pierron and Forquin (2012, Fig. 29, p. 402) (colour figure online)

strength sharply increases above an approximate value of critical strain rate $\left(10^{0} \mathrm{~s}^{-1}\right)$ and loading rate $\left(10^{2} \mathrm{GPa} / \mathrm{s}\right)$. This critical strain rate is consistent with the value in semiempirical equations for concrete (Tedesco and Ross 1998; Zhou and Hao 2008). In Fig. 36a, the normalized dynamic strength from spalling tests is larger than that obtained from other testing methods due to the following possible reasons: (1) input stress waves are theoretically used to calculate the dynamic strength in spalling tests, whereas in fact stress wave propagation is attenuated through the inhomogeneous rock specimens, and thus the value is overestimated; (2) the fracture mode is expected to be a single fracture plane, but it is challenging to achieve this in the test; (3) the diameters of the specimens are usually larger than those in other testing methods, and therefore the wave dispersion effect is more pronounced. In Fig. 36b, it is found that, even though the normalized dynamic tensile strength values are obtained by the BD method, the values of loading rate cannot be well controlled and might depend on the material properties. It is also shown that the flexural strength measured by the bending method is higher than the tensile strength measured by the BD method at given loading rate (Zhao and Li 2000; Dai et al. 2010d). This probably arises because of the nonlinear stress-strain characteristics of the specimen in the tension zone and flexural fracture needs to overcome both compressive and tensile stresses. This effect can also be explained by employing non-local failure theory (Dai et al. 2010d).

\subsection{Dynamic Shear Behaviour}

Figure 37 shows typical shear stress-strain curves for Solnhofen limestone (Lipkin et al. 1977), and strain rate variations are also plotted as a function of strain for each of the stress-strain curves. It can be seen that there is a general trend of decreasing strain rate with increasing stress or strain in the specimen. Variations in strain rate superposed on the trend are mainly due to early-time fluctuations in the input torque-time records. These fluctuations are believed to be associated with release of stored torque energy.

Thin-walled tubular specimens of Westerly granite and Solnhofen limestone were tested at HSRs of $10^{2}$ and $10^{3} \mathrm{~s}^{-1}$ using the TSHB technique (Lipkin et al. 1979). It can be seen from Fig. 38a that the shear strengths of these two rocks are approximately linear with increasing strain rate, and the enhancements of dynamic shear strength are about 90 and $40 \%$ at strain rates ranging from 100 to $500 \mathrm{~s}^{-1}$ for Solnhofen limestone and Westerly granite, respectively. The results of the size effect of the two specimen configurations on the dynamic shear strength are presented in Sect. 4.8.3. The authors pointed out that the relatively high data scatter for Westerly granite could be attributed to its large grain size. The dynamic shear strengths of Bukit Timah granite and Longyou sandstone were determined by punch shear tests at ISR using a pneumatic-hydraulic machine (Zhao et al. 1998) and at HSR using the SHPB (Huang et al. 2011a), respectively. Figure $38 \mathrm{~b}$ shows that these shear strengths increase with increasing loading rate. Furthermore, based on the results of compression, tension and shear tests, Zhao (2000) suggested that the effect of loading rate on shear strength primarily changed with the cohesion but not the friction angle. The dynamic punch shear testing method was also validated by comparing the dynamic $\mathrm{BD}$ tensile strength 


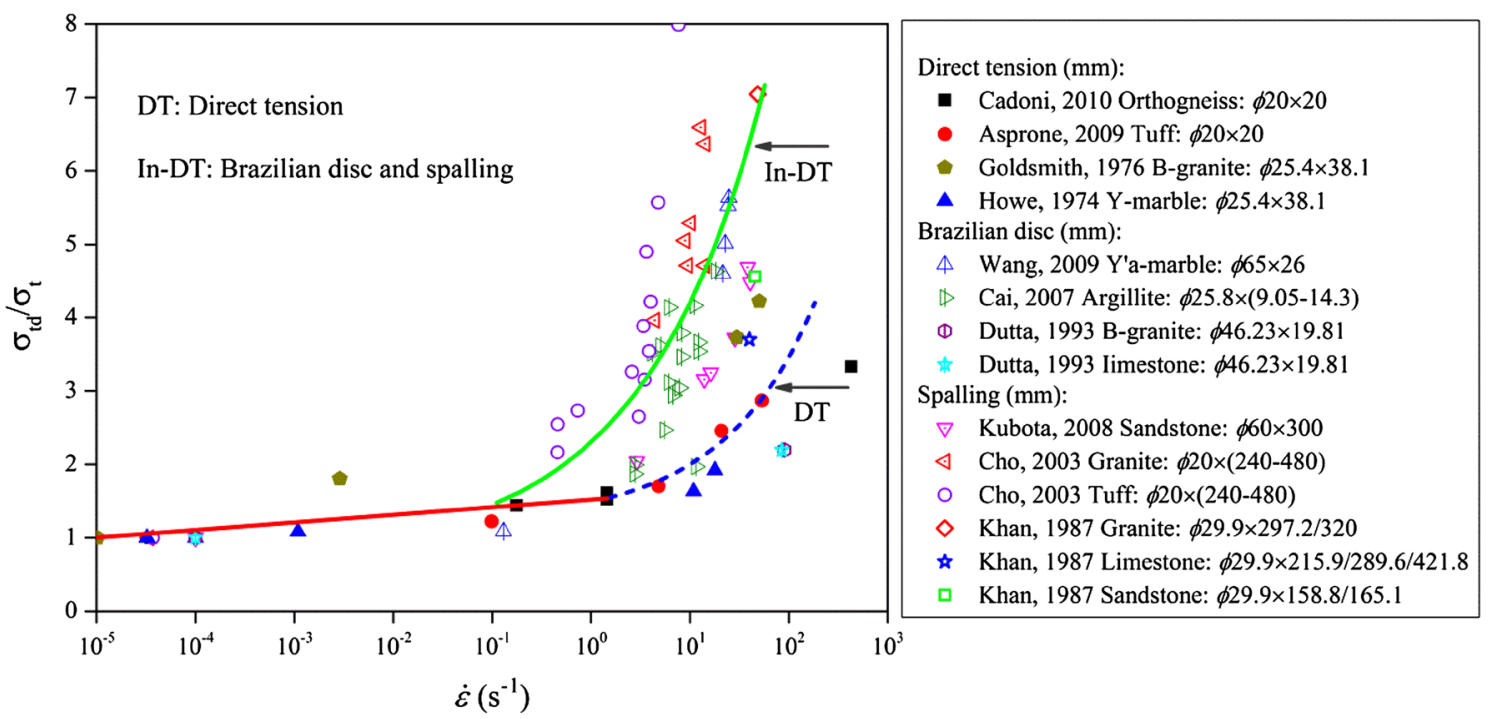

(a)

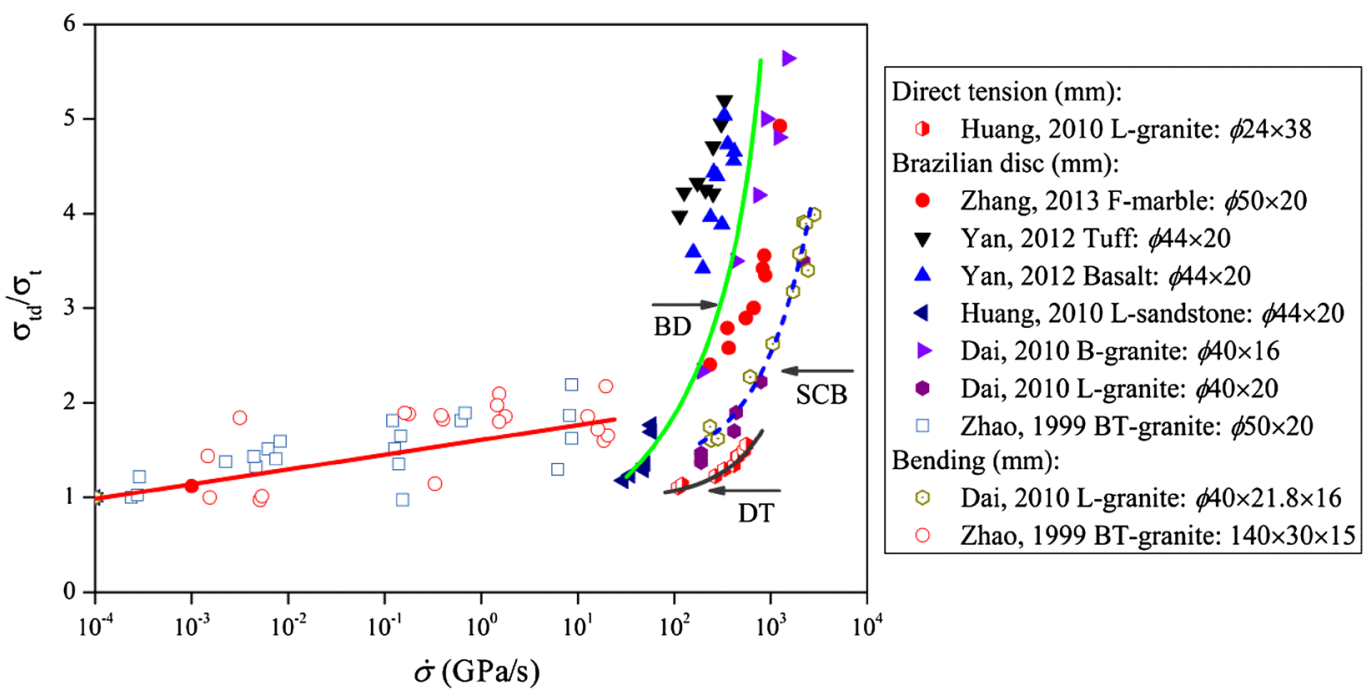

(b)

Fig. 36 Normalized dynamic tensile strength as a function of strain rate (a) (data from Cadoni 2010; Asprone et al. 2009; Goldsmith et al. 1976; Wang et al. 2009; Dutta and Kim 1993; Kubota et al. 2008; Cho et al. 2003; Khan and Irani 1987; Howe et al. 1974) and stress rate (b) (data from Zhang and Zhao 2013a; Yan et al. 2012;

with the theory of the Mohr-Coulomb criterion (Huang et al. 2011a).

\subsection{Dynamic Fracture Behaviour}

\subsubsection{Time to Fracture}

Once the dynamic SIF has been determined by an applicable method, the time to fracture $t_{\mathrm{f}}$ is the only important factor influencing the measurement. The loading rate is
Huang et al. 2010a, b; Dai et al. 2010c, d; Dai and Xia 2010; Zhao and $\mathrm{Li}$ 2000; Zhao et al. 1998). Abbreviations of rock materials: $B$ Barre granite, $B T$ Bukit Timah granite, $L$ Longyou sandstone, $F$ Fangshan marble, $L$ Laurentian granite, $W$ Westerly granite, $Y$ Yule marble, $Y^{\prime} a$ Ya'an marble

generally expressed in terms of the SIF rate, $\dot{K}_{\mathrm{I}}^{\mathrm{dyn}}=K_{\mathrm{Id}} / t_{\mathrm{f}}$, where $K_{\mathrm{Id}}$ is the dynamic crack initiation toughness. The loading rates obtained by certain experimental techniques are limited, as presented in Table 7.

Although strain gauges (Wang et al. 2010c, 2011a; Zhao et al. 1999b; Dai et al. 2010a, 2011), fracture gauges (Chen et al. 2009), crack propagation gauges (Zhang and Zhao 2013b) and more commonly used optical methods such as moiré (Zhang et al. 2000), high-speed photography (Lambert and Ross 2000; Dai et al. 2010b), caustics (Yang et al. 


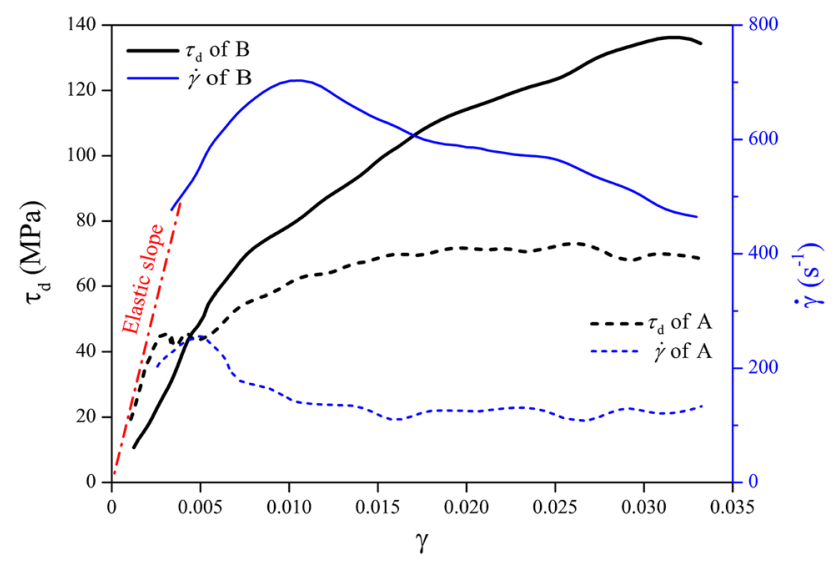

Fig. 37 Typical dynamic shear stress-strain curves and shear strain rate variation of Solnhofen limestone (redrawn from Lipkin et al. 1977, Fig. 4, p. 3) (the elastic slope is computed from density and wave speed measurements)

2009) and DIC (Zhang and Zhao 2013a) have been used for detection of time to fracture, no completely adequate method for its accurate determination has been identified. Readers are referred to the critical review ('5.2 Detection for fracture initiation time' in Jiang and Vecchio 2009) for an evaluation of each method. Considering the heterogeneity of rock materials and the complicated configurations (e.g. chevron notched crack tip: Zhang et al. 2000; Dai et al. 2010a, 2011) for fine-grained rocks, and two crack tips (Wang et al. 2010c, 2011a; Lambert and Ross 2000; Nakano et al. 1994) of rock specimens, a brief summary is presented. It is assumed that the two crack tips should initiate at the same time and propagate symmetrically, although this is violated due to inhomogeneity and misalignment. Therefore, there are difficulties in determining the time to fracture and crack propagation velocity. The time to fracture was first studied by Tang and Xu (1990) using one-bar SHPB and the light passing-detector technique; however, only one value of $28 \mu$ s was given. Values measured by the dynamic moiré method are in the range of 22-60 $\mu$ s for SR specimens of Fangshan gabbro (Zhang et al. 1999), as shown in Fig. 39a. However, due to the configuration of the crack tip, the complicated data processing, and without careful consideration of the inertia effect, the normalized dynamic fracture toughness seems much higher. The values detected by two strain gauges near crack tips are in the range of 52-114 $\mu$ s (HCFBD specimens with diameter from 42 to $155 \mathrm{~mm}$ ) (Wang et al. 2010c) and 61-100 $\mu$ s (CSTBD specimens with diameter from 50 to $200 \mathrm{~mm}$ ) (Wang et al. 2011a) for Ya' an marble. The size effect on the dynamic fracture toughness is presented in Sect. 4.8.3. The SE condition is challenging in specimens with very large diameter. Thus, the scatter in time to fracture values might be due to the size effect, averaging the values of the two strain gauges, and the SE

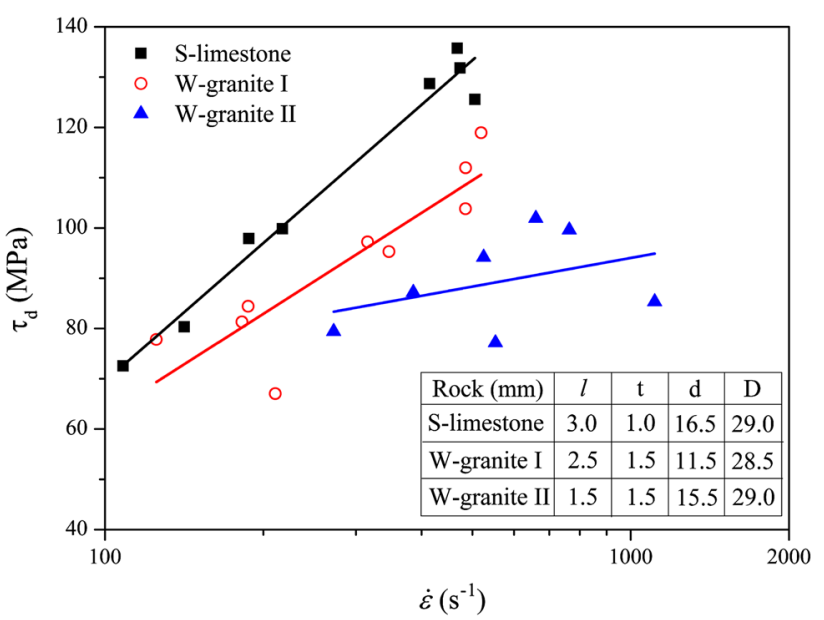

(a)

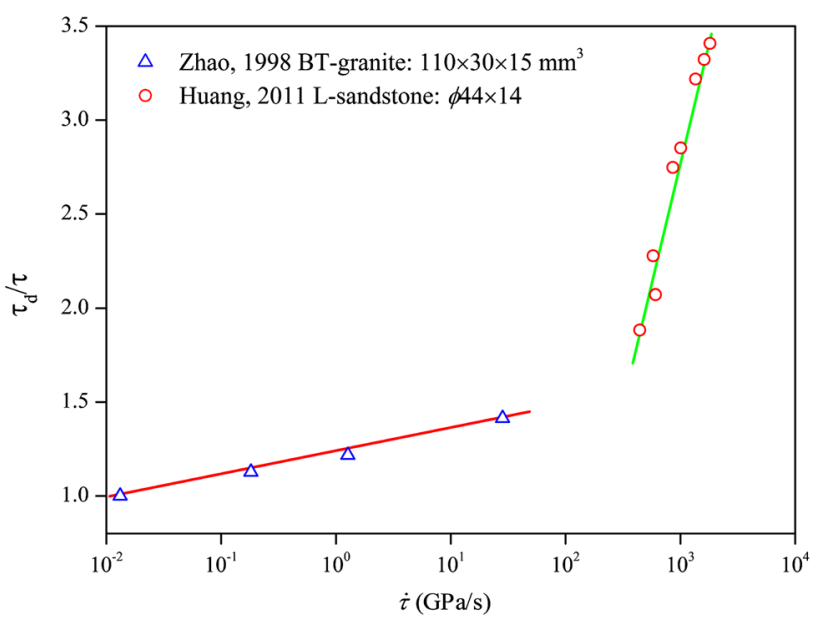

(b)

Fig. 38 Strain rate dependence of shear strength in TSHB tests (a) (data from Lipkin et al. 1979), and normalized dynamic punch shear strength as a function of loading rate (b) (data from Zhao et al. 1998; Huang et al. 2011a; Zhao 2000). Abbreviations of rock materials: $S$ Solnhofen limestone, $B T$ Bukit Timah granite, $L$ Longyou sandstone, $W$ Westerly granite

condition. The value determined by a strain/crack gauge near a crack tip is regarded as the same as the time of peak load in the NSCB test (Chen et al. 2009; Dai et al. 2010b). However, HS photographs provide a synchronized link between the times of crack initiation and propagation of the fracture process and the stress history, showing that the time to fracture is prior to the time of peak load (Chen et al. 2009; Dai et al. 2010b; Lambert and Ross 2000; Zhang and Zhao 2013a; Yu and Zhang 1995; Zhang et al. 1999, 2000). Measured values of normalized dynamic fracture toughness at crack initiation for Fangshan marble are plotted against time to fracture obtained by high-speed photography (Zhang and Zhao 2013a) in Fig. 39b in comparison with two results for homogeneous materials (Ravi-Chandar and Knauss 1984; Owen et al. 1998). 
Table 7 Range of loading rates and time to fracture for various loading techniques (after Table 6.1, p. 82 in Ravi-Chandar 2004)

\begin{tabular}{|c|c|c|c|c|c|c|}
\hline $\begin{array}{l}\text { Fracture } \\
\text { parameter }\end{array}$ & $\begin{array}{l}\text { Servo-hydraulic } \\
\text { machines }\end{array}$ & $\begin{array}{l}\text { Pneumatic-hydraulic } \\
\text { machines }^{\text {a }}\end{array}$ & $\begin{array}{l}\text { Drop-weight } \\
\text { machines }\end{array}$ & $\begin{array}{l}\text { Charpy } \\
\text { pendulum }^{\mathrm{b}}\end{array}$ & $\begin{array}{l}\text { Split } \\
\text { Hopkinson bar }\end{array}$ & $\begin{array}{l}\text { Projectile impact } \\
\text { technique }\end{array}$ \\
\hline$\dot{K}_{\mathrm{I}}^{\mathrm{dyn}}(\mathrm{MPa} \sqrt{\mathrm{m}} / \mathrm{s})$ & 1 & $10^{1}-10^{3}$ & $10^{4}$ & $10^{4}$ & $10^{4}-10^{6}$ & $10^{4}-10^{8}$ \\
\hline$t_{\mathrm{f}}(\mu \mathrm{s})$ & $>10^{6}$ & $10^{5}-10^{3}$ & $\sim 100$ & $\sim 100$ & $1-100$ & $1-100$ \\
\hline
\end{tabular}

${ }^{a}$ Refer to Zhao et al. (1999b)

b Refer to Costin (1981)

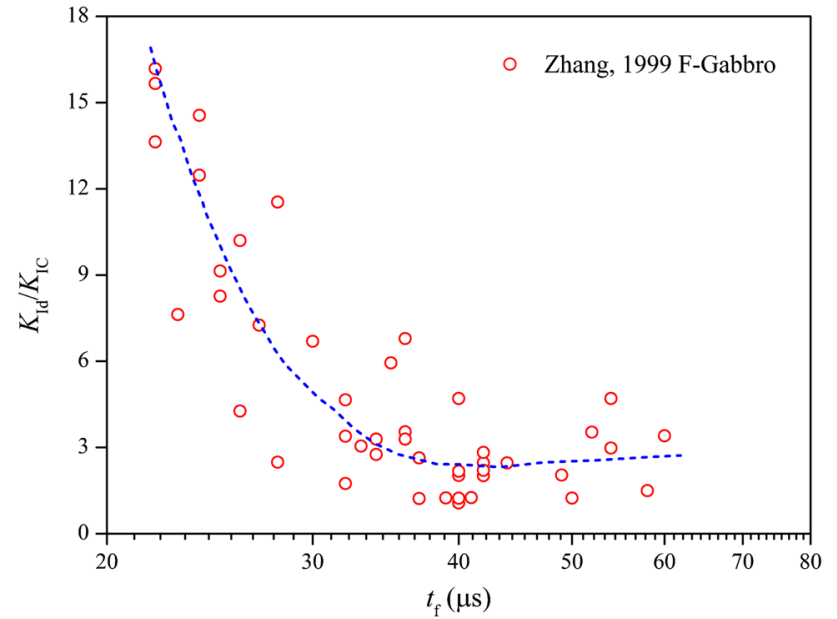

(a)

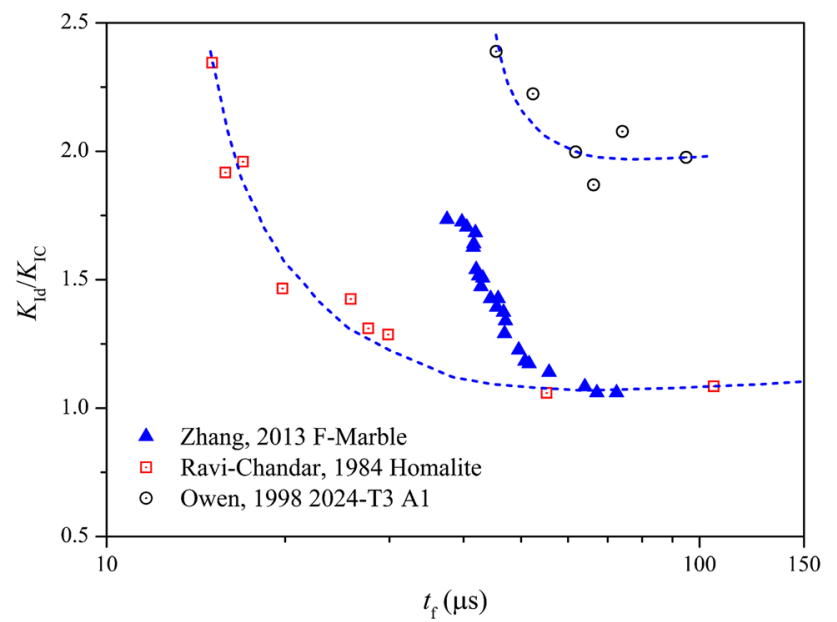

(b)

Fig. 39 Normalized dynamic crack initiation toughness as a function of time to fracture for Fangshan gabbro measured by dynamic moiré (data from Zhang et al. 1999) (a), and for Fangshan marble measured by HS-DIC (b) (data from Ravi-Chandar and Knauss 1984; Owen et al. 1998; Zhang and Zhao 2013a). Abbreviations of rock materials: $F$ Fangshan gabbro, $F$ Fangshan marble

\subsubsection{Dynamic Crack Initiation Toughness}

The dynamic crack initiation toughness $K_{\text {Id }}$ is determined by the time to fracture $t_{\mathrm{f}}$ and is given by the equation $K_{\mathrm{Id}}\left(\dot{K}_{\mathrm{I}}^{\mathrm{dyn}}\right)=K_{\mathrm{I}}^{\mathrm{dyn}}\left(t_{\mathrm{f}}\right)$. Bazant et al. (1993) performed
SENB tests on limestone with three different sizes at loading rates ranging over four orders of magnitude under quasi-static loads, in which the range of $t_{\mathrm{f}}$ was from 2 to $82,500 \mathrm{~s}$. It was found that the fracture toughness increased slightly with increasing loading rate. Due to the complication of data processing, only limited data were presented for intermediate loading rates. SENB tests have been conducted to determine the fracture toughness of oil shale using an instrumented Charpy impact machine at loading rate on the order of $10^{4} \mathrm{MPa} \sqrt{\mathrm{m}} / \mathrm{s}$ (Costin 1981), Bukit Timah granite by means of an air-oil hydraulically driven machine in the range of $10^{-1}-10^{3} \mathrm{MPa} \sqrt{\mathrm{m}} / \mathrm{s}$ (Zhao et al. 1999b), and rock using a drop-weight machine at loading rate on the order of $10^{3} \mathrm{MPa} \sqrt{\mathrm{m}} / \mathrm{s}$ (Yang et al. 2009). At higher strain rates, the SENB method has been extended into a dynamic test using the one-bar SHPB loading configuration with loading rate on the order of $10^{5} \mathrm{MPa} \sqrt{\mathrm{m}} / \mathrm{s}$ (Tang and Xu 1990). The SENB method/one-bar SHPB methods are extensively discussed and the methods of BDbased specimens/two-bar SHPB are briefly reviewed by Jiang and Vecchio ('4.2.2 One-bar/3PB fracture test' and '4.4.2 Brazilian disk test technique' in 2009).

Nakano et al. (1994) might be the first authors to have investigated a BD-type specimen using the CSTBD method to determine the dynamic fracture toughness of ceramic and glass under mode I and mixed mode I/II loading conditions, performed by changing the angle $\alpha . t_{\mathrm{f}}$ was detected by a strain gauge mounted near the crack tip, and the SIF was evaluated using FEM modelling. Recently, the CSTBD method was theoretically evaluated (Dong et al. 2004) and employed for an application of polymethyl methacrylate (PMMA) (Dong et al. 2006). Wang et al. (2011a) modified the CSTBD to the flattened Brazilian disc type to determine the dynamic fracture toughness of rock material under mode I and mixed mode I/II loading conditions. Two strain gauges were glued near each crack tip, and the average value was used to determine $t_{\mathrm{f}}$; the SIF was also evaluated using the method of FEM modelling and the signals from the strain gauges. In addition, the size effect on the dynamic mode I fracture toughness was also studied. Dai et al. (2010a) extended one of the ISRM SMs, i.e. the CCNBD method, to measure the dynamic fracture 
toughness of Laurentian granite; the experimental procedure is the same as the previously proposed NSCB method (Chen et al. 2009; Dai et al. 2010b) introduced below.

Use of a NSCB specimen loaded by a SHPB in TPB configuration was proposed to measure dynamic fracture parameters of Laurentian granite (Chen et al. 2009; Dai et al. 2010b) and PMMA (Huang et al. 2011b) by Xia and co-workers. Another similar method, namely CCNSCB, has also been extended into dynamic testing (Dai et al. 2011). In these studies, the dynamic SIF was determined using a pulse shaper to achieve stress equilibrium with the theory of quasi-static fracture mechanics, and $t_{\mathrm{f}}$ was treated as the same as the time of peak load. These methods provide convenient alternatives, in terms of specimen manufacturing, experimental setup and data processing, to obtain the initiation toughness, propagation toughness and fracture energy. However, they still have the same limitations as the BD specimen (Sect. 4.5), in addition to the dubious determination of the time to fracture, particularly for the latter method (Chen et al. 2009; Dai et al. 2010b). Recently, Zhang and Zhao (2013a) performed NSCB tests to measure the strain field using the HS-DIC technique and to exactly determine the time to fracture in relation to results from strain gauges, crack propagation gauges and HS photograph; validation of this method under dynamic loading has also been discussed.

The WLCT method for rock materials was first performed by Klepaczko et al. (1984), who might also be the first authors to have measured the dynamic fracture toughness of rock material using the SHPB. In their innovative research, stress equilibrium and friction conditions are analysed, and experimental results show that the dynamic fracture toughness of coal is about 13 times higher than the quasi-static values. Zhang et al. $(1999,2000)$ extended the ISRM SR method to dynamic fracture testing, and the maximum values of dynamic fracture toughness of Fangshan gabbro and Fangshan marble were found to be about 20 and 40 times higher than the quasi-static values, respectively. Although quasi-static stress equilibrium is examined to determine the dynamic fracture toughness in CT-type methods, the stress equilibrium condition is still violated due to the large nonuniform section between the bars. Figure 40 [Quasi-static fracture toughness of Ya'an marble from Zhang and Wang (2009) and Laurentian granite from Nasseri and Mohanty (2008)] shows the normalized dynamic crack initiation toughness as a function of normalized loading rate for several materials.

\subsubsection{Crack Propagation Velocity}

Dynamic fracture experiments have been widely performed on homogeneous amorphous materials to investigate physical aspects of dynamic fracture, e.g. limiting crack

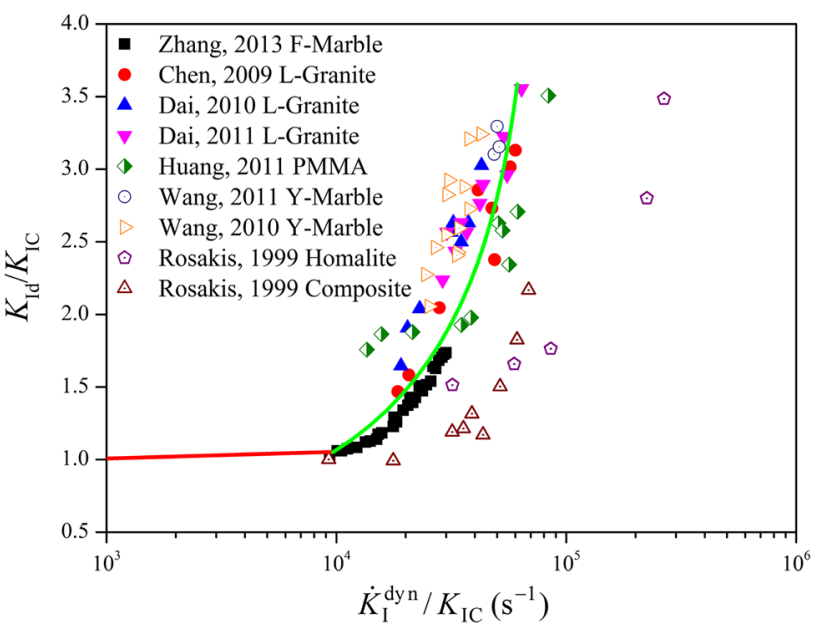

Fig. 40 Normalized dynamic crack initiation toughness as a function of normalized loading rate for several materials (data from Zhang and Zhao 2013a; Chen et al. 2009; Dai et al. 2010a, 2011; Wang et al. 2010c, 2011a; Huang et al. 2011b; Rosakis 1999). Abbreviations of rock materials: $S$ Solnhofen limestone, $Y$ Ya'an marble, $F$ Fangshan marble, $L$ Laurentian granite.

speeds, crack branching and fracture surface roughness (Ravi-Chandar 2004). However, for brittle heterogeneous materials, in particular rock materials, there have been very few investigations, probably due to difficulties associated with conducting such experiments. Experimental results pertaining to the physics of dynamic fracture are summarized here to provide a mechanistic basis for understanding fracture processes and failure mechanisms.

Cracking in 12 types of rock was initiated in two ways: with a high-velocity striker and by detonation of an explosive charge, and the crack propagation velocities were measured by a designed electrical circuit (Lagunov and Mambetov 1965). Values were in the range between 1,000 and $2,700 \mathrm{~m} / \mathrm{s}$, and the ratio $v / C_{\mathrm{L}}$ was from 0.34 to 0.51 (Table 1, p. 65 in Lagunov and Mambetov 1965). Crack propagation velocities, the corresponding experimental techniques and the values of the ratio $v_{\max } / C_{\mathrm{R}}$ for rock materials and some comparisons are presented in Table 8 , $C_{\mathrm{R}}$ being the Rayleigh wave speed given by:

$C_{\mathrm{R}}=(0.862+1.14 v) /(1+v) C_{\mathrm{S}}$,

where $v$ and $C_{\mathrm{S}}$ are the Poisson ratio and the shear wave speed of the material, respectively.

A survey of measured limiting crack speed, which is considered as a physical constant for nominally brittle materials, has been presented for crack growth in noncrystalline materials (Table 11.1, p. 191 in Ravi-Chandar 2004), with the ratio $v_{\lim } / C_{\mathrm{R}}$ being in the range from 0.33 to 0.66. Experimental studies performed on norite rock by Bieniawski (1968) have also shown that the limiting crack speed is a phenomenon characteristic of brittle fracture. 
Table 8 Crack propagation velocities of rock-like materials under dynamic loading

\begin{tabular}{|c|c|c|c|c|c|c|c|}
\hline $\begin{array}{l}\text { Loading } \\
\text { technique }\end{array}$ & $\begin{array}{l}\text { Testing } \\
\text { method }\end{array}$ & Rock type & $\begin{array}{l}\text { Measurement } \\
\text { technique }\end{array}$ & $v(\mathrm{~m} / \mathrm{s})$ & $C_{\mathrm{R}}(\mathrm{m} / \mathrm{s})$ & $\frac{v_{\max }}{C_{\mathrm{R}}}$ & References \\
\hline \multirow{6}{*}{$\begin{array}{l}\text { Drop-weight } \\
\text { machine }\end{array}$} & \multirow[t]{6}{*}{ SENB } & Concrete & Electrical circuit & $500-700$ & 2,115 & 0.30 & Curbach and Eibl (1990) \\
\hline & & Rock & Caustic & 400 & & & Yang et al. (2009) \\
\hline & & Limestone & HS camera & 1,332 & 2,773 & 0.48 & Liu et al. (2010) \\
\hline & & Marble & & 1,218 & 2,670 & 0.46 & \\
\hline & & Gneiss & & 1,045 & 2,516 & 0.42 & \\
\hline & & Concrete & SG & $208-417$ & 2,120 & 0.20 & Zhang et al. (2010) \\
\hline \multirow[t]{10}{*}{ Split Hopkinson bar } & NSCB & L-granite & Crack gauge & $300-850$ & $2,300-2,500^{\mathrm{a}}$ & 0.37 & Chen et al. (2009) \\
\hline & CCNBD & & $\mathrm{SG}+\mathrm{FEM}$ & $80 ;^{\mathrm{b}} 150^{\mathrm{c}}$ & & 0.065 & Dai et al. (2010a) \\
\hline & CCNSCB & & $\mathrm{SG}+\mathrm{FEM}$ & $\begin{array}{l}65-9,911 \\
135-17,612\end{array}$ & & 0.07 & Dai et al. (2011) \\
\hline & $\mathrm{UC}$ & Ceramic & HS images & 1,500 & 5,820 & 0.25 & Hu et al. (2011) \\
\hline & RST & Concrete & Crack gauge + HS-DIC & 1,300 & 2,300 & 0.57 & Forquin (2012) \\
\hline & \multirow[t]{4}{*}{ NSCB } & Sandstone & \multirow{4}{*}{$\begin{array}{l}\text { Electrical circuit }+ \text { SG }+ \text { HS- } \\
\text { DIC }\end{array}$} & $300-650$ & 1,800 & 0.36 & \multirow[t]{4}{*}{ Zhang and Zhao (2013d) } \\
\hline & & Gabbro & & $430-1,120$ & 3,200 & 0.35 & \\
\hline & & Y-marble & & $280-480$ & 1,450 & 0.33 & \\
\hline & & F-marble & & $320-1,000$ & 2,640 & 0.38 & \\
\hline & LECEI & S-limestone & $\mathrm{SG}+\mathrm{HS}$ camera & 2,000 & & & $\begin{array}{l}\text { Bertram and Kalthoff } \\
\text { (2003) }\end{array}$ \\
\hline
\end{tabular}

The available maximum crack propagation velocities of rock-like materials under dynamic loading are in the range from $0.2 C_{\mathrm{R}}$ to $0.57 C_{\mathrm{R}}$, except for the values obtained by coupled SG results and numerical modelling (Dai et al. 2010a, 2011). Although there have been very few investigations on rock-like materials, it has been demonstrated that specimens with simple configuration and optical measurement techniques, in particular several comprehensive methods, provide promising ways to determine reliable results.

It has also been found that, once the limit is reached, the phenomenon of crack branching takes place; that is, the propagating crack forms additional multiple cracks at an angle to the original path. Crack branching was firstly recorded by Schardin (1959) in glass, being subsequently observed by many researchers in amorphous materials, as critically reviewed by Ravi-Chandar ("11.3 Crack branching' in 2004). It has also been observed in rock (Bieniawski 1968), as shown in Fig. 41; the measured limiting crack speed was about $1,875 \mathrm{~m} / \mathrm{s}$ and the ratio $v_{\lim } / C_{\mathrm{R}}$ was 0.679 .

\subsubsection{Crack Opening Displacement}

In addition to determination of the dynamic SIF using the measured load as a variable parameter, some researchers have used the COD in calculating the dynamic SIF. Since there is a relationship between the SIF and COD for a bent sample under quasi-static loading and assuming that this relation is maintained under dynamic loading, the dynamic SIF can be determined from the measured COD. Laser/ light passing-detection techniques (Chen et al. 2009; Tang and Xu 1990) and the dynamic moiré method (Zhang et al. 1999; Yu and Zhang 1995) have been used to measure calibrated crack-tip opening displacement (CTOD) histories. However, there are also some limitations: the effect of the rough surface induced by coarse-grained materials on the passed light results in inaccurate results, and synchronization with loading techniques is still unresolved. The HS-DIC technique has been applied to determine the CTOD and the position of the crack tip, as shown in Fig. 42, exhibiting great promise for research on dynamic fracture testing of rock materials.

\subsubsection{Dynamic Fracture Energy}

Stable and unstable fracture propagation have been discussed, and it was shown that the transition between these two processes in rock is determined by the critical energy release during fracturing (Bieniawski 1967b).

Zhang et al. (2000) used a high-speed camera to estimate the kinetic energy of the fragments in SR testing as 


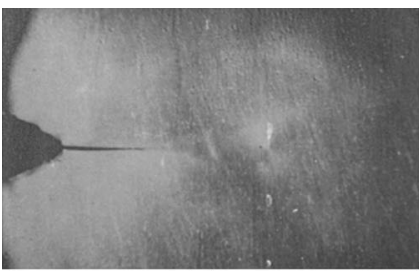

(a)

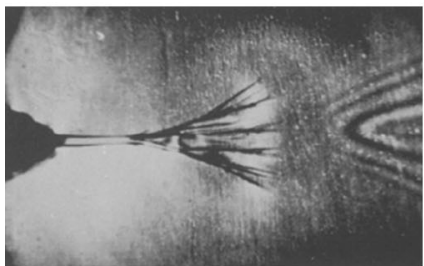

(e)

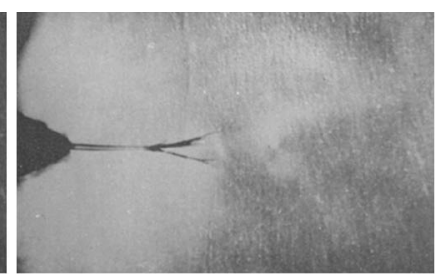

(b)

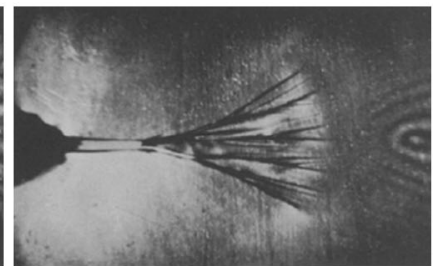

(f)

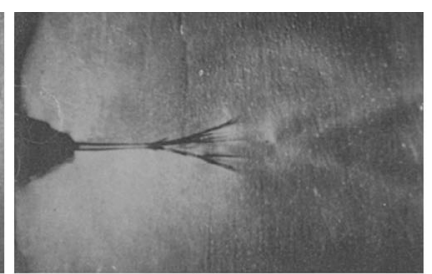

(c)

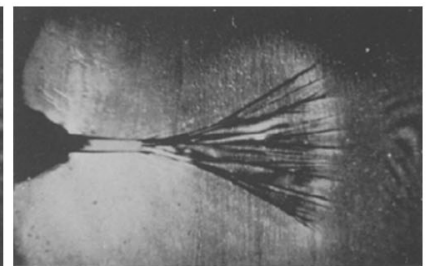

(g)

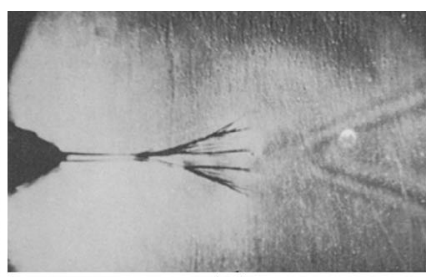

(d)

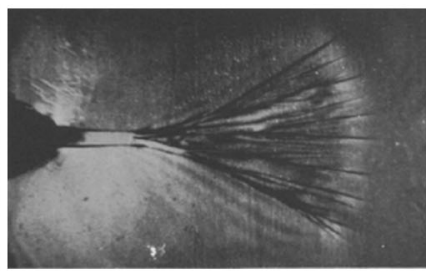

(h)

Fig. 41 Photographic record of crack propagation obtained by high-speed camera at 1.5 million frames per second (reproduced from Bieniawski 1968 Fig. 5, pp. 426-427)

$K=\frac{1}{2} \mathrm{~m}\left(v_{1}^{2}+v_{2}^{2}\right)$. Assuming that the energy lost at the interfaces between the specimen and the bars is negligible and given the total energy absorbed by the specimen $\left(W_{\mathrm{s}}=W_{\text {In. }}-W_{\text {Re. }}-W_{\text {Tr. }}\right)$, the fracture and damage energy can be estimated as $W_{\mathrm{FD}}=W_{\mathrm{s}}-K$. Experimental results showed that the percentage contribution of $W_{\mathrm{FD}}$ to the energy $W_{\mathrm{s}}$ decreases when the loading rate increases markedly. A similar method was conducted to calculate the kinetic energy from the angular velocity of fragments $\omega$ using COD data measured by a LGG in NSCB testing as $K=\mathrm{I} \omega^{2} / 2$, as also validated by high-speed photography (Fig. 43) (Chen et al. 2009). While great attention should be paid to the dynamic fracture energy for complete fracturing of the specimen, theoretically stress is not in equilibrium during this period and/or the effect of multiple pulse waves should be well eliminated. Therefore, single pulse loading is obligatory by using either a longer length of the incident bar than transmitted bar or the momentum trap for brittle materials introduced by Nemat-Nasser et al. (1991).

\subsubsection{Dynamic Crack Propagation Toughness}

The dynamic crack propagation toughness $K_{\mathrm{ID}}$ is the critical dynamic SIF at a specific crack propagation velocity $v$, which is given by the equation $K_{\mathrm{ID}}\left(v ; \dot{K}_{\mathrm{I}}^{\mathrm{dyn}}\right)=K_{\mathrm{I}}^{\mathrm{dyn}}(t, v)$. Most of the prior research on dynamic crack propagation toughness has been performed on Solnhofen limestone (Bertram and Kalthoff 2003). Recently, propagation toughness has been estimated on the basis of the energy conservation principle, applied to Laurentian rock using the NSCB method in SHPB testing (Chen et al. 2009). The dynamic fracture energy is estimated from the dissipated energy per unit area $A_{\mathrm{s}}$ as $G_{\mathrm{dC}}=\partial\left(W_{\mathrm{s}}-K\right) / \partial A_{\mathrm{s}}$, and then the average propagation fracture toughness is determined as $K_{\mathrm{ID}}=\sqrt{G_{\mathrm{dC}} E /\left(1-v^{2}\right)}$. This method provides a simpler way to estimate the propagation fracture toughness, which has been used in the CCNBD method (Dai et al. 2010a) and the CCNSCB method (Dai et al. 2011). However, the equation lacks the universal function $A(v) \approx\left(1-\frac{v}{C_{\mathrm{R}}}\right)$, which is only applicable to quasi-static fracture, and moreover the definition of propagation toughness needs to be validated by theoretical and numerical work. In the work of Zhang and Zhao (2013b), the dynamic SIF was calculated by using a chain of strain gauges positioned along the prospective crack propagation path, and the measured crack propagation toughness was found to be significantly (almost a factor of ten) higher than the crack initiation toughness. Figure 44 [Laurentian granite $C_{\mathrm{R}} \quad(2,300-2,500 \mathrm{~m} / \mathrm{s})$ calculated from $C_{\mathrm{s}}$ $(2,550-2,740 \mathrm{~m} / \mathrm{s})$ from Nasseri and Mohanty (2008) and Poisson's ratio (0.21) from Dai et al. (2011)] shows the normalized dynamic crack propagation toughness for fracture propagation as a function of crack propagation velocity for various materials.

\subsubsection{Microscopic Aspects}

It has been recognized that the fracture surface topography reveals inherent details of the deformation and associated energy dissipation mechanisms that govern the process of fracturing. Great effort has been devoted to performing reliable microscopic observations on fracture surfaces, and it is well established that fracture surfaces satisfy a scaling invariance known as fractal dimension or self-affinity (Bonamy and Bouchaud 2011). The effect of crack velocity on the surface roughness of homogeneous amorphous materials is also widely recognized, and 
Fig. 42 Crack-tip position and crack opening displacement of a notched semi-circular bending specimen using high-speed digital image correlation and the split Hopkinson pressure bar (reproduced from Zhang and Zhao 2013b)
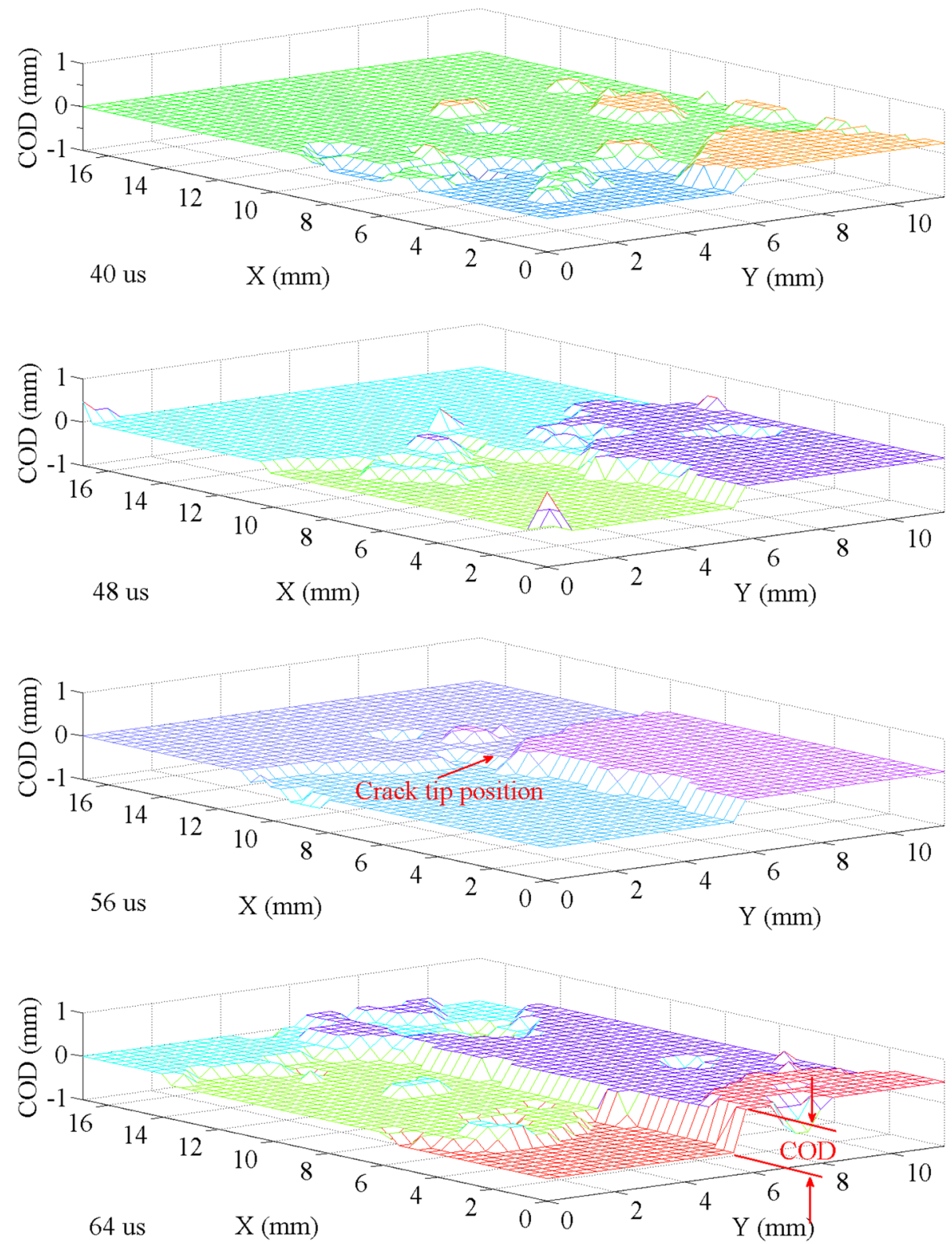

various works have shown that surface roughness increases with increasing crack velocity ('11.2 Fracture surface roughness' in Ravi-Chandar 2004). However, for brittle heterogeneous materials, in particular rock materials, the effect of crack propagation velocity on the fracture surface is yet to be satisfactorily determined. Zhang et al. (2000, 2001b) performed measurements on the fracture surface of gabbro at a measurement scale of $2 \mathrm{~mm}$ and presented that the fractal dimensions of fracture surfaces increased with increasing loading rate. Backers et al. (2003) measured the fracture surface of sandstone using a 3D laser scanner with resolution of $0.1 \mathrm{~mm}$, and argued that the surface roughness was independent of loading rate. One of the important factors resulting in these different conclusions was the coarse resolution of the measurement techniques. Recently, highresolution micromeasurement techniques, i.e. SEM and 3D optical profilometry, have been employed to systematically investigate the effect of loading rate on the fracture surfaces of four types of rock materials (Zhang and Zhao 2013b, d). Micro-measurements revealed that the failure mechanism operating in quasi-static tests was mostly intergranular fracture, which formed a rougher surface and resulted in a higher fractal dimension value. With increasing loading rate, a flatter fracture surface with more transgranular fracture led to a lower value of fractal dimension. In other words, the fractal dimension of marble decreased with increasing loading rate. 



Fig. 43 High-speed photographs showing the process of dynamic fracturing of a notched semi-circular bending specimen (reproduced from Chen et al. 2009, Fig. 7, p. 1,274)

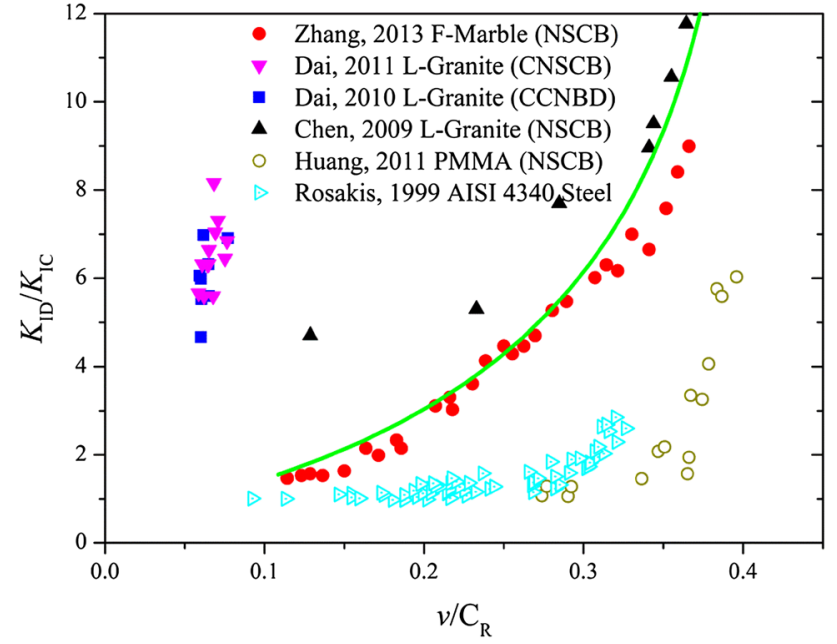

Fig. 44 Normalized dynamic crack propagation toughness for fracture propagation as a function of crack propagation velocity for various materials (data from Zhang and Zhao 2013b; Dai et al. 2010a, 2011; Chen et al. 2009; Huang et al. 2011b; Rosakis 1999). Abbreviations of rock materials: $F$ Fangshan marble, $L$ Laurentian granite.

\subsection{Factors Influencing Dynamic Mechanical Behaviour}

It is well known that the mechanical and physical behaviour of rock material are affected by environmental factors such as confining pressure (see Sect. 4.4 for details), temperature and water saturation, as well as by rock factors, such as mineralogical composition, grain size and anisotropy. In the following subsections, the available laboratory data are used to explain and discuss the systematic influence of temperature, water saturation, specimen size and shape, and microstructure on dynamic mechanical properties of rock materials.

\subsubsection{Influence of Temperature}

The influence of temperature on brittle failure stresses for various rocks in uniaxial and triaxial compression tests under quasi-static loads is summarized in the monograph by Paterson and Wong (2005). Experimental results show that there is some decrease in strength with increase in temperature. Temperature and strain rate have opposite effects on the stress and strain. Increasing the strain rate or decreasing the temperature will lead to higher stress levels, but lower values of strain. Major developments in dynamic testing of rock materials at various temperatures are summarized in Table 9.

When the specimen temperature differs from room temperature, the timing of the mechanical load becomes a variable due to heat conduction. There are two approaches to conduct experiments with the specimen heated or 
Table 9 Major developments in dynamic testing of rock materials at various temperatures

\begin{tabular}{|c|c|c|c|c|c|c|}
\hline $\begin{array}{l}\text { Testing } \\
\text { method }\end{array}$ & $\begin{array}{l}\text { Dynamic } \\
\text { property }\end{array}$ & Rock type & $\begin{array}{l}\text { Range of } T \\
\left({ }^{\circ} \mathrm{C}\right)^{\mathrm{a}}\end{array}$ & $\begin{array}{l}\dot{\varepsilon}\left(\mathrm{s}^{-1}\right) \text { or } \\
\dot{K}_{\mathrm{I}}^{\mathrm{dyn}}(\mathrm{MPa} \sqrt{\mathrm{m}} / \mathrm{s})\end{array}$ & Research results & References \\
\hline \multirow[t]{2}{*}{ TC } & $\sigma_{\mathrm{tcd}}$ & $\begin{array}{l}\text { B-sandstone, } \\
\text { S-limestone }\end{array}$ & 25 to 149 & $\sim 10^{-1}$ & $P_{\mathrm{c}}, T$ and $\dot{\varepsilon}$ dependent & $\begin{array}{r}\text { Serdengecti and } \\
\text { Boozer (1961) }\end{array}$ \\
\hline & & Y-marble & 25 to 500 & $\sim 10^{-1}$ & $\begin{array}{l}\text { Strong strain hardening, characteristic at } \\
\text { lower } T \text { and higher } \dot{\varepsilon} \text {, changes gradually } \\
\text { to steady-state flow as } \dot{\varepsilon} \text { decreases or } T \\
\text { increases }\end{array}$ & Heard (1963) \\
\hline \multirow[t]{4}{*}{$\mathrm{UC}$} & $\sigma_{\mathrm{ucd}}$ & Basalt & -196 to 23 & $\sim 10^{3}$ & Thermal activation dominates fracture & Kumar (1968) \\
\hline & & $\begin{array}{l}\text { Porphyritic } \\
\text { tonalite }\end{array}$ & -191 to 23 & $\sim 10^{3}$ & $\begin{array}{l}\text { Increased stiffness and strength with } \\
\text { increasing } \dot{\varepsilon} \text { and decreasing } T\end{array}$ & $\begin{array}{l}\text { Perkins et al. } \\
\text { (1970) }\end{array}$ \\
\hline & & Siltstone & 20 to 300 & $\sim 10^{2}$ & $\begin{array}{l}\sigma_{\text {ucd }} \text { increases when } 100 \geq T \geq 20 \text { but } \\
\text { decreases when } T>100\end{array}$ & Li et al. (2010b) \\
\hline & & Marble & 25 to 1,000 & $\sim 10^{2}$ & $\begin{array}{l}\sigma_{\text {ucd }} \text { fluctuates slightly when } 400 \geq T \geq 25 \\
\text { but decreases nearly linearly when } \\
T>400\end{array}$ & Liu and $\mathrm{Xu}$ (2013) \\
\hline \multirow[t]{2}{*}{$\mathrm{UC}, \mathrm{TC}$} & $\sigma_{\mathrm{ucd}}, \sigma_{\mathrm{tcd}}$ & Basalt & -193 to 527 & $\sim 10^{3}$ & $\begin{array}{l}\text { Specimen and anvils heated by radiation } \\
\text { from quartz lamps }\end{array}$ & $\begin{array}{l}\text { Lindholm et al. } \\
\text { (1974) }\end{array}$ \\
\hline & & Salt rock & 40 to 80 & $\sim 10^{2}$ & $P_{\mathrm{c}}(0.5 \mathrm{MPa}), T$ and $\dot{\varepsilon}$ dependent & Fang et al. (2012) \\
\hline $\mathrm{BD}$ & $\sigma_{\mathrm{td}}$ & B-granite & -40 to 24 & $\sim 10^{2}$ & More sensitive to $\dot{\varepsilon}$ than $T$ & $\begin{array}{l}\text { Dutta and Kim } \\
\text { (1993) }\end{array}$ \\
\hline \multirow[t]{2}{*}{ SR } & $K_{\text {Id }}$ & F-gabbro & $\begin{array}{l}600,{ }^{\mathrm{b}} 100 \text { to } \\
330\end{array}$ & $\sim 10^{3}$ & $T$ influences $K_{\text {Id }}$ to a limited extent & $\begin{array}{l}\text { Zhang et al. } \\
\text { (2001a) }\end{array}$ \\
\hline & & F-marble & $\begin{array}{l}200,{ }^{\mathrm{b}} 100 \text { to } \\
330\end{array}$ & & & \\
\hline NSCB & $K_{\text {Id }}$ & L-granite & 25 to 85,014 & $10^{0}-10^{2}$ & $\begin{array}{l}\text { Thermally induced cracks induce } \\
\text { decrease of } K_{\text {Id }} \text { at higher } T\end{array}$ & Yin et al. (2012a) \\
\hline
\end{tabular}

${ }^{\text {a }}$ For both quasi-static and dynamic tests

b Pre-heat-treated temperature

cooled: one is to heat/cool the specimen with the bars attached, and the other is to bring the bars into contact with the specimen after it reaches a desired temperature. The latter is preferred, particularly at very high temperatures, since temperature gradients in the bars affect wave propagation, which must be corrected. Thus, there is generally some influence of strain rate, temperature and time on brittle fracture, which may vary with the material and the experimental conditions. This observation points to there being some participation of thermally activated processes in brittle fracture. However, if the effect is assumed to follow an Arrhenius law, the apparent activation energies are low; For example, Kumar (1968) deduces values of $0.8-2 \mathrm{~kJ} / \mathrm{mol}$, while the 'heats of activation' quoted by Serdengecti and Boozer (1961) are equivalent to even lower values of activation energy.

Tension-type tests are seldom used to determine tensile strength or fracture toughness at high temperatures, since the fracture commonly cannot satisfy the principle of the test (e.g. the crack initiates from the contact point rather than from the centre of the BD specimen; Nojima and Ogawa 1989), or crack initiation and propagation do not occur from the crack tip in fracture toughness tests (Zhang et al. 2001a; Yin et al. 2012a)

Due to the lack of quasi-static results and/or the accessible range of strain rate, only limited data are available. Figure 45 summarizes observations on rocks, where one can see a decrease in normalized dynamic compressive strength with increasing temperature. The effect of temperature on the failure mode in uniaxial compression tests can be seen in Fig. 46. As the temperature decreases, a transition from apparent cataclasis to cataclasis/cleavage, a more brittle variant of cataclasis, occurs just above room temperature.

\subsubsection{Influence of Water Saturation}

Pore fluid affects fracture strength through a direct pressure effect as well as through chemical interactions with the rock matrix. It can also reduce the tensile strength by providing chemically reactive species to facilitate molecular bond breaking at crack tips (Ahrens and Rubin 1993). Effects of saturation and strain rate on the uniaxial compressive strength of sandstone (Wang et al. 2010a), the BD 


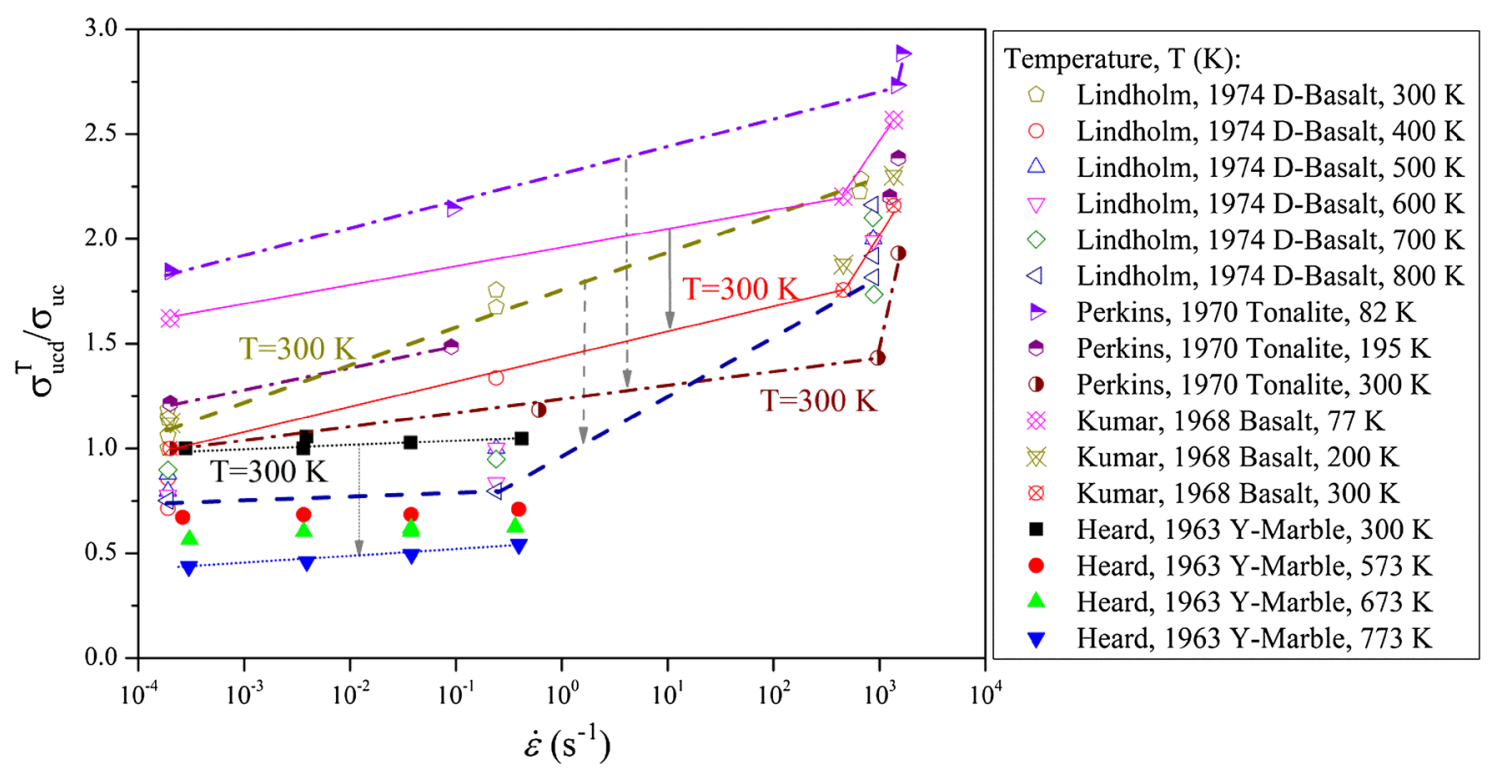

(a)

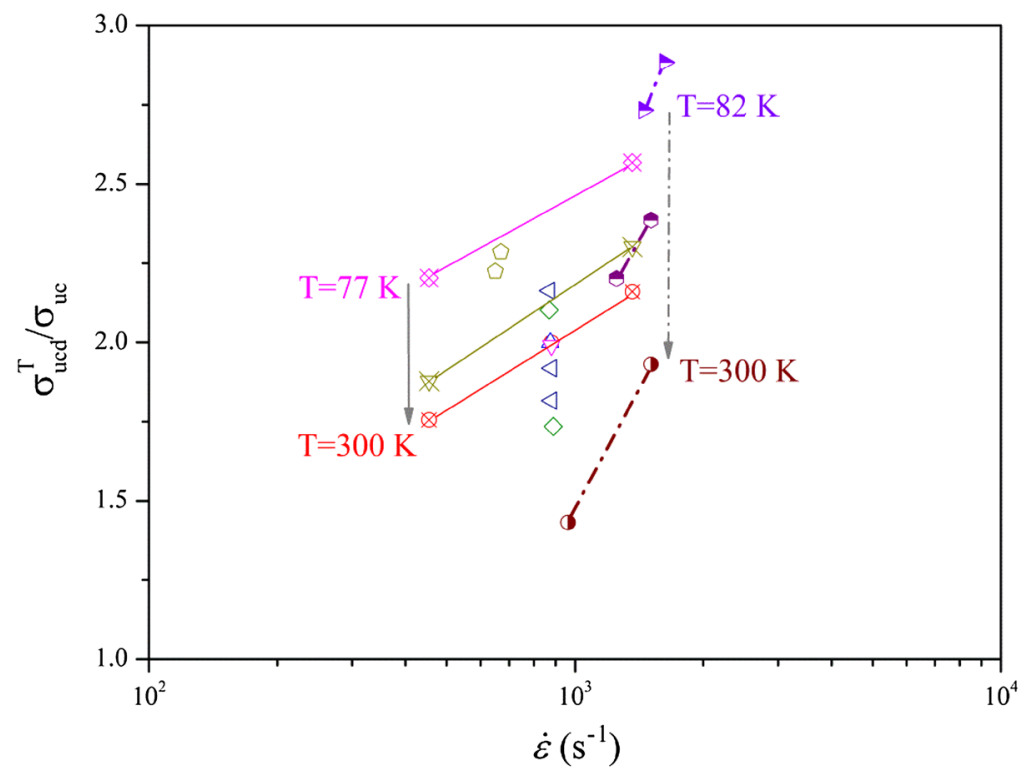

(b)

Fig. 45 a Effects of temperature and strain rate on normalized dynamic compressive strength, and b magnified view of (a) (data from Lindholm et al. 1974; Perkins et al. 1970; Heard 1963; Kumar

tensile strength of Longyou sandstone (Huang et al. 2010b) and the spalling strength of three kinds of rock material (Ogata et al. 2004; Lou 1994) are shown in Fig. 47. It can be seen that the strain rate effects are larger in rock materials under fully saturated conditions, which is usually explained by the Stefan effect (see Sect. 5.1 for details).

\subsubsection{Influence of Size and Shape}

Experimental observations on the size dependence of rock material properties have been made primarily in uniaxial
1968) (arrows indicate increasing temperature; room temperature $300 \mathrm{~K}$ or $27^{\circ} \mathrm{C}$ ). Abbreviations of rock materials: $D$ Dresser basalt, $Y$ Yule marble

compression or $\mathrm{BD}$ tests in general, and they show a decrease in fracture stress with increase in dimensions. This topic has been critically reviewed for quasi-static loading by Paterson and Wong ('3.5 Size and shape effects' in 2005). As presented above, the scatter in experimental results for dynamic mechanical properties of rock materials are due to the size and/or shape of specimens. Table 10 summarizes the size effects on mechanical properties of rock-like materials under dynamic loading. Due to the small Poisson's ratio and small axial failure strain, the lateral deformation of a specimen is very limited during 


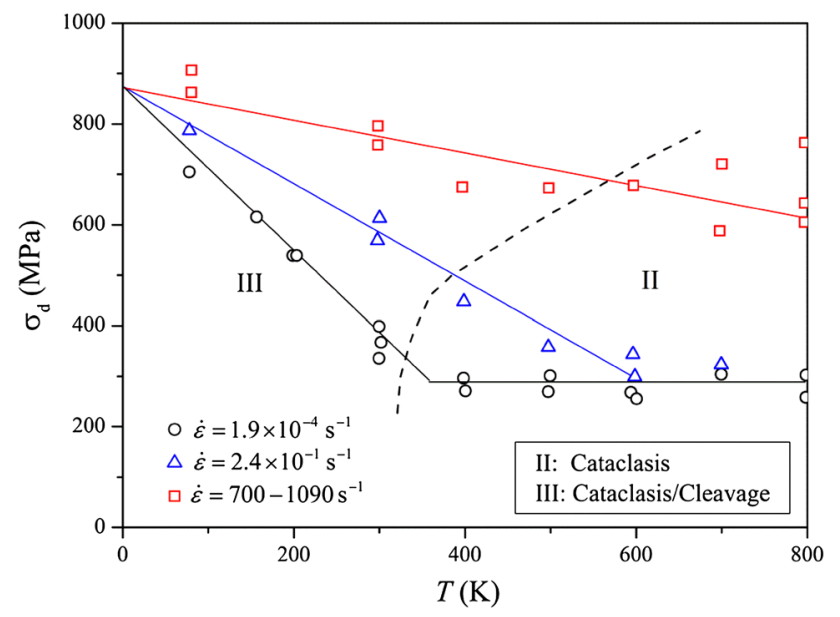

Fig. 46 Effects of temperature and strain rate on failure modes (data from Lindholm et al. 1974; failure modes refer to Fig. 32a)

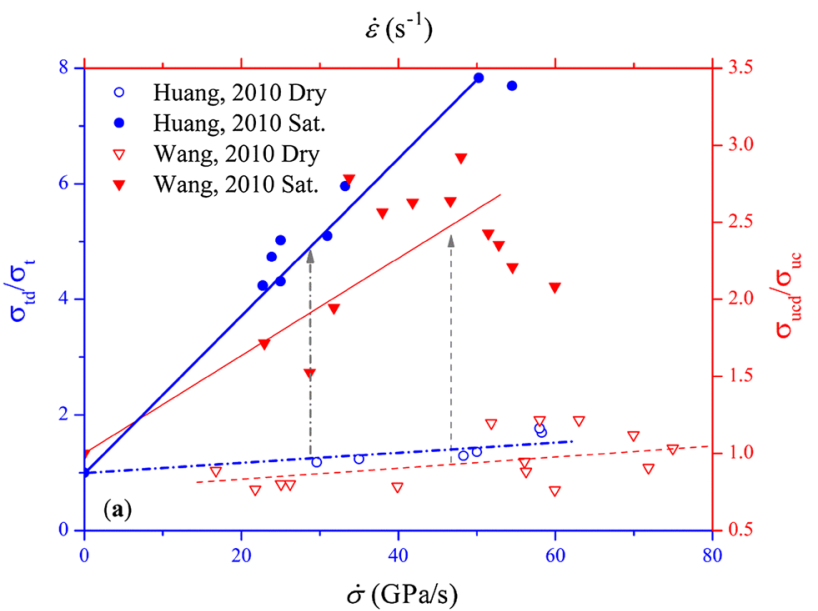

(a)

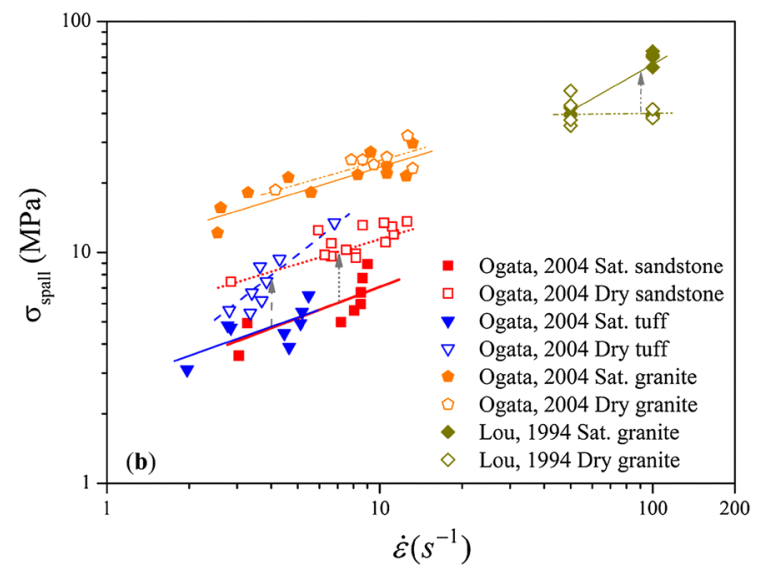

(b)

Fig. 47 Effects of saturation and strain rate on uniaxial compressive strength (data from Wang et al. 2010a), Brazilian disc tensile strength of sandstone (a) (data from Huang et al. 2010b) and spalling strength of three kinds of rock material (b) (data from Ogata et al. 2004; Lou 1994) (arrows indicate saturated results) axial compression, causing only small effects on the axial response. The uncertainty of some conclusions may also result from insufficient data, and thus additional tests are required to examine various possibilities.

\subsubsection{Influence of Microstructure}

In many rocks, the presence of bedding or cleavage planes, such as in Yule marble (Howe et al. 1974), argillite (Cai et al. 2007) and orthogneiss (Cadoni 2010), the degree of the volumetric organic content, such as in oil shale (Lankford 1976; Chong et al. 1980; Chong and Boresi 1990), and some preferred orientation of fabric or microstructure, for example in Barre granite (Goldsmith et al. 1976; Xia et al. 2008; Dai and Xia 2010, 2013), affect the mechanical behaviour. Several forms of anisotropy with various degrees of complexity strongly influence the mechanical properties of rock materials (Paterson and Wong 2005). However, only limited works have been conducted under dynamic loading, and the conclusions are still unclear.

Pioneering work was performed by Howe et al. (1974) and Goldsmith et al. (1976) using the SHB. The enhancement of compressive strength is more pronounced along the axis of transverse isotropy, while this trend was reversed in direct tension tests on Yule marble (Howe et al. 1974). Cai et al. (2007) performed compression tests on argillite along both directions, perpendicular and parallel to bedding, using the SHPB, and observed that the dynamic compressive strength is similar in both directions. Cadoni (2010) conducted direct tension tests on orthogneiss with three orientations of schistosity using a pneumatichydraulic machine and a SHTB, and concluded that the effect of the orientation on the dynamic tensile strength is dispersive except for the case of the parallel plane of schistosity.

Various dynamic compression tests have been performed on oil shale with different organic volumes at strain rates on the order of $10^{3} \mathrm{~s}^{-1}$ by Lankford (1976) and on the order of $10^{0} \mathrm{~s}^{-1}$ by Chong and Boresi (1990) and Chong et al. (1980). It was found that the dynamic compressive strength orders consistently with respect to kerogen content.

Dynamic compression, direct tension and torsion tests have been conducted on Barre granite along three directions (Goldsmith et al. 1976), showing that the normalized factor $\sigma_{\text {ucd }} / \sigma_{\text {uc }}$ was $1.62,1.52$ and 1.41 for directions 2 (maximum Young's modulus, $E_{\max }$ ), 3 (minimum, $E_{\min }$ ) and 1 (average, $E_{\text {avg }}$ ), respectively; the normalized factor $\sigma_{\mathrm{td}} / \sigma_{\mathrm{t}}$ was $1.40,1.92$ and 1.57 for the corresponding directions; direction 2 yielded the greatest compressive and tensile strength, but the lowest value in torsion. Xia et al. 
Table 10 Size effects on dynamic mechanical properties of rock-like materials

\begin{tabular}{|c|c|c|c|c|c|}
\hline $\begin{array}{l}\text { Loading } \\
\text { technique }\end{array}$ & Rock type & $\begin{array}{l}\text { Testing } \\
\text { method }\end{array}$ & Specimen size $(\mathrm{mm})$ & Comments & Reference \\
\hline $\begin{array}{l}\text { Drop-weight } \\
\text { machine }\end{array}$ & Concrete & TPB & $\begin{array}{l}50 \times 50 \times 150 ; 100 \times 100 \times 300 \\
150 \times 150 \times 450\end{array}$ & $\begin{array}{l}\text { Size effect is more sensitive under } \\
\text { dynamic loading }\end{array}$ & $\begin{array}{l}\text { Bindiganavile and } \\
\text { Banthia (2006) }\end{array}$ \\
\hline $\mathrm{SHPB}, D_{\mathrm{B}} 19.05$ & T-marble & $\mathrm{UC}$ & $\begin{array}{l}D_{\mathrm{s}} 19.05 \\
L_{\mathrm{s}} / D_{\mathrm{s}} 1 / 7,2 / 3,11 / 3,2,22 / 3\end{array}$ & $\begin{array}{l}\text { The shorter specimen transmits the } \\
\text { greater energy }\end{array}$ & Hakalehto (1967) \\
\hline $\begin{array}{l}\mathrm{SHPB}, D_{\mathrm{B}} 22, \\
36,50,75\end{array}$ & Granite & $\mathrm{UC}$ & $\begin{array}{l}D_{\mathrm{s}} 22,36,50,75 \\
L_{\mathrm{s}} / D_{\mathrm{s}} 0.5-0.6\end{array}$ & $\begin{array}{l}\text { The smaller bar obtains the higher } \\
\text { strain rate }\end{array}$ & Li et al. (2008a) \\
\hline SHPB, $D_{\text {B }} 12.7$ & S-limestone & $\mathrm{UC}$ & $\begin{array}{l}D_{\mathrm{s}} 12.7 \\
L_{\mathrm{s}} / D_{\mathrm{s}} 1.0,1.5,2.0\end{array}$ & $\begin{array}{l}\text { No significant difference of } \sigma_{\mathrm{ucd}} \\
\text { high-speed photography is }\end{array}$ & Frew et al. (2001) \\
\hline $\mathrm{SHPB}, D_{\mathrm{B}} 75$ & BT-granite & UC & $\begin{array}{l}D_{\mathrm{s}} 70 \\
L_{\mathrm{s}} / D_{\mathrm{s}} 0.5,1.0\end{array}$ & $\begin{array}{l}\text { necessary to check the stress } \\
\text { equilibrium condition when } \\
L_{\mathrm{s}} / D_{\mathrm{s}}>1\end{array}$ & Li et al. (2005) \\
\hline $\mathrm{SHPB}, D_{\mathrm{B}} 25$ & L-granite & $\mathrm{UC}$ & $\begin{array}{l}D_{\mathrm{s}} 25 \\
L_{\mathrm{s}} / D_{\mathrm{s}} 0.5,1.0,1.5,2.0\end{array}$ & & Dai et al. (2010c) \\
\hline TSHB $D_{\mathrm{B}} 25.4$ & W-granite & Shear & $L 2.5, D 11.5 ; L 1.5, D 15.5$ & $\begin{array}{l}\text { Insufficient data available to } \\
\text { assess, see Fig. } 38 \text { a }\end{array}$ & Lipkin et al. (1979) \\
\hline SHPB, $D_{\mathrm{B}} 100$ & Y-marble & CSTFBD & $\begin{array}{l}D_{\mathrm{s}} 42,80,122,155 \\
B_{\mathrm{s}} 16.8,32,48.8,62 \\
D_{\mathrm{s}} 50,130,200 \\
B_{\mathrm{s}} 16,42,64\end{array}$ & $\begin{array}{l}K_{\mathrm{Id}}, K_{\mathrm{IId}} \text { increase with increasing } \\
\text { size; the stress equilibrium } \\
\text { condition is challenged due to } \\
\text { the large diameter }\end{array}$ & Wang et al. (2010c) \\
\hline
\end{tabular}

$B_{\mathrm{s}}$ specimen thickness

(2008) also performed compression, BD (Dai and Xia 2010), SCB (Dai et al. 2013) and NSCB (Dai and Xia 2013) tests on Barre granite using the SHPB, concluding that the effect of anisotropy on strength is not sensitive to strain rate.

Although various phenomenological conclusions have been obtained as mentioned above, substantial efforts are needed to determine the intrinsic physical mechanisms of these microstructure effects. Quantitative understanding of texture, and thus the intrinsic contribution of single crystals and their orientation with respect to anisotropy, may help us to better evaluate the effects of oriented fracture and pore fabric and porosity by using 3D optical scanning reconstruction (Siviour et al. 2012; Cho et al. 2005) and microscopic techniques on the fracture surface (Zhang et al. 2000; Bonamy and Bouchaud 2011; Zhang and Zhao 2013b).

\subsection{Semi-Empirical Equations for Rate-Dependent Strength}

As presented above, experimental results show that dynamic mechanical properties increase sharply when the loading rate exceeds a critical value. There have been many attempts to derive semi-empirical equations to express the relationship between strain/loading rate and the mechanical properties of rock materials, as summarized in Table 11. Two well-known equations suggested by the CEB (1988) and proposed by Tedesco and Ross (1998) for concrete are provided as references. It should be noted that these equations are only semi-empirical within a range of strain rates, rather than being true constitutive models (see Sect. 6 for details), since these equations ignore the effect of strain or the history of deformation.

\section{Physical Mechanisms of the Strain Rate Effect}

Although attempts have been made to minimize some key effects in order to characterize the dynamic response (Sect. 2.2), they can never be completely eliminated. These contributions to dynamic mechanical properties are not physical mechanisms of the strain rate effect. A brief review of investigations on the physical mechanisms of the dynamic tensile behaviour of concrete was given by Rossi and Toutlemonde (1996). The much higher strain rate sensitivity of strength observed in SHB tests with rock is an apparent effect, which was concluded by Janach (1976) to be due to bulking of the failing material and the resulting additional radial inertia forces. It is still not completely clear how dynamic mechanical properties are influenced by strain rate.

Efforts have been made to study the mechanism governing the rate-dependent behaviour of rock materials, yet it is still not well understood. In studies of the mechanical response of materials under dynamic loading, two dynamic 
Table 11 Semi-empirical rate-dependent strength equations for rock-like materials

\begin{tabular}{|c|c|c|c|c|}
\hline Rock type & $\begin{array}{l}\text { Strain rate } \\
\left(\mathrm{s}^{-1}\right)\end{array}$ & Semi-empirical equation & Material constants & References \\
\hline Granite & $10^{-8}-10^{-4}$ & $\sigma_{\mathrm{ucd}}=C \log (\dot{\varepsilon})+\sigma_{\mathrm{uc}}$ & $\begin{array}{l}C=13 M P a / \log \left(s^{-1}\right) \\
\sigma_{\mathrm{uc}}=340 M P a\end{array}$ & Masuda et al. (1987) \\
\hline Granite & $10^{-4}-10^{0}$ & $\sigma_{\mathrm{ucd}}=\mathrm{RSC}_{\mathrm{d}} \log \left(\dot{\sigma}_{\mathrm{d}} / \dot{\sigma}_{\mathrm{s}}\right)+\sigma_{\mathrm{uc}}, \dot{\sigma}_{\mathrm{s}}=0.5-1 \mathrm{MPa} / \mathrm{s}$ & $\mathrm{RSC}_{\mathrm{d}}=11.9 M P a, \sigma_{\mathrm{uc}}=170 M P a$ & Zhao et al. (1999a) \\
\hline Rocks & $10^{0}-10^{5}$ & $\sigma_{\mathrm{ucd}}=a \dot{\varepsilon}^{n}$ & $a, n_{\max }=1 / 3$ & Grady and Lipkin (1980) \\
\hline Limestone & $10^{-6}-10^{4}$ & $\sigma_{\text {ucd }} \propto \dot{\varepsilon}^{1 /\left(1+n_{\mathrm{c}}\right)}\left(\dot{\varepsilon}<10^{2}\right) ; \sigma_{\text {ucd }} \propto \dot{\varepsilon}^{1 / n}\left(\dot{\varepsilon} \geq 10^{2}\right)$ & $n_{\mathrm{c}}=130, n=0.3$ & Lankford (1981) \\
\hline Tuff & $10^{-6}-10^{3}$ & $\sigma_{\text {ucd }} \propto \dot{\varepsilon}^{0.007}\left(\dot{\varepsilon}<76 \mathrm{~s}^{-1}\right) ; \sigma_{\text {ucd }} \propto \dot{\varepsilon}^{0.35}\left(\dot{\varepsilon}>76 \mathrm{~s}^{-1}\right)$ & & Olsson (1991) \\
\hline Limestone & $10^{-5}-10^{-1}$ & $\begin{array}{l}\sigma_{\mathrm{tcd}}=k_{0} \mathrm{e}^{\frac{\left(\sigma-\sigma_{0}\right)}{k_{1} \sigma_{0}}}\left\{\dot{\varepsilon} \mathrm{e}^{U / \mathrm{RT}}\right\}^{\left\{r_{0}+\frac{\left(\sigma_{3}-\sigma_{0}\right)}{k_{2} \sigma_{0}}\right\}}, \sigma_{0}=\sigma_{3}^{\mathrm{ref}} \\
\quad k_{0}, r_{0}=f\left(\sigma_{0}\right) \\
\quad \text { e.g. } \sigma_{3}=138 \mathrm{MPa}\end{array}$ & $k_{1}=40, k_{2}=725, U$ & $\begin{array}{l}\text { Serdengecti and Boozer } \\
\text { (1961) }\end{array}$ \\
\hline Granite & $10^{-4}-10^{0}$ & $\sigma_{\mathrm{tcd}}=\sigma_{\mathrm{uc}}+M \log \left(\dot{\sigma}_{\mathrm{d}} / \dot{\sigma}_{\mathrm{s}}\right)+N \sigma_{3}$ & $M=34.46, N=3.95$ & Li et al. (1999) \\
\hline \multirow[t]{5}{*}{ Concrete } & $10^{-5}-10^{3}$ & $\sigma_{\mathrm{ucd}}=\sigma_{\mathrm{uc}}\left(\frac{\dot{\varepsilon}}{\dot{\varepsilon}_{\mathrm{s}}}\right)^{1.026 \alpha_{\mathrm{s}}}\left(\dot{\varepsilon} \leq 30 \mathrm{~s}^{-1}\right)$ & $\alpha_{\mathrm{s}}=1 /\left(5+\sigma_{\mathrm{uc}} / 10\right)$ & CEB (1988) \\
\hline & & $\sigma_{\mathrm{ucd}}=\sigma_{\mathrm{uc}} \gamma_{\mathrm{s}}\left(\frac{\dot{\varepsilon}}{\dot{\varepsilon}_{\mathrm{s}}}\right)^{\frac{1}{3}}\left(\dot{\varepsilon}>30 \mathrm{~s}^{-1}\right), \dot{\varepsilon}_{\mathrm{s}}=3.0 \times 10^{-5} \mathrm{~s}^{-1}$ & $\gamma_{\mathrm{s}}=10^{\left(6.156 \alpha_{\mathrm{s}}-2.0\right)}$ & \\
\hline & $10^{-6}-10^{3}$ & $\begin{aligned} \sigma_{\mathrm{td}} & =\sigma_{\mathrm{t}}\left(\frac{\dot{\varepsilon}}{\dot{\varepsilon}_{\mathrm{s}}}\right)^{1.016 \beta_{\mathrm{s}}}\left(\dot{\varepsilon} \leq 30 \mathrm{~s}^{-1}\right) ; \sigma_{\mathrm{td}}=\sigma_{\mathrm{t}} \delta_{\mathrm{s}}\left(\frac{\dot{\varepsilon}}{\dot{\varepsilon}_{\mathrm{s}}}\right)^{1 / 3} \\
& \left(\dot{\varepsilon}>30 \mathrm{~s}^{-1}\right) \\
\dot{\varepsilon}_{\mathrm{s}} & =3.0 \times 10^{-6} \mathrm{~s}^{-1}\end{aligned}$ & $\begin{array}{l}\beta_{\mathrm{s}}=1 /\left(10+6 \sigma_{\mathrm{t}} / 10\right) \\
\delta_{\mathrm{s}}=10^{\left(7.11 \beta_{\mathrm{s}}-2.33\right)}\end{array}$ & \\
\hline & $10^{-6}-10^{3}$ & $\begin{array}{c}\sigma_{\mathrm{ucd}}=\sigma_{\mathrm{uc}}[0.00965 \log \dot{\varepsilon}+1.058]\left(\dot{\varepsilon} \leq 63.1 \mathrm{~s}^{-1}\right) \\
\sigma_{\mathrm{ucd}}=\sigma_{\mathrm{uc}}[0.758 \log \dot{\varepsilon}-0.289]\left(\dot{\varepsilon}>63.1 \mathrm{~s}^{-1}\right)\end{array}$ & & Tedesco and Ross (1998) \\
\hline & $10^{-5}-10^{1}$ & $\begin{array}{l}\sigma_{\mathrm{td}}=\sigma_{\mathrm{t}}[0.1425 \log \dot{\varepsilon}+1.833]\left(\dot{\varepsilon} \leq 2.32 \mathrm{~s}^{-1}\right) \\
\sigma_{\mathrm{td}}=\sigma_{\mathrm{t}}[2.929 \log \dot{\varepsilon}+0.814]\left(\dot{\varepsilon}>2.32 \mathrm{~s}^{-1}\right)\end{array}$ & Brazilian disc tests & \\
\hline
\end{tabular}

effects, i.e. the inertia effect and the strain rate effect, should be taken into consideration. Study of the former results in analyses of wave propagation in various forms, either explicitly or implicitly; study of the latter has promoted research into all kinds of nonlinear rate-dependent constitutive relations and fracture criteria. The main difficulty is that these two effects are usually inter-coupled. In fact, on the one hand, no wave propagation can be analysed without knowing the dynamic constitutive relation of the material; consequently the basic characteristics of wave propagation inevitably depend on the strain rate dependence of the mechanical behaviour of the material. On the other hand, in the study of dynamic constitutive relations and failure criteria of materials at HSRs, wave propagation effects should not be neglected (Wang et al. 2010b). Use of a simple geometry as mentioned in Sect. 2.2.3 with the optimal length-to-diameter ratio $\left(L_{\mathrm{s}} / D_{\mathrm{s}}=\sqrt{3 v} / 2\right)$ can be used to minimize wave propagation effects. Inertial effects can be decoupled from the material response in the SHPB test.

Swan et al. (1989) performed triaxial tests and microscopic observations on shale for strain rates from $10^{-5}$ to $10^{-1} \mathrm{~s}^{-1}$ and claimed that the strain rate effect is an intrinsic property. However, Blanton (1981) argued that an apparent strain rate sensitivity resulted from machine inertia and may not reflect an intrinsic increase in rock strength. Taking inertia into account, his study indicated that the actual failure stresses of three types of rocks are relatively independent of strain rate between $10^{-2}$ and $10^{1} \mathrm{~s}^{-1}$.

From a macroscale point of view, strain rate dependence is due to the following factors (Ozbolt et al. 2011; Bazant et al. 1993): inertia effects at the microcrack level, viscous behaviour of the bulk material between cracks and structural inertia forces depending on the specimen geometry.

\subsection{Thermal Activation Effect}

As previously noted in Sect. 4.8.1, the compressive strength of rock materials is increased by either an increase in strain rate or a decrease in temperature. This type of behaviour has usually been explained using the thermal activation theory for metals (Zener and Hollomon 1944), which can be expressed by the Arrhenius equation

$\dot{\varepsilon}=f \mathrm{e}^{-Q / \mathrm{R} T}$,

where $\dot{\varepsilon}$ is the strain rate, $f$ is the frequency factor, $Q$ is the activation energy, $\mathrm{R}$ is the air constant, and $T$ is the absolute temperature.

Serdengecti and Boozer (1961) performed uniaxial and triaxial compression tests on Solnhofen limestone, Berea sandstone and Pala gabbro at ISR, and the Arrhenius equation was employed to interpret the experimental data. Kumar (1968) obtained the activation energy equation $Q=$ 
$\frac{\Delta \ln \dot{\sigma}}{\Delta(-1 / \mathrm{R} T)}$ by differentiating the Arrhenius equation and relating the strain rate to the stress rate. The fracture mechanisms of basalt and granite at HSR are thermally activated, and the activation energies were calculated using the proposed equation. Green and Perkins (1968) performed compressive tests on Solnhofen limestone, Westerly granite and volcanic tuff over a wide range of strain rates from $10^{-4}$ to $10^{4} \mathrm{~s}^{-1}$, and pointed out that the most reasonable explanation for the strain rate effect is that fracture mechanisms are thermally activated. Lindholm et al. (1974) performed uniaxial and triaxial compression tests at strain rates from $10^{-4}$ to $10^{3} \mathrm{~s}^{-1}$ and temperatures from -193 to $1,127^{\circ} \mathrm{C}$, reaching the same conclusion. Qi et al. (2009) recently proposed that both a heat activation mechanism and macro-viscosity mechanism exist in the strain rate-dependent behaviour. It is worth pointing out that quantitative determination of $Q$ and $T$ in the Arrhenius equation is a challenge.

\subsection{The Stefan Effect}

At ISRs, Rossi and Toutlemonde (1996) and Rossi (1991) proposed that the strain rate effect of concrete is due to a viscous mechanism. The Stefan effect can be used to explain the mechanism: when a thin viscous film (e.g. water or oil) is trapped between two plane plates that are separated at a velocity, the film exerts a return force on the two plates, which can be expressed by the equation

$F=\frac{3 \eta V^{2}}{2 \pi h^{5}} \cdot \dot{h}$,

where $F$ is the return force, $\eta$ is the viscosity of the liquid, $V$ is the volume of liquid, $h$ is the initial distance between the two plates, and $\dot{h}$ is the velocity of the two plates.

If it is assumed that the solid skeletons of rock materials can be regarded as plates, the free water in the micropores is the origin of the physical mechanism. Since the velocity $\dot{h}$ is proportional to the loading rate, it can be understood that, in saturated rock materials, the higher the loading rate applied, the higher the induced return force will be. Therefore, this can easily explain why, as presented in Sect. 4.8.2, strain rate effects are larger in rock materials under fully saturated condition, especially for sedimentary rocks that have many micropores. It should be noted that the original application of the Stefan effect was only for concrete in ISR tests (Rossi and Toutlemonde 1996; Rossi 1991), but it has also been used to explain the strain rate effect of the BD tensile strength of Longyou sandstone in water saturation at HSR obtained by the SHPB technique (Huang et al. 2010b). The Stefan effect is obviously regarded as an explanatory model instead of a quantitative method because it is difficult to measure the diameter of the micropores in rock materials.

\subsection{Micromechanics-Based Effect}

Rock materials are typically quasi-brittle and inhomogeneous, containing initial defects such as grain boundaries, microcracks and pores. Consideration of the influence of intrinsic material characteristics on the macroscopic deformation of rock materials can shed much light on the constitutive behaviour, in the sense of supplying estimates of mechanical properties. Recently, there have been increasing numbers of studies of the inhomogeneity effect on the failure mechanism of rock materials. Some researchers (e.g. Cho et al. 2003; Zhu and Tang 2006; Zhou and Hao 2008) incorporated the rock inhomogeneity into numerical methods, and successfully simulated progressive failure of rock materials under both quasi-static and dynamic loading. These analyses revealed that the differences are due to the stress concentrations and redistribution mechanisms in the rock. The rock inhomogeneity also contributes to the difference between the dynamic and static tensile strengths.

At ISR, the increase of strength is assumed to be related to the moisture effect in micropores of the material (Rossi et al. 1994), whereas the enhancement effect at higher strain rates is mainly caused by a change of failure mechanism and by the effect of micro/meso-inertia (Reinhardt and Weerheijm 1991). There are at least three aspects which require attention: first, the bond breaking process; second, the inertia effect of the material adjacent to the crack; and third, the crack propagation velocity. A dominant micromechanism that commonly characterizes damage in brittle materials is microcracking, which may nucleate either at inhomogeneities such as inclusions and reinforcements or at defects such as microcracks and pores. Microcrack inertia effects in the fracture zone might be a mechanism that comes into play at very HSRs for brittle materials.

\subsection{Dynamic Fragmentation Effect}

Observations of fracture processes and failure patterns exhibit a general trend; i.e. dynamic fracture changes from simple fracturing to multiple fragmentation and even to pulverization with increasing strain rate (Yuan et al. 2011; Doan and Gary 2009; Hogan et al. 2012; Li et al. 2005; Cai et al. 2007; Xia et al. 2008). During dynamic fracturing, the primary absorbed energy contributes to the generation of new surfaces, the number and size of fragments, and the kinetic energy of moving fragments. Grady and Lipkin (1980), Grady and Kipp (1987) and Grady (1982) established energy-balance models and argued that the rate sensitivity is caused by dynamic fragmentation. Based on results from laboratory and controlled blasting experiments, a relationship between the strain rate and the grain 
size $d, \dot{\varepsilon}=\sqrt{20} K_{\text {IC }} /\left(\rho C d^{3 / 2}\right)$ (Grady and Kipp 1987) was established through three other material parameters $\left(K_{\mathrm{IC}}, \rho\right.$, $C)$. Recently, Kazerani and Zhao (2010) studied rock fracturing with micromechanics-based discrete-element modelling and revealed that the rate dependence may be due to several causes: the intrinsic rate-dependent properties of the microstructure, the structural rate dependence of the composition, and the testing conditions.

\section{Rate-Dependent Constitutive Models}

The qualitative dependence of mechanical behaviour on strain rate is now well known; however, the quantitative relation between stress, strain and strain rate has been established for only a limited range. This relation, the socalled constitutive equation, must be known before plasticity or plastic-wave propagation theory can be used to predict the stress or strain distribution in parts subjected to impact stresses above the yield strength.

Dynamic experiments have shown that the flow stress of materials depends on the strain, strain rate, temperature, and deformation or loading history H, i.e. $\sigma=f(\varepsilon, \dot{\varepsilon}, T, \mathrm{H})$. The most widely used method for determining the deformation history is the strain rate jump test introduced by Campbell and Dowling (1970). Plastic deformation is an irreversible and path-dependent process, whereas rock materials are quasi-brittle or brittle. Each proposed constitutive equation must have a few (typically $3-5$ ) constants that have to be determined by experiment.

Accurate modelling of the mechanical behaviour of materials and engineering structures over a wide range of strain rates requires a reliable constitutive model. Over recent years, some attempts have been made to develop constitutive models, including several phenomenological and physically based constitutive models. Phenomenological constitutive models provide a definition of the flow stress based on semi-empirical observations, and consist of some mathematical functions. On the other hand, constitutive models considering physical mechanisms of the strain rate effect are known as physically based constitutive models.

\subsection{Phenomenological Constitutive Models}

The most widely used phenomenological constitutive models for rock-like materials are those of Johnson and Holmquist (1992, 1994), used to model the impact performance of ceramics under ballistically delivered loads. The first version, usually called the JH-1 model (Johnson and Holmquist 1992), was developed to account for large strains under HSRs and pressures, but did not take into consideration progressive damage with the increase of deformation. The JH-2 model (Johnson and Holmquist 1994) assumed that the material strength was dependent on the strain rate, pressure and damage, and incorporated a damage evolution rule. The dependence of the strength was represented by a set of constants that were derived from experimental data. Ai and Ahrens (2006) might be the first authors to have applied the JH-2 model to simulate the dynamic response of granite, in which an in-depth description of the determination of proper parameters for the $\mathrm{JH}-2$ model for granite is presented. The JH-2 model was also used to model blasting-induced rock fractures of a borehole under several loading and boundary conditions (Ma and An 2008). Banadaki and Mohanty (2012) performed single-hole blast experiments on cylindrical specimens to study the fracture patterns induced by stress waves. A detailed calibration procedure of the $\mathrm{JH}-2$ model using experimental results was also included.

Phenomenological constitutive models do not embody either the microstructure or normative material properties, and thus they cannot be connected to microstructureproperty relationships. Therefore, they are usually used in limited application fields.

\subsection{Physically Based Constitutive Models}

Concurrently with phenomenological constitutive models, there has been a continuing effort to describe the macroscopic stress in terms of microscopic/physical mechanisms as predominately described in Sect. 5. Compared with phenomenological models, these allow for accurate definition of the material behaviour under a wide range of loading conditions based on some physical assumptions and a larger number of material constants. Constitutive models based on thermally activated mechanisms are usually developed for modelling the mechanical behaviour of metal materials, as presented in the critical review by Liang and Khan (1999); to the best of our knowledge, only one model has been proposed for rock materials at ISR (Serdengecti and Boozer 1961).

\subsubsection{Visco-Elastic and Plastic Models}

Various researchers (Chong et al. 1980; Chong and Boresi 1990; Blanton 1981) have modelled the rate dependence by employing various spring-dashpot models (viscoelastic and visco-plastic models). The elastic strain rate depends on the stress rate applied, with the elastic response to a change in stress rate occurring almost instantaneously. However, the time dependence of the total strain is due principally to the presence of the plastic strain component. 


\subsubsection{Continuum Damage Mechanics Models}

Continuum damage mechanics (CDM) was pioneered by Kachanov (1958) and Rabotnov (1963). There are usually three basic elements to any CDM model: a definition of damage, a damage evolution equation, and a constitutive equation which relates the strain or the stress to the damage (Wang and Shrive 1995). A simple way to develop a ratedependent CDM model is to derive it from a traditional CDM model by modifying the expression of the damage evolution equation (Dubé et al. 1996; Ju 1989). Fahrenthold (1991) proposed a meso-mechanical CDM, in which the damage evolution equation is expressed in terms of a tensor power function. Ren and Li (2013) developed a unified damage model on the basis of visco-elasticity and a rate-dependent model to represent the mechanical behaviour of concrete under dynamic loading. In theory, this approach is very flexible and allows consideration of the physical processes triggering macroscopic damage at small length scales. In practice, it is difficult to measure the damage variables directly. In addition, the CDM model lacks an explicit representation of the material microstructure and does not take into account post-failure deformation and damage response. Therefore, so-called micromechanics-based constitutive models that consider the interactions of pre-existing flaws have been developed.

\subsubsection{Micromechanics-Based Constitutive Models}

Micromechanics-based constitutive models for damage evolution in brittle materials under HSR loading provide a quantitative understanding for the observed rate sensitivity in rock-like materials, as presented and critically assessed in this section and summarized in Table 12.

The 2D sliding crack model (SCM) was originally proposed by Brace and Bombolakis (1963) and later quantified analytically, as well as confirmed experimentally, by many investigators, especially Nemat-Nasser and Horii (1982), Ashby and Hallam (1986) and Ashby and Sammis (1990), as shown schematically in Fig. 48. Nemat-Nasser and Deng (1994) and Deng and Nemat-Nasser (1992) extended the SCM model to simulate the dynamic damage evolution and failure mechanisms. The effect of strain rate was included through the dependence of the dynamic SIF at the crack tips on the crack growth speed. The model reveals that the growth and nucleation of sliding cracks dominate the failure and macroscopic properties of rock materials.

The above models attempt to model dynamic crack growth by solving for a crack speed that ensures that the dynamic SIF of the crack always equals the fracture toughness. Most models do not account for the fact that the fracture toughness of the material is itself sensitive to the strain rate.
The micromechanical damage mechanics formulated by Ashby and Sammis (1990) models the nucleation, growth and interaction of a distribution of mono-sized cracks having fixed orientation. Based on the AS model, Deshpande and Evans (2008) proposed a micromechanically motivated model (DE model) that incorporates microstructure. Deshpande et al. (2011) and Bhat et al. (2012) extended this model to incorporate three principal deformation mechanisms for the dynamic mechanical behaviour. Bhat et al. (2012) recently extended the AS and DE models to allow for a more generalized stress state and to incorporate an experimentally motivated new damage evolution law. Figure 49 shows numerical modelling of stress-strain curves and peak stresses at different strain rates for Dionysos-Pentelicon marble.

The statistical crack mechanical model (SCRAM) is a physically based micromechanical approach for large deformation and cracking of brittle materials (Dienes 1985). During deformation, the crack distribution is assumed to remain random, and the size of the distribution of the cracks is exponential. On the basis of the SCRAM, Zuo et al. (2006) presented a dominant crack algorithm (DCA). This model assumes that a brittle material contains a large number of penny-shaped microcracks with different sizes and orientations, and the macroscopic damage of the material is the result of the response of all the cracks to the stress field. The response of the cracks considered in the model includes opening, shear and growth. The rate dependence is introduced by relating the rate of crack growth to the energy release rate for the dominant crack. Rate dependence helps keep the model mathematically well-posed, which can be difficult for a damage model when applications involve simulating the strain-softening response of a material. Zuo et al. (2010) recently improved the physics of the model by incorporating plasticity and a nonlinear equation of state (Deganis and Zuo 2011), and applied it to study damage in concrete. Rate-dependent damage models are widely used for concrete under dynamic loads (Dubé et al. 1996).

\subsubsection{Other Models}

A brief description of some other models is presented in this subsection. Based on the TCK model (Taylor et al. 1986), Chen (1999) developed a non-local formulation of the dynamic damage accumulation process. Yu (1992) proposed an overstress model after the work of Malvern (1984) to simulate the stress-strain behaviour of several rocks at strain rate of $10^{3} \mathrm{~s}^{-1}$. Gary and Bailly (1998) proposed an analogous rheological model by introducing a second time derivative of the strain to take inertia effects into account. The model shows good agreement with experimental results for concrete at HSR, also correctly 


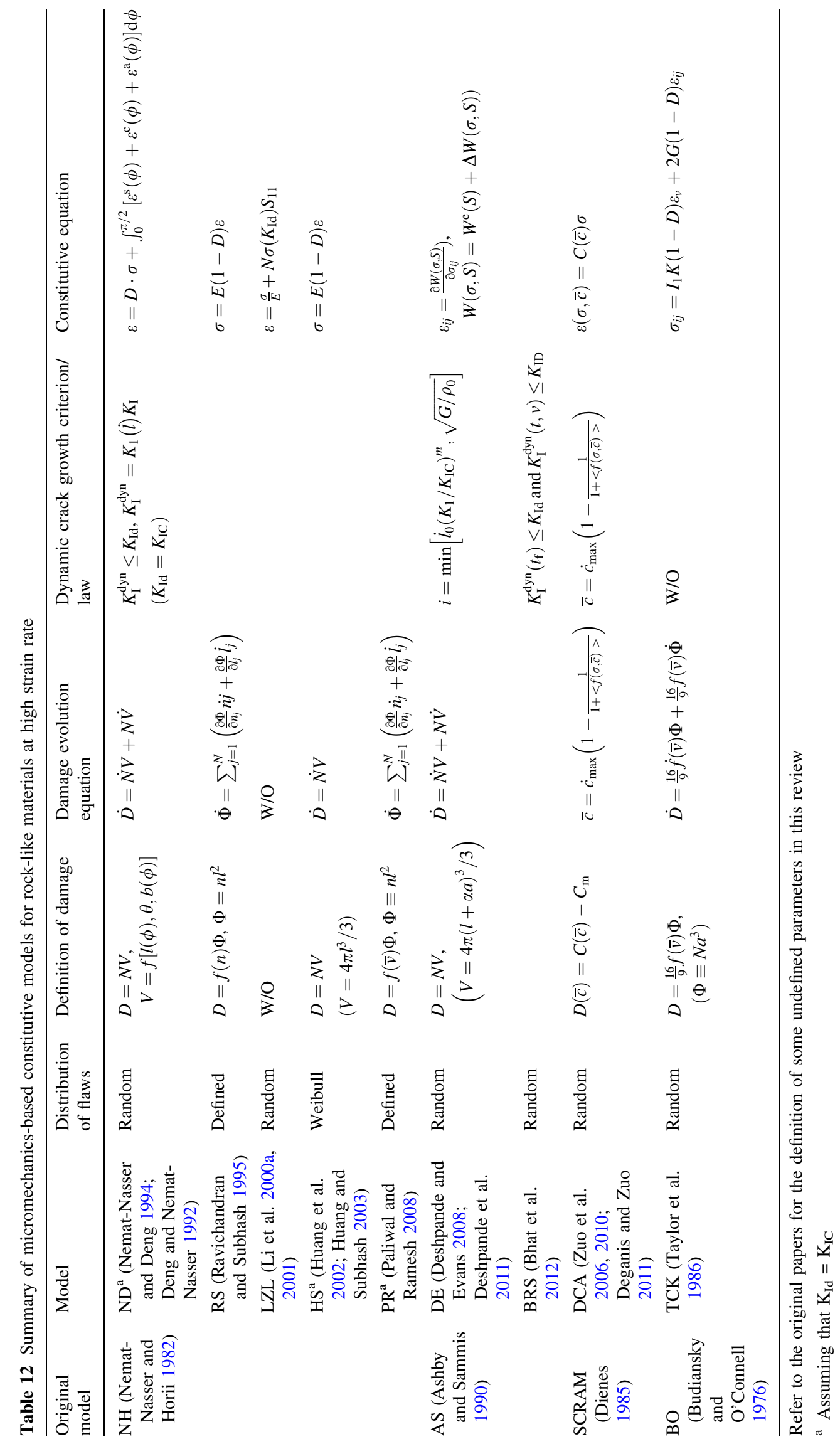


Fig. 48 Schematics of classic microcrack models: a $\mathrm{NH}$ model (Nemat-Nasser and Horii 1982) and b AH model (Ashby and Hallam 1986) for individual microcracks, and c AS model (Ashby and Sammis 1990) for distributed microcracks subjected to far-field biaxial compression

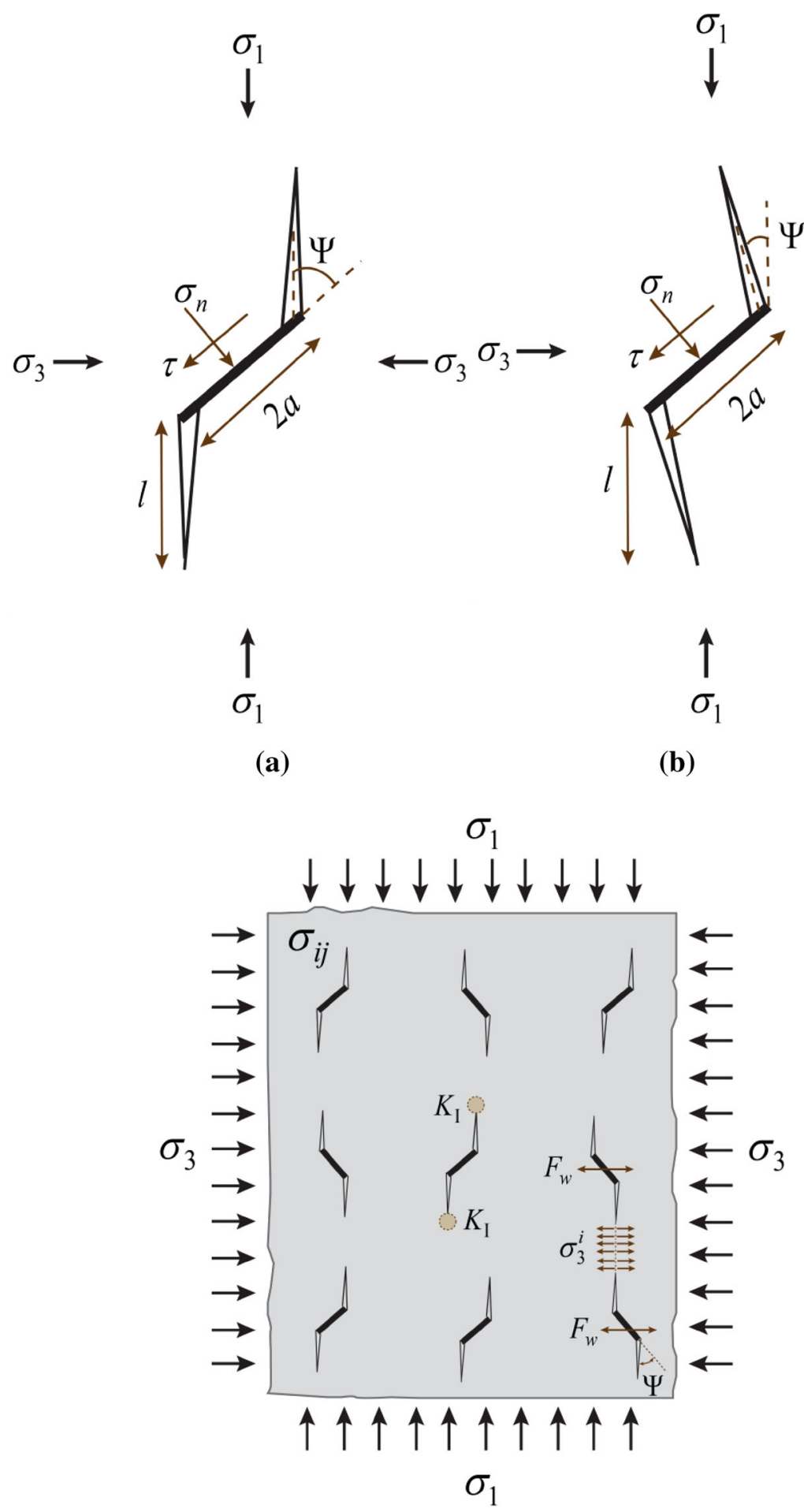

(c) describing the effect of confining pressure. Ragueneau and Gatuingt (2003) proposed coupled plasticity damage models considering the anisotropy of the response induced by complex cracking patterns and irreversible deformation due to frictional sliding or non-closing cracks. Pedersen et al. (2008) proposed a continuum visco-elastic viscoplastic damage model. Desmorat et al. (2010) proposed a delay-active damage model. Saksala (2010) proposed a damage visco-plastic cap model, combining the viscoplastic constitutive model (Wang et al. 1997) and a cap 


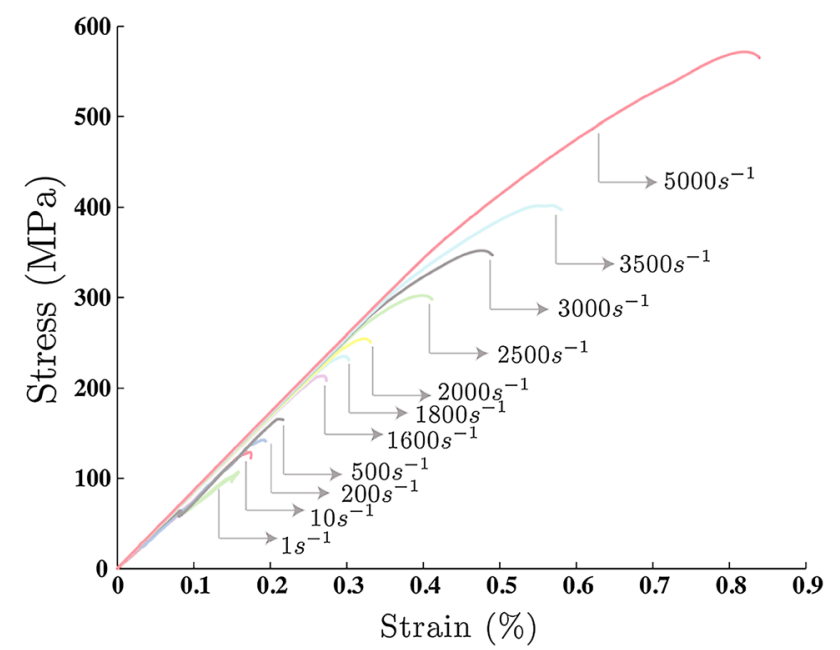

(a)

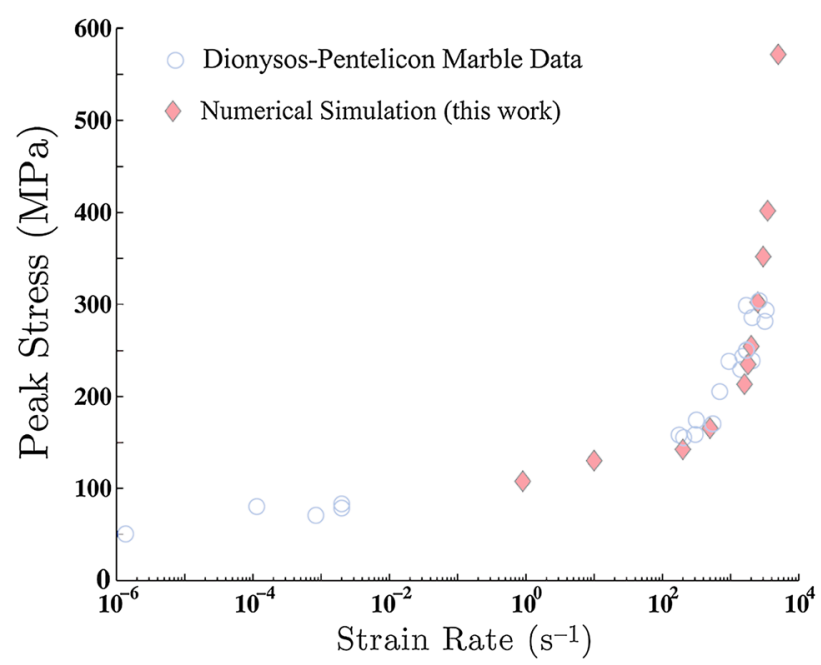

(b)

Fig. 49 Numerical modelling of stress-strain curves (a) and peak stresses (b) at different strain rates for Dionysos-Pentelicon marble using a micromechanics-based model (reproduced from Bhat et al. 2012, Figs. 9, 12, pp. 9-10)

hardening model, for rock materials to account for the failure modes and rate effects under low-velocity impact loading. A non-local visco-elastic damage model and dynamic fracturing were considered by Lyakhovsky et al. (2011).

\section{Dynamic Fracture Criteria}

A fracture criterion describes the conditions for which failure occurs in a material, and moreover constitutive models depend on the fracture criteria. Fracture criteria for rock materials under quasi-static loads were critically reviewed by Zang and Stephansson (2010) and recently proposed as ISRM suggested methods (Haimson and Bobet
2012). However, there are only limited works on dynamic fracture criteria for quasi-brittle materials. We provide a summary of these criteria in Table 13 and present a brief description of their applications to rock materials.

Sato et al. (1981) firstly proposed that the Mohr-Coulomb criterion can be extended to dynamic triaxial compressive strength, although this cannot explain the changes of cohesion and internal friction angle under dynamic loading. Based on experimental data from a series of dynamic uniaxial and triaxial compression, indirect tension and punch shear tests performed on Bukit Timah granite, Zhao (2000) examined the application of the Mohr-Coulomb and the Hoek-Brown criteria to rock materials in the dynamic range. The Mohr-Coulomb criterion is only applicable to dynamic triaxial strength in the low confining pressure range. This shows that the change in strength with loading rate is primarily due to the change of cohesion, while the internal friction angle seems unaffected by the loading rate. The dynamic triaxial strength is better represented by the Hoek-Brown criterion at both low and high confining pressures. It may be assumed that the parameter $m$ is unaffected by the loading rate. The dynamic MohrCoulomb criterion (Zhao 2000) has been successfully implemented in numerical software to simulate dynamic uniaxial compression (Zhu et al. 2004), Brazilian disc (Zhu and Tang 2006), spalling (Zhu 2008) and combined staticdynamic loading (Zhu et al. 2012). Recently, Huang et al. (2012) and Xia (2013a) also examined the application of the Mohr-Coulomb criterion to three dynamic mechanical properties, i.e. the compressive strength, tensile strength and punch shear strength of Longyou sandstone, obtained by using the SHPB technique.

The theory of the dynamic SIF-based criterion is heavily discussed in the book by Ravi-Chandar (2004), and thus, within the scope of this review, only applications to micromechanics-based constitutive models as listed in Table 12 are presented (Nemat-Nasser and Deng 1994; Deng and Nemat-Nasser 1992; Ravichandran and Subhash 1995; Li et al. 2000a, 2001; Huang et al. 2002; Huang and Subhash 2003; Paliwal and Ramesh 2008; Deshpande and Evans 2008; Deshpande et al. 2011; Bhat et al. 2012).

The incubation-time fracture criterion (ITFC) originally proposed by Petrov and Morozov (1994) and Petrov and Utkin (1989) has been widely used to describe dynamic crack initiation of quasi-brittle materials (Morozov and Petrov 2000; Bratov et al. 2009). Wang et al. (2010c) employed the ITFC to explain the size effect of the dynamic crack initiation toughness of Ya'an marble obtained by the HCFBD method and the SHPB technique. On the basis of the ITFC, Ou et al. $(2010,2012)$ derived two explicit analytic expressions to predict the dynamic tensile load-carrying capacity of quasi-brittle material, which are in good agreement with experimental data for 
Table 13 Summary of dynamic fracture criteria for quasi-brittle materials

\begin{tabular}{|c|c|c|c|}
\hline $\begin{array}{l}\text { Name of } \\
\text { criterion }\end{array}$ & Fracture criterion formula & Applicability and comments & References \\
\hline \multirow{2}{*}{$\begin{array}{l}\text { Mohr- } \\
\text { Coulomb } \\
\text { criterion }\end{array}$} & $\sigma_{1 \mathrm{~d}}=\sigma_{\mathrm{ucd}}+q \sigma_{3}$ & $q$ is hardly influenced by $\dot{\varepsilon}$ & Li et al. (1999) \\
\hline & $\begin{array}{c}\sigma_{1 \mathrm{~d}}=\sigma_{\mathrm{ucd}}+\sigma_{3}(1+\sin \varphi) /(1-\sin \varphi) \\
c_{\mathrm{d}}=\sigma_{\mathrm{ucd}}(1-\sin \varphi) / 2 \cos \varphi\end{array}$ & $\begin{array}{l}\text { Only applicable for low confining pressure; } \phi \text { is unaffected } \\
\text { by } \dot{\varepsilon}\end{array}$ & Zhao (2000) \\
\hline $\begin{array}{l}\text { Hoek-Brown } \\
\text { criterion }\end{array}$ & $\sigma_{1 \mathrm{~d}}=\sigma_{3}+\sigma_{\mathrm{ucd}}\left(m \sigma_{3} / \sigma_{\mathrm{ucd}}+1.0\right)^{0.5}$ & $m$ is not affected by $\dot{\varepsilon}$ & Zhao (2000) \\
\hline $\begin{array}{l}\text { Dynamic } \\
\text { SIF-based } \\
\text { criterion }\end{array}$ & $\frac{1+v}{E} \frac{v^{2} \alpha_{\mathrm{d}}}{C_{\mathrm{s}}^{2} R(v)}\left[k(v) K_{\mathrm{I}}(t, l(t), 0)\right]^{2}=\gamma$ & Widely used in micromechanics-based constitutive models & Ravi-Chandar (2004) \\
\hline $\begin{array}{l}\text { Tuler- } \\
\text { Butcher } \\
\text { criterion }\end{array}$ & $\int_{0}^{t_{\mathrm{f}}}\left(\sigma_{0}-\sigma\right)^{\lambda} \mathrm{d} t=K$ & $\begin{array}{l}\text { Predicting spalling tensile strength and the location of the } \\
\text { failure plane }\end{array}$ & $\begin{array}{l}\text { Tuler and Butcher } \\
\text { (1968) }\end{array}$ \\
\hline $\begin{array}{l}\text { Modified TB } \\
\text { criterion }\end{array}$ & $\int_{t_{0}}^{t_{1}} \frac{\left(K-K_{\mathrm{Id}}\right)^{2}}{\epsilon} \mathrm{d} t=C$ & $\begin{array}{l}\text { Dimensionally equivalent to Tuler and Butcher (1968); } \\
\text { predicting dynamic fracture toughness }\end{array}$ & Zhao (1995) \\
\hline $\begin{array}{l}\text { Critical } \\
\text { impulse } \\
\text { criterion }\end{array}$ & $(2 E)^{-1} \int_{0}^{\tau} \sigma^{2} \mathrm{~d} t=\gamma / 3 a$ & $\begin{array}{l}\text { Assumes the pulse duration is constant; without physical } \\
\text { explanation }\end{array}$ & $\begin{array}{l}\text { Steverding and } \\
\text { Lehnigk (1970) }\end{array}$ \\
\hline $\begin{array}{l}\text { Incubation- } \\
\text { time } \\
\text { fracture } \\
\text { criterion }\end{array}$ & $\begin{array}{l}\frac{1}{\tau} \frac{1}{\mathrm{~d}} \int_{x-d}^{x} \int_{t-\tau}^{t} \sigma(x, t) \mathrm{d} x \mathrm{~d} t=\sigma_{\mathrm{t}} \\
\quad \frac{1}{\tau} \int_{t-\tau}^{t} K_{\mathrm{I}}(t) \mathrm{d} t=K_{\mathrm{IC}}\end{array}$ & $\begin{array}{l}\text { Time-space domain is discretized by assuming two material } \\
\text { constants, i.e. incubation time } \tau \text { and characteristic size } d \text {. } \\
\text { Physical meanings of } \tau \text { and } d \text { ? }\end{array}$ & $\begin{array}{l}\text { Petrov and Morozov } \\
\text { (1994), Petrov and } \\
\text { Utkin (1989) }\end{array}$ \\
\hline
\end{tabular}

Refer to the original papers for the definition of some undefined parameters in this review

concrete in spalling tests. They thus argued that the usually termed strain rate effect could no longer be considered an intrinsic material property. Smirnov et al. (2012) presented recent progress in application of the ITFC to rock materials and examined the spalling tensile strength and dynamic fracture toughness. However, there are still uncertainties regarding the definition of the physical meanings of the two assumed material constants (i.e. incubation time $\tau$ and $d$ ).

\section{Conclusions}

This review of 50 years of research since the pioneering work of the 1960s is intended to present the state of the art in both dynamic testing techniques and dynamic mechanical behaviour of rock materials. It appears that full understanding of dynamic mechanical behaviour depends on reliable experimental techniques, testing procedures and effective numerical simulations. This section presents concluding remarks and some prospects requiring investigation.

Loading techniques commonly used for ISR testing of rock materials are pneumatic-hydraulic, completely gasdriven and drop-weight machines. At HSR, the SHB is widely used, and major developments of this technique for rock materials are briefly summarized. Although some key effects for characterizing the dynamic response are considered and attempts have been made to minimize them, they can never be completely eliminated. The strain rate in tests performed by loading techniques should be well controlled, e.g. using electromagnetically driven techniques (Silva et al. 2009, 2012). Mechanical loads on engineering structures are commonly not uniaxial, and moreover the development and calibration of constitutive models for numerical simulations require experimental data under various stress and/or strain paths, strain rates and confinement typically observed in impacts of testing systems. Therefore, loading techniques can be applied to multiaxial stress, such as true-triaxial (Cadoni and Albertini 2011) and compression-shear (Zhao et al. 2011) tests.

In terms of measurement techniques, although highspeed photography has been widely used, the goal of using high-rate imaging is accurate and quantitative measurement of data as another diagnostic tool rather than just imaging in the qualitative sense. Among the outlined frequently used optical techniques for rock-like materials, the DIC technique appears promising and worth exploring across a wide range of length and time scales. Measurement techniques with ultra-high speed and resolution are used for optical reconstruction (Siviour et al. 2012), measurement of deformation fields and identification of constitutive parameters (Pierron et al. 2011; Pierron and Forquin 2012). Micro-measurement techniques, e.g. SEM, optical profilometry and microcomputed tomography are employed for multi-scale 
measurement and reconstruction (Zhang and Zhao 2013b, d; Khokhlov et al. 2012).

Dynamic uniaxial and triaxial compressive, tensile and shear strength and fracture toughness are obtained by quantitative assessment of testing methods, and controlling factors and failure patterns are also discussed to validate these properties. Dynamic mechanical properties and fracture behaviour change with the loading rate; in particular, the responses distinguishably change after the loading rate exceeds a critical value. Estimation methods to obtain stress-strain curves at HSRs are summarized, and some typical results are presented. Although effects of influencing environmental (i.e. confining pressure, temperature and water saturation) and rock (i.e. microstructure, size and shape) factors are considered, it is still not completely clear how dynamic mechanical properties are influenced by intrinsic material characteristics. Several popular semi-empirical rate-dependent equations for predicting dynamic strength are presented. New testing methods are greatly required, e.g. shear (Spray 2010) and multiaxial stress state tests (Zhao et al. 2011; Cadoni and Albertini 2011). Dynamic testing methods should be carefully examined and satisfy the fundamentals of theory, such as the distribution of dynamic stress, stress equilibrium and failure patterns. Phenomenological and physically based rate-dependent constitutive models for estimation of the constitutive behaviour of the strain rate effect based on experimental data and physical mechanisms are presented. Some energy- and/or stress-based dynamic fracture criteria for brittle materials are presented, among which the dynamic Mohr-Coulomb criterion and classic dynamic SIF-based criterion have been widely used. Failure mechanisms of brittle polycrystalline materials at the microscale have been studied using experimental observations (Yang et al. 1991; Hadraba et al. 2008), fractal geometry theory (Xie and Chen 1988; Long et al. 1991), theoretical analysis (Dumont et al. 2004) and numerical modelling (Zavattieri and Espinosa 2001; Kraft and Molinari 2008), though there have been very few studies characterizing failure micromechanisms of rock materials under dynamic loading.

Acknowledgments This work is supported by the Swiss National Science Foundation (no. 200020_129757) and the China Scholarship Council (CSC). During the preparation of this study, the authors contacted many researchers whose research is relevant to the subject matter, and we appreciate the help and support that they provided by sharing their knowledge and resources. They are Gérard Gary (École Polytechnique), Yang Ju and Ruidong Peng (China University of Mining and Technology), Tohid Kazerani (University of Nottingham), Jianchun Li (Institute of Rock and Soil Mechanics, Chinese Academy of Sciences), Xibing Li (Central South University), Xiao Li (Institute of Geology and Geophysics, Chinese Academy of Sciences), Zhuocheng Ou (Beijing Institute of Technology), Yuri Petrov (St. Petersburg State University, Russia), Fabrice Pierron (University of Southampton), Chun'an Tang (Dalian University of Technology), David Taylor (Trinity College, Ireland), Lili Wang (Ningbo
University), Qizhi Wang (Sichuan University), Kaiwen Xia (University of Toronto), Songlin Xu (University of Science and Technology of China), Zhiqiang Yin (Anhui University of Science and Technology), Gaofeng Zhao (The University of New South Wales), Xiaobao Zhao (Nanjing University) and Wancheng Zhu (Northeastern University). A special acknowledgement is given to Mrs Haiying Bian (editorial office of Geomechanics and Geoengineering-An International Journal), who provided language editing for this review.

\section{References}

Agbabian MS (1985) Design of structures to resist nuclear weapons effects, vol 42. Revised edn. Manual 42 of the Committee on Dynamic Effects of the Structural Division of ASCE, New York

Ahrens TJ, Rubin AM (1993) Impact-induced tensional failure in rock. J Geophys Res 98(E1):1185-1203. doi:10.1029/92je02679

Ai HA, Ahrens TJ (2006) Simulation of dynamic response of granite: a numerical approach of shock-induced damage beneath impact craters. Int J Impact Eng 33(1-12):1-10. doi:10.1016/j.ijimpeng. 2006.09.046

Albertini C, Cadoni E, Labibes K (1999) Study of the mechanical properties of plain concrete under dynamic loading. Exp Mech 39(2):137-141. doi:10.1007/bf02331117

Alves M, Karagiozova D, Micheli GB, Calle MAG (2012) Limiting the influence of friction on the split Hopkinson pressure bar tests by using a ring specimen. Int J Impact Eng 49:130-141. doi:10. 1016/j.ijimpeng.2012.04.005

Ashby MF, Hallam SD (1986) The failure of brittle solids containing small cracks under compressive stress states. Acta Metall 34(3):497-510. doi:10.1016/0001-6160(86)90086-6

Ashby MF, Sammis CG (1990) The damage mechanics of brittle solids in compression. Pure Appl Geophys 133(3):489-521. doi: $10.1007 / \mathrm{bf} 00878002$

ASM (2000) High strain rate tension and compression tests. ASM Handbook, Mechanical Testing and Evaluation ASM Int, Materials Park OH 8:429-446

Asprone D, Cadoni E, Prota A, Manfredi G (2009) Dynamic behavior of a Mediterranean natural stone under tensile loading. Int $\mathbf{J}$ Rock Mech Min 46(3):514-520. doi:10.1016/j.ijrmms.2008.09. 010

ASTM (2008a) D2936-08 Standard test method for direct tensile strength of intact rock core specimens. Annual book of ASTM standards. ASTM International, West Conshohocken

ASTM (2008b) D3967-08 Standard test method for splitting tensile strength of intact rock core specimens. Annual book of ASTM standards. ASTM International, West Conshohocken

ASTM (2011) E1820-11 Standard test method for measurement of fracture toughness. Annual book of ASTM standards. ASTM International, West Conshohocken

Atkinson BK (1982) Subcritical crack propagation in rocks: theory, experimental results and applications. J Struct Geol 4(1):41-56. doi:10.1016/0191-8141(82)90005-0

Atkinson BK (1987) Introduction to fracture mechanics and its geophysical applications. In: Atkinson BK (ed) Fracture mechanics of rock. Academic, London, pp 1-26

Atkinson C, Smelser RE, Sanchez J (1982) Combined mode fracture via the cracked Brazilian disk test. Int J Fract 18(4):279-291. doi:10.1007/bf00015688

Avril S, Bonnet M, Bretelle A-S, Grédiac M, Hild F, Ienny P, Latourte F, Lemosse D, Pagano S, Pagnacco E, Pierron F (2008) Overview of identification methods of mechanical parameters based on full-field measurements. Exp Mech 48(4):381-402. doi:10.1007/s11340-008-9148-y 
Backers T, Fardin N, Dresen G, Stephansson O (2003) Effect of loading rate on mode I fracture toughness, roughness and micromechanics of sandstone. Int J Rock Mech Min 40(3): 425-433. doi:10.1016/s1365-1609(03)00015-7

Banadaki MMD, Mohanty B (2012) Numerical simulation of stresswave induced fractures in rock. Int J Impact Eng 40-41:16-25. doi:10.1016/j.ijimpeng.2011.08.010

Barla G, Zhao J (2010) Special issue: rock dynamics and earthquake engineering. Rock Mech Rock Eng 43(6):655-960. doi:10.1007/ s00603-010-0120-7

Bazant ZP, Bai SP, Gettu R (1993) Fracture of rock: effect of loading rate. Eng Fract Mech 45(3):393-398. doi:10.1016/0013-7944 (93) $90024-\mathrm{m}$

Bertram A, Kalthoff JF (2003) Crack propagation toughness of rock for the range of low to very high crack speeds. Key Eng Mater 251-252:423-430. doi:10.4028/www.scientific.net/KEM.251-252. 423

Bhat HS, Rosakis AJ, Sammis CG (2012) A micromechanics based constitutive model for brittle failure at high strain rates. J Appl Mech 79(3):031016. doi:10.1115/1.4005897

Bieniawski ZT (1967a) Mechanism of brittle fracture of rock: part I theory of the fracture process. Int J Rock Mech Min Sci Geomech Abstr 4(4):395-406. doi:10.1016/0148-9062(67)90030-7

Bieniawski ZT (1967b) Stability concept of brittle fracture propagation in rock. Eng Geol 2(3):149-162. doi:10.1016/0013-7952 (67) $90014-2$

Bieniawski ZT (1968) Fracture dynamics of rock. Int J Fract Mech 4(4):415-430. doi:10.1007/bf00186807

Bindiganavile V, Banthia N (2006) Size effects and the dynamic response of plain concrete. J Mater Civ Eng 18(4):485-491. doi:10.1061/(ASCE)0899-1561(2006)18:4(485)

Bischoff P, Perry S (1991) Compressive behaviour of concrete at high strain rates. Mater Struct 24(6):425-450. doi:10.1007/bf02472016

Blanton TL (1981) Effect of strain rates from $10^{-2}$ to $10 \mathrm{~s}^{-1}$ in triaxial compression tests on three rocks. Int J Rock Mech Min Sci Geomech Abstr 18(1):47-62. doi:10.1016/0148-9062(81)90265-5

Bohloli B (1997) Effects of the geological parameters on rock blasting using the Hopkinson split bar. Int J Rock Mech Min 34(3-4):32.e31-32.e39. doi:10.1016/s1365-1609(97)00228-1

Bonamy D, Bouchaud E (2011) Failure of heterogeneous materials: a dynamic phase transition? Phys Rep 498(1):1-44. doi:10.1016/j. physrep.2010.07.006

Brace WF, Bombolakis EG (1963) A note on brittle crack growth in compression. J Geophys Res 68(12):3709-3713. doi:10.1029/ JZ068i012p03709

Brace WF, Jones AH (1971) Comparison of uniaxial deformation in shock and static loading of three rocks. J Geophys Res 76(20):4913-4921. doi:10.1029/JB076i020p04913

Braithwaite C (2009) High strain rate properties of geological materials. PhD., University of Cambridge, Cambridge

Bratov V, Morozov NF, Petrov Y (2009) Dynamic strength of continuum. St.-Petersburg University Press, St.-Petersburg

Budiansky B, O'Connell RJ (1976) Elastic moduli of a cracked solid. Int J Solids Struct 12(2):81-97. doi:10.1016/0020-7683(76) 90044-5

Cadoni E (2010) Dynamic characterization of orthogneiss rock subjected to intermediate and high strain rates in tension. Rock Mech Rock Eng 43(6):667-676. doi:10.1007/s00603-010-0101-x

Cadoni E, Albertini C (2011) Modified Hopkinson bar technologies applied to the high strain rate rock tests. In: Zhou YX, Zhao J (eds) Advances in rock dynamics and applications. CRC Press, USA, pp 79-104

Cai M, Liu D (2009) Study of failure mechanisms of rock under compressive-shear loading using real-time laser holography. Int J Rock Mech Min 46(1):59-68. doi:10.1016/j.ijrmms.2008.03. 010
Cai M, Kaiser PK, Suorineni F, Su K (2007) A study on the dynamic behavior of the Meuse/Haute-Marne argillite. Phys Chem Earth 32(8-14):907-916. doi:10.1016/j.pce.2006.03.007

Campbell J, Dowling AR (1970) The behaviour of materials subjected to dynamic incremental shear loading. J Mech Phys Solids 18(1):43-63. doi:10.1016/0022-5096(70)90013-x

Carmona S, Aguado A (2012) New model for the indirect determination of the tensile stress-strain curve of concrete by means of the Brazilian test. Mater Struct 45(10):1473-1485. doi:10.1617/ s11527-012-9851-0

Carosena M, Giovanni MC (2004) Recent advances in the use of infrared thermography. Meas Sci Technol 15(9):R27. doi:10. 1088/0957-0233/15/9/R01

CEB (1988) Concrete structures under impact and impulsive loading. vol 187. Bulletin d'information, $\mathrm{N}^{\mathrm{o}} 187$, CEB Comité EuroInternational du Béton, Lausanne

Chang S-H, Lee C-I, Jeon S (2002) Measurement of rock fracture toughness under modes I and II and mixed-mode conditions by using disc-type specimens. Eng Geol 66(1-2):79-97. doi:10. 1016/s0013-7952(02)00033-9

Chen EP (1999) Non-local effects on dynamic damage accumulation in brittle solids. Int J Numer Anal Meth Geomech 23(1):1-21. doi:10. 1002/(sici)1096-9853(199901)23:1<1:aid-nag892>3.0.co;2-r

Chen W, Ravichandran G (1996) An experimental technique for imposing dynamic multiaxial-compression with mechanical confinement. Exp Mech 36(2):155-158. doi:10.1007/bf02328712

Chen W, Ravichandran G (1997) Dynamic compressive failure of a glass ceramic under lateral confinement. J Mech Phys Solids 45(8):1303-1328. doi:10.1016/s0022-5096(97)00006-9

Chen WW, Song B (2011) Split Hopkinson (Kolsky) bar: design, testing and applications. Springer, New York

Chen WW, Rajendran AM, Song B, Nie X (2007) Dynamic fracture of ceramics in armor applications. J Am Ceram Soc 90(4):1005-1018. doi:10.1111/j.1551-2916.2007.01515.x

Chen R, Xia K, Dai F, Lu F, Luo SN (2009) Determination of dynamic fracture parameters using a semi-circular bend technique in split Hopkinson pressure bar testing. Eng Fract Mech 76(9):1268-1276. doi:10.1016/j.engfracmech.2009.02.001

Chen G, Kuang YC, Huang XC, Xu AM (2011) Dynamic compressive behavior of granite under active confinement. Adv Mater Res 291-294:1227-1232. doi:10.4028/www.scientific.net/AMR. 291-294.1227

Cho SH, Ogata Y, Kaneko K (2003) Strain-rate dependency of the dynamic tensile strength of rock. Int $\mathrm{J}$ Rock Mech Min 40(5):763-777. doi:10.1016/s1365-1609(03)00072-8

Cho SH, Kubota TS, Ogata Y, Yokota M, Kaneko K (2005) Microscopic visualization of a granitic rock subject to dynamic tensile loading by using a micro X-ray CT system. Sci Technol Energ Mater 66(4):334-339

Chong KP, Boresi AP (1990) Strain rate dependent mechanical properties of New Albany reference shale. Int J Rock Mech Min Sci Geomech Abstr 27(3):199-205. doi:10.1016/01489062(90)94328-q

Chong KP, Kuruppu MD (1984) New specimen for fracture toughness determination for rock and other materials. Int J Fract 26(2): R59-R62. doi:10.1007/bf01157555

Chong KP, Hoyt PM, Smith JW, Paulsen BY (1980) Effects of strain rate on oil shale fracturing. Int J Rock Mech Min Sci Geomech Abstr 17(1):35-43. doi:10.1016/0148-9062(80)90004-2

Christensen R, Swanson S, Brown W (1972) Split-Hopkinson-bar tests on rock under confining pressure. Exp Mech 12(11): 508-513. doi:10.1007/bf02320747

Costin LS (1981) Static and dynamic fracture behaviour of oil shale. In: Freiman SW, Fuller ER (eds) Fracture mechanics for ceramics, rock and concrete, ASTM STP 745, vol 745. American Society for Testing and Materials, USA, pp 169-184 
Cotsovos DM, Pavlovic MN (2008) Numerical investigation of concrete subjected to high rates of uniaxial tensile loading. Int J Impact Eng 35(5):319-335. doi:10.1016/j.ijimpeng.2007.03.006

Coviello A, Lagioia R, Nova R (2005) On the measurement of the tensile strength of soft rocks. Rock Mech Rock Eng 38(4): 251-273. doi:10.1007/s00603-005-0054-7

Curbach M, Eibl J (1990) Crack velocity in concrete. Eng Fract Mech 35(1-3):321-326. doi:10.1016/0013-7944(90)90210-8

Dai F, Xia K (2010) Loading rate dependence of tensile strength anisotropy of Barre granite. Pure Appl Geophys 167(11): 1419-1432. doi:10.1007/s00024-010-0103-3

Dai F, Xia KW (2013) Laboratory measurements of the rate dependence of the fracture toughness anisotropy of Barre granite. Int J Rock Mech Min 60:57-65. doi:10.1016/j.ijrmms. 2012.12.035

Dai F, Xia K, Luo SN (2008) Semicircular bend testing with split Hopkinson pressure bar for measuring dynamic tensile strength of brittle solids. Rev Sci Instrum 79(12):123903-123906. doi:10. 1063/1.3043420

Dai F, Chen R, Iqbal MJ, Xia K (2010a) Dynamic cracked chevron notched Brazilian disc method for measuring rock fracture parameters. Int J Rock Mech Min 47(4):606-613. doi:10.1016/j. ijrmms.2010.04.002

Dai F, Chen R, Xia K (2010b) A semi-circular bend technique for determining dynamic fracture toughness. Exp Mech 50(6): 783-791. doi:10.1007/s11340-009-9273-2

Dai F, Xia K, Tang L (2010c) Rate dependence of the flexural tensile strength of Laurentian granite. Int J Rock Mech Min 47(3): 469-475. doi:10.1016/j.ijrmms.2009.05.001

Dai F, Huang S, Xia K, Tan Z (2010c) Some fundamental issues in dynamic compression and tension tests of rocks using split Hopkinson pressure bar. Rock Mech Rock Eng 43(6):657-666. doi:10.1007/s00603-010-0091-8

Dai F, Xia K, Zheng H, Wang YX (2011) Determination of dynamic rock mode-I fracture parameters using cracked chevron notched semi-circular bend specimen. Eng Fract Mech 78(15): 2633-2644. doi:10.1016/j.engfracmech.2011.06.022

Dai F, Xia K, Zuo JP, Zhang R, Xu NW (2013) Static and dynamic flexural strength anisotropy of Barre granite. Rock Mech Rock Eng. doi:10.1007/s00603-013-0390-y

Daniel IM, Rowlands RE (1975) On wave and fracture propagation in rock media. Exp Mech 15(12):449-457. doi:10.1007/bf0231 8359

Davies EDH, Hunter SC (1963) The dynamic compression testing of solids by the method of the split Hopkinson pressure bar. J Mech Phys Solids 11(3):155-179. doi:10.1016/0022-5096(63)9005 $0-4$

Deganis LE, Zuo QH (2011) Crack-mechanics based brittle damage model including nonlinear equation of state and porosity growth. J Appl Phys 109(7):073504-073511. doi:10.1063/1.3562140

Deng H, Nemat-Nasser S (1992) Dynamic damage evolution in brittle solids. Mech Mater 14(2):83-103. doi:10.1016/0167-6636(92) 90008-2

Deshpande VS, Evans AG (2008) Inelastic deformation and energy dissipation in ceramics: a mechanism-based constitutive model. J Mech Phys Solids 56(10):3077-3100. doi:10.1016/j.jmps.2008. 05.002

Deshpande VS, Gamble EAN, Compton BG, McMeeking RM, Evans AG, Zok FW (2011) A constitutive description of the inelastic response of ceramics. J Am Ceram Soc 94:S204-S214. doi:10. 1111/j.1551-2916.2011.04516.x

Desmorat R, Chambart M, Gatuingt F, Guilbaud D (2010) Delayactive damage versus non-local enhancement for anisotropic damage dynamics computations with alternated loading. Eng Fract Mech 77(12):2294-2315. doi:10.1016/j.engfracmech.2010. 04.006
Dienes JK (1985) A statistical theory of fragmentation processes. Mech Mater 4(3-4):325-335. doi:10.1016/0167-6636(85)90030-4

Doan M-L, Billi A (2011) High strain rate damage of Carrara marble. Geophys Res Lett 38(19):L19302. doi:10.1029/2011g1049169

Doan M-L, Gary G (2009) Rock pulverization at high strain rate near the San Andreas fault. Nat Geosci 2(10):709-712. doi:10.1038/ ngeo640

Dong S, Wang Y, Xia Y (2004) Stress intensity factors for central cracked circular disk subjected to compression. Eng Fract Mech 71(7-8):1135-1148. doi:10.1016/s0013-7944(03)00120-6

Dong S, Wang Y, Xia Y (2006) A finite element analysis for using Brazilian disk in split Hopkinson pressure bar to investigate dynamic fracture behavior of brittle polymer materials. Polym Test 25(7):943-952. doi:10.1016/j.polymertesting.2006.06.003

Dubé JF, Pijaudier-Cabot G, La Borderie C (1996) Rate dependent damage model for concrete in dynamics. J Eng Mater-T ASME 122(10):939-947. doi:10.1061/(ASCE)0733-9399(1996)122: $10(939$

Dumont D, Deschamps A, Brechet Y (2004) A model for predicting fracture mode and toughness in 7000 series aluminium alloys. Acta Mater 52(9):2529-2540. doi:10.1016/j.actamat.2004.01.044

Dutta PK, Kim K (1993) High-strain-rate tensile behavior of sedimentary and igneous rocks at low temperatures. U.S. Army Corps of Engineers, Cold Regions Research \& Engineering Laboratory

Ehrgott JQ, Sloan RC (1971) Development of a dynamic highpressure triaxial test device. U.S. Army Engineer Waterways Experiment Station, Vicksburg

Ellwood S, Griffiths LJ, Parry DJ (1982) Materials testing at high constant strain rates. J Phys E Sci Instrum 15(3):280. doi:10. 1088/0022-3735/15/3/009

Erzar B, Forquin P (2010) An experimental method to determine the tensile strength of concrete at high rates of strain. Exp Mech 50(7):941-955. doi:10.1007/s11340-009-9284-z

Fahrenthold EP (1991) A continuum damage model for fracture of brittle solids under dynamic loading. J Appl Mech 58(4):904-909. doi:10.1115/1.2897704

Fairhurst CE, Hudson JA (1999) Draft ISRM suggested method for the complete stress-strain curve for intact rock in uniaxial compression. Int J Rock Mech Min 36(3):279-289. doi:10.1016/ s0148-9062(99)00006-6

Fang Q, Ruan Z, Zhai C, Jiang X, Chen L, Fang W (2012) Split Hopkinson pressure bar test and numerical analysis of salt rock under confining pressure and temperature. Chin J Rock Mech Eng 31(9):1756-1765

Field JE, Walley SM, Proud WG, Goldrein HT, Siviour CR (2004) Review of experimental techniques for high rate deformation and shock studies. Int J Impact Eng 30(7):725-775. doi:10.1016/ j.ijimpeng.2004.03.005

Fischer MP, Elsworth D, Alleyamp RB, Engelder T (1996) Finite element analysis of the modified ring test for determining mode I fracture toughness. Int J Rock Mech Min 33(5):1-15. doi:10. 1016/0148-9062(96)89926-8

Follansbee PS, Frantz C (1983) Wave propagation in the split Hopkinson pressure bar. J Eng Mater-T ASME 105(1):61-66. doi:10.1115/1.3225620

Forquin P (2012) An optical correlation technique for characterizing the crack velocity in concrete. Eur Phys J Spec Top 206:89-95. doi:10.1140/epjst/e2012-01590-6

Forquin P, Gary G, Gatuingt F (2008) A testing technique for concrete under confinement at high rates of strain. Int J Impact Eng 35(6):425-446. doi:10.1016/j.ijimpeng.2007.04.007

Forrestal MJ, Wright TW, Chen W (2007) The effect of radial inertia on brittle samples during the split Hopkinson pressure bar test. Int J Impact Eng 34(3):405-411. doi:10.1016/j.ijimpeng.2005. 12.001 
Foster JT (2012) Comments on the validity of test conditions for Kolsky bar testing of elastic-brittle materials. Exp Mech 52(9):1559-1563. doi:10.1007/s11340-012-9592-6

Fowell RJ (1995) Suggested method for determining mode I fracture toughness using cracked chevron notched Brazilian disc (CCNBD) specimens. Int J Rock Mech Min 32(1):57-64. doi:10.1016/0148-9062(94)00015-u

Frew D, Forrestal M, Chen W (2001) A split Hopkinson pressure bar technique to determine compressive stress-strain data for rock materials. Exp Mech 41(1):40-46. doi:10.1007/bf02323102

Frew D, Forrestal M, Chen W (2002) Pulse shaping techniques for testing brittle materials with a split Hopkinson pressure bar. Exp Mech 42(1):93-106. doi:10.1007/bf02411056

Frew DJ, Akers SA, Chen W, Green ML (2010) Development of a dynamic triaxial Kolsky bar. Meas Sci Technol 21(10):105704. doi:10.1088/0957-0233/21/10/105704

Friedman M, Logan JM (1973) Lüders' bands in experimentally deformed sandstone and limestone. Geol Soc Am Bull 84(4):1465-1476. doi:10.1130/0016-7606(1973)84<1465: lbieds $>2.0 . c o ; 2$

Friedman M, Perkins RD, Green SJ (1970) Observation of brittledeformation features at the maximum stress of Westerly granite and Solnhofen limestone. Int J Rock Mech Min Sci Geomech Abstr 7(3):297-302. doi:10.1016/0148-9062(70)90043-4

Fu HC, Erki MA, Seckin M (1991) Review of effects of loading rate on concrete in compression. J Struct Eng 117(12):3645-3659. doi:10.1061/(asce)0733-9445(1991)117:12(3645)

Fukui K, Okubo S, Ogawa A (2004) Some aspects of loading-rate dependency of Sanjome andesite strengths. Int J Rock Mech Min 41(7):1215-1219. doi:10.1016/j.ijrmms.2004.06.001

Gálvez F, Rodríguez J, Sánchez V (2002) The spalling of long bars as a reliable method of measuring the dynamic tensile strength of ceramics. Int J Impact Eng 27(2):161-177. doi:10.1016/S0734$743 \mathrm{X}(01) 00039-2$

Gama BA, Lopatnikov SL, Gillespie JW (2004) Hopkinson bar experimental technique: a critical review. Appl Mech Rev 57(4):223-250. doi:10.1115/1.1704626

Gary G, Bailly P (1998) Behaviour of quasi-brittle material at high strain rate. Experiment and modelling. Eur J Mech A Solids 17(3):403-420. doi:10.1016/s0997-7538(98)80052-1

Gerlach R, Sathianathan SK, Siviour C, Petrinic N (2011) A novel method for pulse shaping of split Hopkinson tensile bar signals. Int J Impact Eng 38(12):976-980. doi:10.1016/j.ijimpeng.2011. 08.007

Gilat A (2000) Torsional Kolsky bar testing. ASM handbook, mechanical testing and evaluation. ASM International, Materials Park OH 8:505-515

Gilat A, Matrka TA (2011) A new compression intermediate strain rate testing apparatus. In: Proulx $\mathrm{T}$ (ed) The Society for Experimental Mechanics series, dynamic behavior of materials. Springer, New York, pp 425-429. doi:10.1007/978-1-44198228-5_64

Gilat A, Schmidt T, Walker A (2009) Full field strain measurement in compression and tensile split Hopkinson bar experiments. Exp Mech 49(2):291-302. doi:10.1007/s11340-008-9157-x

Glenn LA, Jaun H (1978) Crack propagation in rock plates loaded by projectile impact. Exp Mech 18(1):35-40. doi:10.1007/ bf02326555

Goldsmith W, Sackman JL, Ewerts C (1976) Static and dynamic fracture strength of Barre granite. Int J Rock Mech Min Sci Geomech Abstr 13(11):303-309. doi:10.1016/0148-9062(76) 91829-5

Gomez JT, Shukla A, Sharma A (2001) Static and dynamic behavior of concrete and granite in tension with damage. Theor Appl Fract Mech 36(1):37-49. doi:10.1016/s0167-8442(01)00054-4
Gomez JT, Shukla A, Sharma A (2002) Photoelastic evaluation of stress fields and fracture during dynamic splitting experiments. J Test Eval 30(3):186-196. doi:10.1520/JTE12306J

Gong J, Malvern L (1990) Passively confined tests of axial dynamic compressive strength of concrete. Exp Mech 30(1):55-59. doi:10.1007/bf02322703

Gong JC, Malvern LE, Jenkins DA (1990) Dispersion investigation in the split Hopkinson pressure bar. J Eng Mater-T ASME 112(3):309-314. doi:10.1115/1.2903329

Gorham DA (1983) A numerical method for the correction of dispersion in pressure bar signals. Phys E Sci Instrum 16(6):477. doi:10.1088/0022-3735/16/6/008

Gorham DA (1989) Specimen inertia in high strain-rate compression. J Phys D Appl Phys 22(12):1888. doi:10.1088/0022-3727/22/12/ 014

Gorham DA, Pope PH, Field JE (1992) An improved method for compressive stress-strain measurements at very high strain rates. Proc R Soc Lond A 438(1902):153-170. doi:10.1098/rspa.1992. 0099

Grady DE (1982) Local inertial effects in dynamic fragmentation. J Appl Phys 53(1):322-325. doi:10.1063/1.329934

Grady DE, Kipp ME (1987) Dynamic rock fragmentation. In: Atkinson BK (ed) Fracture mechanics of rock. Academic, London, pp 429-475

Grady DE, Lipkin J (1980) Criteria for impulsive rock fracture. Geophys Res Lett 7(4):255. doi:10.1029/GL007i004p00255

Gran J, Florence A, Colton J (1989) Dynamic triaxial tests of highstrength concrete. J Eng Mech 115(5):891-904. doi:10.1061/ (ASCE)0733-9399(1989)115:5(891

Grantham SG, Siviour CR, Proud WG, Field JE (2004) High-strain rate Brazilian testing of an explosive simulant using speckle metrology. Meas Sci Technol 15(9):1867. doi:10.1088/09570233/15/9/025

Gray GT III (2000) Classic split Hopkinson pressure bar testing. ASM handbook, mechanical testing and evaluation. ASM International, Materials Park OH 8:462-476

Green SJ, Perkins RD (1968) Uniaxial compression tests at varying strain rates on three geologic materials. The 10th U.S. Symposium on Rock Mechanics (USRMS), Austin, TX

Green S, Leasia J, Perkins R, Jones A (1972) Triaxial stress behavior of Solnhofen limestone and Westerly granite at high strain rates. J Geophys Res 77(20):3711-3724. doi:10.1029/JB077i020 p03711

Hadraba H, Němec O, Dlouhy I (2008) Conversion of transgranular to intergranular fracture in $\mathrm{NiCr}$ steels. Eng Fract Mech 75(12):3677-3691. doi:10.1016/j.engfracmech.2007.08.006

Haimson B, Bobet A (2012) Introduction to suggested methods for failure criteria. Rock Mech Rock Eng 45(6):973-974. doi:10. 1007/s00603-012-0274-6

Hakalehto KO (1967) A study of the dynamic behaviour of rock using the Hopkinson split bar method. M.S., University of Minnesota, Minneapolis

Hakalehto KO (1969) The behaviour of rock under impulse loads: a study using the Hopkinson split bar method. Acta Polytech Scand, Chem Technol Ser 81:1-60

Hakalehto KO (1970) Brittle fracture of rocks under impulse loads. Int J Fract 6(3):249-256. doi:10.1007/bf00212655

Hao Y, Hao H (2013) Numerical investigation of the dynamic compressive behaviour of rock materials at high strain rate. Rock Mech Rock Eng 46(2):373-388. doi:10.1007/s00603-0120268-4

Hartley CS (2008) Materials science for the experimental mechanist. In: Sharpe WN (ed) Springer handbook of experimental solid mechanics. Springer, US, pp 17-48. doi:10.1007/978-0-38730877-7_2 
Hartley RS, Cloete TJ, Nurick GN (2007) An experimental assessment of friction effects in the split Hopkinson pressure bar using the ring compression test. Int J Impact Eng 34(10):1705-1728. doi:10.1016/j.ijimpeng.2006.09.003

Hauser F (1966) Techniques for measuring stress-strain relations at high strain rates. Exp Mech 6(8):395-402. doi:10.1007/ bf02326284

Heard HC (1963) Effect of large changes in strain rate in the experimental deformation of Yule marble. J Geol 71(2): 162-195. doi:10.1086/626892

Hogan JD, Rogers RJ, Spray JG, Boonsue S (2012) Dynamic fragmentation of granite for impact energies of 6-28 J. Eng Fract Mech 79:103-125. doi:10.1016/j.engfracmech.2011.10.006

Holloway DC, Patacca AM, Fourney WL (1977) Application of holographic interferometry to a study of wave propagation in rock. Exp Mech 17(8):281-289. doi:10.1007/bf02324957

Hong L, Zhou Z, Yin T, Liao G, Ye Z (2009) Energy consumption in rock fragmentation at intermediate strain rate. J Cent South Univ Technol 16(4):677-682. doi:10.1007/s11771-009-0112-5

Howe S, Goldsmith W, Sackman J (1974) Macroscopic static and dynamic mechanical properties of Yule marble. Exp Mech 14(9):337-346. doi:10.1007/bf02323559

Hu G, Ramesh KT, Cao B, McCauley JW (2011) The compressive failure of aluminium nitride considered as a model advanced ceramic. J Mech Phys Solids 59(5):1076-1093. doi:10.1016/j. jmps.2011.02.003

Huang C, Subhash G (2003) Influence of lateral confinement on dynamic damage evolution during uniaxial compressive response of brittle solids. J Mech Phys Solids 51(6): 1089-1105. doi:10.1016/s0022-5096(03)00002-4

Huang C, Subhash G, Vitton SJ (2002) A dynamic damage growth model for uniaxial compressive response of rock aggregates. Mech Mater 34(5):267-277. doi:10.1016/s0167-6636(02)00112-6

Huang S, Chen R, Xia KW (2010a) Quantification of dynamic tensile parameters of rocks using a modified Kolsky tension bar apparatus. J Rock Mech Geotech Eng 2:162-168. doi:10.3724/ SP.J.1235.2010.00162

Huang S, Xia K, Yan F, Feng X (2010b) An experimental study of the rate dependence of tensile strength softening of Longyou sandstone. Rock Mech Rock Eng 43(6):677-683. doi:10.1007/ s00603-010-0083-8

Huang S, Feng XT, Xia K (2011a) A dynamic punch method to quantify the dynamic shear strength of brittle solids. Rev Sci Instrum 82(5):053901-053905. doi:10.1063/1.3585983

Huang S, Luo SN, Tatone B, Xia K (2011b) Dynamic fracture tests of PMMA using a dynamic semi-circular bend technique. J Mech Mater Struct 6(6):813-836. doi:10.2140/jomms.2011.6.813

Huang S, Xia K, Dai F (2012) Establishment of a dynamic MohrCoulomb failure criterion for rocks. Int $\mathrm{J}$ Nonlin Sci Numer Simul 13(1):55-60. doi:10.1515/ijnsns.2011.120

Hughes ML, Tedesco JW, Ross CA (1993) Numerical analysis of high strain rate splitting-tensile tests. Comput Struct 47(4-5):653-671. doi:10.1016/0045-7949(93)90349-i

Islam MT, Bindiganavile V (2012) Stress rate sensitivity of Paskapoo sandstone under flexure. Can J Civ Eng 39(11):1184-1192. doi:10.1139/12012-101

ISRM (1978) Suggested methods for determining tensile strength of rock materials. Int $\mathrm{J}$ Rock Mech Min Sci Geomech Abstr 15(3):99-103. doi:10.1016/0148-9062(78)90003-7

ISRM (1979) Suggested methods for determining the uniaxial compressive strength and deformability of rock materials. Int $\mathrm{J}$ Rock Mech Min Sci Geomech Abstr 16(2):135-140. doi:10. 1016/0148-9062(79)91451-7

ISRM (1983) Suggested methods for determining the strength of rock materials in triaxial compression: revised version. Int $\mathrm{J}$ Rock
Mech Min Sci Geomech Abstr 20(6):285-290. doi:10.1016/ 0148-9062(83)90598-3

Iwamoto T, Yokoyama T (2012) Effects of radial inertia and end friction in specimen geometry in split Hopkinson pressure bar tests: a computational study. Mech Mater 51:97-109. doi:10. 1016/j.mechmat.2012.04.007

Jaeger JC (1967) Failure of rocks under tensile conditions. J Rock Mech Min Sci Geomech Abst 4(2):219-227. doi:10.1016/01489062(67)90046-0

Janach W (1976) The role of bulking in brittle failure of rocks under rapid compression. Int J Rock Mech Min Sci Geomech Abstr 13(6):177-186. doi:10.1016/0148-9062(76)91284-5

Jia D, Ramesh K (2004) A rigorous assessment of the benefits of miniaturization in the Kolsky bar system. Exp Mech 44(5):445-454. doi:10.1007/bf02427955

Jiang F, Vecchio KS (2009) Hopkinson bar loaded fracture experimental technique: a critical review of dynamic fracture toughness tests. Appl Mech Rev 62(6):060802-060839. doi:10.1115/1. 3124647

Jin JF, Li XB, Wang GS, Yin ZQ (2012) Failure modes and mechanisms of sandstone under cyclic impact loadings. J Cent South Univ Technol 43(4):1453-1461

Johnson GR, Holmquist TJ (1992) A computational constitutive model for brittle materials subjected to large strains, high strain rates and high pressures. In: Meyers MA, Murr LE, Staudhammer KP (eds) Shock-wave and high strain-rate phenomena in materials. Marcel-Dekker, New York, pp 1075-1081

Johnson GR, Holmquist TJ (1994) An improved computational constitutive model for brittle materials. AIP Conf Proc 309(1):981-984. doi:10.1063/1.46199

Johnstone C, Ruiz C (1995) Dynamic testing of ceramics under tensile stress. Int J Solids Struct 32(17-18):2647-2656. doi:10. 1016/0020-7683(94)00287-7

Ju JW (1989) On energy-based coupled elastoplastic damage theories: constitutive modeling and computational aspects. Int J Solids Struct 25(7):803-833. doi:10.1016/0020-7683(89)90015-2

Ju Y, Sudak L, Xie H (2007) Study on stress wave propagation in fractured rocks with fractal joint surfaces. Int J Solids Struct 44(13):4256-4271. doi:10.1016/j.ijsolstr.2006.11.015

Kachanov LM (1958) Time of the rupture process under creep conditions. Izv Akad Nauk SSSR, Otd Tekh Nauk 8:26-31

Kalthoff JF (1985) On the measurement of dynamic fracture toughnesses: a review of recent work. Int $\mathrm{J}$ Fract 27(3):277-298. doi:10.1007/bf00017973

Kazerani T, Zhao J (2010) Micromechanical parameters in bonded particle method for modelling of brittle material failure. Int $\mathrm{J}$ Numer Anal Meth Geomech 34(18):1877-1895. doi:10.1002/ nag. 884

Khan AS, Irani FK (1987) An experimental study of stress wave transmission at a metallic-rock interface and dynamic tensile failure of sandstone, limestone, and granite. Mech Mater 6(4):285-292. doi:10.1016/0167-6636(87)90027-5

Khokhlov M, Fischer A, Rittel D (2012) Multi-scale stereo-photogrammetry system for fractographic analysis using scanning electron microscopy. Exp Mech 52(8):975-991. doi:10.1007/ s11340-011-9582-0

Kimberley J, Ramesh KT (2011) The dynamic strength of an ordinary chondrite. Meteor Planet Sci 46(11):1653-1669. doi:10.1111/j. 1945-5100.2011.01254.x

Klepaczko JR (1990) Behavior of rock-like materials at high strain rates in compression. Int $\mathrm{J}$ Plast 6(4):415-432. doi:10.1016/ 0749-6419(90)90011-3

Klepaczko JR, Brara A (2001) An experimental method for dynamic tensile testing of concrete by spalling. Int $\mathrm{J}$ Impact Eng 25(4):387-409. doi:10.1016/s0734-743x(00)00050-6 
Klepaczko JR, Bassim MN, Hsu TR (1984) Fracture toughness of coal under quasi-static and impact loading. Eng Fract Mech 19(2):305-316. doi:10.1016/0013-7944(84)90025-0

Kolsky H (1949) An investigation of the mechanical properties of materials at very high rates of loading. Proc Phys Soc B 62(11):676. doi:10.1088/0370-1301/62/11/302

Kraft RH, Molinari JF (2008) A statistical investigation of the effects of grain boundary properties on transgranular fracture. Acta Mater 56(17):4739-4749. doi:10.1016/j.actamat.2008.05.036

Kubota S, Ogata Y, Wada Y, Simangunsong G, Shimada H, Matsui K (2008) Estimation of dynamic tensile strength of sandstone. Int J Rock Mech Min 45(3):397-406. doi:10.1016/j.ijrmms.2007.07. 003

Kuhn H, Medlin D (2000) High strain rate testing. ASM handbook, mechanical testing and evaluation. ASM International, Materials Park OH 8:427-559

Kumar A (1968) The effect of stress rate and temperature on the strength of basalt and granite. Geophysics 33(3):501-510. doi:10.1190/1.1439947

Kuruppu MD (1997) Fracture toughness measurement using chevron notched semi-circular bend specimen. Int J Fract 86(4):L33-L38

Kuruppu MD, Obara Y, Ayatollahi MR, Chong KP, Funatsu T (2013) ISRM-Suggested method for determining the mode I static fracture toughness using semi-circular bend specimen. Rock Mech Rock Eng. doi:10.1007/s00603-013-0422-7

Lagunov VA, Mambetov SA (1965) The rate of growth of cracks in rock specimens. J Appl Mech Tech Phys 6(6):64-66. doi:10. 1007/bf00919315

Lambert DE, Ross AC (2000) Strain rate effects on dynamic fracture and strength. Int J Impact Eng 24(10):985-998. doi:10.1016/ s0734-743x (00)00027-0

Lankford JJ (1976) Dynamic strength of oil shale. Soc Petrol Eng J $16(1): 17-22$

Lankford J (1981) The role of tensile microfracture in the strain rate dependence of compressive strength of fine-grained limestone-analogy with strong ceramics. Int J Rock Mech Min Sci Geomech Abstr 18:173-175. doi:10.1016/0148-9062(81) 90742-7

Li QM, Meng H (2003) About the dynamic strength enhancement of concrete-like materials in a split Hopkinson pressure bar test. Int J Solids Struct 40(2):343-360. doi:10.1016/s0020-7683(02) 00526-7

Li Y, Ramesh KT (2007) An optical technique for measurement of material properties in the tension Kolsky bar. Int J Impact Eng 34(4):784-798. doi:10.1016/j.ijimpeng.2005.12.002

Li XB, Lai HH, Gu DS (1993) Energy absorption of rock fragmentation under impulsive loads with different wave forms. Trans Nonferr Metal Soc 3(1):1-5-9

Li HB, Zhao J, Li TJ (1999) Triaxial compression tests on a granite at different strain rates and confining pressures. Int J Rock Mech Min 36(8):1057-1063. doi:10.1016/s1365-1609(99)00120-3

Li HB, Zhao J, Li TJ (2000a) Micromechanical modelling of the mechanical properties of a granite under dynamic uniaxial compressive loads. Int J Rock Mech Min 37(6):923-935. doi:10. 1016/s1365-1609(00)00025-3

Li XB, Lok TS, Zhao J, Zhao PJ (2000b) Oscillation elimination in the Hopkinson bar apparatus and resultant complete dynamic stress-strain curves for rocks. Int $J$ Rock Mech Min 37(7):1055-1060. doi:10.1016/s1365-1609(00)00037-x

Li HB, Zhao J, Li TJ, Yuan JX (2001) Analytical simulation of the dynamic compressive strength of a granite using the sliding crack model. Int J Numer Anal Meth Geomech 25(9):853-869. doi:10.1002/nag. 156

Li XB, Lok TS, Zhao J (2005) Dynamic characteristics of granite subjected to intermediate loading rate. Rock Mech Rock Eng 38(1):21-39. doi:10.1007/s00603-004-0030-7
Li XB, Hong L, Yin TB, Zhou ZL, Ye ZY (2008a) Relationship between diameter of split Hopkinson pressure bar and minimum loading rate under rock failure. J Cent South Univ Technol 15(2):218-223. doi:10.1007/s11771-008-0042-7

Li XB, Zhou ZL, Lok TS, Hong L, Yin TB (2008b) Innovative testing technique of rock subjected to coupled static and dynamic loads. Int J Rock Mech Min 45(5):739-748. doi:10.1016/j.ijrmms. 2007.08.013

Li QM, Lu YB, Meng H (2009) Further investigation on the dynamic compressive strength enhancement of concrete-like materials based on split Hopkinson pressure bar tests. Part II: numerical simulations. Int J Impact Eng 36(12):1335-1345. doi:10.1016/j. ijimpeng.2009.04.010

Li JC, Ma GW, Huang X (2010a) Analysis of wave propagation through a filled rock joint. Rock Mech Rock Eng 43(6):789-798. doi:10.1007/s00603-009-0033-5

Li XB, Yin TB, Zhou ZL, Hong L, Gao K (2010b) Study of dynamic properties of siltstone under coupling effects of temperature and pressure. Chin J Rock Mech Eng 29(12):2377-2384

Li HB, Li JC, Liu B, Li J, Li S, Xia X (2013) Direct tension test for rock material under different strain rates at quasi-static loads. Rock Mech Rock Eng (in press). doi:10.1007/s00603-0130406-7

Liang R, Khan AS (1999) A critical review of experimental results and constitutive models for BCC and FCC metals over a wide range of strain rates and temperatures. Int J Plast 15(9):963-980. doi:10.1016/s0749-6419(99)00021-2

Lindholm US (ed) (1971) High strain rate tests, techniques of metals research, measurement of mechanical properties, vol 5. Wiley Interscience, New York

Lindholm US (1974) Review of dynamic testing techniques and material behaviour In: Harding $J$ (ed) The 1st Conference on Mechanical Properties of Materials at High Rates of Strain, Oxford, pp 3-21

Lindholm U, Yeakley L (1968) High strain-rate testing: tension and compression. Exp Mech 8(1):1-9. doi:10.1007/bf02326244

Lindholm US, Yeakley LM, Nagy A (1974) The dynamic strength and fracture properties of Dresser basalt. Int J Rock Mech Min Sci Geomech Abstr 11(5):181-191. doi:10.1016/01489062(74)90885-7

Lipkin J, Grady DE, Campbell JD (1977) Dynamic flow and fracture of rock in pure shear. The 18th U.S. Symposium on Rock Mechanics (USRMS), Keystone, pp 77-0180

Lipkin J, Schuler KW, Parry T (1979) Dynamic torsional failure of limestone tubes. In: Harding $\mathrm{J}$ (ed) The 2nd conference on mechanical properties of materials at high rates of strain, Oxford, pp 101-110

Liu S, Xu J (2013) Study on dynamic characteristics of marble under impact loading and high temperature. Int $\mathrm{J}$ Rock Mech Min 62:51-58. doi:10.1016/j.ijrmms.2013.03.014

Liu CP, Ju Y, Duan QQ (2010) Influence of internal characteristic length scale on dynamic crack propagating mechanism in rock materials. Rock Soil Mech 31(Suppl. 1):91-95

Logan JM, Handin J (1970) Triaxial compression testing at intermediate strain rates. The 12th U.S. Symposium on Rock Mechanics (USRMS), Missouri, pp 70-0167

Long QY, Li S, Lung CW (1991) Studies on the fractal dimension of a fracture surface formed by slow stable crack propagation. J Phys D Appl Phys 24(4):602. doi:10.1088/0022-3727/24/4/011

Lou W (1994) Dynamic fracture behaviour of dry and waterlogged granites. Explo Shock Waves 14(3):249-254

Lu YB, Li QM (2011) About the dynamic uniaxial tensile strength of concrete-like materials. Int J Impact Eng 38(4):171-180. doi:10. 1016/j.ijimpeng.2010.10.028

Lu YB, Li QM, Ma GW (2010) Numerical investigation of the dynamic compressive strength of rocks based on split Hopkinson 
pressure bar tests. Int J Rock Mech Min 47(5):829-838. doi:10. 1016/j.ijrmms.2010.03.013

Lundberg B (1976) A split Hopkinson bar study of energy absorption in dynamic rock fragmentation. Int $\mathrm{J}$ Rock Mech Min Sci Geomech Abstr 13(6):187-197. doi:10.1016/0148-9062(76) 91285-7

Lyakhovsky V, Hamiel Y, Ben-Zion Y (2011) A non-local viscoelastic damage model and dynamic fracturing. J Mech Phys Solids 59(9):1752-1776. doi:10.1016/j.jmps.2011.05.016

Ma GW, An XM (2008) Numerical simulation of blasting-induced rock fractures. Int J Rock Mech Min 45(6):966-975. doi:10. 1016/j.ijrmms.2007.12.002

Malvar LJ, Ross CA (1998) Review of strain rate effects for concrete in tension. ACI Mater J 95(6):735-739

Malvern LE (1984) Experimental and theoretical approaches to characterisation of material behaviour at high rates of deformation. In: Harding $\mathbf{J}$ (ed) The 3rd Conference on Mechanical Properties of Materials at High Rates of Strain, Oxford, pp 1-20

Malvern LE, Jenkens DA (1990) Dynamic testing of laterally confined concrete, technical report. Tyndall Air Force Base, Florida

Malvern LE, Jenkinds DA, Tang T, McLure S (1991) Dynamic testing of laterally confined concrete. Micromechanics of failure of quasi brittle materials. Elsevier Applied Science, London

Masuda K, Mizutani H, Yamada I (1987) Experimental study of strain-rate dependence and pressure dependence of failure properties of granite. J Phys Earth 35:37-66

Meyers MA (1994) Dynamic behavior of materials. Wiley, New York

Mohr D, Gary G, Lundberg B (2010) Evaluation of stress-strain curve estimates in dynamic experiments. Int $\mathrm{J}$ Impact Eng 37(2):161-169. doi:10.1016/j.ijimpeng.2009.09.007

Morozov NF, Petrov YV (2000) Dynamics of fracture. SpringerVerlag, New York

Nakano M, Kishida K, Yamauchi Y, Sogabe Y (1994) Dynamic fracture initiation in brittle materials under combined mode I/II loading. J Phys IV Fr 4(C8):695-700. doi:10.1051/jp4:19948106

Nasseri MHB, Mohanty B (2008) Fracture toughness anisotropy in granitic rocks. Int J Rock Mech Min 45(2):167-193. doi:10. 1016/j.ijrmms.2007.04.005

Nemat-Nasser S (2000) Introduction to high strain rate testing. ASM handbook, mechanical testing and evaluation. ASM International, Materials Park OH 8:427-428

Nemat-Nasser S, Deng H (1994) Strain-rate effect on brittle failure in compression. Acta Metall Mater 42(3):1013-1024. doi:10.1016/ 0956-7151(94)90295-x

Nemat-Nasser S, Horii H (1982) Compression-induced nonplanar crack extension with application to splitting, exfoliation, and rockburst. J Geophys Res 87(B8):6805-6821. doi:10.1029/ JB087iB08p06805

Nemat-Nasser S, Jon BI, Starrett JE (1991) Hopkinson techniques for dynamic recovery experiments. Proc R Soc Lond A 435(1894): 371-391. doi:10.1098/rspa.1991.0150

Nemat-Nasser S, Isaacs J, Rome J (2000) Triaxial Hopkinson techniques. ASM handbook, mechanical testing and evaluation. ASM International, Materials Park OH 8:516-518

Nicholas T (1982) Material behavior at high strain rates. In: Zukas JA, Nicholas T, Swift HF, Greszczuk LB, Curran DR (eds) Impact dynamics. Wiley, New York, pp 277-332

Nojima T, Ogawa K (1989) Impact strength of ceramics at high temperatures. In: Harding J (ed) The 4th International Conference on the Mechanical Properties of Materials at High Rates of Strain, Oxford, pp 371-378

Ogata Y, Jung WJ, Kubota S, Wada Y (2004) Effect of the strain rate and water saturation for the dynamic tensile strength of rocks. Forum Mater Sci 465-466:361-366. doi:10.4028/www. scientific.net/MSF.465-466.361
Olsson WA (1991) The compressive strength of tuff as a function of strain rate from $10^{-6}$ to $10^{3} / \mathrm{sec}$. Int J Rock Mech Min Sci Geomech Abstr 28(1):115-118. doi:10.1016/0148-9062(91) 93241-w

Omidvar M, Iskander M, Bless S (2012) Stress-strain behavior of sand at high strain rates. Int J Impact Eng 49:192-213. doi:10. 1016/j.jimpeng.2012.03.004

Ou ZC, Duan ZP, Huang FL (2010) Analytical approach to the strain rate effect on the dynamic tensile strength of brittle materials. Int J Impact Eng 37(8):942-945. doi:10.1016/j.ijimpeng.2010.02.003

Ou ZC, Yan C, Duan ZP, Pi AG, Huang FL (2012) Dynamic behaviors of load-carrying capacity of brittle materials. Int $\mathrm{J}$ Impact Eng 42:59-65. doi:10.1016/j.ijimpeng.2011.11.002

Ouchterlony F (1988) Suggested methods for determining the fracture toughness of rock. Int J Rock Mech Min 25(2):71-96. doi:10. 1016/0148-9062(88)91871-2

Owen DM, Zhuang S, Rosakis AJ, Ravichandran G (1998) Experimental determination of dynamic crack initiation and propagation fracture toughness in thin aluminium sheets. Int $\mathbf{J}$ Fract 90(1):153-174. doi:10.1023/a:1007439301360

Ozbolt J, Sharma A, Reinhardt H-W (2011) Dynamic fracture of concrete-compact tension specimen. Int $\mathrm{J}$ Solids Struct 48(10):1534-1543. doi:10.1016/j.ijsolstr.2011.01.033

Paliwal B, Ramesh KT (2008) An interacting micro-crack damage model for failure of brittle materials under compression. J Mech Phys Solids 56(3):896-923. doi:10.1016/j.jmps.2007.06.012

Paliwal B, Ramesh KT, McCauley JW, Chen M (2008) Dynamic compressive failure of AlON under controlled planar confinement. J Am Ceram Soc 91(11):3619-3629. doi:10.1111/j.15512916.2008.02712.x

Pan Y, Chen W, Song B (2005) Upper limit of constant strain rates in a split Hopkinson pressure bar experiment with elastic specimens. Exp Mech 45(5):440-446. doi:10.1007/bf02427992

Paterson MS, Olgaard DL (2000) Rock deformation tests to large shear strains in torsion. J Struct Geol 22(9):1341-1358. doi:10. 1016/s0191-8141(00)00042-0

Paterson MS, Wong T-F (2005) Experimental rock deformation: The brittle field, 2nd edn. Springer-Verlag, Berlin

Pedersen RR, Simone A, Sluys LJ (2008) An analysis of dynamic fracture in concrete with a continuum visco-elastic visco-plastic damage model. Eng Fract Mech 75(13):3782-3805. doi:10.1016/ j.engfracmech.2008.02.004

Peirs J, Verleysen P, Van Paepegem W, Degrieck J (2011) Determining the stress-strain behaviour at large strains from high strain rate tensile and shear experiments. Int J Impact Eng 38(5):406-415. doi:10.1016/j.ijimpeng.2011.01.004

Pérez-Martín MJ, Erice B, Cendón DA, Gálvez F (2012) Spalling uniaxial strength of $\mathrm{Al}_{2} \mathrm{O}_{3}$ at high strain rates. Eur Phys $\mathrm{J}$ Spec Top 206(1):117-128. doi:10.1140/epjst/e2012-01593-3

Perkins RD, Green SJ (1968) High speed photography in dynamic materials testing. Rev Sci Instrum 39(8):1209-1210. doi:10. $1063 / 1.1683621$

Perkins RD, Green SJ, Friedman M (1970) Uniaxial stress behavior of porphyritic tonalite at strain rates to $10^{3} /$ second. Int J Rock Mech Min Sci Geomech Abstr 7(5):527-528, IN5-IN6, 529-535. doi:10.1016/0148-9062(70)90005-7

Persen LN (1975) Rock dynamics and geophysical exploration, vol 8. Developments in Geotechnical Engineering, Elsevier, New York

Petrov YV, Morozov NF (1994) On the modeling of fracture of brittle solids. J Appl Mech 61:710-712. doi:10.1115/1.2901518

Petrov YV, Utkin AA (1989) Dependence of the dynamic strength on loading rate. Mater Sci 25(2):153-156. doi:10.1007/bf00780499

Pierron F, Forquin P (2012) Ultra-high-speed full-field deformation measurements on concrete spalling specimens and stiffness identification with the virtual fields method. Strain 48(5):388 405. doi:10.1111/j.1475-1305.2012.00835.x 
Pierron F, Sutton M, Tiwari V (2011) Ultra high speed DIC and virtual fields method analysis of a three point bending impact test on an aluminium bar. Exp Mech 51(4):537-563. doi:10.1007/ s11340-010-9402-y

Powell CN (1979) Lateral inertia effects on rock failure in splitHopkinson-bar experiments. M.S., Colorado State University, Golden

Qi CZ, Wang MY, Qian QH (2009) Strain-rate effects on the strength and fragmentation size of rocks. Int J Impact Eng 36(12): 1355-1364. doi:10.1016/j.ijimpeng.2009.04.008

Rabotnov YN (1963) On the equations of state for creep. In: Progress in applied mechanics, the Prager anniversary volume. Macmillan, New York

Ragueneau F, Gatuingt F (2003) Inelastic behavior modelling of concrete in low and high strain rate dynamics. Comput Struct 81(12):1287-1299. doi:10.1016/S0045-7949(03)00043-9

Ramesh KT (2008) High rates and impact experiments. In: Sharpe WN (ed) Springer handbook of experimental solid mechanics. Springer, US, pp 929-960. doi:10.1007/978-0-387-30877-7_33

Ramesh KT, Narasimhan S (1996) Finite deformations and the dynamic measurement of radial strains in compression Kolsky bar experiments. Int J Solids Struct 33(25):3723-3738. doi:10. 1016/0020-7683(95)00206-5

Ravi-Chandar K (2004) Dynamic fracture. Elsevier Science, London

Ravi-Chandar K, Knauss WG (1984) An experimental investigation into dynamic fracture: I. Crack initiation and arrest. Int J Fract 25(4):247-262. doi:10.1007/bf00963460

Ravichandran G, Subhash G (1994) Critical appraisal of limiting strain rates for compression testing of ceramics in a split Hopkinson pressure bar. J Am Ceram Soc 77(1):263-267. doi:10.1111/j.1151-2916.1994.tb06987.x

Ravichandran G, Subhash G (1995) A micromechanical model for high strain rate behavior of ceramics. Int $\mathrm{J}$ Solids Struct 32(17-18):2627-2646. doi:10.1016/0020-7683(94)00286-6

Reinhardt HW, Weerheijm J (1991) Tensile fracture of concrete at high loading rates taking account of inertia and crack velocity effects. Int J Fract 51(1):31-42. doi:10.1007/bf00020851

Ren X, Li J (2013) A unified dynamic model for concrete considering viscoplasticity and rate-dependent damage. Int J Damage Mech 22(4):530-555. doi:10.1177/1056789512455968

Rittel D, Lee S, Ravichandran G (2002) A shear-compression specimen for large strain testing. Exp Mech 42(1):58-64. doi:10.1007/bf02411052

Rodríguez J, Navarro C, Sánchez V (1994) Splitting tests: an alternative to determine the dynamic tensile strength of ceramic materials. J Phys IV Fr 4(C8):101-106. doi:10.1051/jp4:1994815

Rome J, Isaacs J, Nemat-Nasser S (2004) Hopkinson techniques for dynamic triaxial compression tests. In: Gdoutos E (ed) Recent advances in experimental mechanics. Springer, The Netherlands, pp 3-12. doi:10.1007/0-306-48410-2_1

Rosakis AJ (1999) Explosion at the parthenon: can we pick up the pieces? Report No. CalCIT SM report 99-3. California Institute of Technology, Pasadena

Ross CA, Thompson PY, Tedesco JW (1989) Split-Hopkinson pressure-bar tests on concrete and mortar in tension and compression. ACI Mater J 86(5):475-481

Rossi P (1991) A physical phenomenon which can explain the mechanical behaviour of concrete under high strain rates. Mater Struct 24(6):422-424. doi:10.1007/bf02472015

Rossi P, Toutlemonde F (1996) Effect of loading rate on the tensile behaviour of concrete: description of the physical mechanisms. Mater Struct 29(2):116-118. doi:10.1007/bf02486201

Rossi P, Van Mier J, Toutlemonde F, Le Maou F, Boulay C (1994) Effect of loading rate on the strength of concrete subjected to uniaxial tension. Mater Struct 27(5):260-264. doi:10.1007/ bf02473042
Ruiz G, Ortiz M, Pandolfi A (2000) Three-dimensional finite-element simulation of the dynamic Brazilian tests on concrete cylinders. Int J Numer Meth Eng 48(7):963-994. doi:10.1002/(sici)10970207(20000710)48:7<963:aid-nme908>3.0.co;2-x

Saksala T (2010) Damage-viscoplastic consistency model with a parabolic cap for rocks with brittle and ductile behavior under low-velocity impact loading. Int J Numer Anal Meth Geomech 34(13):1362-1386. doi:10.1002/nag.868

Sato K, Kawakita M, Kinoshita S (1981) The dynamic fracture properties of rocks under confining pressure. Mem Fac Eng, Hokkaido Univ 15(4):467-478

Schardin H (1959) Velocity effects in fracture. In: Averbach BL, Felbeck DK, Thomas DA (eds) Fracture. Wiley, New York, pp 297-330

Schuler H, Mayrhofer C, Thoma K (2006) Spall experiments for the measurement of the tensile strength and fracture energy of concrete at high strain rates. Int J Impact Eng 32(10):1635-1650. doi:10.1016/j.ijimpeng.2005.01.010

Serdengecti S, Boozer GD (1961) The effects of strain rate and temperature on the behavior of rocks subjected to triaxial compression. The 4th U.S. Symposium on Rock Mechanics (USRMS), Pennsylvania, pp 83-97

Shan R, Jiang Y, Li B (2000) Obtaining dynamic complete stressstrain curves for rock using the split Hopkinson pressure bar technique. Int J Rock Mech Min 37(6):983-992. doi:10.1016/ s1365-1609(00)00031-9

Shi W, Wu Y, Wu L (2007) Quantitative analysis of the projectile impact on rock using infrared thermography. Int J Impact Eng 34(5):990-1002. doi:10.1016/j.ijimpeng.2006.03.002

Sierakowski RL (1997) Strain rate effects in composites. Appl Mech Rev 50(12):741-761. doi:10.1115/1.3101860

Silva C, Rosa P, Martins P (2009) An innovative electromagnetic compressive split Hopkinson bar. Int J Mech Mater Des 5(3):281-288. doi:10.1007/s10999-009-9101-y

Silva C, Rosa P, Martins P (2012) Electromagnetic cam driven compression testing equipment. Exp Mech 52(8):1211-1222. doi:10.1007/s11340-011-9576-y

Siviour CR, Grantham SG (2009) High resolution optical measurements of specimen deformation in the split Hopkinson pressure bar. Imag Sci J 57(6):333-343. doi:10.1179/174313109x454792

Siviour CR, Arthington MR, Wielewski E, Petrinic N (2012) Increasing data from high rate characterization experiments using optical reconstruction. AIP Conf Proc 1426(1):438-441. doi: $10.1063 / 1.3686312$

Smirnov V, Petrov Y, Bratov V (2012) Incubation time approach in rock fracture dynamics. Sci China, Ser G 55(1):78-85. doi:10. 1007/s11433-011-4579-3

Song B, Syn C, Grupido C, Chen W, Lu WY (2008) A long split Hopkinson pressure bar (LSHPB) for intermediate-rate characterization of soft materials. Exp Mech 48(6):809-815. doi:10. 1007/s11340-007-9095-z

Spray JG (2010) Frictional melting processes in planetary materials: from hypervelocity impact to earthquakes. Annu Rev Earth Planet Sci 38(1):221-254. doi:10.1146/annurev.earth.031208. 100045

Stacey TR (1980) A simple device for the direct shear-strength testing of intact rock. J S Afr Inst Min Metall 80(3):129-130

Steverding B, Lehnigk SH (1970) Response of cracks to impact. J Appl Phys 41(5):2096-2099. doi:10.1063/1.1659170

Stowe RL, Ainsworth DL (1968) Effect of rate of loading on strength and Young's modulus of elasticity of rock. The 10th U.S. Symposium on Rock Mechanics (USRMS), Austin, pp 3-34

Subhash G, Maiti S, Geubelle PH, Ghosh D (2008) Recent advances in dynamic indentation fracture, impact damage and fragmentation of ceramics. J Am Ceram Soc 91(9):2777-2791. doi:10. $1111 / j .1551-2916.2008 .02624 . x$ 
Sutton MA, Orteu J-J, Schreier H (2009) Image correlation for shape, motion and deformation measurements: basic concepts, theory and applications. Springer, New York

Swan G, Cook J, Bruce S, Meehan R (1989) Strain rate effects in Kimmeridge Bay shale. Int J Rock Mech Min Sci Geomech Abstr 26(2):135-149. doi:10.1016/0148-9062(89)90002-8

Sylven ET, Agarwal S, Briant CL, Cleveland RO (2004) High strain rate testing of kidney stones. J Mater Sci Mater Med 15(5):613-617. doi:10.1023/B:JMSM.0000026383.94515.a8

Tang C, Xu X (1990) A new method for measuring dynamic fracture toughness of rock. Eng Fract Mech 35(4-5):783-791. doi:10. 1016/0013-7944(90)90162-a

Taylor LM, Chen E-P, Kuszmaul JS (1986) Microcrack-induced damage accumulation in brittle rock under dynamic loading. Comput Meth Appl Mech Eng 55(3):301-320. doi:10.1016/ 0045-7825(86)90057-5

Tedesco JW, Ross CA (1998) Strain-rate-dependent constitutive equations for concrete. J Press Vess-T ASME 120(4):398-405. doi: $10.1115 / 1.2842350$

Tedesco JW, Ross CA, Brunair RM (1989) Numerical analysis of dynamic split cylinder tests. Comput Struct 32(3-4):609-624. doi:10.1016/0045-7949(89)90350-7

Toutlemonde F, Gary G (2009) Dynamic behavior of concrete: Experimental aspects. In: Mazars J, Millard A (eds) Dynamic behavior of concrete and seismic engineering. ISTE Ltd, London, pp 1-54. doi:10.1002/9780470611555.ch1

Tuler FR, Butcher BM (1968) A criterion for the time dependence of dynamic fracture. Int $\mathrm{J}$ Fract 4(4):431-437. doi:10.1007/ bf00186808

Ulusay R, Gokceoglu C, Sulukcu S (2001) Draft ISRM suggested method for determining block punch strength index (BPI). Int J Rock Mech Min 38(8):1113-1119. doi:10.1016/s1365-1609(01) 00078-8

Van de Ven M, Smit AF, Krans RL (1997) Possibilities of a semicircular bending test. The 8th International Conference on Asphalt Pavements, Seattle, pp 939-950

Walley SM (2010) Historical review of high strain rate and shock properties of ceramics relevant to their application in armour. Adv Appl Ceram 109(8):446-466. doi:10.1179/174367609x 422180

Wang S, Liu KX (2011) Experimental research on dynamic mechanical properties of PZT ceramic under hydrostatic pressure. Mater Sci Eng A 528(21):6463-6468. doi:10.1016/j.msea.2011.05.019

Wang EZ, Shrive NG (1995) Brittle fracture in compression: mechanisms, models and criteria. Eng Fract Mech 52(6): 1107-1126. doi:10.1016/0013-7944(95)00069-8

Wang Y, Tonon F (2011) Dynamic validation of a discrete element code in modeling rock fragmentation. Int $\mathrm{J}$ Rock Mech Min 48(4):535-545. doi:10.1016/j.ijrmms.2011.02.003

Wang WM, Sluys LJ, de Borst R (1997) Viscoplasticity for instabilities due to strain softening and strain-rate softening. Int J Numer Meth Eng 40(20):3839-3864. doi:10.1002/(SICI)10970207(19971030)40:20<3839::AID-NME245>3.0.CO;2-6

Wang QZ, Jia XM, Kou SQ, Zhang ZX, Lindqvist PA (2004) The flattened Brazilian disc specimen used for testing elastic modulus, tensile strength and fracture toughness of brittle rocks: analytical and numerical results. Int $J$ Rock Mech Min 41(2):245-253. doi:10.1016/s1365-1609(03)00093-5

Wang QZ, Li W, Song XL (2006) A method for testing dynamic tensile strength and elastic modulus of rock materials using SHPB. Pure Appl Geophys 163(5):1091-1100. doi:10.1007/ s00024-006-0056-8

Wang QZ, Li W, Xie HP (2009) Dynamic split tensile test of flattened Brazilian disc of rock with SHPB setup. Mech Mater 41(3):252-260. doi:10.1016/j.mechmat.2008.10.004
Wang B, Li X, Yin T, Ma C, Yin Z, Li Z (2010a) Split Hopkinson pressure bar (SHPB) experiments on dynamic strength of watersaturated sandstone. Chin J Rock Mech Eng 29(5):1003-1009

Wang LL, Zhou FH, Sun ZJ, Wang YZ, Shi SQ (2010b) Studies on rate-dependent macro-damage evolution of materials at high strain rates. Int J Damage Mech 19(7):805-820. doi:10.1177/ 1056789509359654

Wang QZ, Zhang S, Xie HP (2010c) Rock dynamic fracture toughness tested with holed-cracked flattened Brazilian discs diametrically impacted by SHPB and its size effect. Exp Mech 50(7):877-885. doi:10.1007/s11340-009-9265-2

Wang QZ, Feng F, Ni M, Gou XP (2011a) Measurement of mode I and mode II rock dynamic fracture toughness with cracked straight through flattened Brazilian disc impacted by split Hopkinson pressure bar. Eng Fract Mech 78(12):2455-2469. doi:10.1016/j.engfracmech.2011.06.004

Wang SS, Zhang MH, Quek ST (2011b) Effect of specimen size on static strength and dynamic increase factor of high-strength concrete from SHPB test. J Test Eval 39(5):898-907. doi:10. 1520/JTE103370

Weerasooriya T, Moy P, Casem D, Cheng M, Chen W (2006) A four point bend technique to determine dynamic fracture toughness of ceramics. J Am Ceram Soc 89(3):990-995. doi:10.1111/j.15512916.2005.00896.x

Whittles DN, Kingman S, Lowndes I, Jackson K (2006) Laboratory and numerical investigation into the characteristics of rock fragmentation. Miner Eng 19(14):1418-1429. doi:10.1016/j. mineng.2006.02.004

Wu PP (1971) The split Hopkinson bar method of rock testing. M.S., Colorado School of Mines, Golden

Wu H, Zhang Q, Huang F, Jin Q (2005) Experimental and numerical investigation on the dynamic tensile strength of concrete. Int $\mathrm{J}$ Impact Eng 32(1-4):605-617. doi:10.1016/j.ijimpeng.2005.05. 008

Wu W, Li J, Zhao J (2012) Loading rate dependency of dynamic responses of rock joints at low loading rate. Rock Mech Rock Eng 45(3):421-426. doi:10.1007/s00603-011-0212-z

Xia K (2013a) A Mohr-Coulomb failure criterion for rocks subjected to dynamic loading. In: Yang Q, Zhang J-M, Zheng H, Yao Y (eds) Constitutive modeling of geomaterials. Springer series in geomechanics and geoengineering. Springer, Berlin, pp 367-370. doi:10.1007/978-3-642-32814-5_51

Xia K (2013b) Status of characterization of strength and fracture properties of rocks under dynamic loading. In: Proceedings of the 10th international symposium on rock fragmentation by blasting, FRAGBLAST, New Delhi, pp 41-51

Xia K, Nasseri MHB, Mohanty B, Lu F, Chen R, Luo SN (2008) Effects of microstructures on dynamic compression of Barre granite. Int J Rock Mech Min 45(6):879-887. doi:10.1016/j. ijrmms.2007.09.013

Xie H, Chen Z (1988) Fractal geometry and fracture of rock. Acta Mech Sin 4(3):255-264. doi:10.1007/bf02486657

Green SJ, Perkins RD (1969) Uniaxial compression tests at strain rates from $0.0001 / \mathrm{sec}$ to $1000 / \mathrm{sec}$ on three geologic materials. General Motors Technical Center, Materials and Structures Lab Report, Warren

Yan F, Feng XT, Chen R, Xia K, Jin C (2012) Dynamic tensile failure of the rock interface between tuff and basalt. Rock Mech Rock Eng 45(3):341-348. doi:10.1007/s00603-011-0177-y

Yang LM, Shim VPW (2005) An analysis of stress uniformity in split Hopkinson bar test specimens. Int J Impact Eng 31(2):129-150. doi:10.1016/j.ijimpeng.2003.09.002

Yang WJ, Yu CT, Kobayashi AS (1991) SEM quantification of transgranular vs intergranular fracture. J Am Ceram Soc 74(2):290-295. doi:10.1111/j.1151-2916.1991.tb06877.x 
Yang RS, Yue ZW, Sun ZH, Xiao TS, Guo DM (2009) Dynamic fracture behavior of rock under impact load using the caustics method. Min Sci Technol 19(1):79-83. doi:10.1016/s16745264(09)60015-6

Yin TB, Li XB, Xia K, Huang S (2012a) Effect of thermal treatment on the dynamic fracture toughness of Laurentian granite. Rock Mech Rock Eng 45(6):1087-1094. doi:10.1007/s00603-0120240-3

Yin ZQ, Li XB, Jin JF, He XQ, Du K (2012b) Failure characteristics of high stress rock induced by impact disturbance under confining pressure unloading. Trans Nonferr Metal Soc 22(1):175-184. doi:10.1016/s1003-6326(11)61158-8

Young C, Powell CN (1979) Lateral inertia effects on rock failure in split-Hopkinson-bar experiments. The 20th U.S. Symposium on Rock Mechanics (USRMS), Austin, pp 79-0299

Yu Y (1992) Study on dynamic characteristic of rocks using triaxial SHPB. Chin J Geotech Eng 14(3):76-79

Yu Y, Zhang ZX (1995) Determining critical time of rock dynamic fracture by dynamic Moire method. J Univ Sci Tech Beijing 2(2):109-113

Yu Y, Zhang J, Zhang J (2009) A modified Brazilian disk tension test. Int J Rock Mech Min 46(2):421-425. doi:10.1016/j.ijrmms. 2008.04.008

Yuan F, Prakash V (2008) Use of a modified torsional Kolsky bar to study frictional slip resistance in rock-analog materials at coseismic slip rates. Int J Solids Struct 45(14-15):4247-4263. doi:10.1016/j.ijsolstr.2008.03.012

Yuan F, Prakash V, Tullis T (2011) Origin of pulverized rocks during earthquake fault rupture. J Geophys Res 116(B6):B06309. doi:10.1029/2010jb007721

Zang A, Stephansson O (2010) Rock fracture criteria. In: Zang A, Stephansson O (eds) Stress field of the earth's crust. Springer, The Netherlands, pp 37-62. doi:10.1007/978-1-4020-8444-7_3

Zavattieri PD, Espinosa HD (2001) Grain level analysis of crack initiation and propagation in brittle materials. Acta Mater 49(20):4291-4311. doi:10.1016/s1359-6454(01)00292-0

Zener C, Hollomon JH (1944) Effect of strain rate upon plastic flow of steel. J Appl Phys 15(1):22-32. doi:10.1063/1.1707363

Zhang S, Wang QZ (2009) Determination of rock fracture toughness by split test using five types of disc specimens. Rock Soil Mech 30(1):12-18

Zhang QB, Zhao J (2013a) Determination of mechanical properties and full-field strain measurements of rock material under dynamic loads. Int J Rock Mech Min 60:423-439. doi:10. 1016/j.ijrmms.2013.01.005

Zhang QB, Zhao J (2013b) Effect of loading rate on fracture toughness and failure micromechanisms in marble. Eng Fract Mech 102:288-309. doi:10.1016/j.engfracmech.2013.02.009

Zhang QB, Zhao J (2013c) A micromechanics-based model for dynamic behaviour of rock. Int J Rock Mech Min submitted

Zhang QB, Zhao J (2013d) Quasi-static and dynamic fracture behaviour of rock materials: phenomena and mechanisms. Rock Mech Rock Eng submitted

Zhang ZX, Kou SQ, Yu J, Yu Y, Jiang LG, Lindqvist PA (1999) Effects of loading rate on rock fracture. Int J Rock Mech Min 36(5):597-611. doi:10.1016/s0148-9062(99)00031-5

Zhang ZX, Kou SQ, Jiang LG, Lindqvist PA (2000) Effects of loading rate on rock fracture: fracture characteristics and energy partitioning. Int J Rock Mech Min 37(5):745-762. doi:10.1016/ s1365-1609(00)00008-3

Zhang ZX, Yu J, Kou SQ, Lindqvist PA (2001a) Effects of high temperatures on dynamic rock fracture. Int J Rock Mech Min 38(2):211-225. doi:10.1016/s1365-1609(00)00071-x

Zhang ZX, Yu J, Kou SQ, Lindqvist PA (2001b) On study of influences of loading rate on fractal dimensions of fracture surfaces in gabbro. Rock Mech Rock Eng 34(3):235-242. doi:10. 1007/s006030170011

Zhang M, Wu HJ, Li QM, Huang FL (2009) Further investigation on the dynamic compressive strength enhancement of concrete-like materials based on split Hopkinson pressure bar tests. Part I: experiments. Int J Impact Eng 36(12):1327-1334. doi:10.1016/j. ijimpeng.2009.04.009

Zhang XX, Yu RC, Ruiz G, Tarifa M, Camara MA (2010) Effect of loading rate on crack velocities in HSC. Int $\mathrm{J}$ Impact Eng 37(4):359-370. doi:10.1016/j.ijimpeng.2009.10.002

Zhao YP (1995) Suggestion of a new criterion of dynamic fracture initiation. Int J Fract 71(4):R77-R78. doi:10.1007/bf00037822

Zhao J (2000) Applicability of Mohr-Coulomb and Hoek-Brown strength criteria to the dynamic strength of brittle rock. Int $\mathrm{J}$ Rock Mech Min 37(7):1115-1121. doi:10.1016/s1365-1609 (00)00049-6

Zhao J (2011) An overview of some recent progress in rock dynamics research. In: Zhou YX, Zhao J (eds) Advances in rock dynamics and applications. CRC Press, USA, pp 5-33

Zhao H, Gary G (1996) On the use of SHPB techniques to determine the dynamic behavior of materials in the range of small strains. Int J Solids Struct 33(23):3363-3375. doi:10.1016/00207683(95)00186-7

Zhao H, Gary G (1997) A new method for the separation of waves. Application to the SHPB technique for an unlimited duration of measurement. J Mech Phys Solids 45(7):1185-1202. doi:10. 1016/s0022-5096(96)00117-2

Zhao J, Li HB (2000) Experimental determination of dynamic tensile properties of a granite. Int J Rock Mech Min 37(5):861-866. doi:10.1016/s1365-1609(00)00015-0

Zhao J, Li HB, Zhao YH (1998) Dynamics strength tests of the Bukit Timah granite. Geotechnical research report NTU/GT/98-2. Nanyang Technological University, Singapore

Zhao J, Li HB, Wu MB, Li TJ (1999a) Dynamic uniaxial compression tests on a granite. Int J Rock Mech Min 36(2):273-277. doi:10. 1016/s0148-9062(99)00008-X

Zhao J, Zhou YX, Hefny AM, Cai JG, Chen SG, Li HB, Liu JF, Jain M, Foo ST, Seah CC (1999b) Rock dynamics research related to cavern development for ammunition storage. Tunn Undergr Sp Tech 14(4):513-526. doi:10.1016/s0886-7798(00)00013-4

Zhao J, Zhou YX, Ma GW (2008) Rock failure, wave propagation and tunnel stability under dynamic loads. In: Majdi A (ed) The 5th Asian rock mechanics symposium, Tehran, pp 167-181

Zhao PD, Lu FY, Chen R, Lin YL, Li JL, Lu L, Sun GL (2011) A technique for combined dynamic compression-shear test. Rev Sci Instrum 82(3):035110-035110. doi:10.1063/1.3557826

Zhao J, Zhou YX, Xia KW (2012) Advances in rock dynamics modelling, testing and engineering. In: Qian QH, Zhou YX (eds) Harmonising rock engineering and the environment, CRC Press/ Balkema, The Netherlands, pp 147-154

Zhou XQ, Hao H (2008) Modelling of compressive behaviour of concrete-like materials at high strain rate. Int J Solids Struct 45(17):4648-4661. doi:10.1016/j.ijsolstr.2008.04.002

Zhou YX, Zhao J (eds) (2011) Advances in rock dynamics and applications. CRC Press, USA

Zhou ZL, Li XB, Ye ZY, Liu KW (2010) Obtaining constitutive relationship for rate-dependent rock in SHPB tests. Rock Mech Rock Eng 43(6):697-706. doi:10.1007/s00603-010-0096-3

Zhou ZL, Li XB, Liu AH, Zou Y (2011) Stress uniformity of split Hopkinson pressure bar under half-sine wave loads. Int J Rock Mech Min 48(4):697-701. doi:10.1016/j.ijrmms.2010.09.006

Zhou YX, Xia K, Li XB, Li HB, Ma GW, Zhao J, Zhou ZL, Dai F (2012) Suggested methods for determining the dynamic strength parameters and mode-I fracture toughness of rock materials. Int J Rock Mech Min 49:105-112. doi:10.1016/j.ijrmms.2011.10.004 
Zhou ZL, Li XB, Zou Y, Jiang YH, Li GN (2013a) Dynamic Brazilian tests of granite under coupled static and dynamic loads. Rock Mech Rock Eng (in press). doi:10.1007/s00603-013-0441-4

Zhou ZL, Zou Y, Li XB, Jiang YH (2013b) Stress evolution and failure process of Brazilian disc under impact. J Cent South Univ 20(1):172-177. doi:10.1007/s11771-013-1473-3

Zhu WC (2008) Numerical modelling of the effect of rock heterogeneity on dynamic tensile strength. Rock Mech Rock Eng 41(5):771-779. doi:10.1007/s00603-006-0117-4

Zhu WC, Tang CA (2006) Numerical simulation of Brazilian disk rock failure under static and dynamic loading. Int J Rock Mech Min 43(2):236-252. doi:10.1016/j.ijrmms.2005.06.008

Zhu WC, Tang CA, Huang ZP, Liu JS (2004) A numerical study of the effect of loading conditions on the dynamic failure of rock.
Int J Rock Mech Min 41(Suppl 1):348-353. doi:10.1016/j. ijrmms.2004.03.065

Zhu WC, Bai Y, Li XB, Niu LL (2012) Numerical simulation on rock failure under combined static and dynamic loading during SHPB tests. Int J Impact Eng 49:142-157. doi:10.1016/j.ijimpeng.2012. 04.002

Zuo QH, Addessio FL, Dienes JK, Lewis MW (2006) A ratedependent damage model for brittle materials based on the dominant crack. Int J Solids Struct 43(11-12):3350-3380. doi:10.1016/j.ijsolstr.2005.06.083

Zuo QH, Disilvestro D, Richter JD (2010) A crack-mechanics based model for damage and plasticity of brittle materials under dynamic loading. Int J Solids Struct 47(20):2790-2798. doi:10. 1016/j.ijsolstr.2010.06.009 